\title{
Long Term Corrosion/Degradation Test Six Year Results
}

M. K. Adler Flitton

C. W. Bishop

M. E. Delwiche

T. S. Yoder

September 2004

Idaho National Engineering and Environmental Laboratory Bechtel BWXT Idaho, LLC 



\section{Long Term Corrosion/Degradation Test Six Year Results}

M. K. Adler Flitton

C. W. Bishop

M. E. Delwiche

T. S. Yoder

Published September 2004

Idaho National Engineering and Environmental Laboratory

Idaho Falls, Idaho 83415

Prepared for the U.S. Department of Energy

Under DOE Idaho Operations Office

Contract DE-AC07-99ID13727 
(This page intentionally left blank.) 


\section{ABSTRACT}

The Subsurface Disposal Area (SDA) of the Radioactive Waste Management Complex (RWMC) located at the Idaho National Engineering and Environmental Laboratory (INEEL) contains neutronactivated metals from non-fuel, nuclear reactor core components. The Long-Term Corrosion/Degradation (LTCD) Test is designed to obtain site-specific corrosion rates to support efforts to more accurately estimate the transfer of activated elements to the environment. The test is using two proven, industry-standard methods - direct corrosion testing using metal coupons, and monitored corrosion testing using electrical/resistance probes - to determine corrosion rates for various metal alloys generally representing the metals of interest buried at the SDA, including Type 304L stainless steel, Type 316L stainless steel, Inconel 718, Beryllium S200F, Aluminum 6061, Zircaloy-4, low-carbon steel, and Ferralium 255. In the direct testing, metal coupons are retrieved for corrosion evaluation after having been buried in SDA backfill soil and exposed to natural SDA environmental conditions for times ranging from one year to as many as 32 years, depending on research needs and funding availability. In the monitored testing, electrical/resistance probes buried in SDA backfill soil will provide corrosion data for the duration of the test or until the probes fail.

This report provides an update describing the current status of the test and documents results to date. Data from the one-year and threeyear results are also included, for comparison and evaluation of trends.

In the 6-year results, most metals being tested showed extremely low measurable rates of general corrosion. For Type 304L stainless steel, Type 316L stainless steel, Inconel 718, and Ferralium 255, corrosion rates fell in the range of "no reportable" to 0.0002 mils per year (MPY). Corrosion rates for Zircaloy-4 ranged from no measurable corrosion to $0.0001 \mathrm{MPY}$. These rates are two orders of magnitude lower than those specified in the performance assessment for the SDA.

The corrosion on the carbon steel, beryllium, and aluminum were more evident with a clear difference in corrosion performance between the 4-ft and 10-ft levels. Notable surface corrosion products were evident as well as numerous pit initiation sites. Since the corrosion of the beryllium and aluminum is characterized by pitting, the geometrical character of the corrosion becomes more significant than the general corrosion rate. Both pitting factor and weight loss data should be used together. For 6-year exposure, the maximum carbon steel corrosion rate was 0.3643 MPY while the maximum beryllium corrosion rate was $0.3282 \mathrm{MPY}$ and the maximum aluminum corrosion rate was 0.0030 MPY. 
(This page is intentionally left blank.) 


\section{ACKNOWLEDGMENTS}

The support necessary to successfully pursue the objectives of the test has been vast, and in addition to the authors of this document, many have contributed to the success of the test over the years. Foremost has been the programmatic support from Waste Management Low-Level Waste Support group who continue to champion funding for the test's continuation. An integrated team of engineers and scientists participated in both test and laboratory analysis support. Operation support included planners, schedulers, Craft personnel, Safety, and Industrial Hygienists. Paramount has been the challenge to obtain high quality results with impeccable technical credibility while maintaining a safe work environment. As the test continues into successive phases and as new challenges arise, we extend our acknowledgement and appreciation to all who have made significant contributions.

The authors also would like to acknowledge the lifetime accomplishments of the late John Logan. This test is one small effort he has endowed to us for completion. John was an accomplished nuclear intellectual and was instrumental in pursuing field validation of models used for performance assessments. John inspired this and other tests at the INEEL to assist in understanding the nuclear life-cycle. 
(This page intentionally left blank.) 


\section{CONTENTS}

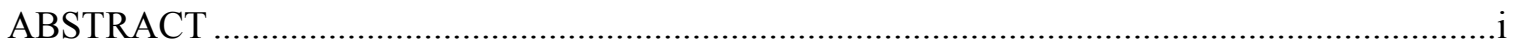

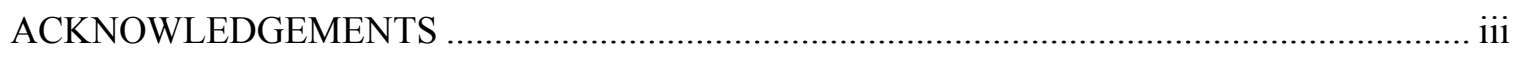

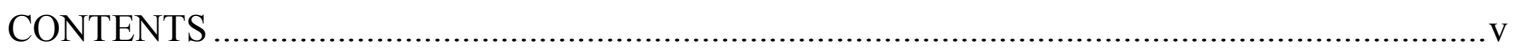

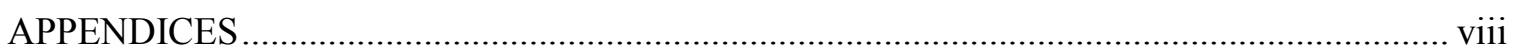

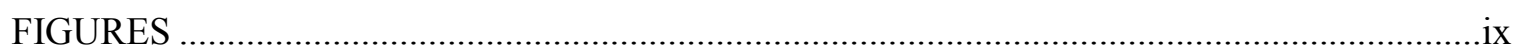

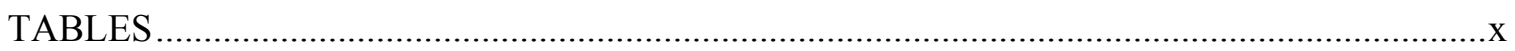

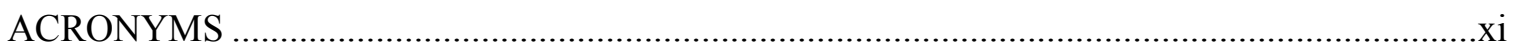

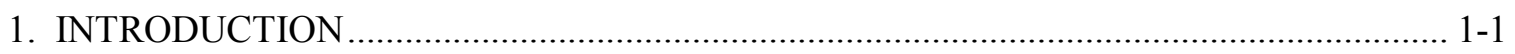

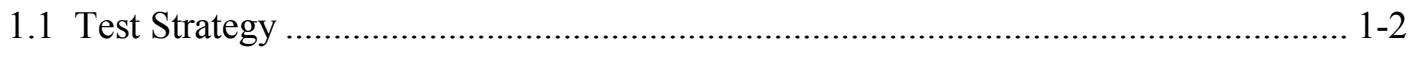

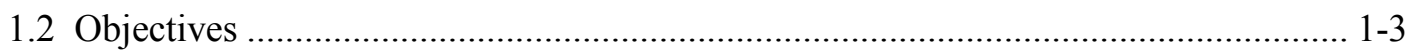

1.3 Test Location ................................................................................................. 1-4

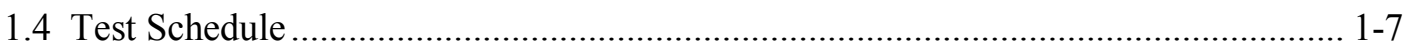

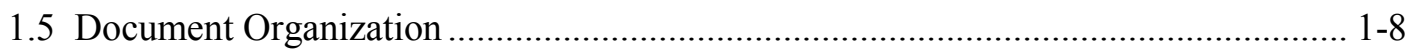

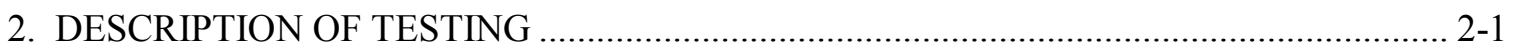

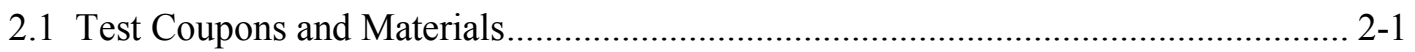

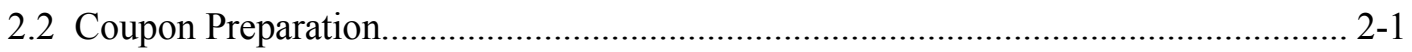

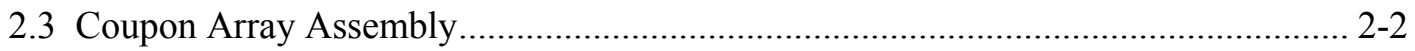

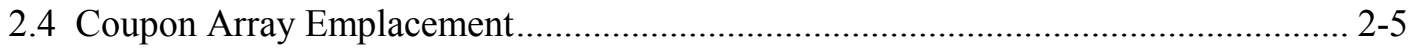

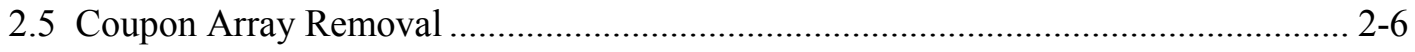

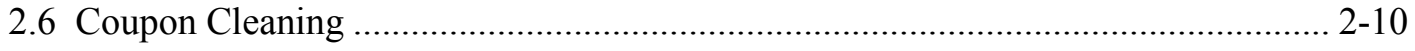

2.7 Mass-Loss Measurement Method .................................................................... 2-11

2.8 Mass-Loss Measurement Uncertainties ........................................................ 2-11

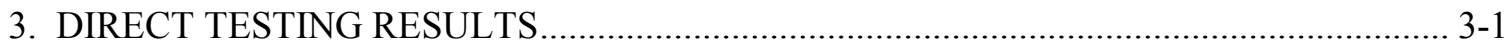

3.1 Mass-Loss Measurements Results ……................................................................. 3-1

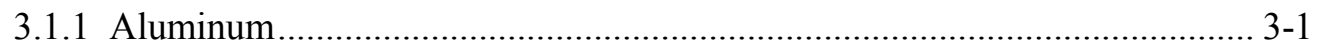

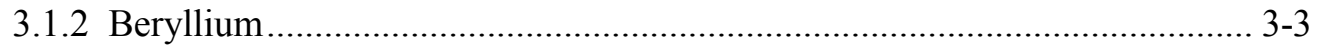

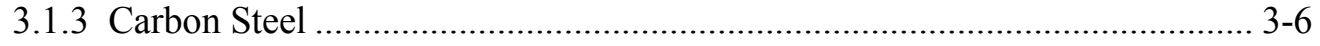

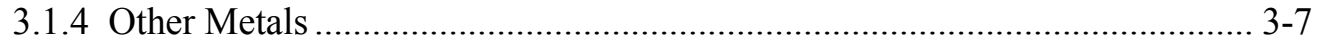

3.2 Preliminary Evaluation of Trends ....................................................................... 3-9 
4. DESCRIPTION OF MONITORED CORROSION TESTING …....................................... 4-1

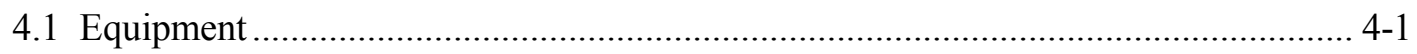

4.2 Probe Selection and Preparation ........................................................................ 4-2

4.3 Probe Array Emplacement ............................................................................ 4-3

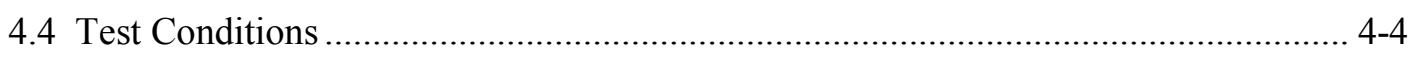

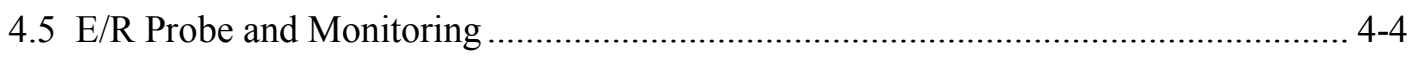

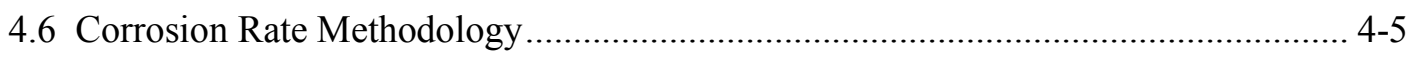

4.7 Monitored Testing Results ................................................................................ $4-5$

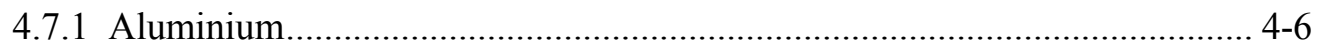

4.7.2 Carbon Steel ............................................................................. 4-6

4.7.3 Other Metals ................................................................................... 4-7

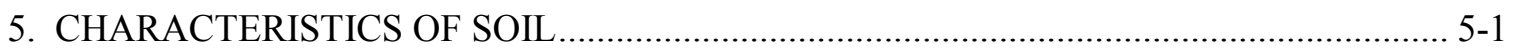

5.1 Factors Describing Soil Corrosivity .................................................................. 5-1

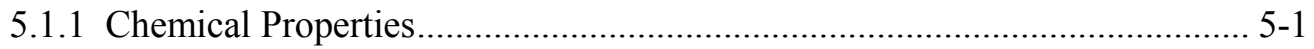

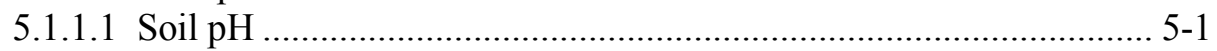

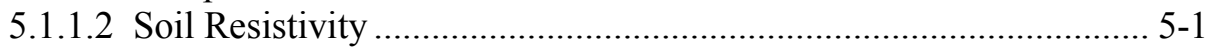

5.1.1.3 Soluble Ion Concentration...................................................... 5-2

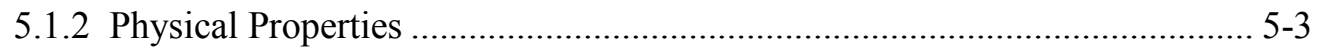

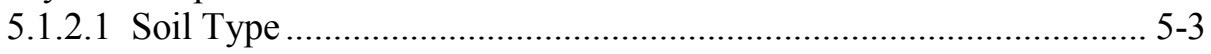

5.1.2.2 Soil Moisture............................................................................ 5-3

5.2 Underground Corrosion Testing Comparisons …................................................ 5-3

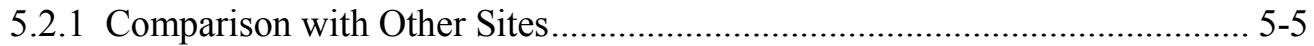

5.2.2 Corrosion in Similar Soils ........................................................................ 5-5

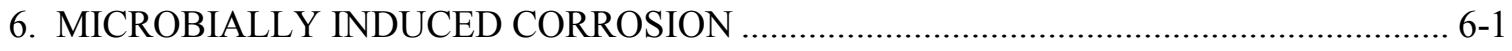

6.1 Description of Microbiological Testing ............................................................ 6-1

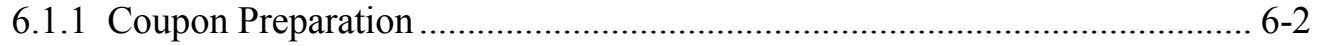

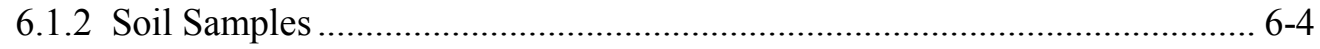

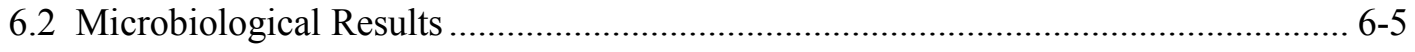

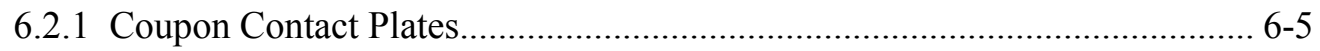

6.2.2 Liquid Enrichments ......................................................................... 6-6

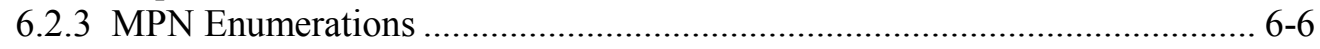

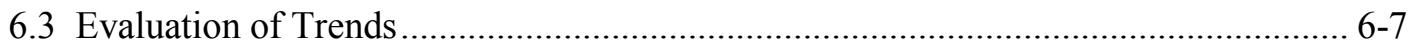


6.3.1 Microbial Trend Discussion ............................................................ 6-8

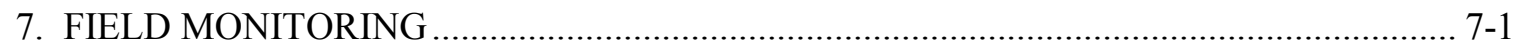

7.1 Precipitation Monitoring .............................................................................. $7-1$

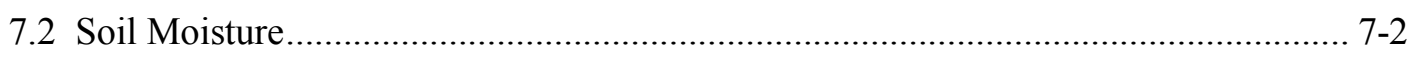

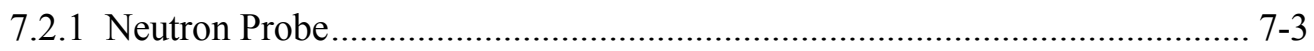

7.2.1.1 Neutron Probe Operation .......................................................... 7-3

7.2.1.2 Neutron Probe Monitoring ............................................................... 7-4

7.2.1.3 Neutron Probe Monitoring Results ............................................ 7-4

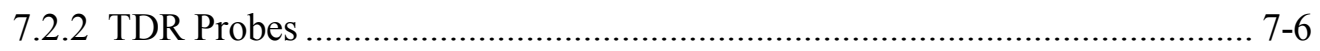

7.2.2.1 TDR Operation.................................................................. 7-6

7.2.2.2 TDR Monitoring............................................................... 7-6

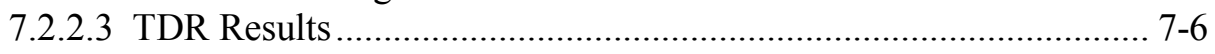

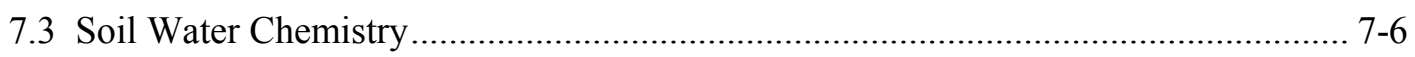

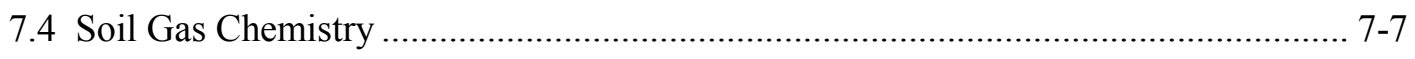

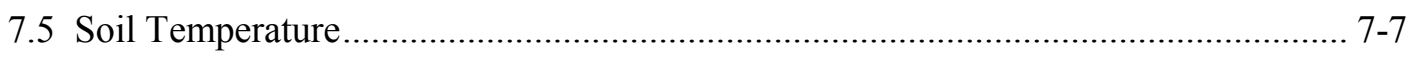

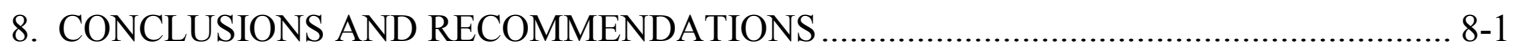

8.1 Summary of Six-Year Corrosion Results........................................................ 8-1

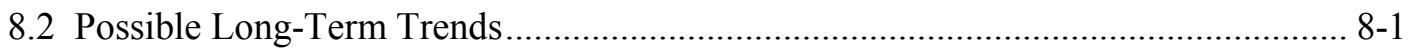

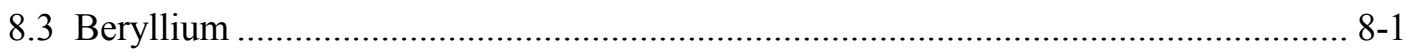

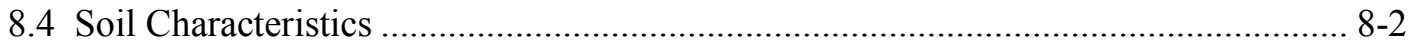

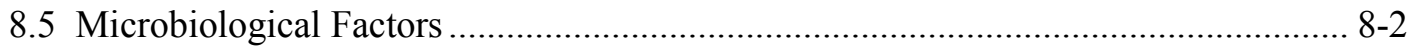

9. REFERENCES 


\section{APPENDICES}

Appendix A-Material Test Report

Appendix B - Cleaning Curves

Appendix C - Mass Loss Tables

Appendix D - Vertical Scanning-Interferometry Measurements

Appendix E - Beryllium Adhering Soil

Appendix F - Scanning Electron Microscope Images of Beryllium Coupons

Appendix G - Mass Loss Graphs

Appendix H - Electrical Resistance Probe Results

Appendix I - Soil Properties

Appendix $\mathbf{J}$ - Microbially Induced Corrosion

Appendix K - Soil Moisture

Appendix L - Soil Gas 


\section{FIGURES}

Figure 1-1. Location of the LTCD testing near the RWMC SDA at the INEEL ............................... 1-4

Figure 1-2. Location and layout of the corrosion test berm. ............................................................ 1-5

Figure 1-3. Locations for placement of coupon and probe arrays at the corrosion test berm ............... 1-6

Figure 2-1. Typical corrosion coupon; this one is 304L stainless steel..........................................2-2

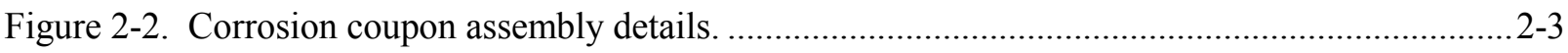

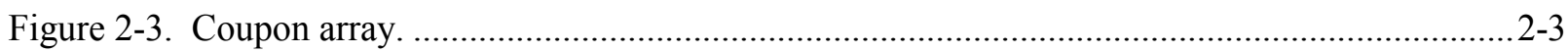

Figure 2-4. Numbering system for coupons installed in a coupon array............................................2-4

Figure 2-5. Drill rig with 6-ft-diameter auger. ............................................................................2-5

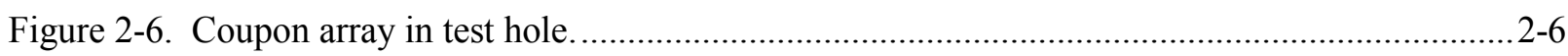

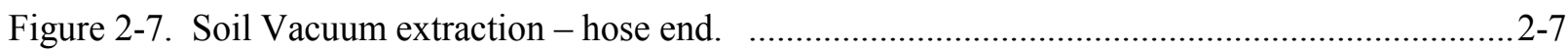

Figure 2-8. Soil vacuum extractor - hopper/vacuum end. ...............................................................2-7

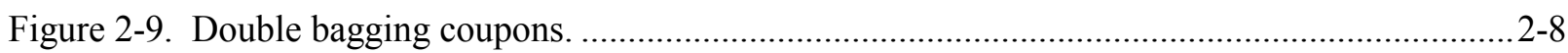

Figure 2-10. One year exposed rod from coupon array after arrival at laboratory...............................2-8

Figure 2-11. Three-year exposed rod from 4-ft coupon array.........................................................2-9

Figure 2-12. Six-year exposed rod from 10-ft coupon array.........................................................

Figure 2-13. Six-year exposed rod from 10-ft coupon array. ...........................................................2-10

Figure 3-1. Aluminum coupon (\#3497) before cleaning. 6-yr exposure at 4-ft. .................................3-2

Figure 3-2. Aluminum coupon (\#3497) after cleaning. 6-yr exposure at 4-ft. .....................................3-2

Figure 3-3. Beryllium coupon (\#24) before cleaning. 6-yr exposure at 10-ft .....................................3-4

Figure 3-4. Beryllium coupon (\#24) after cleaning. 6-yr exposure at 10-ft ......................................... 3-4

Figure 3-5. SEM image: uncorroded beryllium coupon surface. .......................................................... 3-5

Figure 3-6. SEM image: a corroded beryllium coupon pit............................................................... 3-5

Figure 3-7. Carbon steel coupon (\#3348) before cleaning. 6-yr exposure at 10-ft.............................. 3-6

Figure 3-8. Carbon steel coupon (\#3348) after cleaning. 6-yr exposure at 10-ft .................................3-7

Figure 3-9. Zircaloy-4 coupon (\#3808) before cleaning. 6-yr exposure at 10-ft................................. 3-8

Figure 3-10. Zircaloy-4 coupon (\#3808) after cleaning. 6-yr exposure at 10-ft................................... 3-8

Figure 4-1. A sketch showing two types of E/R probes ................................................................. $4-1$

Figure 4-2. Electrical Resistance (E/R) probe ............................................................................. 4-2

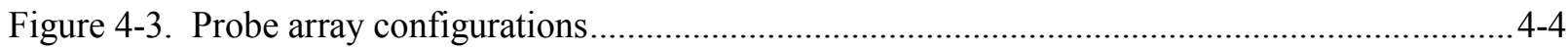

Figure 4-4. Aluminum E/R probes vs. coupons. ........................................................................ 4-6

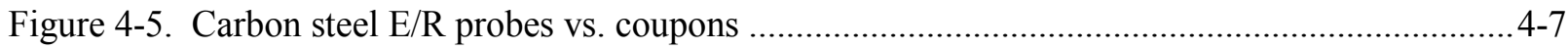

Figure 5-1. Resistivity as a function of $\mathrm{CaSO}_{4}$ and $\mathrm{NaCl}$ solutions. ..................................................5-2

Figure 6-1. Removal of soil and loose debris for microbial testing. ................................................. 6-3

Figure 6-2. Swabbing corrosion coupon for enrichments. ..........................................................6-4

Figure 6-3. Microbial growth on contact plates imprinted from carbon steel coupons.........................6-5

Figure 6-4. Microbial growth on contact plates imprinted from a beryllium coupon. ........................ 6-6

Figure 7-1. Arrangement of coupon arrays, probe arrays and support instrumentation.......................7-1

Figure 7-2. Graph showing monthly precipitation totals for the years 1997 through May 2004..........7-2

Figure 7-3. CPN 503DR hydroprobe neutron moisture gauge.................................................... 7-3

Figure 7-4. Comparison of March 15, 2004 moisture profiles. .......................................................... $7-5$ 


\section{TABLES}

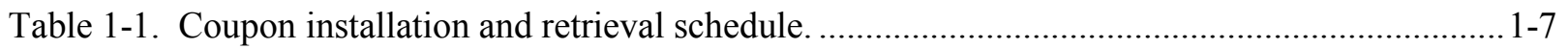

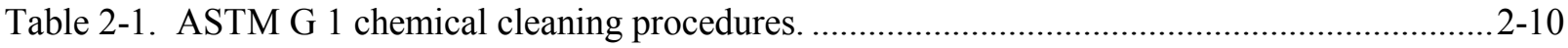

Table 3-1. Aluminum 6-year exposure corrosion rate summary....................................................... 3-1

Table 3-2. Aluminum 6-year exposure pitting corrosion summary. ................................................ 3-1

Table 3-3. Beryllium 6-year exposure corrosion rate summary .......................................................3-3

Table 3-4. Beryllium 6-year exposure pitting corrosion summary ...................................................3-3

Table 3-5. Carbon Steel 6-year exposure corrosion rate summary. .....................................................3-6

Table 3-6. Carbon Steel 6-year exposure pitting corrosion summary.................................................. 3-6

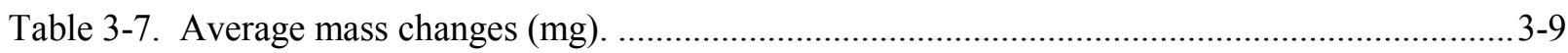

Table 4-1. Probe array locations, conditions, and placement ............................................................4-3

Table 4-2. Aluminum E/R probe corrosion rate summary. ............................................................ 4-6

Table 4-3. Carbon steel E/R probe corrosion rate summary. .............................................................. 4-7

Table 4-4. E/R probe corrosion rate summary. ................................................................................. 4-8

Table 5-1. Average corrosion rates at the 4 - $\mathrm{ft}$ level for comparison....................................................5-1

Table 5-2. Resistivity classifications for carbon steel pipe .............................................................5-2

Table 5-3. Soil resistivity and corrosion rate of stainless steel. ..........................................................5-3

Table 5-4. Results from the Hanford site. .......................................................................................

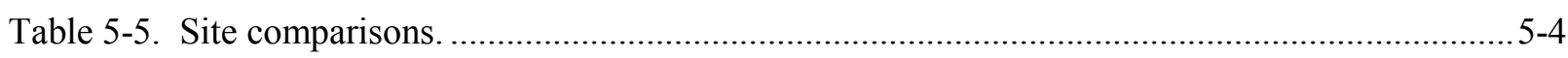

Table 5-6. Results for stainless steels exposed to Sagemoor sandy loam soils....................................5-5

Table 6-1. MPN estimates for 6-yr exposed beryllium and carbon steel coupons...............................6-7

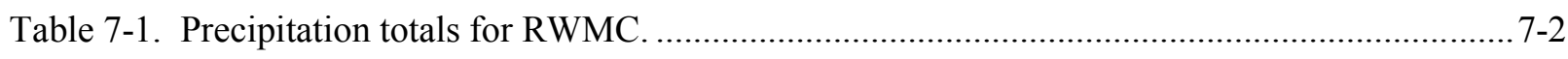

Table 7-2. NP5 and excavation samples, moisture comparison. ........................................................ 7-4 


\section{ACRONYMS}

\begin{tabular}{|c|c|}
\hline ASTM & American Society for Testing and Materials \\
\hline CFU & colony forming units \\
\hline DOE & Department of Energy \\
\hline EBTF & Engineered Barriers Test Facility \\
\hline $\mathrm{E} / \mathrm{R}$ & Electrical Resistance (Probes) \\
\hline HET & Heterotrophs \\
\hline Inconel & Trade Mark of Special Metals Corporation \\
\hline INEEL & Idaho National Engineering and Environmental Laboratory \\
\hline LTCD & long term corrosion/degradation \\
\hline MPN & most probable number \\
\hline MPY & mils per year \\
\hline NBS & National Bureau of Standards \\
\hline NIST & National Institute for Standards Testing \\
\hline NR & nitrate reducers (denitrifiers) \\
\hline OA & organic acid (producers) \\
\hline PBS & phosphate buffered saline \\
\hline PPE & personal protection equipment \\
\hline RMS & root mean square \\
\hline RWMC & Radioactive Waste Management Complex \\
\hline SDA & Subsurface Disposal Area \\
\hline SEM & scanning electron microscope \\
\hline SRB & sulfate reducing bacteria \\
\hline TDR & time domain reflectometry \\
\hline
\end{tabular}


(This page intentionally left blank.) 


\section{Long Term Corrosion/Degradation Test Six-Year Results}

\section{INTRODUCTION}

The Radioactive Waste Management Complex (RWMC) Subsurface Disposal Area (SDA) at the Idaho National Engineering and Environmental Laboratory (INEEL) has been a major disposal site for solid radioactive waste since the early 1950s. The SDA contains low-level waste, transuranic waste, hazardous waste, and mixed waste. Since 1970, incoming waste generally has been segregated according to waste type before disposal, and transuranic waste has been stored instead of being place in disposal. A large portion of the radionuclide inventory disposed at the SDA consists of neutron-irradiated metals, mostly reactor core structural components (subassemblies, cladding, and other non-fuel reactor core components) composed of stainless steel, nickel-based alloys (such as Inconel 718), and other metals.

The neutron-irradiated metal buried at the SDA represents an environmental concern. The irradiation produces long lived (e.g., C-14, Ni-59, Nb-94, Tc-99) and short lived (e.g. Co-60, Ni-63, H-3) radioactive isotopes (10 CFR 61). The radioactive isotopes are contained inside the crystalline structure of the metal, and the assumption is that the isotopes are released into the environment as the metal corrodes (Rood and Adler Flitton, 1997). Thus, for these waste forms, the assumption is the calculated release rate is driven by the corrosion rate.

Department of Energy (DOE) Order 435.1, "Radioactive Waste Management," requires a radiological composite analysis and a performance assessment of existing and proposed DOE low-level waste facilities. In the original performance assessment for the SDA (Maheras et al. 1994), release rates for a variety of reactor components were obtained using the IMPACTS methodology (Oztunali and Roles $1986)$ and were based on corrosion rates of 4 mils per year (MPY) $\left(1.02 \times 10^{-4} \mathrm{~m} /\right.$ year $)$ for carbon steel and 0.3 MPY $\left(7.62 \times 10^{-6} \mathrm{~m} /\right.$ year $)$ for stainless steel. The corrosion rates for the stainless steel are rates from the IMPACTS study for austenitic stainless steels (Types 304 and 316) in natural waters and seawater.

Corrosion rates cited in the literature are typically derived from testing in water or in soils that are wetter and less alkaline than SDA soils. Such generic corrosion rates were used in the original 1994 version of the performance assessment for the SDA LLW disposal facility. Since that time there have been efforts to produce more representative corrosion rates for the conditions at the SDA. For example, a 1996 study reviewed corrosion rates for low carbon steels, Types 304 and 316 stainless steels, and Inconel 600, 601, and 718 alloys in SDA-type soils (Nagata and Banaee 1996). That study estimated that the corrosion rate for the stainless steels and the Inconel 718 in environments with geochemistry similar to that of the SDA soils was $0.00047 \mathrm{MPY}\left(1.2 \times 10^{-8} \mathrm{~m} /\right.$ year $)$, which is about two orders of magnitude lower than the corrosion rate assumed in the original 1994 SDA performance assessment for stainless steel based on "textbook" corrosion rates.

The current composite analysis (McCarthy et al. 2000) and the supplementary update for the SDA performance assessment (Case et al. 2000) use the Disposal Unit Source Term-Multiple Species (DUST-MS) software to model the container failures and release mechanisms. Corrosion rate data entered into the model were $2.2 \times 10^{-7} \mathrm{MPY}\left(5.6 \times 10^{-12} \mathrm{~m} /\right.$ year $)$ (from Nagata 1997) for stainless steels, and $2.2 \times 10^{-6}$ to $1.5 \times 10^{-6} \mathrm{MPY}\left(5.6 \times 10^{-11}\right.$ to $3.8 \times 10^{-11} \mathrm{~m} /$ year)(from Banaee and Nagata 1996$)$ for carbon steels. 
Site-specific underground corrosion rate are limited to the early data acquired from the Long-Term Corrosion/Degradation (LTCD) Test for metals exposed to SDA soils (Mizia, et al. 2000 and AdlerFlitton, et al. 2001). This document reports the most recent results of that ongoing test intended to provide a defensible basis for corrosion rates being used to calculate the release rates for irradiated metals buried at the SDA.

\section{$1.1 \quad$ Test Strategy}

The LTCD test described in this report will determine site-specific corrosion rates for metals representing the neutron-activated metals buried at the SDA. The test will collect data to satisfy the requirements of the radiological composite analysis, the performance assessment, the environmental baseline risk assessment for the SDA, and closure monitoring.

The test consists of four main components:

- Direct corrosion testing, using metal coupons buried in the soil

- Monitored corrosion testing, using electrical resistance probes

- Soil characterization (sampling and analysis), including analysis for physical, chemical, hydraulic, and microbiological properties

- Monitoring of field conditions, including precipitation, soil moisture, soil-water chemistry, soil-gas composition, and soil temperature.

The direct corrosion testing and the monitored testing provide corrosion rate data. The soil characterization and field monitoring aid in the evaluation of the corrosion results.

The direct testing uses buried coupons - the most widely used and simplest method of underground corrosion testing. Clean coupons are measured for dimension and mass before being buried, so that corrosion rates can be determined by measuring the resulting coupon mass loss upon coupon recovery and cleaning, after a known time period. Corrosion times will range from one to as many as 32 years.

The monitored testing uses electrical resistance $(E / R)$ probes. The E/R technique is an online method of measuring the extent of total metal loss, based on the electrical resistance of an exposed metallic strip subjected to corrosion conditions, compared to that of an equivalent metal strip protected from corrosion. The electrical resistance of metals changes as corrosion occurs over time, allowing determination of the corrosion rate.

Both the buried coupon method and the E/R method are industry standard methods for measuring corrosion. The corrosion tests (both methods) are being conducted in soil brought to the test location from Spreading Area B, the source of the soil used as backfill to cover the wastes buried at the SDA.

The test began in 1997 with burial of metal coupons for direct testing. Additional coupons were buried in 1998 and 2000. The direct testing will continue, as necessary, until enough data have been collected to satisfy the requirements of the radiological composite analysis, the performance assessment, and the risk assessment conducted to support closure of the SDA under CERCLA. One-year coupons (coupons exposed to environmental conditions for one year) were removed and examined in 1998, Mizia, et al. (2000) reported the results. Three-year coupons (coupons exposed to environmental conditions for three years) were removed and examined in 2000, the results were reported by Adler-Flitton, et al. (2001). 
Monitored testing began in 2000 when the first set of E/R probes were installed. A second set was installed after the 6 -year coupons were recovered in 2003 . E/R probe monitoring will continue, funding permitting, until the end of the test period or until the probes fail.

The timing and extent of soil characterization work monitoring depends on funding availability and research needs. Field conditions will be monitored during the entire test period as funding and schedule allows. Schedule details are provided later in this report.

The direct testing is using non-radioactive coupons of various metals and alloys selected to generally represent the irradiated metals buried at the SDA. The materials included in the direct testing are Type 304L stainless steel, Type 316L stainless steel, welded Type 316L stainless steel, Inconel 718, Beryllium S200F, Aluminum 6061, and Zircaloy-4 (the list recommended by Rood and Adler Flitton, 1997). In addition, low-carbon steel (the material presently used in the disposal liners of the 55-ton scrap casks and other disposal liners and containers) and Ferralium 255 (a duplex stainless steel material proposed for construction of high-integrity disposal containers) are included as part of the test. The monitored testing is using E/R probes equipped with metal strips of the following materials: Type 304L stainless steel, Type 316L stainless steel, Inconel 718, Aluminum 6061, Zircaloy-4, and low-carbon steel.

This report describes the corrosion test, documents the second scheduled placement of E/R probes, presents the results of the 6-year coupon retrieval and evaluation, compares the 6-year results with the first- and third-year results as well as comparing the results to other corrosion tests, draws tentative conclusions, and makes recommendations for the future conduct of the testing.

\subsection{Objectives}

The corrosion test is designed to determine the corrosion rates of neutron-irradiated metallic materials buried at the SDA. The corrosion rate data are needed to confirm that rates used in the performance assessment, composite analysis, and CERCLA risk assessments are appropriate. Of interest are the metallic materials used in fabricating nuclear reactor components that are exposed to high neutron fluxes in a reactor environment, such that they became activated with long-lived radioactive isotopes. After disposal of the irradiated metallic waste at the SDA, corrosion processes can cause these radioactive isotopes to be released to the environment. The current SDA performance assessment (Case et al. 2000; see also Maheras et al. 1994) and composite analysis (McCarthy et al. 2000) postulate that the largest release factor during the corrosion process will be from carbon-14 or other activation products that are released only as the metal corrodes.

The corrosion test is designed to provide an underground environment similar to that in which the neutron-activated metals are buried at the SDA. The objective is to obtain site-specific corrosion rates that will support accurate estimates of the transfer of radioactive isotopes to the environment (release rate). Corrosion rates will be established for non-radioactive metals, representing the prominent activated material buried at the SDA. The test's use of non-radioactive metal coupons, as well as use of probes equipped with non-radioactive metal strips, assumes that activation does not affect corrosion characteristics or corrosion mechanisms.

Environmental conditions existing or potentially existing at the SDA affect the corrosion rates of metals buried there. Underground corrosion rates are directly related to soil characteristics. The test includes characterization of soil at the test location (soil brought in from Spreading Area B), with analysis for chemical, physical, hydraulic, and microbiological characteristics, along with characterization of soil at the SDA for comparison purposes. Soil moisture and other soil conditions will be monitored, and timing and amounts of precipitation will be monitored. 


\subsection{Test Location}

The corrosion test location is just outside of the SDA boundary. The corrosion coupons and E/R probes buried at the test location are exposed to the same soil and environmental conditions as the activated metals buried in the SDA. The tests are being conducted at a specially constructed test site adjacent to the Engineered Barriers Test Facility (EBTF) located about $900 \mathrm{ft}$ north of the SDA, as shown in Figure 1-1.

Direct burial in the SDA was not feasible, for the following reasons:

- The SDA has limited access because of radiological concerns

- Limited space is available in the SDA for coupon emplacement

- The logistics of handling samples with possible radiological contamination are too complex

- The final soil cover might be placed on the SDA before the end of the test.

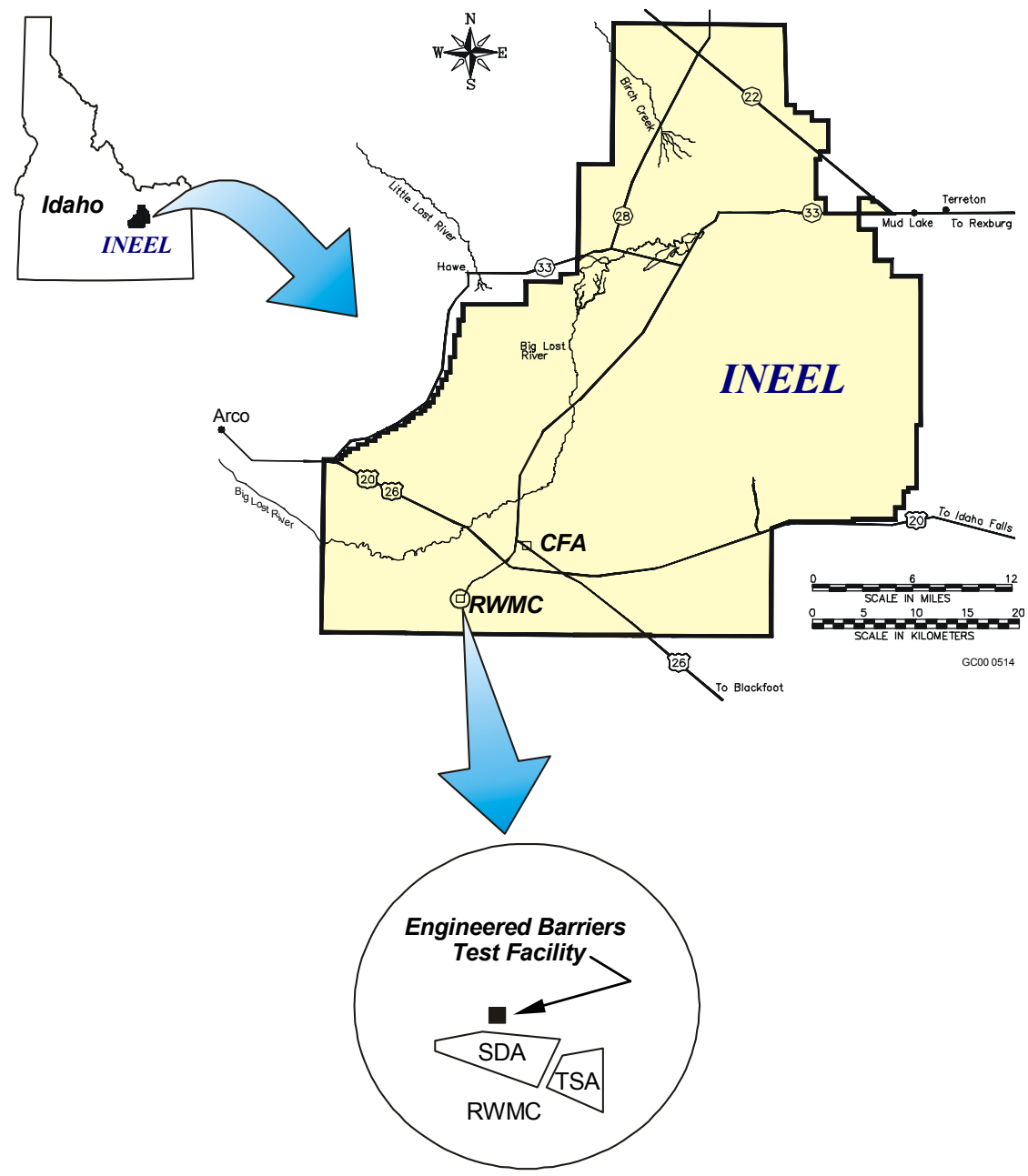

Figure 1-1. Location of the LTCD testing near the RWMC SDA at the INEEL. 
The EBTF was constructed earlier to test the hydraulic performance of prospective engineered barriers for use at the SDA. The berm on the east side of the EBTF was expanded from its original dimensions to form the corrosion test berm, where the corrosion tests are being conducted (see Figure 1-2). Native soil underlying the corrosion test berm area was excavated to a depth of $2 \mathrm{ft}$, and soil from Spreading Area B was brought in to form a rectangular berm, to replicate soil conditions in the SDA where the activated metals are buried. The corrosion berm has sloping sides and a flat top. The height of the corrosion test berm (above the existing grade) is $10 \mathrm{ft}$; the top surface dimensions are $85 \mathrm{ft}$ east to west and $88 \mathrm{ft}$ north to south. The test location includes a frustum-shaped, flat-topped mound, centered and just north of the corrosion test berm, where testing for specific environmental effects might be conducted as part of a separate test.

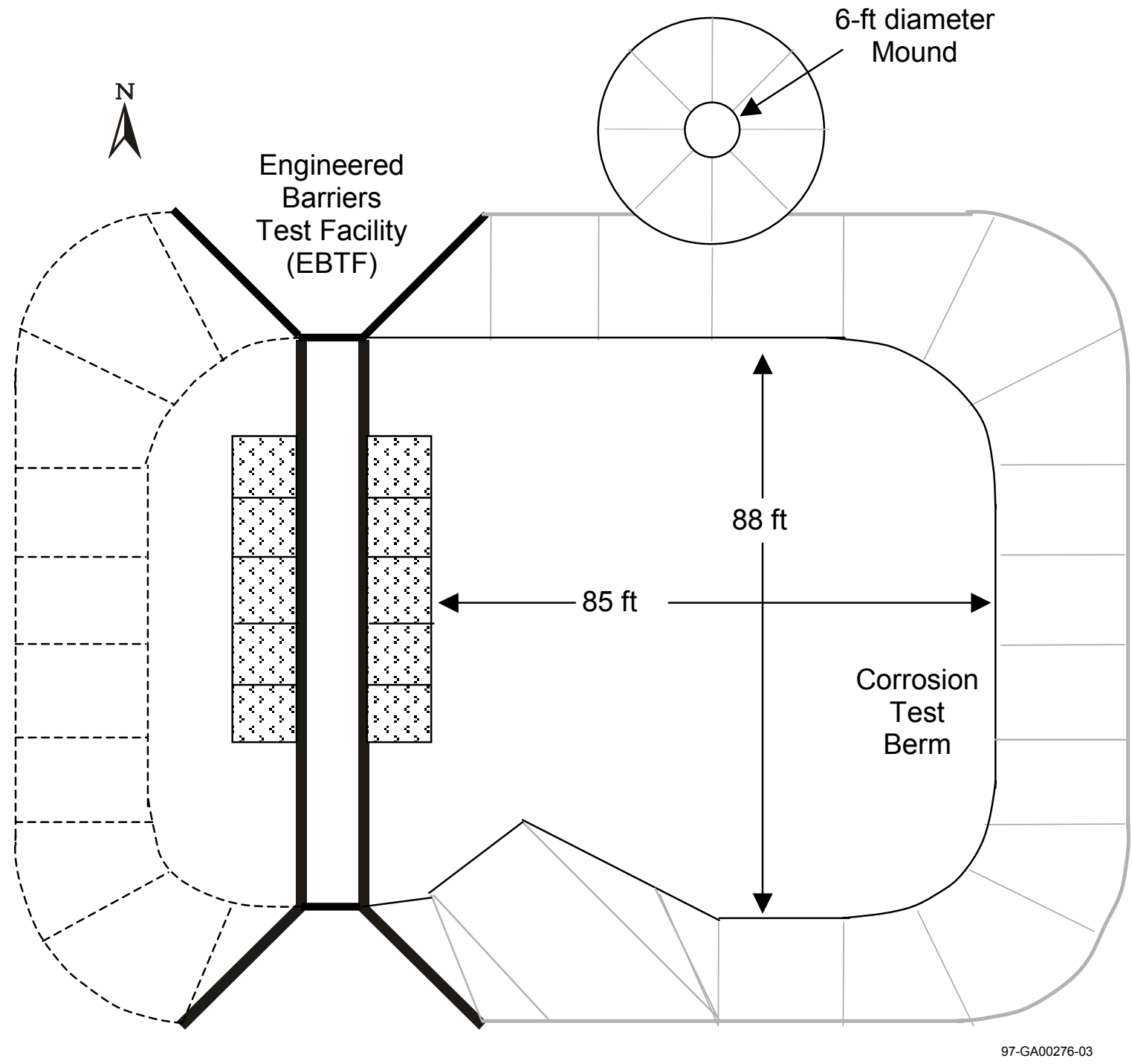

Figure 1-2. Location and layout of the corrosion test berm.

The test plan (Adler-Flitton, et al. 2001) calls for burial of coupons and/or probes at as many as ten designated locations in the berm, as shown in Figure 1-3. Each set of 36 coupons, after assembly, is referred to in this report as a coupon array. Each set of six probes and associated instrumentation is referred to as a probe array. In general, two arrays of coupons or probes make up one set and will be 
buried at each location, one array at $4 \mathrm{ft}$ deep and one array at $10 \mathrm{ft}$ deep. In some instances, a probe array and a coupon array might be buried at the same location at the same depth. Some of the locations can be used more than once; for example, if two coupon arrays are removed for evaluation after only a year or a few years, new arrays can be installed at that location as part of the ongoing test.

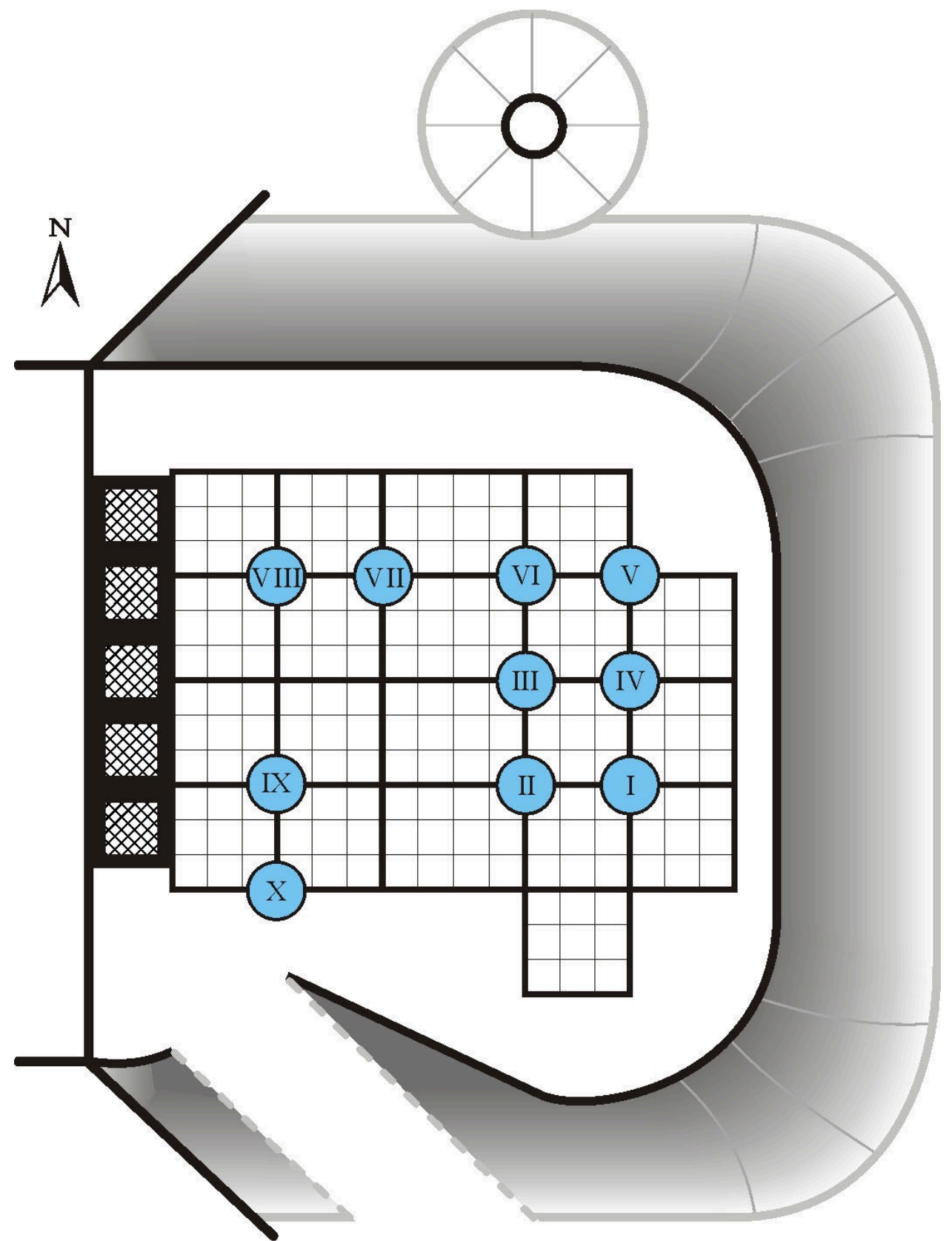

Figure 1-3. Locations for placement of coupon arrays and probe arrays at the corrosion test berm.

The configuration shown in Figure1-3 arranges the coupon/probe placement locations in a grid within the berm, with spacing of $15-\mathrm{ft}$ center to center. The berm size is limited and the placement arrangement is purposefully non-random to optimize the number of arrays that can be placed in the berm. This arrangement separates the coupon arrays (edge to edge) by a minimum of $10 \mathrm{ft}$, so that retrieval of 
any one array will not disturb the soil and corresponding soil characteristics (soil gas, soil moisture, and soil chemistry) in other test locations. (Different coupon arrays will be in place for different time periods.) The array placement locations were arranged to be at least $20 \mathrm{ft}$ from the edge of the mound to minimize any edge effects. A setback of $10 \mathrm{ft}$ from the existing EBTF (the facility adjacent to the mound) ensures a buffer zone and allows the corrosion test to exist independently.

The construction of the berm was completed in June 1997. The berm was constructed in accordance with Specification A-ECS 40902 (LMITCO 1996), including specifications for compaction (more than 85\%) and soil moisture levels (15 to 18\%).

\subsection{Test Schedule}

The coupon installation and retrieval schedule is shown in Table 1-1. The original schedule provided for corrosion measurements to be performed after 1, 2, 4, 8, 16, and 32 years. Reductions in funding for the program have impacted that schedule, such that the current schedule calls for corrosion measurements after 1, 3, and 6 years, with out-years essentially following the reporting requirements of the Composite Analysis and Performance Assessment or when programmatic funding is identified.

Table 1-1. Coupon installation and retrieval schedule.

\begin{tabular}{|c|c|c|c|c|}
\hline Coupon array & $\begin{array}{l}\text { Depth } \\
\text { (ft) }\end{array}$ & Installation date & Retrieval date & $\begin{array}{c}\text { Location } \\
\text { (Figure 1-3) }\end{array}$ \\
\hline CA01 & 4 & Oct. 22, 1997 & Oct. 23, 1998 & \multirow{2}{*}{ Berm, I } \\
\hline CA02 & 10 & Oct. 21, 1997 & Nov. 3-5, 1998 & \\
\hline CA03 & 4 & Oct. 22, 1997 & Oct. 15,2000 & \multirow{2}{*}{ Berm, II } \\
\hline CA04 & 10 & Oct. 21, 1997 & Oct. 23,2000 & \\
\hline CA05 & 4 & Nov. 3, 1997 & Oct. 30,2003 & \multirow{2}{*}{ Berm, III } \\
\hline CA06 & 10 & Nov. 3, 1997 & Nov. 132003 & \\
\hline CA07 & 4 & Oct. 22, 1997 & October 2008 & \multirow{2}{*}{ Berm, IV } \\
\hline CA08 & 10 & Oct. 22, 1997 & October 2008 & \\
\hline CA09 & 4 & Nov. 10, 1998 & October 2013 & \multirow{2}{*}{ Berm, I } \\
\hline CA10 & 10 & Nov. 11, 1998 & October 2013 & \\
\hline CA11 & 4 & October 26,2000 & October 2018 & \multirow{2}{*}{ Berm, II } \\
\hline CA12 & 10 & October 26,2000 & October 2018 & \\
\hline CA13 & 4 & To be determined & To be determined & Mound \\
\hline
\end{tabular}




\subsection{Document Organization}

This report documents work to date related to the LTCD test.

- Section 2 describes the test location, materials, and coupon emplacement process.

- Section 3 describes the results of the 6-year coupon retrieval and evaluation, including measurement results, corrosion rates, and uncertainties.

- Section 4 evaluates the results against the previous first-year results (reported by Mizia, et al. 2000), the 3-year results (reported by Adler Flitton, et al. 2001), and results from other non-site corrosion tests. Section 4 also explores the evidence of trends, and tentatively estimates corrosion rates for some of the metals.

- Section 5 discusses the characteristics of the soil and the role the physical and chemical make-up of the soil influences corrosion.

- Section 6 discusses the microbiological aspects influencing corrosion.

- Section 7 presents the field monitoring to date.

- Section 8 presents conclusions and recommendations.

- Section 9 lists the references.

- Appendix A provides a summary of the material test reports for all metals used in the test.

- Appendix B provides cleaning curves for the metals that were cleaned using chemical cleaning methods.

- Appendix C provides mass loss and corrosion rate details for the 6-, 3- and 1-year exposed coupons.

- Appendix D provides the vertical scanning-interferometry measurements of select year exposed metal coupons and blanks.

- Appendix E provides analytical chemistry details for adhering soils and blank soils for the beryllium at the $10-\mathrm{ft}$ level for select exposures.

- Appendix F provides scanning electron microscope images and spectra for beryllium samples from the 1-, 3-, and 6-year exposed coupons.

- Appendix G provides mass loss comparison graphs.

- Appendix H provides electrical resistance probe graphs.

- Appendix I provides soil chemistry and properties for the soil being tested.

- Appendix J provides microbiological results in detail.

- Appendix K provides soil moisture profiles.

- Appendix L provides soil gas analysis. 


\section{DESCRIPTION OF DIRECT TESTING}

The direct corrosion testing focuses on a timed study of corrosion under natural SDA environmental conditions. The testing consists of burying metal coupons assembled in arrays, then retrieving the coupons after various time intervals ranging from one year to as many as 32 years. Corrosion rates are determined from the change in coupon weights over time. Activities associated with the direct corrosion testing are being conducted in accordance with standard practices and guidelines, as appropriate, including but not limited to American Society for Testing and Materials (ASTM) Methods G 1, G 4, G 15, G 16, G 30, and G 46.

\subsection{Test Coupons and Materials}

Each coupon array consists of four test coupons of each of the following nonradioactive metals: low-carbon steel, Type 304L stainless steel, Type 316L stainless steel, welded Type 316L stainless steel, Inconel 718, Beryllium S200F, Aluminum 6061, Zircaloy-4, and welded Ferralium 255, for a total of 36 coupons in each coupon array.

The selection of test materials is based mostly on a study by Rood and Adler Flitton (1997), which determined that Types 304/304L and 316/316L stainless steels, Inconel 718, Beryllium S200F, Aluminum 6061, and Zircaloy-4 were appropriate materials to be included in the corrosion test. The decision was based on the amounts and types of material present at the SDA, and on the conclusion that these alloys produce activation products after exposure in a neutron flux. Welded Type 316L stainless steel was included to investigate stress-corrosion cracking. Carbon steel was added because of the large underground corrosion database available for this material and because it is used for the disposal liners of the 55-ton scrap casks and for various other disposal containers buried at the SDA. Welded Ferralium 255 (a duplex stainless steel) was also added to the list, as it was the prospective material for high integrity disposal containers that might be used in the future for disposal of some wastes.

The corrosion coupons are $3 \times 3 \times 1 / 8$ in. (Figure 2-1) with a 0.56 -in.-diameter hole in the center. The certified material test reports for the coupons were previously provided in Appendix A of the first year report (Mizia, et al. 2000); and Appendix A in this report provides a summary version. In general, the coupon surface finish is 120 grit; the exception is the beryllium coupons, which have a 125 Root Mean Square (RMS) finish (the same surface finish as the beryllium waste disposed at the SDA).

\subsection{Coupon Preparation}

The corrosion coupons were obtained from a commercial vendor who has an implemented INEELapproved quality program. When the coupons arrived at the INEEL, they were handled with tongs or gloved hands. All coupons except those composed of beryllium were stamped with a unique INEEL identification number; the brittleness of the beryllium material precludes stamping, so an alternate identification method was used (chemical etching at the beryllium supplier). All coupons were measured, cleaned, and pre-weighed at the vendor in accordance with the requirements of ASTM Method G 1. Certification papers for the chemical composition and physical properties of all coupons were archived. Mass, dimensional measurements, and calculated surface area for all coupons was subjected to independent verification. Each coupon was individually photographed on a background sheet that contains the coupon number, material, surface area, and mass (Figure 2-1 is an example). All coupon data are recorded in controlled laboratory. 


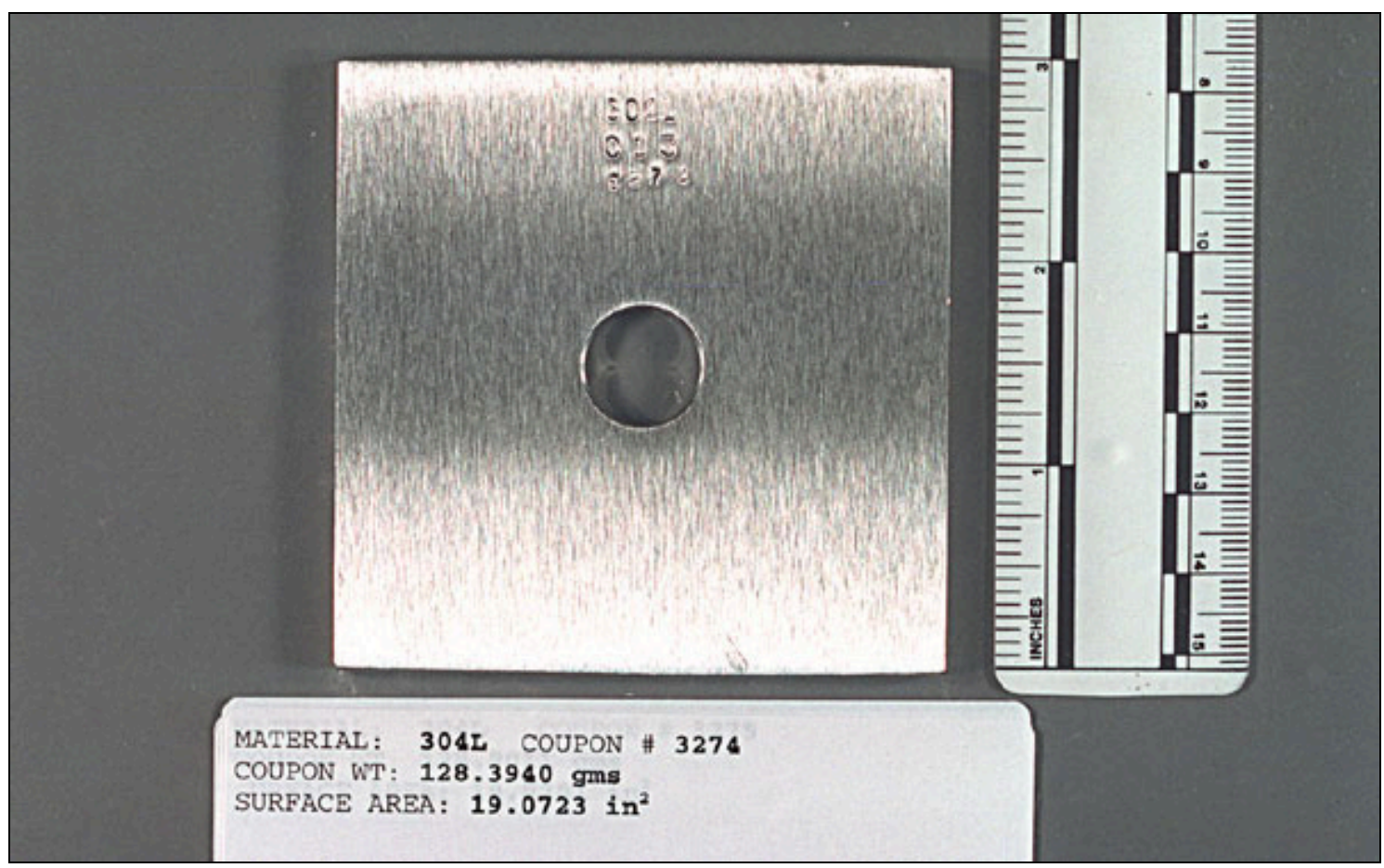

Figure 2-1. Typical corrosion coupon; this one is 304L stainless steel.

\subsection{Coupon Array Assembly}

The coupons were assembled onto coupon arrays constructed of polypropylene rods with Teflon tubing as spacers (Figure 2-2), with a 6-in. minimum separation between coupons. Polypropylene and Teflon were selected because these inert materials are expected not to chemically or electrically interfere with the corrosion of the coupons. Each coupon array consists of six polypropylene rods (of three different lengths), with the coupons and Teflon spacers installed on the rods as shown in Figure 2-3. Each end of the polypropylene rod has engraved Teflon identification markers and is secured with a threaded nylon nut. Each coupon array consists of four test coupons of each of the following metals: low-carbon steel, Type 304L stainless steel, Type 316L stainless steel, welded Type 316L stainless steel, Inconel 718, Beryllium S200F, Aluminum 6061, Zircaloy-4, and Ferralium 255, for a total of 36 coupons. In the assembly of the coupon arrays, the locations of coupons of various material types were randomly selected.

Twelve sets of 36 coupons were prepared and have been installed for testing. In addition, two complete sets are stored as archived sets. One of these is maintained as a reserve set, for possible burial at a later date, and the other was archived for comparison with the timed test. 


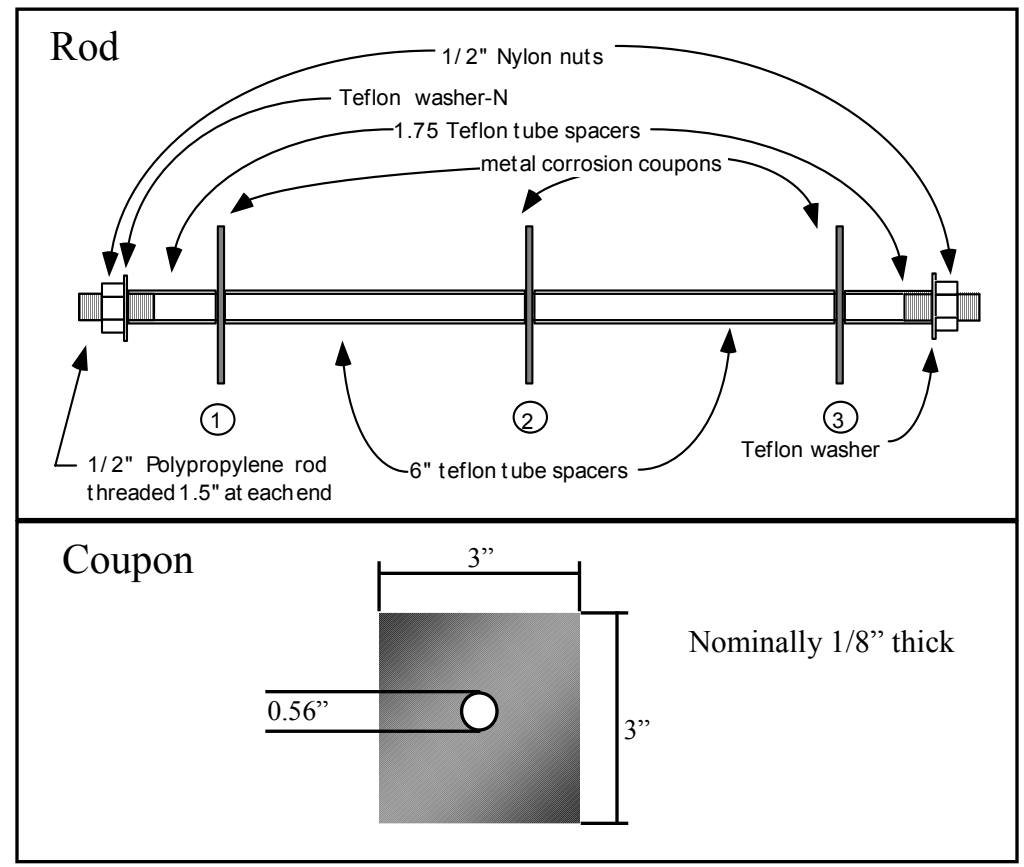

Figure 2-2. Corrosion coupon assembly details.

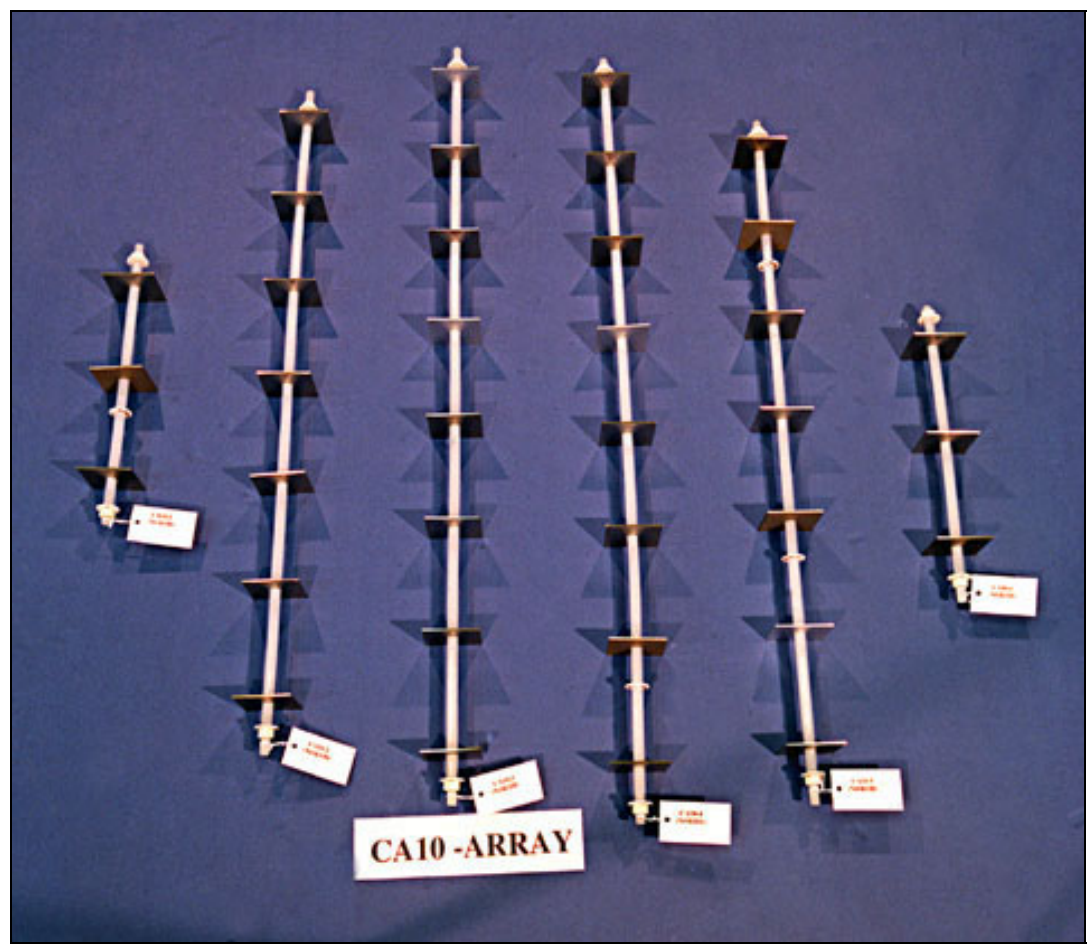

Figure 2-3. Coupon array. 
Since identification numbers on the individual coupons might degrade during the test, a secondary method of identification is also employed. Each coupon has a specific coordinate in the coupon array and is assigned a test identification number based on this placement. An example of the coupon array/corrosion coupon nomenclature is: CA01-1-1. The first four digits refer to the coupon array number, the next number refers to the rod number in the array, and the last number refers to the coupon position on that rod. Figure 2-4 illustrates this nomenclature system. After the corrosion coupons were placed on the coupon arrays, photographs were taken of each array for baseline documentation. A table documents the location of each coupon as originally placed on the coupon array.

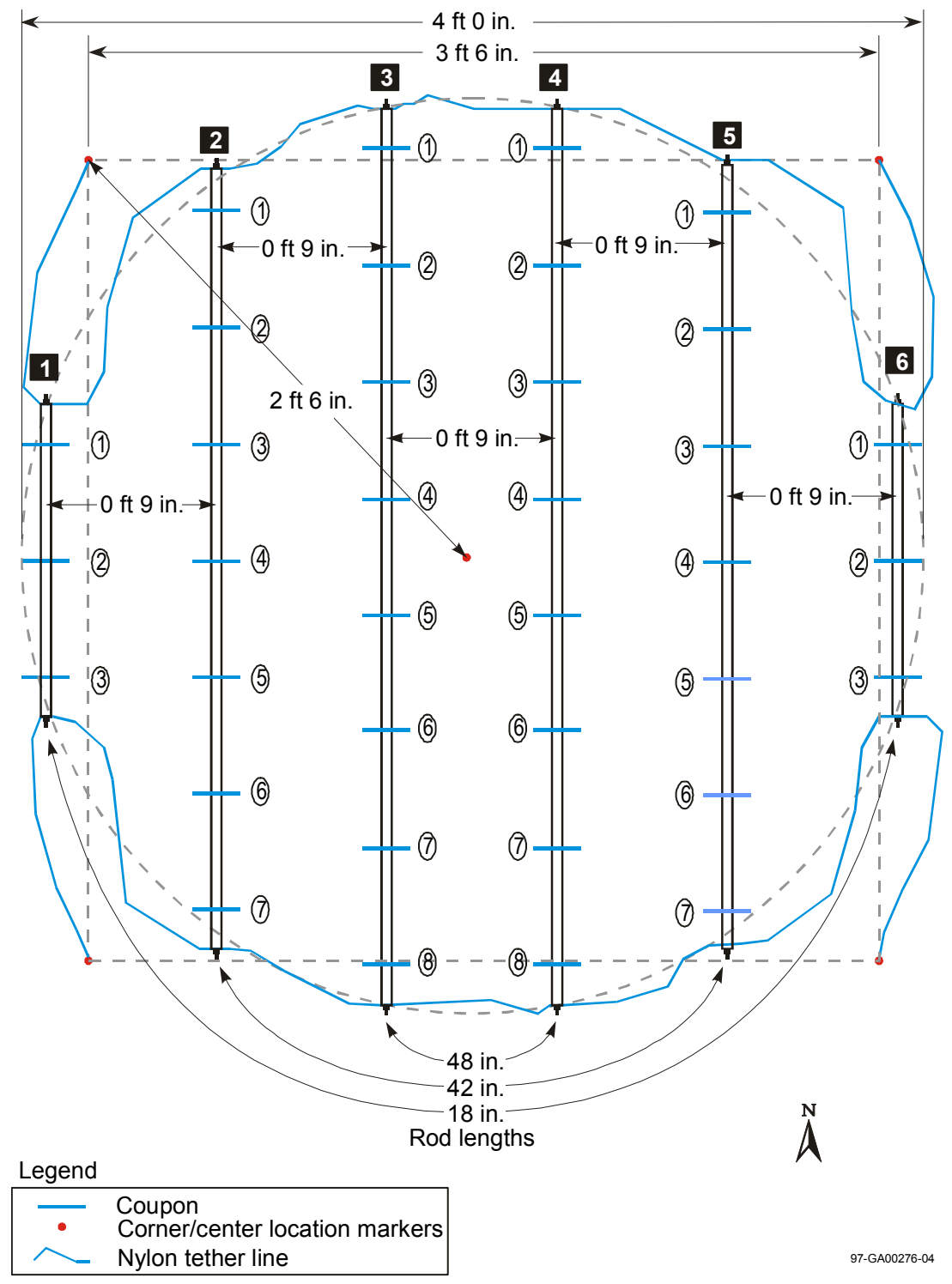

Figure 2-4. Numbering system for coupons installed in a coupon array. 


\subsection{Coupon Array Emplacement}

In general, coupon arrays are buried at depths of $4 \mathrm{ft}$ and $10 \mathrm{ft}$ at each of the designated locations in the berm, as shown in Figure 1-3. The 4- and 10-ft burial depths were chosen to represent the activated core components that are buried from $4 \mathrm{ft}$ to a maximum of $20 \mathrm{ft}$ below the surface in the SDA. The 4-ft depth provides a high level of exposure to changing environmental conditions, while the $10-\mathrm{ft}$ depth more closely represents actual conditions for waste buried at the SDA. At each location, a hole was drilled using a drill rig equipped with a 6-ft-diameter auger (see Figure 2-5). Coupon arrays, each consisting of six polypropylene rod assemblies, were placed in the holes at the $10-\mathrm{ft}$ depth, with nine inches separation between the rods. Following burial of each coupon array at the $10-\mathrm{ft}$ level, the 6 - $\mathrm{ft}$ diameter hole was back-filled in 8-in. lifts with Spreading Area B soil and manually compacted to approximately the 4-ft level, at which point the second coupon array was placed. The hole was then back-filled to the surface in 8 -in. lifts with manual compaction. Figure 2-6 shows a typical coupon array placed in a hole. The emplacement procedure is documented in "Corrosion Coupon Installation," TPR-1659.

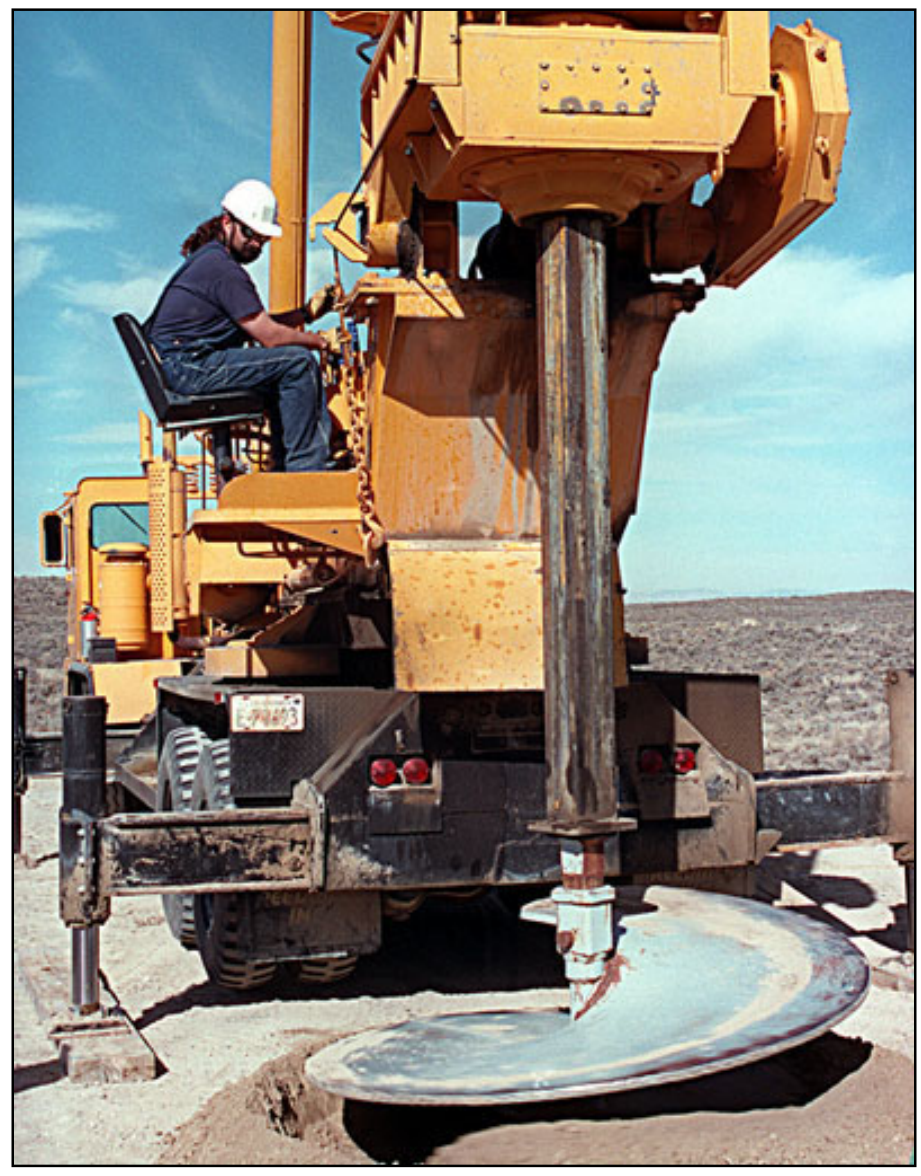

Figure 2-5. Drill rig with 6-ft-diameter auger. 


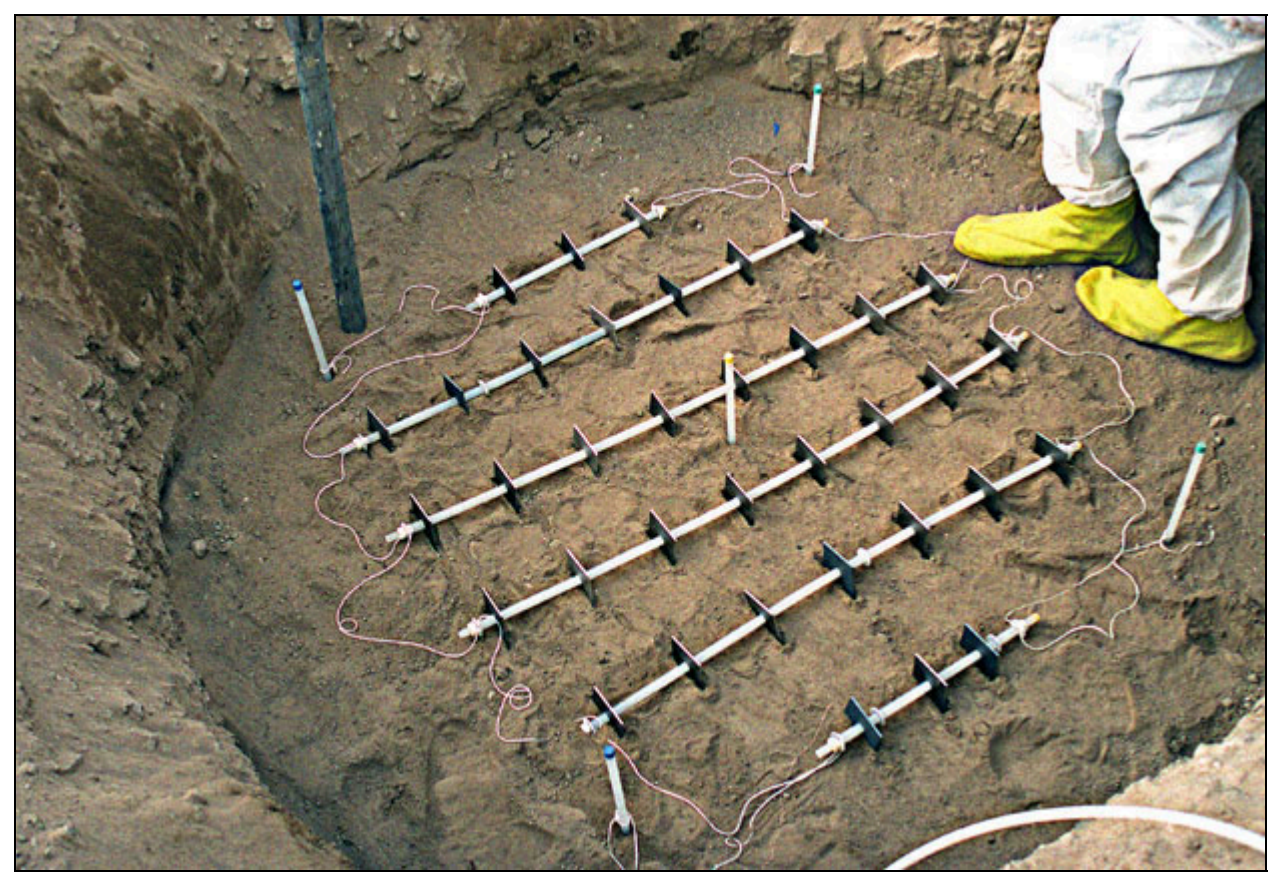

Figure 2-6. Coupon array in test hole.

\subsection{Coupon Array Removal}

After coupon arrays have been exposed to corrosion conditions for the scheduled exposure time (1, 3,6 years or more), they are removed for evaluation. The coupons are recovered by reopening the hole manually and by using soil excavation equipment. The procedure documenting the recovery is "Corrosion Coupon Recovery," TPR 1660. The drill is used to dig to $3 \mathrm{ft}$ or the hole is excavated manually, then the hole is manually opened from the 3-ft level to the 4-ft level, and coupon array was removed. Using either the drill or soil vacuum extractor (see Figures 2-7 and 2-8), the hole is then dug to approximately $8 \mathrm{ft}$, with the remaining soil excavated manually to recover the coupon array. The coupons are extracted carefully from the hole, with care not to lose the adhering soil around them. The excavated coupons are double bagged and transported to the appropriate laboratory, disassembled, and the corrosion products sampled. Figure 2-9 depicts containment process. A 1-year exposed coupon rod after transport to the laboratory is shown in Figure 2-10. Figure 2-11 shows a coupon rod after three years of exposure (note a carbon steel coupon centered on rod). Figures 2-12 and 2-13 shows coupon rods from the 10-ft level after six years of exposure. 


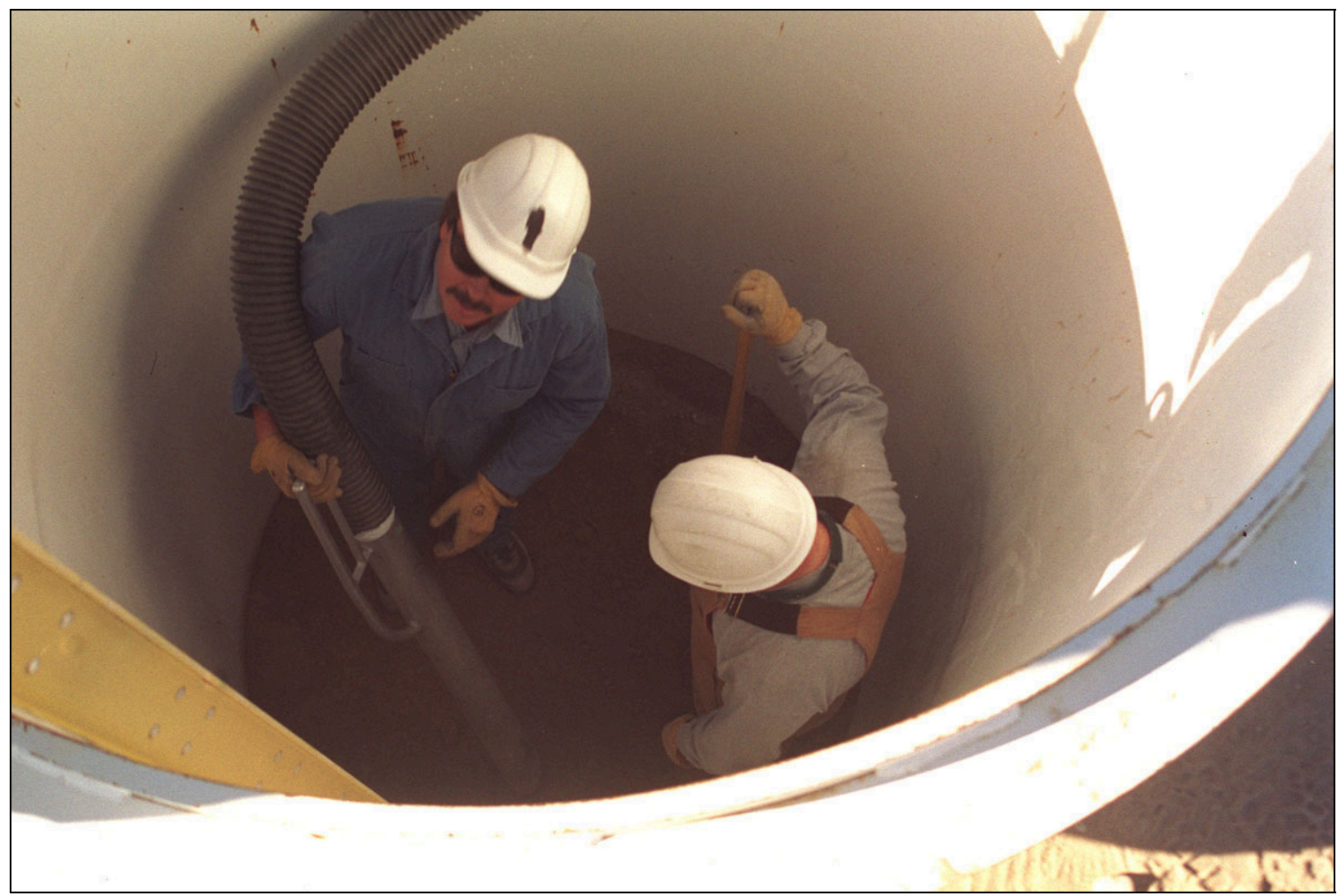

Figure 2-7. Soil Vacuum extraction - hose end.

Workers vacuum soil while in the cave-in-protection sleeve.

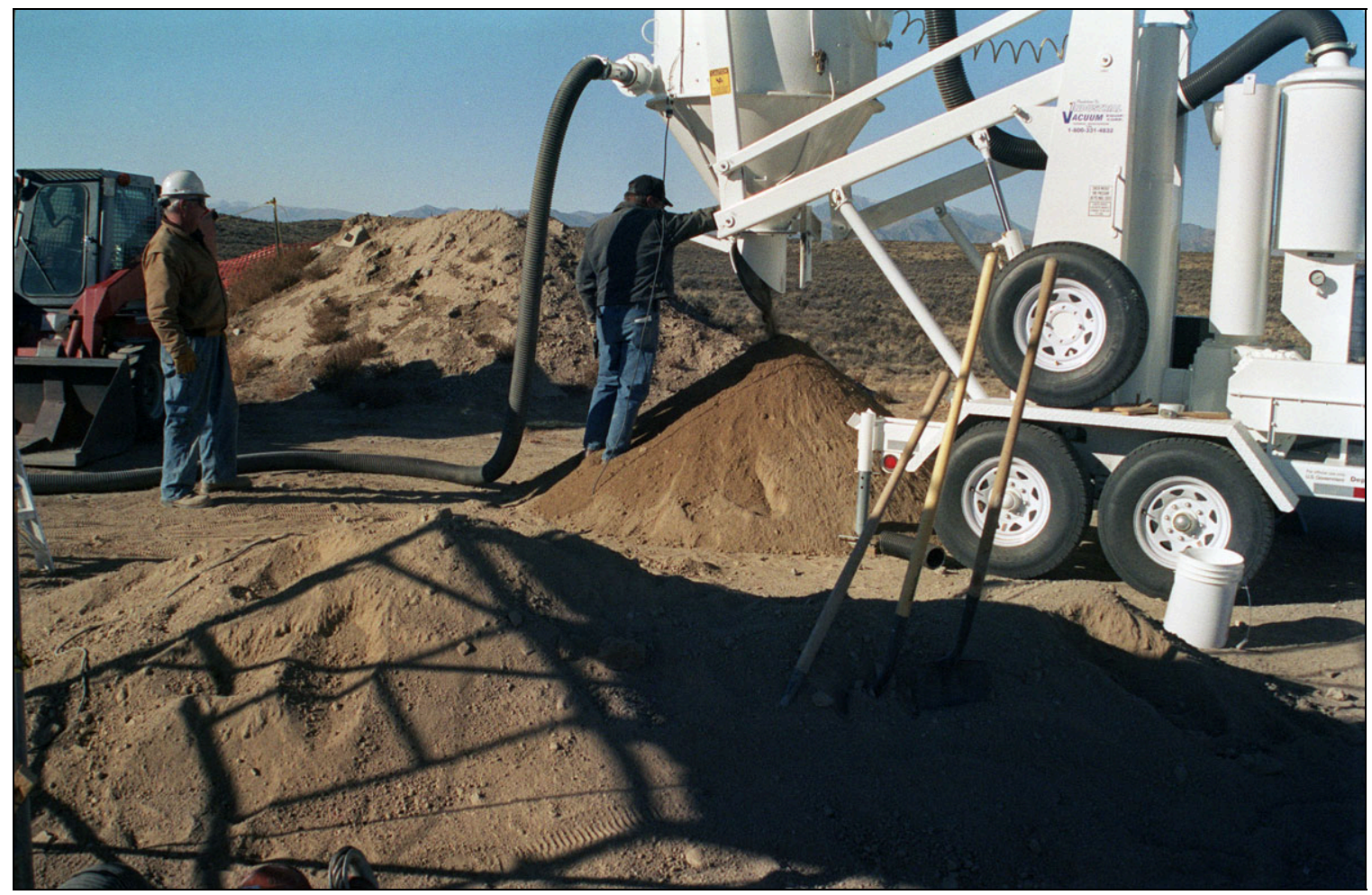

Figure 2-8. Soil vacuum extractor - hopper/vacuum end. 


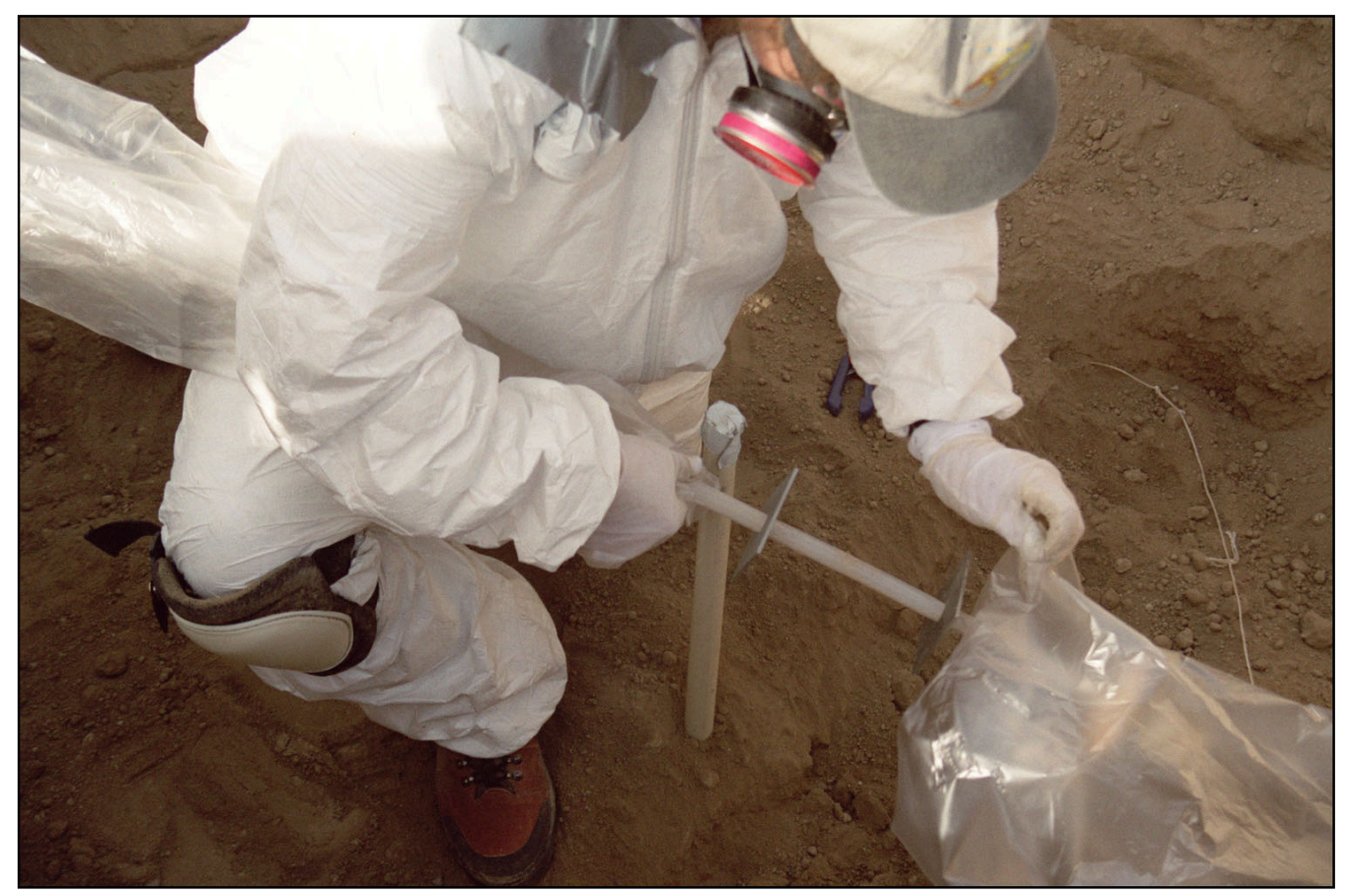

Figure 2-9. Double bagging coupons.

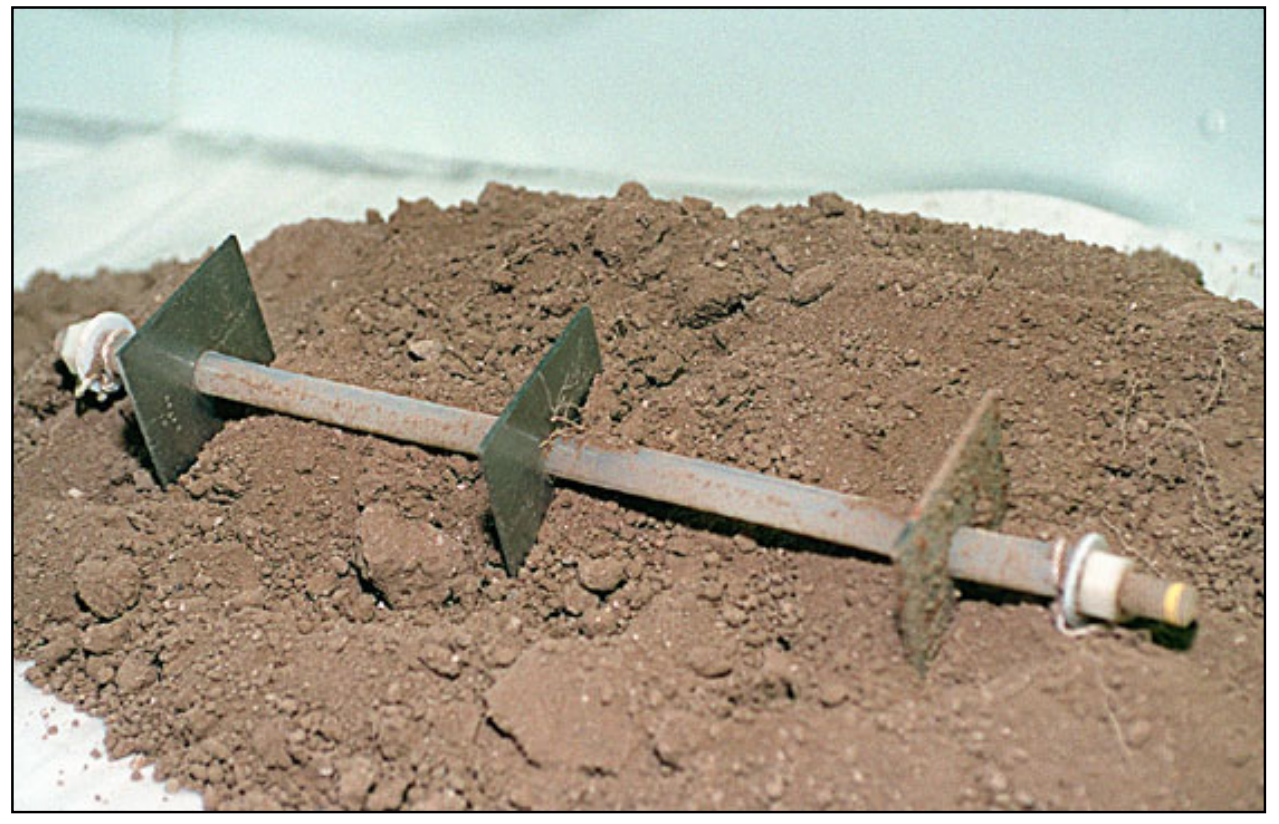

Figure 2-10. One year exposed rod from coupon array after arrival at laboratory. 


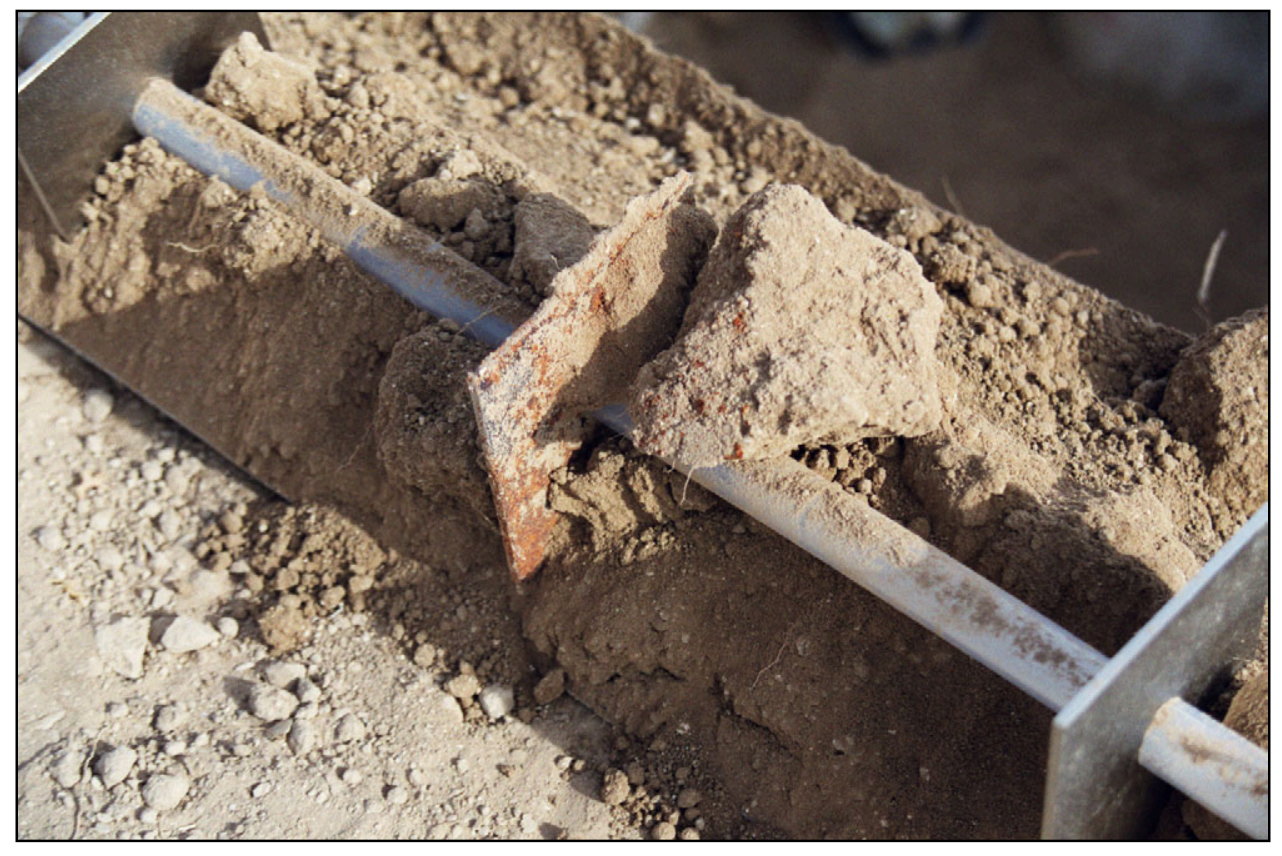

Figure 2-11. Three-year exposed rod from 4-ft coupon array.

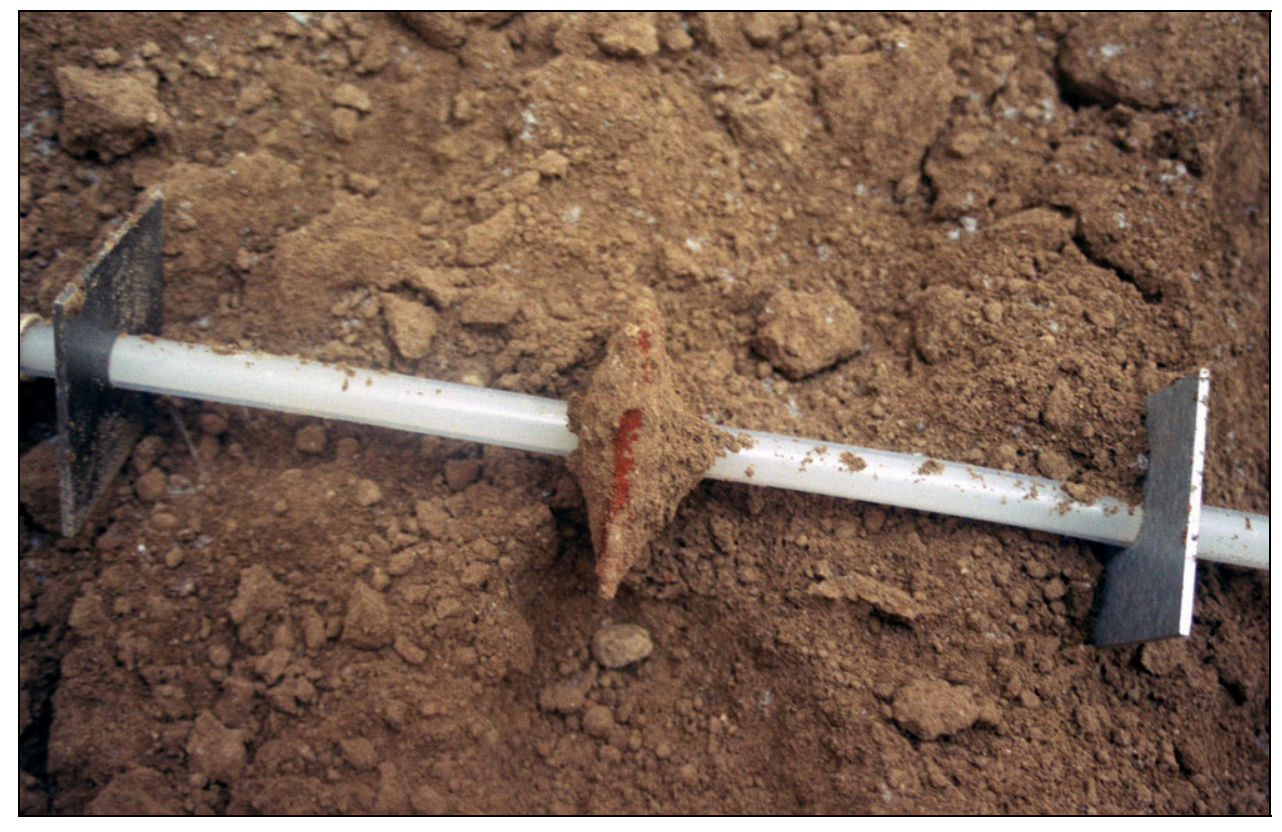

Figure 2-12. Six-year exposed rod from 10-ft coupon array.

Note the carbon steel sample, centered on the rod, with adhering soil. 


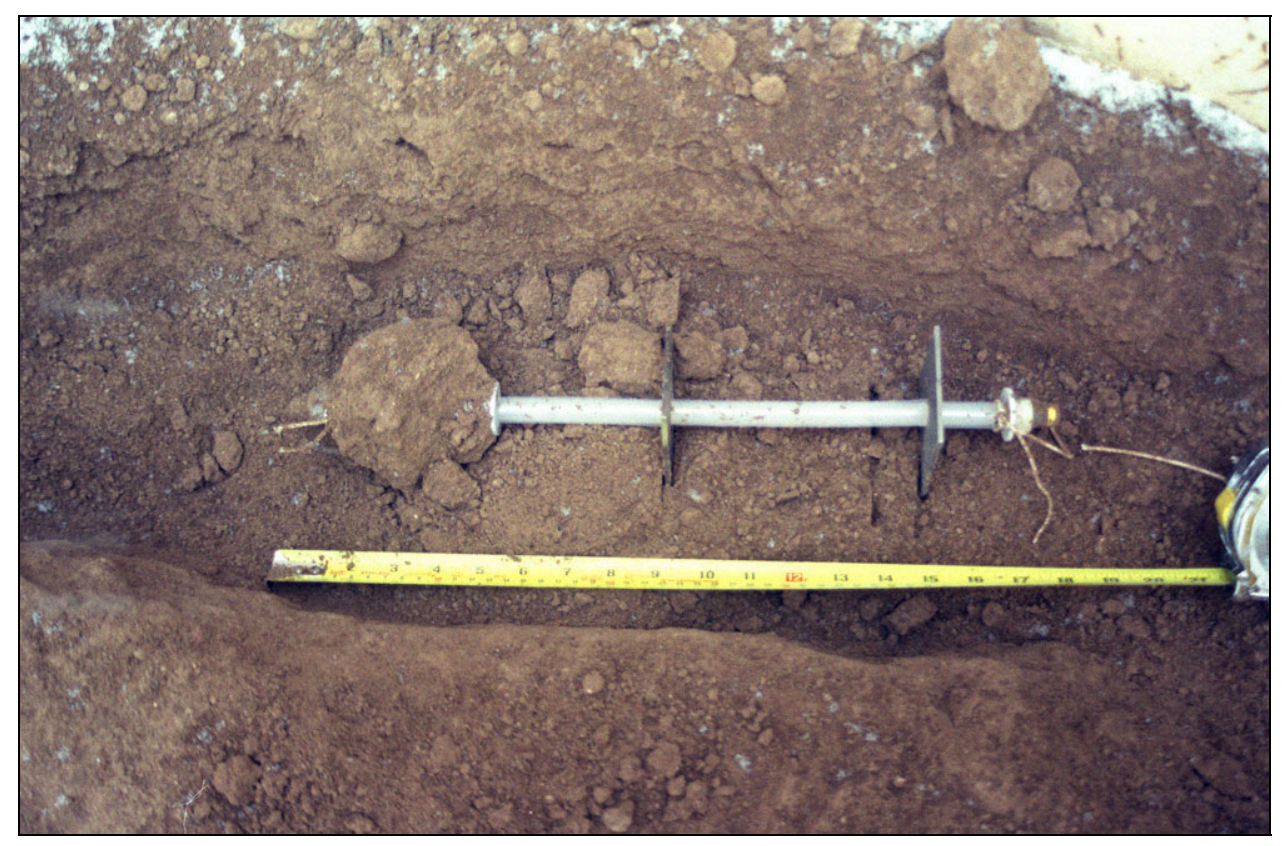

Figure 2-13. Six-year exposed rod from 10-ft coupon array.

Note the beryllium sample, leftmost, with adhering soil approximately the size of a softball.

\subsection{Coupon Cleaning}

The coupon cleaning process is designed to remove all corrosion products from the coupons. The mass of the coupon after corrosion and cleaning is compared to the original mass, and the difference represents the loss of metal to corrosion. A corrosion rate can be calculated then based upon the metal type (density of material), the mass change and the exposure time.

All coupons were cleaned with a washing/brushing process, per the requirements of ASTM G 1 6.2.1, using deionized water and a nonmetallic soft bristle brush. The Ferralium 255, 304L and 316L stainless steels, Inconel 718, and Zircaloy-4 coupons required no further cleaning. The aluminum and carbon steel coupons were chemically cleaned according to the appropriate method defined in Table A1 of ASTM G 1 (in addition to the wash/brush process). Beryllium has no ASTM G 1 cleaning procedure; however, the beryllium vendor recommended using either the ASTM G 1 magnesium or aluminum cleaning procedure for the beryllium. At first the magnesium cleaning procedure was used, but due to the costs and requirements of obtaining the proper chemicals, the aluminum procedure was used after the first year recovery. A summary of applicable ASTM G 1 procedure designations is in Table 2-1:

Table 2-1. ASTM G 1 chemical cleaning procedures.

\begin{tabular}{|l|c|l|}
\hline \multicolumn{1}{|c|}{ Metal } & Procedure & \multicolumn{1}{c|}{ Comments } \\
\hline \multirow{2}{*}{ Beryllium ${ }^{\text {a }}$} & C.5.2 & Magnesium cleaning procedure used on samples exposed 1 year. \\
\cline { 2 - 3 } & C.1.1 & Aluminum cleaning procedure used on samples exposed 3 and 6 years. \\
\hline Carbon Steel & C.3.5. & Cleaning procedure used on samples exposed 1, 3, and 6 years. \\
\hline Aluminum & C.1.1 & Cleaning procedure used on samples exposed 1, 3, and 6 years. \\
\hline
\end{tabular}


All cleaning activities for all alloys, along with masses measured after each cleaning cycle, were recorded in the lab notebooks. To ensure that all deposits were removed and that the coupons were clean, cleaning curves were calculated for the coupons in accordance with ASTM Method G 1. Appendix B details cleaning curves for the aluminum, beryllium and carbon steel for the 6-year mass-loss measurements.

\subsection{Mass-Loss Measurement Method}

After the coupons were cleaned, they were weighed on the Mettler 163 balance. The mass was subtracted from the original mass of the coupon (before exposure), as recorded in the laboratory notebooks, to calculate the mass loss due to corrosion, and the corresponding corrosion rate was calculated. The coupons were also examined with a stereo microscope for localized corrosion (pitting, etc). All samples, including the coupons and metallographic specimens, are archived and stored.

Mass loss was measured in grams, and the corrosion rate was calculated in mils per year (MPY). MPY is the conventional notation for corrosion rates and is commonly converted into $\mathrm{mm} / \mathrm{y}$ or shown as the inverse relation of $\mathrm{y} / \mathrm{mm}$. The typical corrosion rate calculation is as follows:

$$
\text { CorrosionRate }=\frac{K \times \Delta M}{D \times A \times T}
$$

Where:

$$
\begin{aligned}
& \mathrm{K}=\text { conversion constant } \\
& \Delta \mathrm{M}=\text { change in mass }(\mathrm{g}) \\
& \mathrm{D}=\text { material density }\left(\mathrm{g} / \mathrm{cm}^{3}\right) \\
& \mathrm{A}=\text { exposed surface area }\left(\mathrm{cm}^{2}\right) \\
& \mathrm{T}=\text { exposure time in years }(\mathrm{y})
\end{aligned}
$$

Conversion factors:

$1 \mathrm{~cm}=10 \mathrm{~mm}$

1 in. $=1000$ Mils

1 in. $=2.54 \mathrm{~cm}=25.4 \mathrm{~mm}$

$1 \mathrm{MPY}=39.37 \mathrm{~mm} / \mathrm{y}$

The results are presented in Section 3.

\subsection{Mass-Loss Measurement Uncertainties}

The corrosion rate is calculated from a coupon mass-loss measurement, so it is important that uncertainties associated with the mass-loss measurement be accounted for. This is especially true for the stainless steels and other metals whose corrosion rates are anticipated to be very low. Measurement uncertainties for the corrosion test are of three types:

- $\quad$ Statistical errors for the Mettler 163 balance used to weigh the coupons

- Possible loss of base metal (in addition to corrosion material) to the wash/brush process

- $\quad$ Possible loss of base metal (in addition to corrosion material) to the chemical treatment.

As part of the evaluation of the first year corrosion results, Wilkins (Wilkins, et al. 1998) lead the investigation of the laboratory balance measurement uncertainty for the range of corrosion coupon masses, that is, at 50, 100, and 150 grams. (Coupon mass range from a low of about $37 \mathrm{~g}$ for the 
beryllium coupons to a high of about $146 \mathrm{~g}$ for the Inconel 718 coupons.) Balance uncertainties (2 $\sigma, 95 \%$ confidence level) were found to be $\pm 0.4 \mathrm{mg}$ for the 50 - and 100 -gram balance ranges and $\pm 0.8 \mathrm{mg}$ for the 150 -gram balance range.

The measurement uncertainty study also investigated the corrosion coupon mass loss due to wash/brush cleaning, chemical cleaning, and jet abrasion cleaning. As part of the study, a series of coupon cleaning tests were conducted to collect statistically reliable mass-loss data for typical coupon cleaning processes. The tests consisted of cleaning unexposed archived Type 304L and Type 316L stainless steels and Inconel 718 coupons and recording the subsequent mass change. The results apply directly to the compositions tested: Type 304L and Type 316L stainless steels and Inconel 718.

The data from the balance uncertainties and cleaning uncertainties were combined to describe the total uncertainties attributed to the minimum detectable corrosion rates. A sufficient number of coupons and cleaning cycles were used to provide statistically significant uncertainties for the processes. The combined uncertainties found for the wash/brush cleaning process (the cleaning method applied to the corrosion test), at a $95 \%$ confidence level, were $\pm 0.89 \mathrm{mg}$ for $304 \mathrm{~L}$ stainless steel, $\pm 0.98 \mathrm{mg}$ for $316 \mathrm{~L}$ stainless steel, and $\pm 0.92 \mathrm{mg}$ for Inconel 718 . Again, these combined results apply only to the three materials that were tested and applies when the wash/brush process is used whereas the uncertainties determined for the mass measurement process apply to all coupon compositions.

Together, the studies show a small uncertainty. For most of the coupons, the measurement of very low mass losses from the 1, 3, and now the 6-year exposures fall within the balance variability and cleaning mass-loss measurements. For the results reported in Section 3, whenever the measured mass loss is less than either the balance variability or the combined uncertainty (as applicable), the corrosion rate is listed as "No reportable corrosion." With exception to the Zircaloy-4 coupons, the mass losses from 6-year exposure generally fall outside of the balance variability and cleaning mass-loss measurements, so corrosion rates are reported for these results.

Six-year corrosion coupons composed of beryllium, aluminum, and carbon steel were subjected to a chemical cleaning process (in addition to the wash/brush process). To address concerns about uncertainties introduced by the chemical cleaning process, a blank (unexposed) specimen of the same material was run through the chemical cleaning process along with the corroded test specimens. The blank specimen was one of the reserved archived samples and thus from the same heat (lot) as the corroded test coupons. The mass losses measured after cleaning the blank coupons are subtracted from the mass losses of the corresponding corroded coupons to arrive at the mass loss due to corrosion, as reported in Section 3. 


\section{DIRECT TESTING RESULTS}

Two coupon arrays were retrieved in the fall of 2003 (6-year coupons). The results of the corrosion evaluation are reported here along with and in comparison to the coupon arrays that were retrieved in the fall of 1998 (1-year coupons) and the fall of 2000 (3-year coupons). The coupons were subjected to the mass-loss corrosion evaluation described in the previous subsections. Tables with mass losses for the individual coupons, along with the corresponding corrosion rates for the corrosion evaluation from the 1-, 3-, and 6- year coupons are presented in Appendix $\mathrm{C}$ with the associated cleaning curves presented in Appendix B.

\subsection{Mass-Loss Measurement Results}

In all, 72 6-year coupons were recovered, cleaned, and weighed. A discussion of significant results from the 6-year coupons follows.

\subsubsection{Aluminum}

The corrosion rates (see Table 3-1) for the aluminum coupons were higher at the 4-ft level than at the $10-\mathrm{ft}$ level. All of the aluminum coupons had pit initiation sites or pitting with the 4-ft level coupons showing the most pitting. Two aluminum coupons, one from the 4-ft level and one from the 10 -ft level were measured with vertical scanning-interferometry (see Appendix D). This technique maps the surface of the samples and measures pit depth. Pit depth analysis is summarized in Table 3-2. Photos of one aluminum sample (front and back) from the 4-ft level are shown in Figure 3-1 and Figure 3-2.

Table 3-1. Aluminum 6-year exposure corrosion rate summary.

\begin{tabular}{cc|cc|cc}
\hline \multicolumn{2}{c|}{$\begin{array}{c}\text { Level below surface } \\
\mathrm{Ft}\end{array}$} & $\mathrm{m}$ & $(\mathrm{MPY})$ & $(\mathrm{y} / \mathrm{mm})$ & \multicolumn{2}{c}{ Average for 4 coupons } \\
\cline { 3 - 5 } & $(\mathrm{MPY})$ & 0.0015 & $(\mathrm{y} / \mathrm{mm})$ \\
\hline 4 & 1.22 & $0.0005-0.0030$ & $13,123-78,405$ & 25,816 \\
10 & 3.05 & $0.0005-0.0009$ & $43,668-65,789$ & 0.0006 & 60,569 \\
\hline
\end{tabular}

Table 3-2. Aluminum 6-year exposure pitting corrosion summary.

\begin{tabular}{cc|cc}
\hline \multicolumn{2}{c|}{ Level below surface } & \multicolumn{2}{|c}{ Maximum pit depth } \\
$\mathrm{Ft}$ & $\mathrm{m}$ & Sample number & $\mu \mathrm{m}$ \\
\hline 4 & 1.22 & 3497 & 218 \\
10 & 3.05 & 3500 & 212 \\
\hline
\end{tabular}




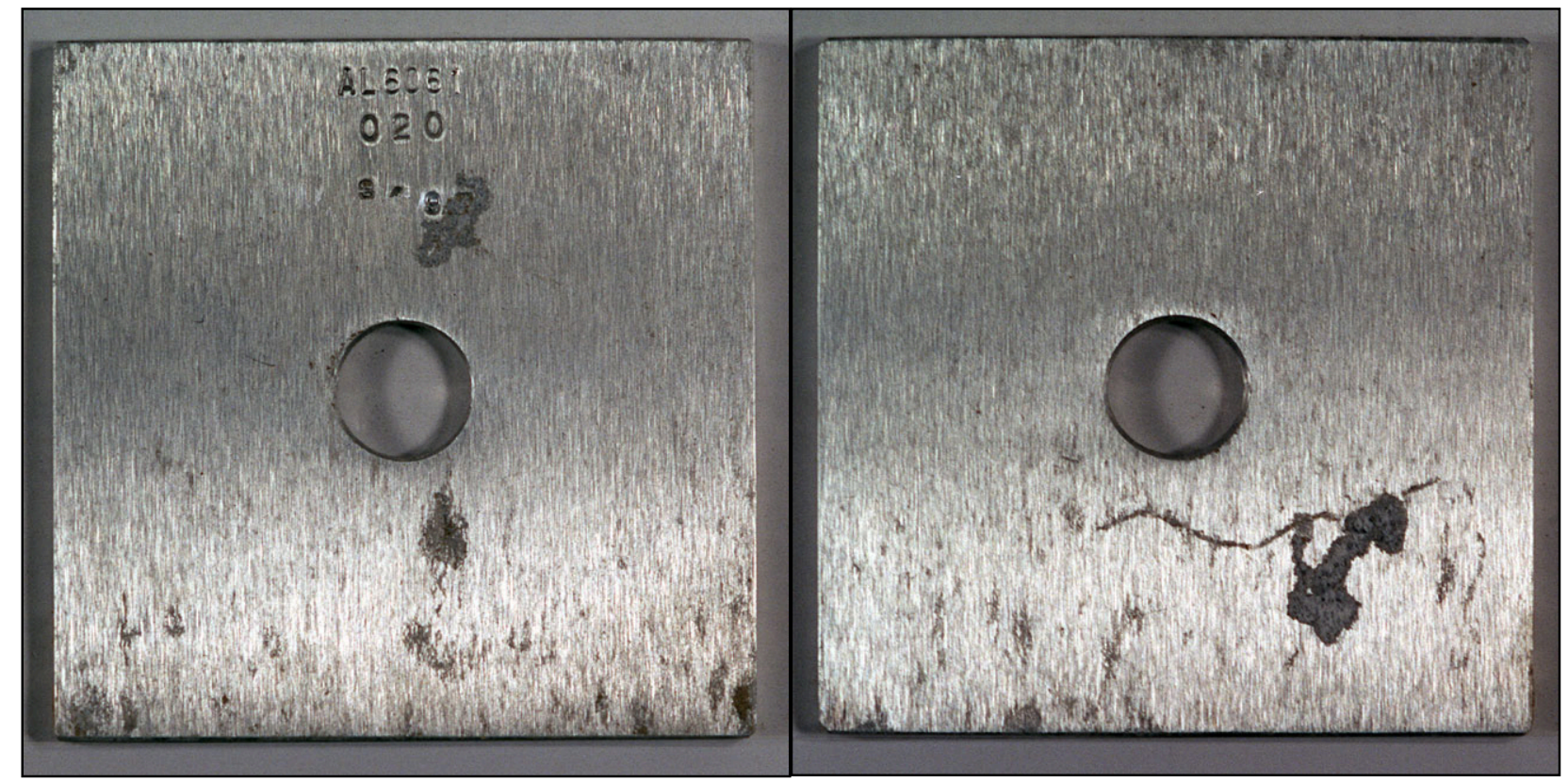

Figure 3-1. Aluminum coupon (\#3497) before cleaning. 6-yr exposure at 4-ft front and back views.

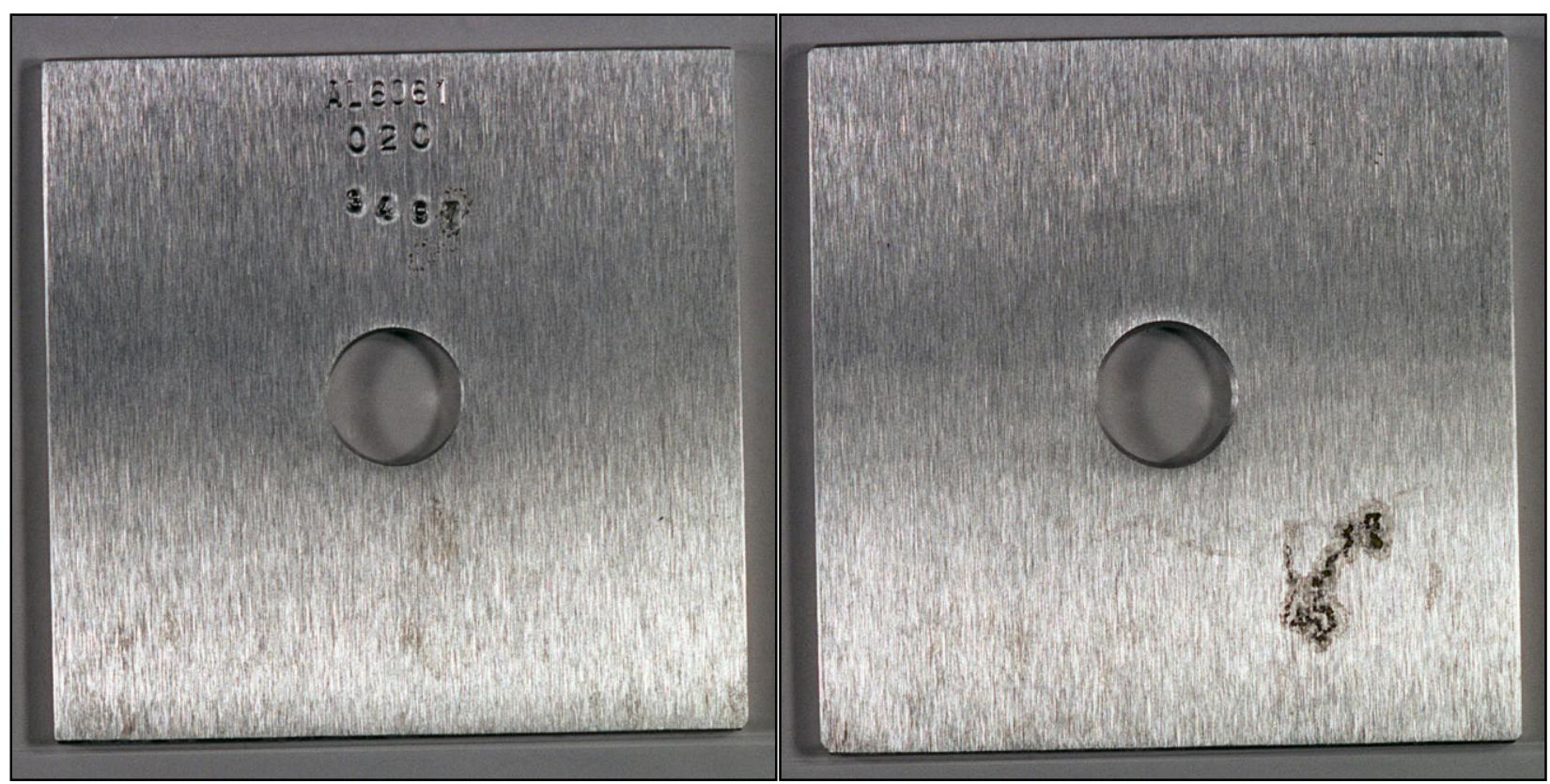

Figure 3-2. Aluminum coupon (\#3497) after cleaning. 6-yr exposure at 4-ft, front and back views. 


\subsubsection{Beryllium}

The beryllium coupons all had localized corrosion and exhibit corrosion in the form of pitting. The corrosion rates (see Table 3-3) for the beryllium coupons were higher at the 10-ft level than at the 4-ft level. All of the beryllium corrosion sites had soil and corrosion products tightly adhering to the surface of the coupon (see Figure 3-3). The corrosion product was observed as primarily soil with some white flakes. The adhering corrosion product was carefully removed for further chemical analysis and comparison to background soils. Appendix E contains the analytical results from the corrosion products removed from the coupons at the $10-\mathrm{ft}$ level, an analysis of a background soil sample taken at the $10-\mathrm{ft}$ level during recovery, and the analysis of the 3-yr exposure, 10-ft level corrosion product analysis. The corrosion scale remaining in the pitted areas after cleaning were black (see Figure 3-4). Further investigation of the pitted area were conducted using a Scanning Electron Microscope (SEM). Figure 3-5 shows an uncorroded beryllium coupon surface and Figure 3-6 shows a corroded beryllium coupon pit area. Further SEM analyses including surface chemical properties are in Appendix F. Each of the 6-year beryllium coupons were measured with vertical scanning-interferometry. Pit depth analysis is summarized in Table 3-4 with further measurement results in Appendix D.

Table 3-3. Beryllium 6-year exposure corrosion rate summary.

\begin{tabular}{cc|cc|cc}
\hline \multicolumn{2}{c|}{$\begin{array}{c}\text { Level below surface } \\
\mathrm{Ft}\end{array}$} & $\mathrm{m}$ & \multicolumn{2}{|c|}{ Range } & \multicolumn{2}{c}{ Average for 4 coupons } \\
& $(\mathrm{MPY})$ & $(\mathrm{y} / \mathrm{mm})$ & $(\mathrm{MPY})$ & $(\mathrm{y} / \mathrm{mm})$ \\
\hline 4 & 1.22 & $0.0043-0.0115$ & $3,423-9,156$ & 0.0085 & 4,618 \\
10 & 3.05 & $0.2002-0.3282$ & $120-195$ & 0.2611 & 151 \\
\hline
\end{tabular}

Table 3-4. Beryllium 6-year exposure pitting corrosion summary.

\begin{tabular}{cc|cc}
\multicolumn{2}{c|}{ Level below surface } & \multicolumn{2}{c}{ Maximum pit depth } \\
$\mathrm{Ft}$ & $\mathrm{m}$ & Sample number & $\mu \mathrm{m}$ \\
\hline 4 & 1.22 & 22 & 108 \\
10 & 3.05 & 26 & 189 \\
\hline
\end{tabular}




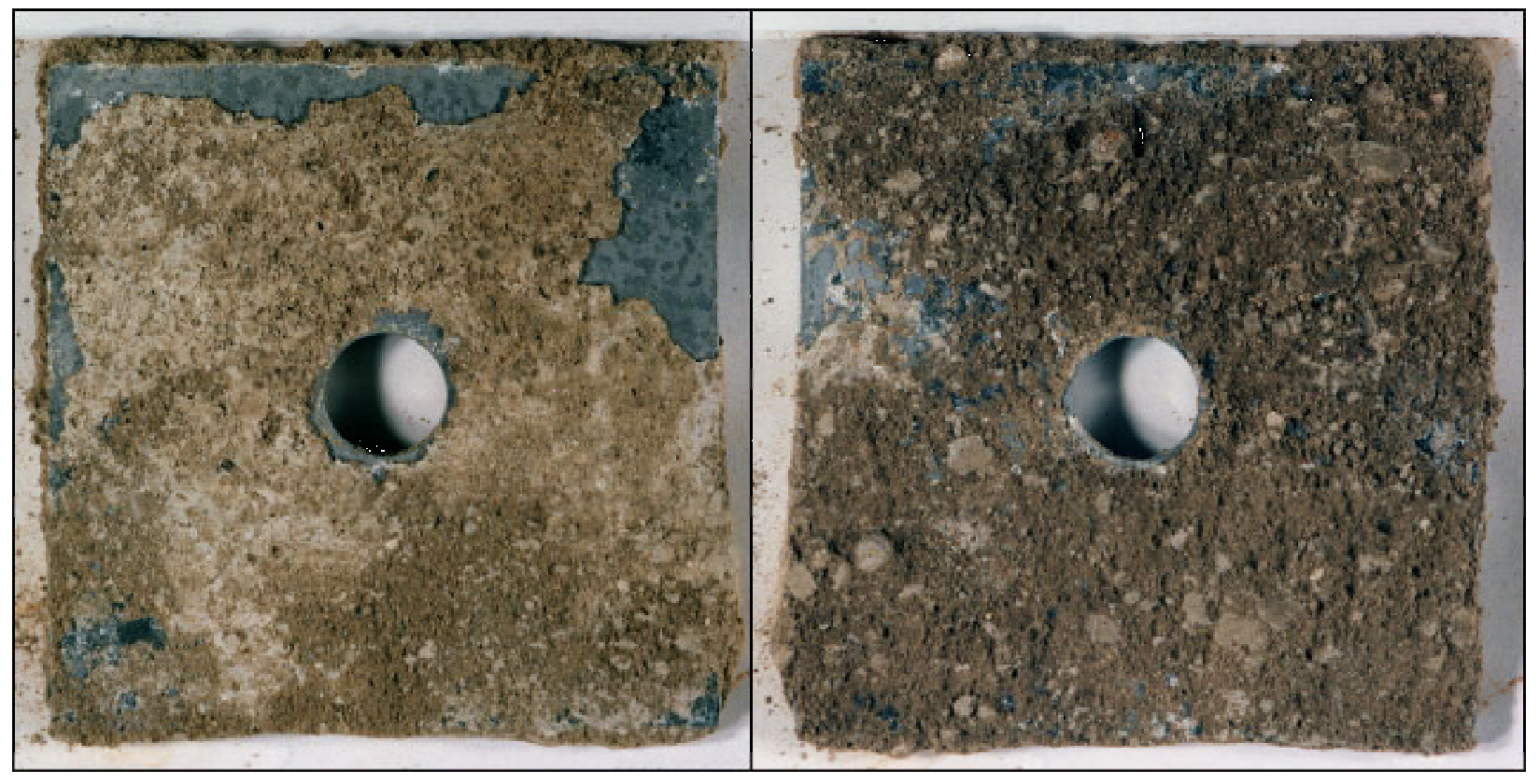

Figure 3-3. Beryllium coupon (\#24) before cleaning. 6-yr exposure at 10-ft, front and back views.
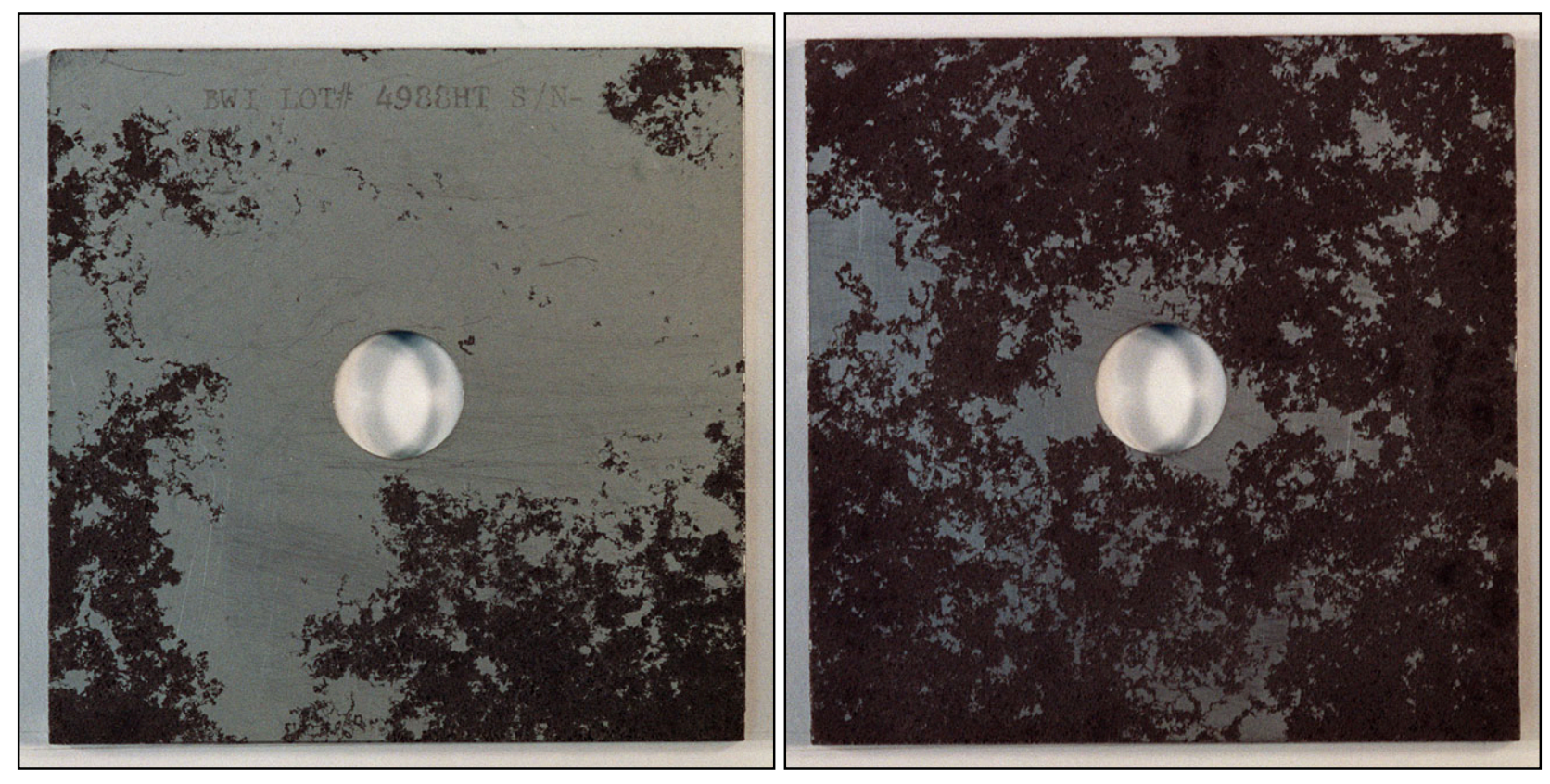

Figure 3-4. Beryllium coupon (\#24) after cleaning. 6-yr exposure at 10-ft, front and back views. 


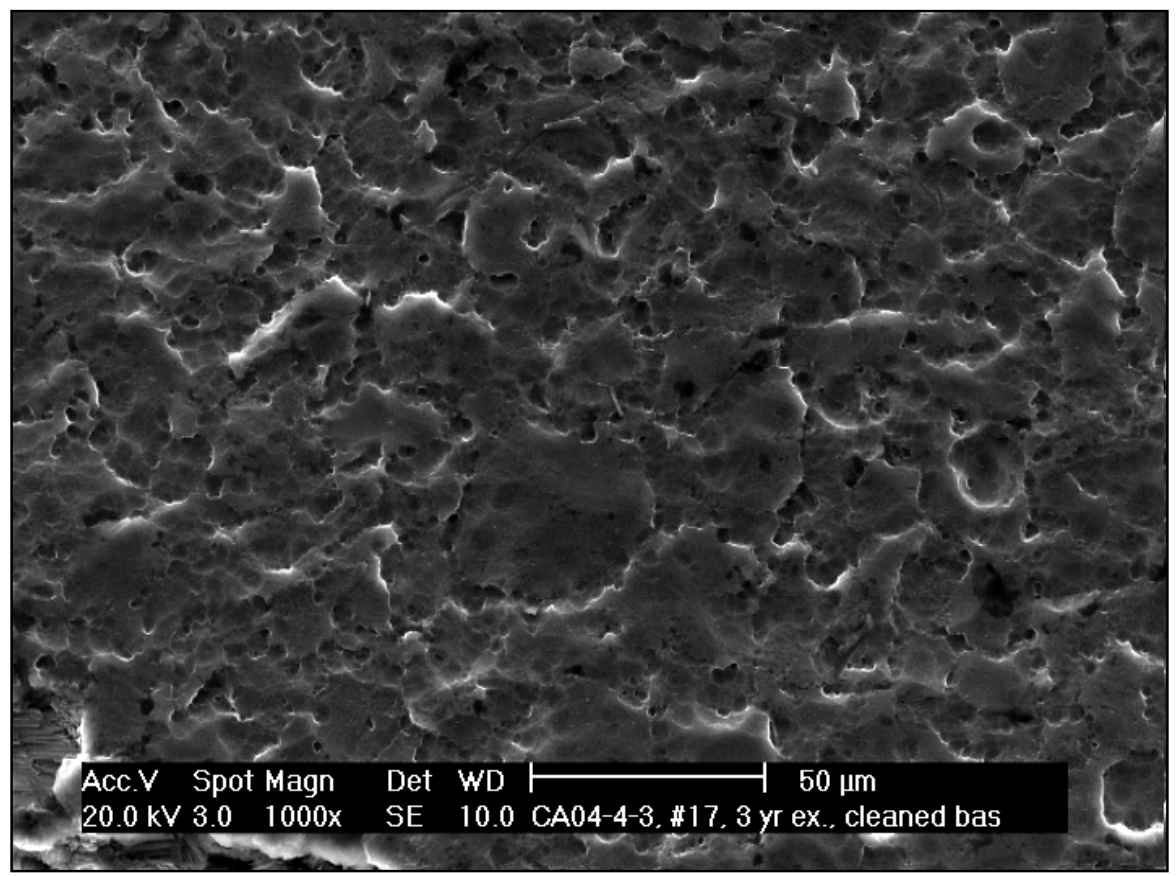

Figure 3-5. SEM image: uncorroded beryllium coupon surface.

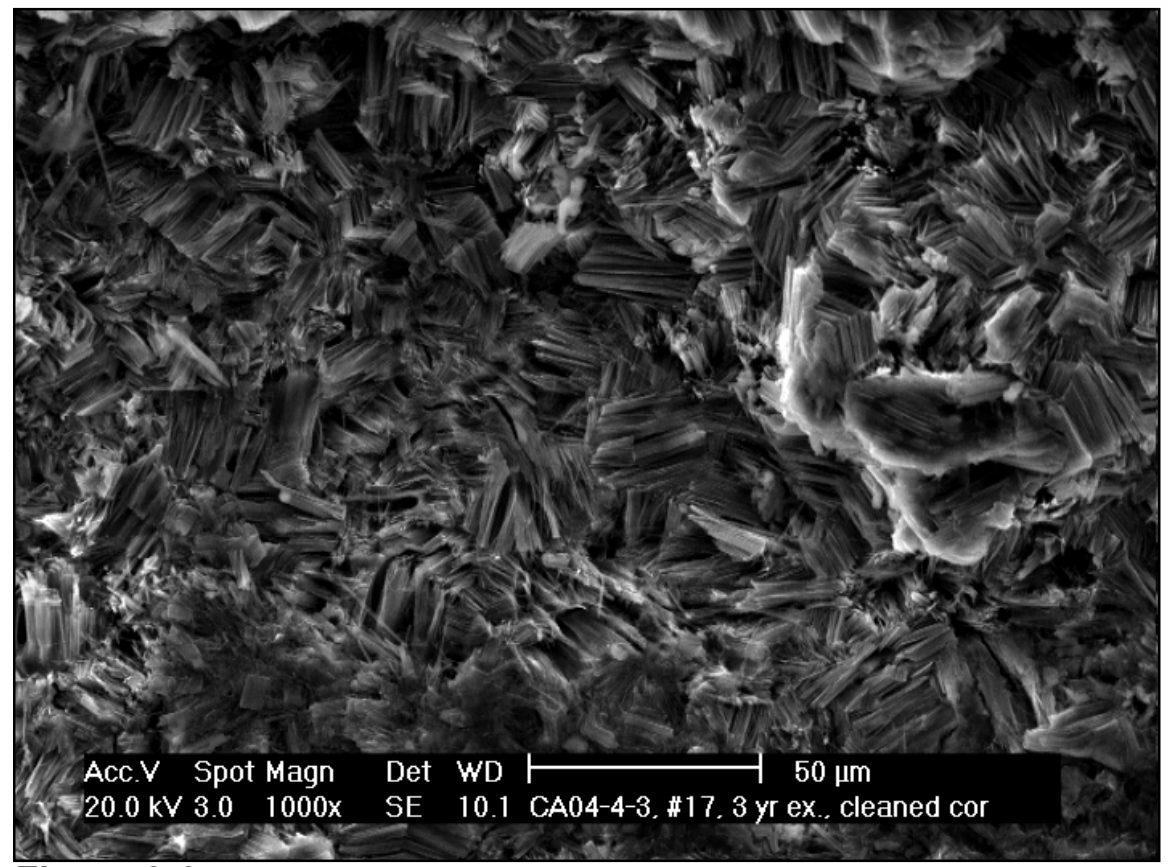

Figure 3-6. SEM image: a corroded beryllium coupon pit. 


\subsubsection{Carbon Steel}

The carbon steel coupons all had general and pitting corrosion. For summary results, see Table 35. The 10-ft level coupons experienced both visually (see Figure 3-7 and Figure 3-8) and measurably higher corrosion rates than at the 4-ft level. All coupons were covered with an orange colored corrosion product $(\mathrm{FeO})$. Two carbon steel coupons, one from the 4-ft level and one from the 10 -ft level, were measured with vertical scanning-interferometry, see Table 3-6 with further measurement results in Appendix D.

Table 3-5. Carbon Steel 6-year exposure corrosion rate summary.

\begin{tabular}{cc|cc|cc}
\hline \multicolumn{2}{c|}{$\begin{array}{c}\text { Level below surface } \\
\mathrm{Ft}\end{array}$} & \multicolumn{2}{|c|}{ Range } & \multicolumn{2}{c}{ Average for 4 coupons } \\
$(\mathrm{M}$ & $(\mathrm{MPY})$ & $(\mathrm{y} / \mathrm{mm})$ & $(\mathrm{MPY})$ & $(\mathrm{y} / \mathrm{mm})$ \\
\hline 4 & 1.22 & $0.1286-0.1806$ & $218-306$ & 0.1554 & 253 \\
10 & 3.05 & $0.2924-0.3643$ & $120-195$ & 0.2611 & 151 \\
\hline
\end{tabular}

Table 3-6. Carbon Steel 6-year exposure pitting corrosion summary.

\begin{tabular}{cc|cc}
\hline \multicolumn{2}{c|}{ Level below surface } & \multicolumn{2}{|c}{ Maximum pit depth } \\
$\mathrm{Ft}$ & $\mathrm{m}$ & Sample number & $\mu \mathrm{m}$ \\
\hline 4 & 1.22 & 3343 & 504 \\
10 & 3.05 & 3347 & 379 \\
\hline
\end{tabular}
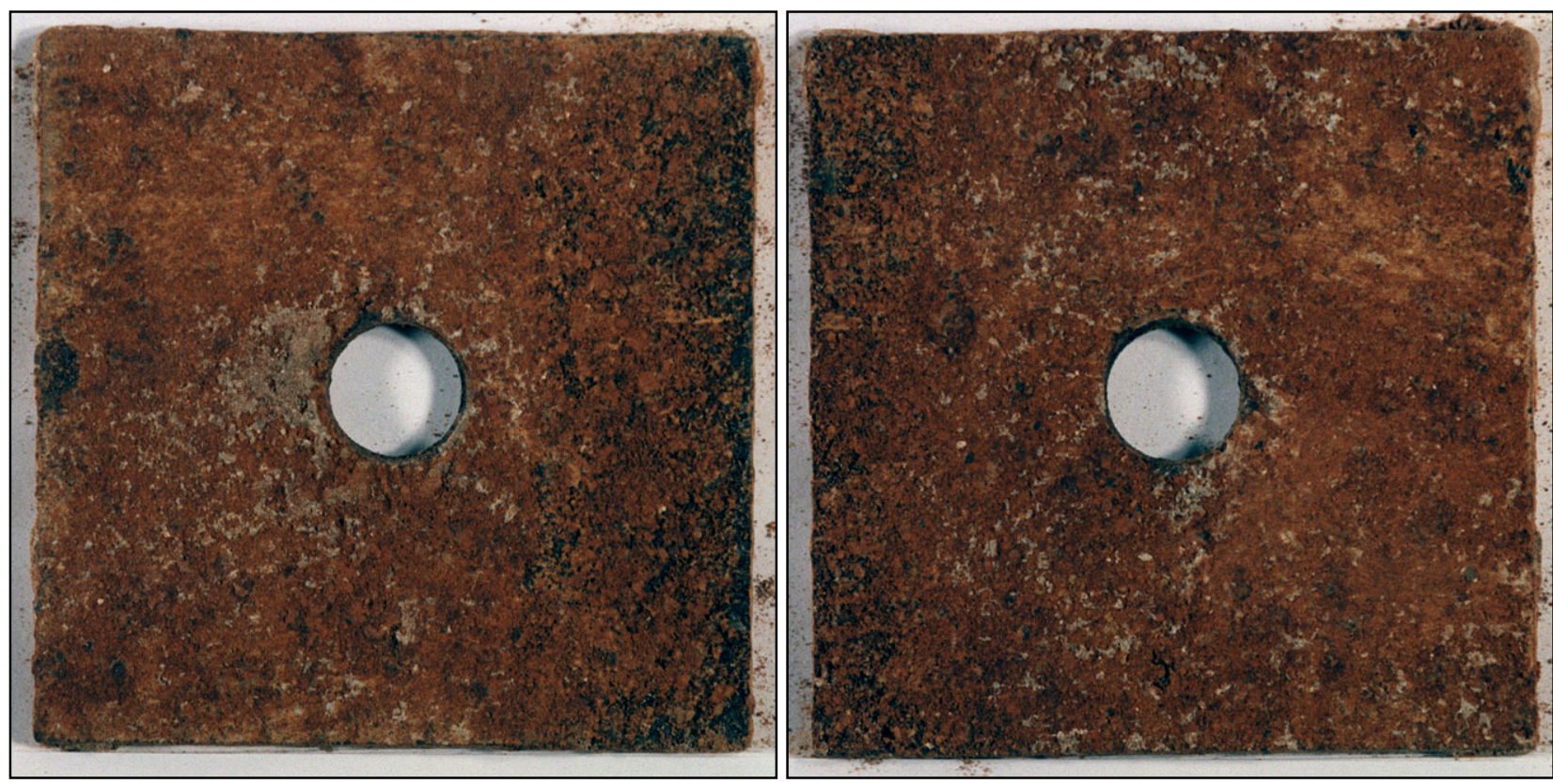

Figure 3-7. Carbon steel coupon (\#3348) before cleaning. 6-yr exposure at 10-ft, front and back views. 


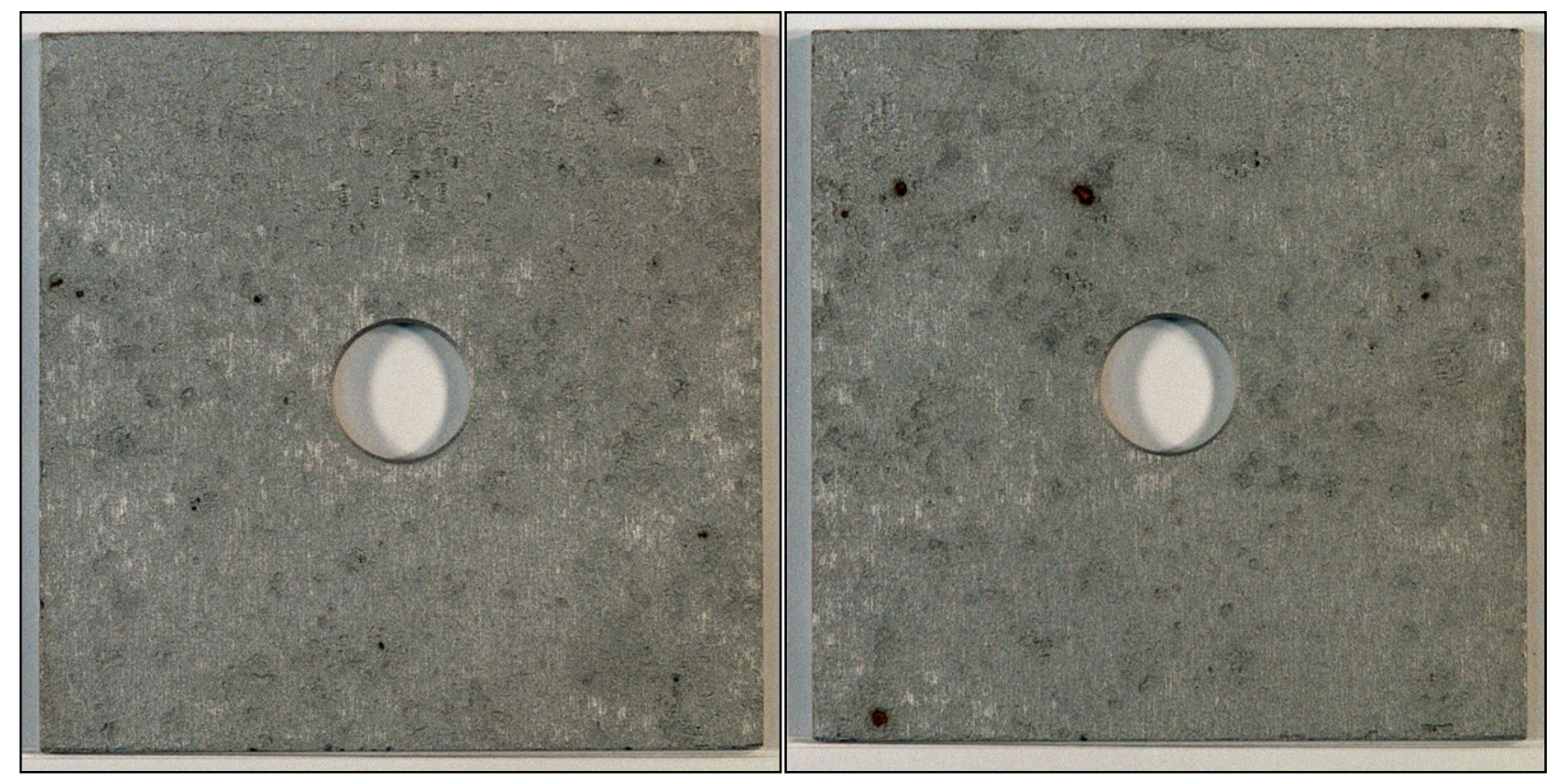

Figure 3-8. Carbon steel coupon (\#3348) after cleaning. 6-yr exposure at 10-ft, front and back views.

\subsubsection{Other Metals}

Coupons of the other 6 compositions (Ferralium 255, Inconel 718, 304L stainless steel, 316L stainless steel, 316L welded stainless steel, and Zircaloy-4) showed little or no evidence of corrosion. No signs of corrosion attack were visible on any of the coupons of these compositions. Figures 3-9 and 3-10 are typical of these coupons. The measured mass losses were within the no reportable corrosion range or just slightly above the reportable threshold with exception to the Zircaloy-4 coupons. Of the Zircaloy- 4 coupons, two of the coupons on the 4-ft level had very slight measurable mass gain possibly due to the development of a very thin, tightly adhering $\mathrm{ZrO}_{2}$ corrosion film on the coupons (Hillner et al. 1994; Franklin 1997). 


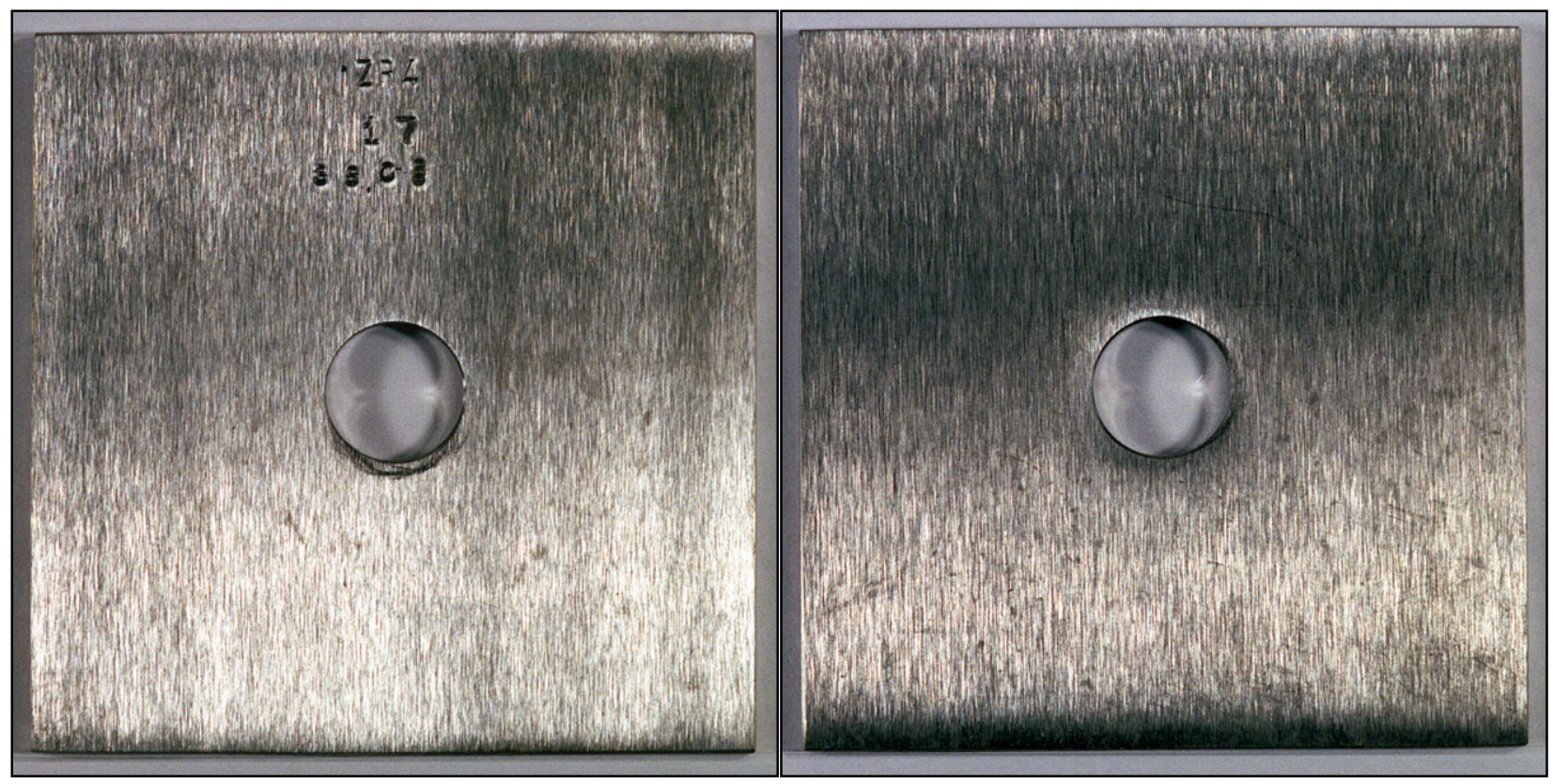

Figure 3-9. Zircaloy-4 coupon (\#3808) before cleaning. 6-yr exposure at 10-ft, front and back views.

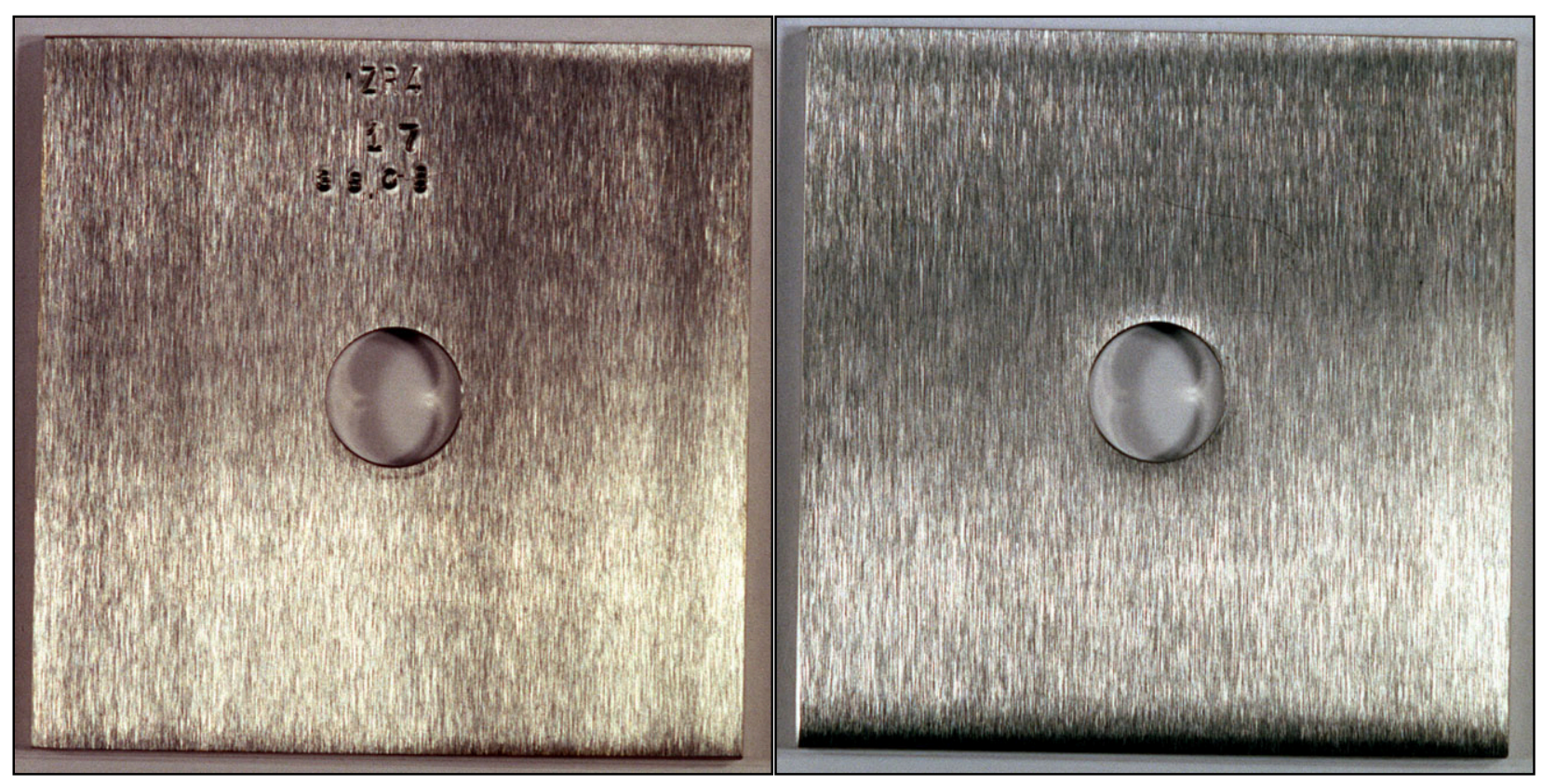

Figure 3-10. Zircaloy-4 coupon (\#3808) after cleaning. 6-yr exposure at 10-ft, front and back views. 


\subsection{Preliminary Evaluation of Trends}

Table 3-7 summarizes the average measured mass losses after 1, 3 and 6 years for sets of four coupons of each composition buried for corrosion testing. Apparent from Table 3-7 is that the averages from the measured mass losses for the beryllium and carbon steel continues to be much greater than for any other coupon compositions. For the 6-year averaged mass loss data, the compositions not exceeding the $2 \sigma$ balance uncertainty are the welded Type $316 \mathrm{~L}$ stainless steel and Zircaloy- 4 . Aside from the welded Type 316L stainless steel and Zircaloy-4, all other compositions have average mass losses above the $2 \sigma$ balance uncertainty.

Table 3-7. Average mass changes (mg).

\begin{tabular}{|c|c|c|c|c|c|c|}
\hline \multirow{2}{*}{$\begin{array}{c}\text { Material } \\
\text { Type }\end{array}$} & \multicolumn{3}{|c|}{ 4-Ft Depth } & \multicolumn{3}{|c|}{ 10-Ft Depth } \\
\hline & 1-Year & 3-Year & 6-Year & $1-$ Year & 3-Year & 6-Year \\
\hline Aluminum $6061^{\mathrm{a}}$ & -0.98 & -12.32 & -7.62 & -0.55 & -5.07 & -3.2 \\
\hline Beryllium S200F ${ }^{a}$ & -47.0 & -32.07 & -30.30 & -109.8 & -507.25 & -928.9 \\
\hline Carbon Steel $1018^{b}$ & -312.2 & -891.1 & -2296.3 & -642.8 & -3306.15 & -5053.9 \\
\hline Ferralium $255^{\mathrm{b}}$ & -0.53 & -2.22 & -1.2 & -1.0 & -1.77 & -1.1 \\
\hline Inconel $718^{\mathrm{b}, \mathrm{c}}$ & +0.10 & -2.55 & -1.7 & -0.05 & -3.57 & -1.6 \\
\hline $304 \mathrm{~L}^{\mathrm{b}, \mathrm{d}}$ & -0.08 & -1.82 & -1.6 & -0.45 & -2.52 & -0.9 \\
\hline $316 \mathrm{~L}^{\mathrm{b}, \mathrm{e}}$ & -0.53 & -2.67 & -1.5 & -0.43 & -3.57 & -1.3 \\
\hline 316L Welded ${ }^{\text {bee }}$ & +0.48 & -1.45 & -0.8 & +0.58 & -2.22 & -0.8 \\
\hline Zircaloy-4 ${ }^{\text {b }}$ & +0.98 & -0.27 & +0.8 & +1.15 & -0.97 & +0.4 \\
\hline
\end{tabular}

a. $2 \sigma$ balance uncertainty $= \pm 0.4 \mathrm{mg}$

b. $2 \sigma$ balance uncertainty $= \pm 0.8 \mathrm{mg}$

c. $2 \sigma$ cleaning +balance uncertainty $= \pm 0.92 \mathrm{mg}$

d. $2 \sigma$ cleaning +balance uncertainty $= \pm 0.89 \mathrm{mg}$

e. $2 \sigma$ cleaning +balance uncertainty $= \pm 0.98 \mathrm{mg}$

Individual coupon mass losses from the 1-, 3-, and 6-year coupons for each composition with balance uncertainties and combined cleaning/balance uncertainties noted as error bands as applicable are detailed in Appendix G. These data plots illustrate the fact that for most compositions, with exposure times increasing, the mass losses are being to have significance. 
(This page intentionally left blank.) 


\section{DESCRIPTION OF MONITORED CORROSION TESTING}

The most widely used automatic corrosion-rate measurement system relies on electrical resistance (E/R) corrosion probes, which can be used in any environment (liquid, gas, or solid), both conductive and nonconductive. The probes measure the thinning (general corrosion) of the sample electrode (metal strip) by an increase of the electrical resistance of the sample electrode in comparison with the reference electrode, which is protected from corrosion. This technique is especially sensitive to pitting corrosion near the end of the probe's life. An advantage of the use of $E / R$ probes is that they do not require removal from the ground to measure corrosion rates. In addition, the probes provide remote corrosion rate measurements and permit online data collection.

Before installation, the $\mathrm{E} / \mathrm{R}$ probes and other support instruments are gather to form a probe array. A single probe array consists of one E/R probe for each of the six metals of interest (316L stainless steel, 304L stainless steel, carbon steel, aluminum 6061, Inconel 718, and Zircaloy-4), one or two time domain reflectometry (TDR) probe for moisture monitoring, and one or two thermocouples for temperature monitoring. The probe array elements are individually checked in a laboratory setting before burial.

After burial, E/R probes are manually monitored periodically. Soil temperature (using thermocouples) and soil moisture (using TDR probes) are continuously monitored using a data logger. The E/R probe data will be analyzed and correlated with the data from the direct corrosion testing.

\subsection{Equipment}

The E/R probes provide real-time, remote measurement of the corrosion rates of selected materials of interest. The typical probe design uses two thin metal strips that serve as electrical elements, one exposed to corrosion and one protected. In each probe, the two strips are composed of the metal being tested for corrosion (carbon steel, aluminum, etc.) The corrosion measurement is based on the increase in electrical resistance in the exposed elements caused by the thinning due to corrosion and degradation. The change in resistance is calibrated to a corrosion rate through the use of an electrical bridge circuit that compares resistance in the corroding test strip to that in the protected one. In the particular probe employed for this test, the thin metal strip consists of a small thin plate, cut (etched) to form a relatively longer "path" than is possible with the rectangular strip. Figure 4-1 shows both kinds of probes and Figure 4-2 is a photo of a probe just prior to installation at the corrosion berm.
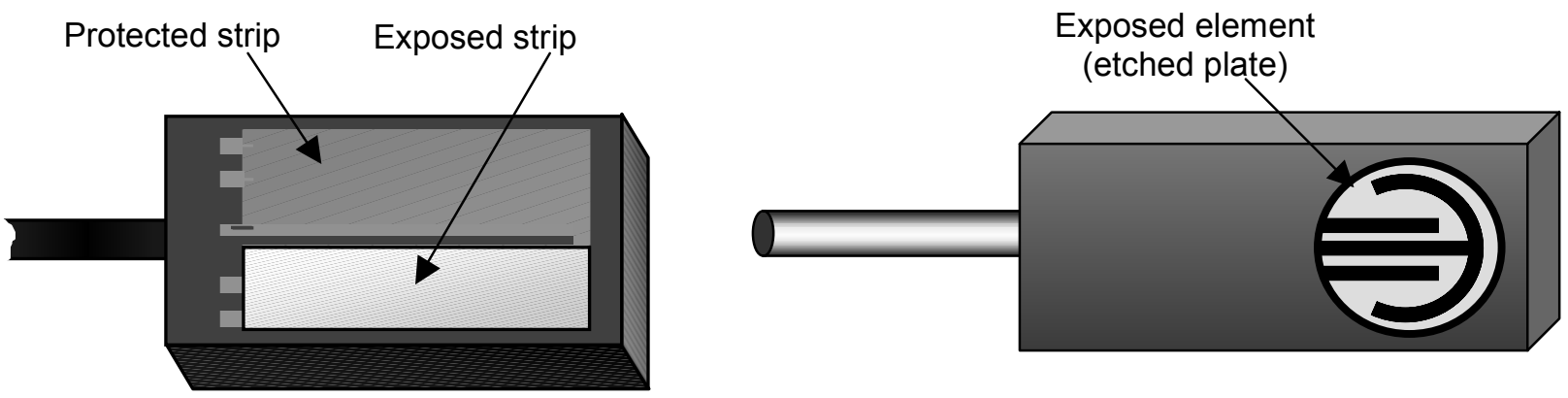

Figure 4-1. A sketch showing two types of E/R probes. In one, the electrical element is a thin rectangular strip of the metal being tested for corrosion. In the other, an etched plate is used instead. 


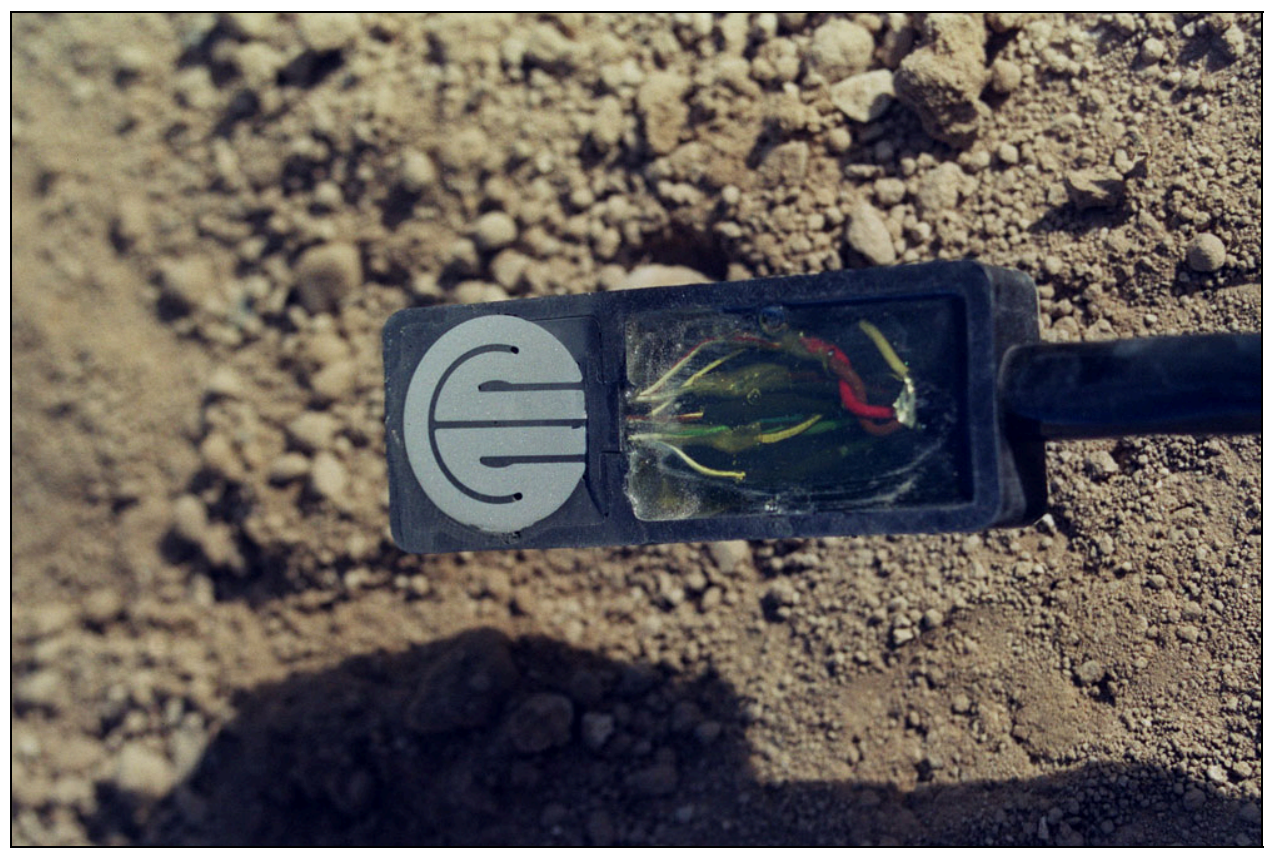

Figure 4-2. Electrical Resistance (E/R) probe. Photo shows the probe just before installation at the corrosion test berm.

\subsection{Probe Selection and Preparation}

The corrosion test uses $\mathrm{E} / \mathrm{R}$ probes to assess corrosion rates in the following materials: low-carbon steel, Type 304L stainless steel, Type 316L stainless steel, Inconel 718, Aluminum 6061, and Zircaloy-4. Commercially available are low-carbon steel, Type 304L stainless steel, Type 316 stainless steel, and Aluminum $6061 \mathrm{E} / \mathrm{R}$ probes. The corrosion test supplied metal to the vendor to fabricate experimental Inconel 718 and Zircaloy-4 E/R probes. Ferralium 255 is not included in the monitored testing, because Ferralium thin enough for use in an E/R probe is not available and working the metal to a reasonable probe thickness would induce undesirable material property affects. Beryllium S200F is also excluded from the monitored testing due to the probe vendor not having procedures to deal with the health and safety concerns. In order to obtain beryllium E/R probe, the beryllium vendor would need to be contracted to fabricate the $\mathrm{E} / \mathrm{R}$ probe elements to the probe vendor's proprietary specifications resulting in a very long lead-time and excessive costs. Furthermore, beryllium has not been previously used as an E/R probe material, so the results would be experimental. Welded Type 316 stainless steel is also excluded from this part of the testing, because the nature of the thin metal strips in the E/R probes precludes the use of welded metals.

The E/R probes are grouped as probe arrays. Each probe array consists of one probe of each of the six metals, plus one or two time domain reflectometry (TDR) probe (for moisture monitoring) and one or two thermocouples (for temperature monitoring), along with the associated wiring. Each probe is tested before installation in a controlled laboratory setting to verify system operation and to verify the probe output with the vendor supplied calibration data. 


\subsection{Probe Array Emplacement}

The test plan calls for deployment of six probe arrays in the corrosion berm. A seventh probe array will be reserved for possible placement in the mound north of the corrosion berm for testing of specific environmental effects (as part of a separate test). Most of the probe arrays will be placed at the 4-ft depth. At least two probe arrays will be placed in the berm at a depth of $10 \mathrm{ft}$. At least two probe arrays will be subjected to application of supplemental moisture, in addition to natural precipitation, to evaluate the effects of additional moisture on corrosion rates. Table 4-1 provides details regarding probe array (PA) designations (PA01, etc.), placement locations, test conditions, and schedule.

Table 4-1. Probe array locations, conditions, and placement.

\begin{tabular}{ccccc}
\hline $\begin{array}{c}\text { Probe } \\
\text { array }\end{array}$ & Test conditions & $\begin{array}{c}\text { Depth } \\
(\mathrm{ft})\end{array}$ & Installation date & Location \\
\hline PA01 & Natural precipitation & 10 & October 23, 2000 & Berm, II \\
PA02 & Natural precipitation & 4 & October 26, 2000 & Berm, II \\
PA03 & Natural precipitation & 10 & November 17, 2003 & Berm, III \\
PA04 & Natural precipitation & 4 & November 17, 2003 & Berm, III \\
PA05 & Supplemental precipitation & 4 & To be determined & Berm, X \\
PA06 & Supplemental precipitation & 4 & To be determined & Berm, IX \\
PA07 & To be determined & 4 & To be determined & Mound \\
\hline
\end{tabular}

The probes arrays are arranged at the berm location dependent upon whether the probe array is placed with a coupon array or just as a probe array. In instances where a probe array and a coupon array are buried together at the same location and depth, as shown on the left in Figure 4-3, the probes are placed in the 6-ft-diameter hole along with the coupons. Where a probe array is placed in a location separately, as shown on the right in Figure 4-3, a 2-ft-diameter hole will be sufficient as a minimum. Procedures for placement, backfilling, and compaction are the same for the probe arrays as for the coupon arrays. 

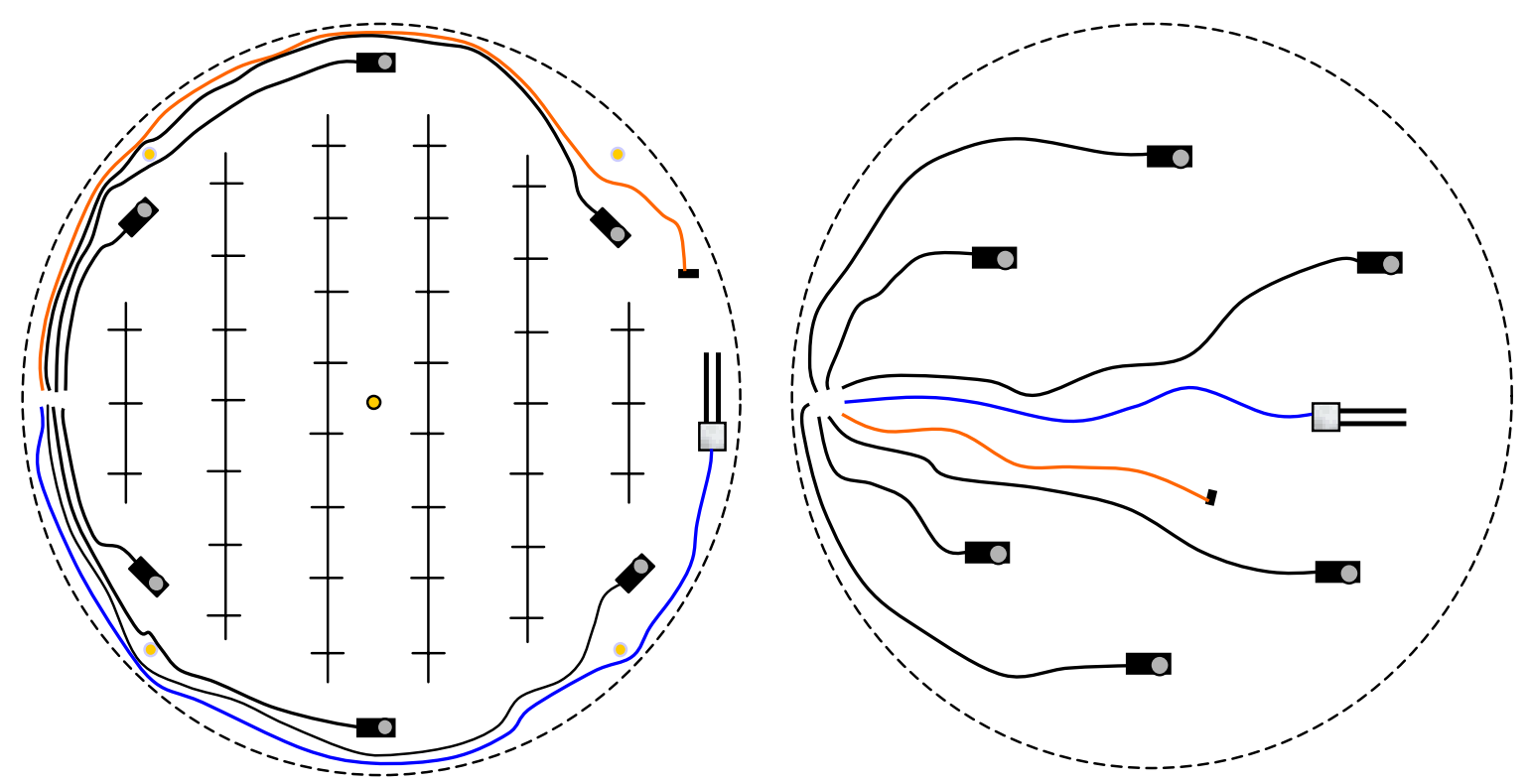

Figure 4-3. Probe array configurations. The left shows installation with a coupon array, the right shows installation without a coupon array.

\subsection{Test Conditions}

Primarily, probes are exposed to natural environmental conditions, namely, the naturally occurring weather conditions at the SDA. These are the conditions that generally govern corrosion rates at the SDA. For probes subjected to natural conditions, soil moisture and temperature are monitored, precipitation at the SDA are recorded for comparison but no attempt is made to control or otherwise alter the moisture that the coupons and probes are exposed to.

For probes exposed to supplemental moisture, controlled application of water to the ground surface at these locations permits measurement of corrosion rates as influenced by the resulting high moisture levels. Monitoring of the soil moisture by TDR probes at these locations is complemented by neutron probe data collected from nearby neutron probe access tubes. The test plan also calls for use of suction lysimeters to collect soil water samples for analysis of soil water chemistry. The corrosion monitoring with supplemental moisture is included in the test strategy because high moisture is one of the variables that can significantly affect corrosion rates. High moisture levels are known to occur in the SDA at some locations, typically where water ponds with spring snowmelts and heavy rainstorms.

\subsection{E/R Probe and Monitoring}

The data from the E/R probes can be retrieved manually or sent to a data logger. When the data logger is used, data are read at a time interval of once per day. When the manual system is used, data are taken less frequently, for example, once per week, once per month, or once quarterly per calendar year. ASTM Method G 96 governs the operation of and data collection from the E/R probes.

The test plan calls for installation of six probe arrays in the berm. Initially, probe arrays were scheduled for installation at the same time as all the coupon arrays. However, funding and schedule changed so two probe arrays were installed in the fall of 2000 following excavation and removal of 3-year coupons. Along with the first two probe arrays, additional coupon arrays were installed. Again, following the excavation and removal of the 6 -year coupons in the fall of 2003, an additional two probe 
arrays were placed. The associated support instrumentation, thermocouples and TDRs, were connected to a data logger in the spring of 2004 and tested for system operability. Data from the support instrumentation started being recorded via the data-logger as of May 24, 2004.

\subsection{Corrosion Rate Methodology}

Operation of the monitoring device used with the Electrical Resistance (E/R) corrosion probes is based on the fact that the electrical conductivity of most metals is very great, while the conductivity of non-metals is negligible by comparison. The electrical resistance of a metal wire is proportional to its cross-sectional area. Therefore, when a metal sensing element corrodes, the corrosion process converts metal into non-metal (metal-oxide), the cross-sectional area of the metal decreases and consequently the electrical resistance of the uncorroded portion of the metal sensing element increases. The circuit uses this change of resistance to indicate the metal loss on the exposed probe surface.

Two elements, one exposed and one protected, make up the probe circuit. The protected element is connected in series with the exposed element and the two are part of a bridge circuit. The protected element retains its original cross-sectional area while the exposed element varies due to corrosion. The resistance ratio between the two elements is translated into units of metal loss by the monitoring device. At the time of monitoring, two readings from the monitoring device need to be recorded, one representing the protected element and one the exposed element. Time also needs to be recorded as the data are plotted as a function of time to derive the corrosion rate.

In general, corrosion rates are not calculated by taking individual differences between each successive pair readings, but rather readings should be plotted against time and the best straight line drawn to obtain the slope of the line. The corrosion rate is calculated as the slope of the line and converted to mils per year (MPY) following the formula:

$$
\text { Corrosion } \cdot \text { Rate }=\frac{\Delta D}{\Delta T} \times 0.365 \times S
$$

Where

Corrosion Rate is in mils per year (MPY)

$D=$ Dial Reading (corrosion probe monitoring device)

$T=$ Time in Days

$S=$ Probe Span (span is the usable thickness of the life of the probe and varies with each probe)

The results are presented in Section 4.7.

\subsection{Monitored Testing Results}

Four E/R probe arrays were monitored. Those in location II on the corrosion berm (see Figure 1-3) have been in service since the fall of 2000 and those in location III have been in service since the fall of 2003. A discussion of significant results from the $E / R$ probes follows and detailed graphs for each probe array can be found in Appendix H. 


\subsubsection{Aluminum}

The corrosion rates for the aluminum E/R probes were higher at the 4-ft level than at the 10 - $\mathrm{ft}$ level (see Table 4-2). These data roughly correlates with that found with the mass-loss data from the aluminum coupons. Figure 4-4 shows the aluminum E/R probe data in relationship to averaged coupon data.

Table 4-2. Aluminum E/R probe corrosion rate summary.

\begin{tabular}{cc|cc|cc}
\hline \multicolumn{2}{c|}{ Level below surface } & \multicolumn{2}{|c|}{ Location II } & \multicolumn{2}{c}{ Location III } \\
$(\mathrm{ft})$ & $(\mathrm{m})$ & $(\mathrm{MPY})$ & $(\mathrm{mm} / \mathrm{y})$ & $(\mathrm{MPY})$ & $(\mathrm{mm} / \mathrm{y})$ \\
\hline 4 & 1.22 & 0.5566 & 0.0141 & 0.2237 & 0.0057 \\
10 & 3.05 & 0.0149 & 0.0004 & 0.1274 & 0.0032 \\
\hline
\end{tabular}

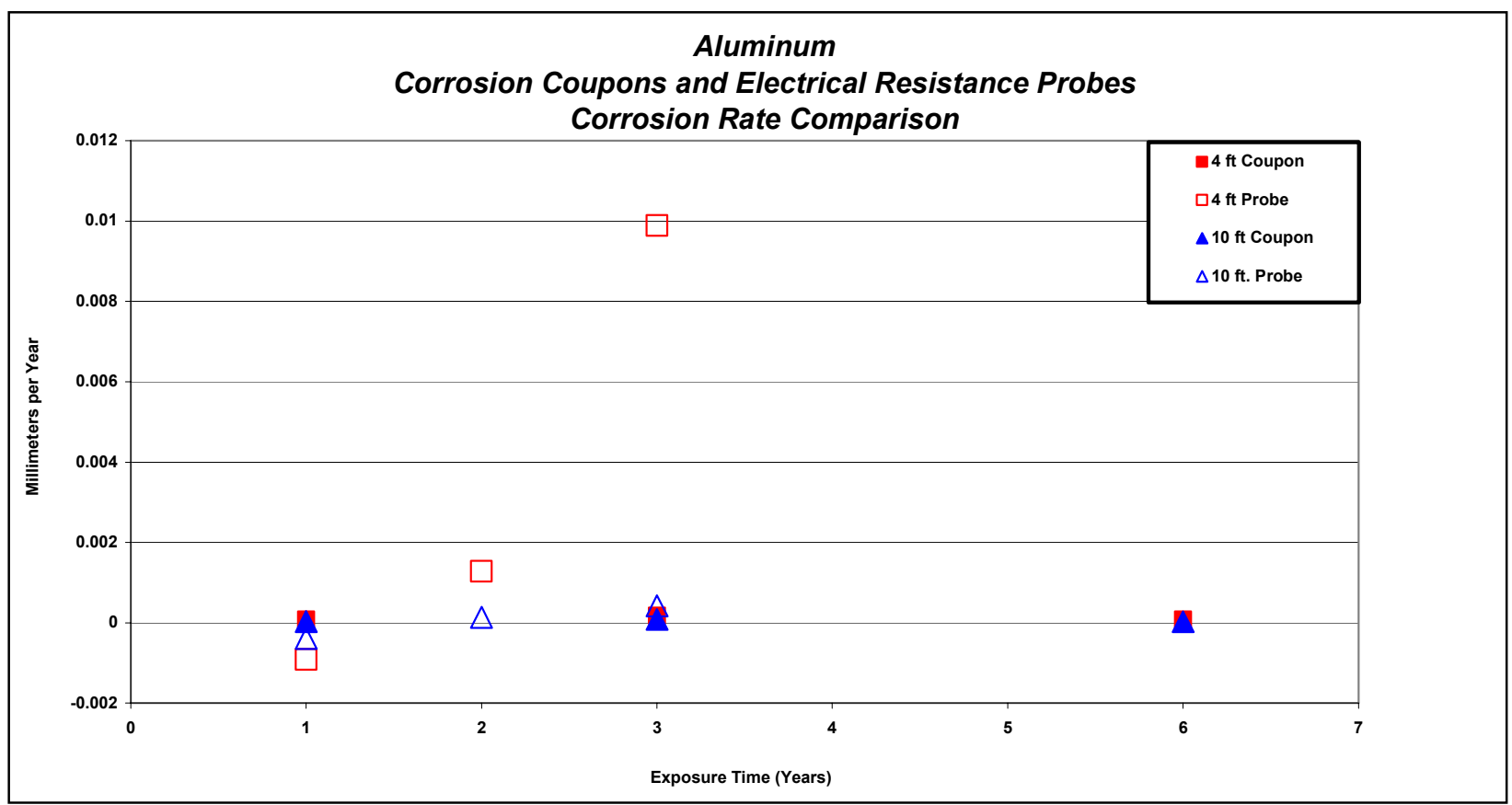

Figure 4-4. Aluminum E/R probes vs. coupons.

\subsubsection{Carbon Steel}

The corrosion rates for the carbon steel E/R probes were higher at the $10-\mathrm{ft}$ level than at the 4-ft level (see Table 4-3). These data roughly correlates with that found with the mass loss data from the carbon steel coupons. Figure 4-5 shows the carbon steel E/R probe data in relationship to averaged coupon data. 
Table 4-3. Carbon steel E/R probe corrosion rate summary.

\begin{tabular}{cc|cc|cc}
\hline \multicolumn{2}{c|}{$\begin{array}{c}\text { Level below surface } \\
(\mathrm{ft})\end{array}$} & \multicolumn{2}{|c|}{ Location II } & \multicolumn{2}{c}{ Location III } \\
\hline 4 & $(\mathrm{~m})$ & $(\mathrm{MPY})$ & $(\mathrm{mm} / \mathrm{y})$ & $(\mathrm{MPY})$ & $(\mathrm{mm} / \mathrm{y})$ \\
\hline 10 & 1.22 & 0.0485 & 0.0012 & 0.0329 & 0.0008 \\
\hline
\end{tabular}

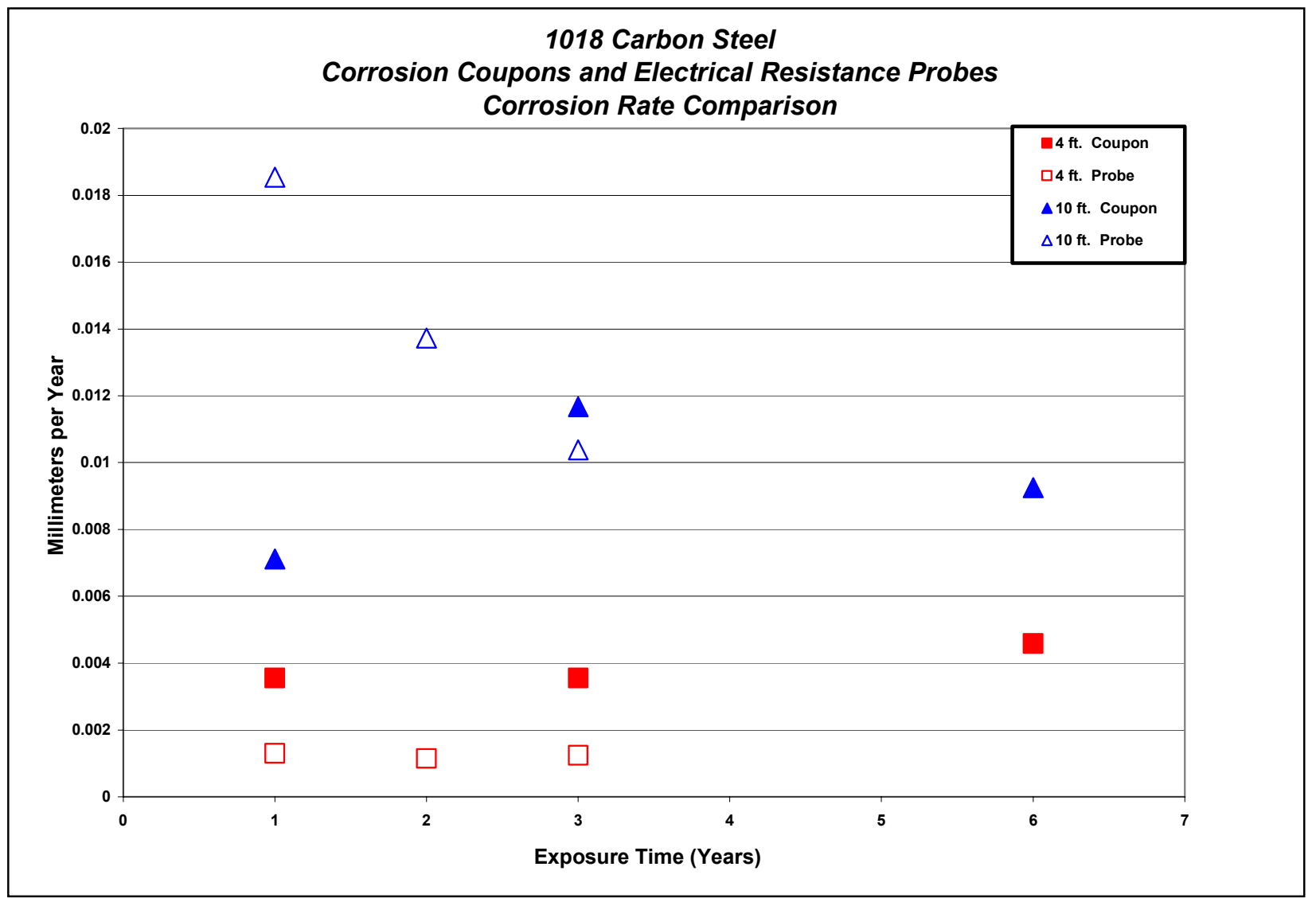

Figure 4-5. Carbon steel E/R probes vs. coupon

\subsubsection{Other Metals}

E/R probes of the other 4 compositions (Inconel 718, 304L stainless steel, 316L stainless steel, and Zircaloy-4) showed little response to corrosion as indicated by the corrosion rates in Table 4-4. The stainless steels are commonly used $\mathrm{E} / \mathrm{R}$ probes but will require time to establish a corrosion rate. Inconel 718 and Zircaloy 4 have never been used in an E/R application, so the rates should be considered experimental. As data are gathered at the second installation location, they will be compared with the first set of probes and the exhumed corrosion coupons. 
Table 4-4. E/R probe corrosion rate summary.

\begin{tabular}{c|cc|cc|cc}
\hline Material & \multicolumn{2}{|c|}{$\begin{array}{c}\text { Level below surface } \\
(\mathrm{ft})\end{array}$} & \multicolumn{2}{|c|}{ Location II } & \multicolumn{2}{c}{ Location III } \\
& $(\mathrm{m})$ & $(\mathrm{MPY})$ & $(\mathrm{mm} / \mathrm{y})$ & $(\mathrm{MPY})$ & $(\mathrm{mm} / \mathrm{y})$ \\
\hline $\begin{array}{c}\text { Type 304L } \\
\text { stainless steel }\end{array}$ & 4 & 1.22 & -0.0129 & -0.0003 & -0.0230 & -0.0006 \\
\hline $\begin{array}{c}\text { Type 316L } \\
\text { stainless steel }\end{array}$ & 4 & 3.05 & -0.0016 & -0.00004 & 0.0039 & 0.0001 \\
\hline Inconel 718 & 10 & 1.22 & -0.0014 & -0.00003 & -0.0030 & -0.00008 \\
& 4 & 1.05 & -0.0036 & -0.00009 & -0.0061 & -0.0002 \\
\hline Zircaloy-4 & 10 & 3.05 & -0.0057 & -0.0001 & -0.0047 & -0.0001 \\
\hline & 4 & 1.22 & -0.0013 & -0.00003 & 0.0024 & 0.00006 \\
& 10 & 3.05 & 0.0325 & 0.0008 & -0.0239 & -0.0006 \\
\hline
\end{tabular}




\section{CHARACTERISTICS OF SOIL}

Soils vary widely in physical and chemical characteristics and in their corrosivity towards metals. This section is split into two main parts, the first describing soil corrosivity factors and the second comparing the corrosion berm soils to other underground corrosion tests.

\subsection{Factors Describing Soil Corrosivity}

\subsubsection{Chemical Properties}

A large number of chemical elements exist in soils, but most combine as insoluble compounds and do not influence underground metal corrosion. Therefore, chemical analyses of soils are usually limited to constituents that are soluble in water under standardized conditions. Elements of particular importance are the alkaline-forming elements (i.e., sodium, potassium, calcium, and magnesium) and the acid-forming elements (i.e., carbonate, bicarbonate, chloride, nitrate, and sulfate). Chemical properties of the soil at the corrosion test berm and subsequently at the SDA are described in subsections following.

\subsubsection{Soil $\mathrm{pH}$}

The standard method for in-situ soil pH measurements, ASTM G-51, requires a good liquid junction between the $\mathrm{pH}$ electrode and the test soil. Due to the low moisture content in the Spreading Area B soil, this method was not used.

Samples of Spreading Area B soils were analyzed for $\mathrm{pH}$ using the methods described by Black et al. (1965), and the results were reported by Tullis, et al. (1993). The $\mathrm{pH}$ of Spreading Area B Soil is mildly alkaline ( $\mathrm{pH} 8.1$ to 8.3 ). This $\mathrm{pH}$ would generally be expected to form a passive film on the carbon steel and stainless alloys.

An analysis by Durr and Beavers (1998) looked at the combined effect of $\mathrm{pH}$ and resistivity on corrosion of carbon steel in soil above the water table. The study used published data to plot the corrosion versus the product of the $\mathrm{pH}$ and the $\log$ of the soil resistivity. Using the INEEL values of $\mathrm{pH} 8.2$ and a resistivity of 5,000 ohm-cm, we get a corrosion rate of 0.1 MPY, which compares favorably with the average carbon steel INEEL rates at the 4-ft level, see Table 5-1.

Table 5-1. Average corrosion rates at the 4-ft level for comparison.

\begin{tabular}{cccc}
\hline & 1 Year & 3 Years & 6 Years \\
\hline Carbon Steel Corrosion Rates (MPY) & 0.12 & 0.12 & 0.15 \\
\hline
\end{tabular}

\subsubsection{Soil Resistivity}

The conductivity of the environment on the area of contact between underground metallic structures and the soil has been recognized as an important factor in the activity of the resultant corrosion cell. Soil resistivity is the reciprocal of conductivity and is a measure of the current carrying capacity of the soil. The resistivity of unsaturated soils depends primarily on the soil moisture content, electrical resistivity of the pore fluids, and to a lesser extent, the clay content (Tullis, et al. 1993). 
The results of a study by Palmer $(1974,1989)$ on the relationship between soil resistivity and corrosivity of buried carbon steel are shown in Table 5-2.

Table 5-2. Resistivity classifications for carbon steel pipe (Palmer 1974, 1989).

\begin{tabular}{|c|c|}
\hline $\begin{array}{c}\text { Resistivity Range } \\
(\text { ohm-cm) }\end{array}$ & Corrosivity \\
\hline $0-1000$ & Very severe \\
$1001-2000$ & Severe \\
$2001-5000$ & Moderate \\
$5001-10,000$ & Mild \\
$10,001-$ & Very mild \\
\hline
\end{tabular}

\subsubsection{Soluble Ion Concentration}

The underground corrosion of metals will be affected by soluble ions present in the soil (Piciulo et al. 1985; Chaker 1995; Durr and Beavers 1998). Soluble ions present in the Spreading Area B soils are included in Appendix I. Generally accepted is that the presence of chloride ions will be detrimental to stainless steels, aiding corrosion and decreasing resistance to pitting. Although there is no underground corrosion data available on beryllium, corrosion tests performed in natural seawater and $\mathrm{NaCl}$ solutions pitted the beryllium.

The soluble ion concentration can increase the soil conductivity (reduce the resistivity), which will increase the corrosivity. In a study cited by Durr and Beavers (1998), increasing concentrations of $\mathrm{CaSO}_{4}$ and $\mathrm{NaCl}$ in solutions decreased the soil resistivity, see Figure 5-1.

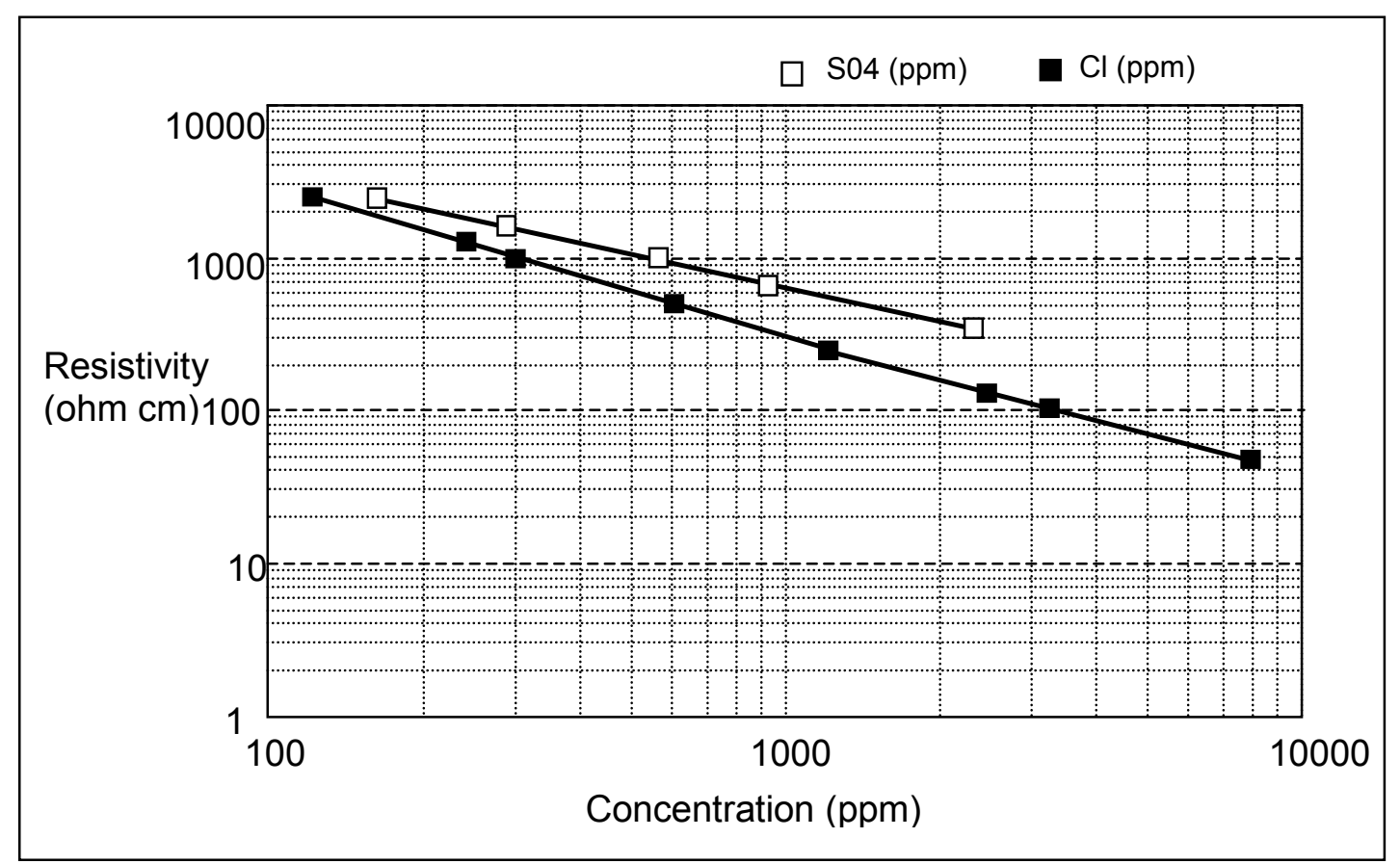

Figure 5-1. Resistivity as a function of $\mathrm{CaSO}_{4}$ and $\mathrm{NaCl}$ solutions. 


\subsubsection{Physical Properties}

The physical properties of soil that are important to corrosion are those related to the permeability of the soil to air (or oxygen) and to water. Soil type and particle size distribution are important factors with respect to both aeration and to moisture content.

\subsubsection{Soil Type}

The SDA and the corrosion test site are located in a vadose zone that consists of finegrained aeolian-deposited sediments. Tullis, et al. (1993) describe the Spreading Area B soils as being composed of primary loess deposition and loess erosion and redeposition. The soil texture is a silty loam with a maximum clay component of approximately $25 \%$. It is expected that the soil in the test berm is free of stratification.

\subsubsection{Soil Moisture}

Soil moisture at the corrosion test site is influenced by two factors - precipitation and infiltration. National Oceanic and Atmospheric Administration (NOAA) records indicate the INEEL receives an average of 8.65 in. of precipitation annually. In recent years - 2001, 2002 and 2003 - the recorded precipitation is only half of the average. Infiltration, primarily from snowmelt in February and March, has a greater impact for the subsurface since there is little opportunity for evapotranspiration.

\subsection{Underground Corrosion Testing Comparisons}

The soil resistivity of the Spreading Area B soils was measured by Tullis, et al. in the borrow pit using the Four Electrode Wenner array (ASTM G 57) and reported as 8,500-10,000 $\mathrm{ohm}-\mathrm{cm}$. The measured values for the Spreading Area B soil put it into the mildly corrosive category, as shown in Table 5-2. A comparison of soil resistivities and corrosion rates of stainless steel at various sites that have performed underground corrosion tests is shown in Table 5-3. Additional details comparing soil properties of Hanford site and INEEL are in Appendix I.

Table 5-3. Soil resistivity and corrosion rate of stainless steel.

\begin{tabular}{ccc}
\hline & $\begin{array}{c}\text { Resistivity } \\
(\text { ASTM G57) } \\
(\text { ohm-cm) }\end{array}$ & $\begin{array}{c}\text { Corrosion Rate (MPY) } \\
304 / 304 \text { L stainless steel }\end{array}$ \\
\hline NBS Test Site, A & $400^{\mathrm{a}}$ & $3.9 \times 10^{-4}$ (8.2 years @ $\left.2.5 \mathrm{ft}\right)$ \\
INEEL & $2600-2700^{\mathrm{b}}$ & No Reportable Corrosion \\
INEEL & $8,500-10,000^{\mathrm{c}}$ & No Reportable Corrosion \\
Hanford & 50,000 & $2.1 \times 10^{-2}(1$ year @ $10 \mathrm{ft})$ \\
\hline
\end{tabular}
a. Gerhold, et al. 1976
b. Pfeifer 1997
c. Tullis, et al. 1993 
Corrosion testing was performed at the Hanford site at the 200 West Area. Carbon and stainless steel corrosion samples were buried at depths of up to $30 \mathrm{ft}$. The soil is characterized as wind blown loess down to a level of about $4 \mathrm{ft}$, with an underlying layer of Hanford formation sediments (Bunnel et al, 1994). The corrosion rates for the available exposure times are given in Table 5-4.

Table 5-4. Results from the Hanford site.

\begin{tabular}{|c|c|c|c|c|c|}
\hline \multirow{2}{*}{ Materials } & \multirow{2}{*}{$\begin{array}{l}\text { Burial Depth } \\
\text { (Ft.) }\end{array}$} & \multicolumn{4}{|c|}{ Corrosion Rate (MPY) } \\
\hline & & 9 months & 1 Year & 2 Year & Average \\
\hline \multirow[t]{5}{*}{ Carbon Steel } & 5 & 1.7 & - & - & 1.7 \\
\hline & 10 & 0.9 & 1.0 & 1.4 & 1.1 \\
\hline & 15 & - & - & 1.0 & 1.0 \\
\hline & 20 & 0.3 & 0.6 & 0.4 & 0.4 \\
\hline & 30 & - & 0.2 & 0.6 & 0.4 \\
\hline \multirow{5}{*}{$\begin{array}{c}\text { Stainless } \\
\text { Steel (304L) }\end{array}$} & 5 & 0.0065 & - & - & 0.0065 \\
\hline & 10 & 0.0096 & 0.0210 & 0.0029 & 0.0012 \\
\hline & 15 & - & - & 0.0036 & 0.0036 \\
\hline & 20 & - & 0.0180 & 0.0075 & 0.0127 \\
\hline & 30 & - & 0.0190 & 0.0049 & 0.0119 \\
\hline
\end{tabular}

The Hanford results are compared to the INEEL results in Table 5-5. The corrosion rate for stainless steel at the INEEL was essentially non-detectable for the years tested. The results of soil analyses, including soluble ions, for the Hanford Site and for the Spreading Area B soils at the INEEL, are shown further in Appendix I.

Table 5-5. Site comparisons.

\begin{tabular}{|c|c|c|c|c|c|c|c|}
\hline \multirow[b]{2}{*}{ Material } & \multirow[b]{2}{*}{ Location } & \multirow{2}{*}{$\begin{array}{c}\text { Burial } \\
\text { Depth } \\
(\mathrm{Ft})\end{array}$} & \multicolumn{5}{|c|}{ Corrosion Rate (MPY) } \\
\hline & & & 9 months & 1 year & 2 year & 3 year & 6 year \\
\hline \multirow{4}{*}{$\begin{array}{c}\text { Carbon } \\
\text { Steel }\end{array}$} & \multirow{2}{*}{ Hanford Site } & 5 & 1.7 & - & - & - & - \\
\hline & & 10 & 0.9 & 1.0 & 1.4 & - & - \\
\hline & \multirow{2}{*}{ INEEL } & 4 & - & 0.125 & - & 0.1215 & 0.1554 \\
\hline & & 10 & - & 0.25 & - & 0.4454 & 0.3417 \\
\hline \multirow{2}{*}{$\begin{array}{c}\text { Stainless } \\
\text { Steel }\end{array}$} & \multirow{2}{*}{ Hanford Site } & 5 & 0.0065 & - & - & - & - \\
\hline & & 10 & 0.0096 & 0.0210 & 0.0029 & - & - \\
\hline \multirow{2}{*}{$\begin{array}{l}\text { 304L- } \\
\text { annealed }\end{array}$} & \multirow{2}{*}{ INEEL } & 4 & - & No Reportable & - & 0.0002 & 0.0001 \\
\hline & & 10 & - & No Reportable & - & 0.0003 & 0.0001 \\
\hline
\end{tabular}




\subsubsection{Comparison With Other Sites}

The results of underground corrosion tests performed by Gerhold, et al. (1981) for the National Bureau of Standards (NBS), now the National Institute for Standards Testing (NIST), are shown in Table 5-6. The Gerhold measurements were from exposure to Sagemoor Sandy Loam soil located at the Yakama Indian Reservation, Toppenish, Washington. The Sagemoor Sandy Loam soil is characterized as a well-drained alkaline soil with a resistivity of $400 \mathrm{ohm}-\mathrm{cm}$ and a $\mathrm{pH}$ of 8.8. It is typical of soils found in eastern Washington and Oregon.

As can be seen, the corrosion rates for annealed and as-welded material are extremely low. The corrosion rates from the NBS study do not correlate well with data from Palmer (1974) on the relationship of resistivity and the corrosion rate of carbon steel.

Table 5-6. Results for stainless steels exposed to Sagemoor sandy loam soils.

\begin{tabular}{|c|c|c|c|c|c|}
\hline Material & Sample Form & Treatment & $\begin{array}{c}\text { Exposure Time } \\
\text { Days }\end{array}$ & $\begin{array}{c}\text { Weight Loss } \\
\mathrm{mg} / \mathrm{dm}^{2}\end{array}$ & $\begin{array}{c}\text { Corrosion Rate } \\
\text { mils/year }\end{array}$ \\
\hline 304 & Sheet & Annealed & 2989 & 8 & $3.9 \times 10^{-4}$ \\
\hline 304 & Sheet & Sensitized & 413 & 20 & $6.9 \times 10^{-3}$ \\
& & & 791 & 18 & $3.3 \times 10^{-3}$ \\
& & & 1442 & 49 & $4.9 \times 10^{-3}$ \\
& & & 2989 & 68 & $3.3 \times 10^{-3}$ \\
\hline 304 & \multirow{2}{*}{ Welded sheet } & As-welded & 2989 & 17 & $8.2 \times 10^{-4}$ \\
\hline \multirow{2}{*}{316} & \multirow{2}{*}{ Sheet } & \multirow{2}{*}{ Annealed } & 2989 & 0.0 & 0 \\
\hline \multirow{2}{*}{ Sheet } & \multirow{2}{*}{ Sensitized } & 791 & 5 & $9.1 \times 10^{-4}$ \\
& & & 1442 & 31 & $5.7 \times 10^{-4}$ \\
& & & 2989 & 12 & $5.8 \times 10^{-4}$ \\
\hline
\end{tabular}

\subsubsection{Corrosion In Similar Soils}

An earlier study performed at the INEEL by Nagata and Banaee (1996) used literature sources to estimate the corrosion rates for low carbon steels, Types 304 and 316 stainless steels, and Inconel 600, 601, and 718 alloys in SDA-type soils. The study compared those estimates to the corrosion rates specified in the SDA performance assessment (Maheras et al. 1994), which were based on the IMPACTS study (Oztunali and Roles 1986). The results of the INEEL study by Nagata and Banaee are summarized here. The study made the following assumptions:

- The underground corrosion behavior of Type 304 stainless steel at the SDA can be estimated by the behavior of Type 304 stainless steel in similar soils.

- The corrosion behavior of neutron-irradiated metals is not very different from that of their unirradiated state; that is, the concentration of activation products is so small that they do not significantly change the chemical composition, and hence the corrosion behavior, of the alloy. 
- The activated elements in the neutron-irradiated metals are uniformly distributed, so the uniform corrosion rate describes the release of the activated elements to the environment. (The uniform corrosion rate, for "corrosion that proceeds at about the same rate over a metal surface," is used because the volume of metal corroded determines the release of radionuclides to the environment. Therefore, even if corrosion proceeds by pitting, as it does for austenitic stainless steel in underground corrosion, the uniform corrosion rate is always reported because the loss in metal volume to pitting cannot be easily measured, whereas the uniform corrosion rate can. Furthermore, if the concentration of the activated elements is fairly uniform, the mechanism of metal loss, i.e., by pitting or uniform corrosion, is unimportant; only the volume lost is important.)

The study estimated that the corrosion rate for the stainless steels and Inconels in environments with geochemistry similar to that of the SDA soils was 0.00047 MPY $\left(1.2 \times 10^{-8}\right.$ $\mathrm{m} /$ year), which is about two orders of magnitude lower than the corrosion rates specified in the SDA performance assessment for stainless steel. The study considered the corrosion rate for Inconel 718 to be the same as for the austenitic stainless steels. 


\section{MICROBIALLY INDUCED CORROSION}

\subsection{Description of Microbiological Testing}

The scope of microbiological investigation for this test is to perform sampling activities during recovery periods to identify microbes that are present on the coupons and in the surrounding soil. An assessment can then be made to determine if these microbes influence the corrosion reactions. The objectives continue to include strong culture based analyses; and, when possible, an attempt was made to leave the door open to application of supporting molecular biological methods in the future on materials preserved from this sample period or in future sampling.

Several parameters are considered when attempting to detect microbial active in soil systems. They include: isolation of colony forming units (CFU); content of select gases in the soil atmosphere; soil moisture content; availability and type of electron acceptors; soil solution $\mathrm{pH}$; soil temperature; nutrient supply; and available microbial inhibitors.

The most direct method for determination of numbers and types of viable microbes present in the soil environment is through the attempt to isolate and grow them on artificial media. Then by conducting an elementary morphological examination of the isolates, it is possible to gain knowledge of the broad spectrum of microbial types (i.e. bacteria, fungi, and actinomycetes) present in the soil sample. Generally, exacting, biochemical tests can also be used (depending on available resources) to identify the genus and species of microbes. These tests can be tailored to identifying a few general classes of microbes (i.e. aerobes, anaerobes, heterotrophies, autotrophes) of specific interest.

As in previous years, culture methods used have focused on 4 physiological types of microorganisms:

- Heterotrophs (HTR) are organisms that utilize organic carbon. This is a very broad category that encompasses a great many narrower types. An organism that is not a heterotroph must be an autotrophy that uses (fixes) inorganic carbon (such as $\mathrm{CO}_{2}$ ) into organic matter. All green plants and many types of microorganism are autotrophs. The other three physiological types are generally also heterotrophs.

- Organic acid (OA) producers decompose complex carbon fermentatively. In this process complex molecules are split, and energy is derived by oxidizing one part while reducing the other. The oxidized products contain acidic moieties from which the group name is derived.

- Nitrate reducers, or denitrifiers, (NR) use nitrate in place of oxygen in their respiratory processes. They reduce nitrate only in the absence of oxygen; the reduced nitrogen products are volatile gases and that are lost to the atmosphere, hence the name denitrifier.

- Sulfate reducers (SRB) use sulfate in place of oxygen for respiration. Sulfide, the end product of this respiration, is toxic in high enough concentrations and forms highly insoluble minerals with free metal ions. 
For this study, isolation of microbes and soil atmospheres were used as indicators of microbial activity associated with the buried coupons. Activity, then, was assessed both directly (isolation and culturing of microorganism obtained from the surface of recovered coupons) and indirectly (analysis of the soil atmosphere).

The methods described above can also be used to detect the presence of soil microbes, which are associated with material buried in a soil profile. Once again, the methods used can be as involved as need and resources dictate. That can range from simply swabbing the surface and then conducting isolation work to preparing the surface of interest then subjecting it to visual and electron microscopic examination. Swabbing is a rapid method used to confirm the presence of microbes adhering to the surface. Visual and electron microscopy is particularly important when there is an interest in knowing if the attached microbes are involved with visible surface effects such as corrosion. Typically, such involved examinations are conducted after the presence of microbes and corrosion has been indicated by initial examination.

Classification of microbes based on their need for oxygen as an electron acceptor has produced categories that range from aerobic to facultative aerobic to strict anaerobic. There are physical/chemical methods such as redox potential and actual measurement of oxygen $\left(\mathrm{O}_{2}\right)$ in the soil atmosphere. For this study, $\mathrm{O}_{2}$ and other select soil atmospheric gases were used.

Oxygen (as an electron acceptor) concentration is important in determining the physiological type of microbes that can exist in a soil environment. The content of $\mathrm{O}_{2}$ in the soil depends on the percent of the volume of soil pores and what portions of those pores are filled with water. So it is expected that as the volume of water increases in a soil pore, the volume of $\mathrm{O}_{2}$ and other soil gases (the soil atmosphere) will decrease. The soil atmosphere is replenished by the infiltration of atmospheric gases into the soil pores as they drain. Because infiltration decreases as a function of depth in soil, gas exchange in deeper soil horizons (i.e., greater than a meter) can be limited. However, the concentration of individual gases in the soil horizon is not only dependent on soil permeability but also on the activity of the microbes present. When aerobic microbes metabolize available carbon compounds, they use $\mathrm{O}_{2}$ as an electron acceptor and respire carbon dioxide $\left(\mathrm{CO}_{2}\right)$. Therefore, it is expected that $\mathrm{O}_{2}$ concentrations will decrease in horizons where gas exchange is limited. In addition, it is to be expected that even in well aerated soils that the concentration of $\mathrm{CO}_{2}$ will be at a level several times above that of the atmosphere (Alexander, 1961). In horizons with limited $\mathrm{O}_{2}$, it is expected that other gases such as methane $\left(\mathrm{CH}_{4}\right)$ will be also be elevated above the atmospheric values. Concentration of atmospheric gases in a soil profile can also be used as an indicator of microbial activity and to some extent physiology. Therefore, measurement of the concentration of various gases (i.e. $\mathrm{O}_{2}$, nitrogen $\left(\mathrm{N}_{2}\right), \mathrm{CO}_{2}$, and $\mathrm{CH}_{4}$ ) serves as indicators of microbial activity. Because they do have a microbial linkage, monitoring of soil atmospheres at various depths in a soil profile can be used as a remote indicator of microbial activity.

\subsubsection{Coupon Preparation}

For the 6-year samples, at both the 4- and 10-ft intervals, coupon arrays were recovered as in the 3-year recovery and to accommodate scheduling were placed in a $4^{\circ} \mathrm{C}$ incubator to hold for processing. In both cases, processing was delayed 3 days. Once begun, processing took place in one working day within a 6-hour period. To minimize temperature effects while processing, coupon arrays were maintained at $4{ }^{\circ} \mathrm{C}$ until removed one at a time for treatment. 
Personal protective equipment (PPE) requirements had been relaxed from previous years; so initial handling of arrays in the lab including detachment of coupons and inoculation of imprint plates could be performed on the lab bench. Inoculation of liquid media was performed in the laboratory fume hood. PPE in both tasks consisted of lab coats, safety glasses, and nitrile gloves.

Coupons were processed as described in reports from previous sample years. Repeatability of this process is critical to comparison of data points. All soil particles and loose debris were removed from coupons with sterile implements, see Figure 6-1. This process was particularly critical when handling heavily corroded coupons such as carbon steel, beryllium, and aluminum.

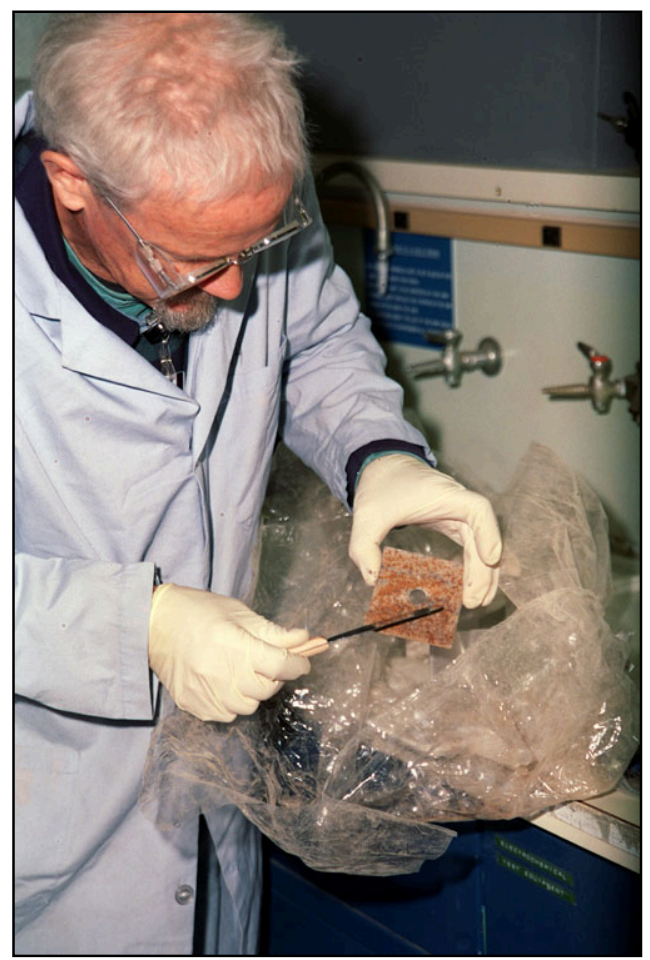

Figure 6-1. Removal of soil and loose debris for microbial testing.

As in previous years, contact nutrient agar plates were made of all coupons. In addition, the 6-year coupons from 4-ft depth were also imprinted on nutrient agar plates containing fungusinhibiting antibiotic. All coupons were tested in liquid media for the presence of SRB, NR, OA producing, and HET physiologies. Positive responses in these media are identified by visible changes to medium color, precipitate formation, or turbidity. To create inoculums for enrichments, $5 \mathrm{~cm}^{2}$ of each coupon was treated, see Figure 6-2, with a phosphate buffered saline (PBS) soaked sterile swab and thoroughly rinsing the swab in $5 \mathrm{ml}$ of buffer. Then each enrichment vial was inoculated with $1 \mathrm{ml}$ of the resulting rinsate or the equivalent of $1 \mathrm{~cm}^{2}$ of coupon area. 


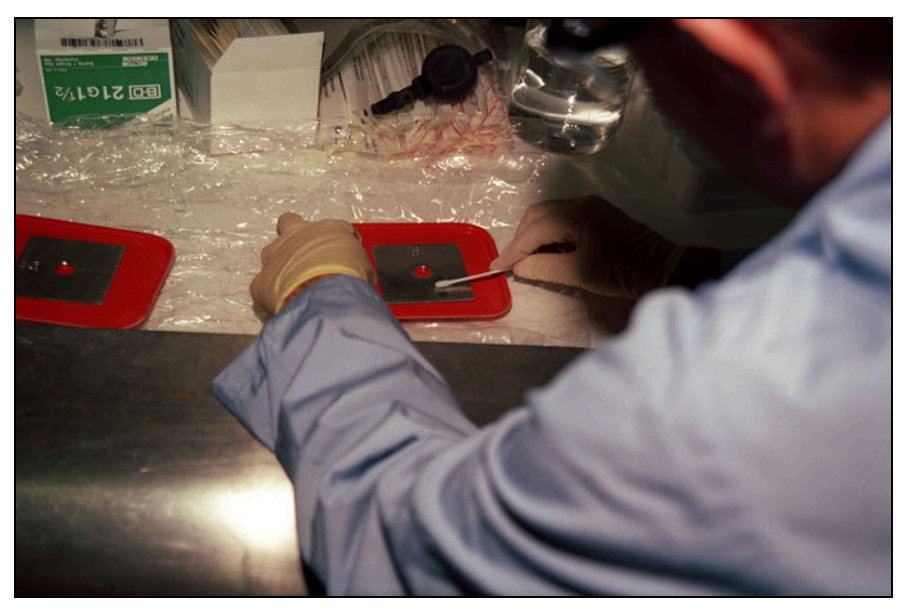

Figure 6-2. Swabbing corrosion coupon for enrichments.

For estimation of numbers of specific microbial types on all beryllium and carbon steel coupons, serial dilutions were performed into the four liquid media types. These dilutions were performed in a manner to allow estimation of the most probable numbers (MPN) of each type on $1 \mathrm{~cm}^{2}$ of the coupon.

For comparison of microbial communities on and adjacent to beryllium coupons, contact plates were also made from labeling rings that marked position of beryllium coupons on the coupon arrays. Treatment of rings was as described for coupons.

Prevalent microbial types from coupons selected on the basis of the appearance of colonies growing on plates were sub-cultured repeatedly to insure purity, grown to high density, concentrated, and frozen at $-80^{\circ} \mathrm{C}$ in sealed containers. These cultures will be identified by genetic sequencing methods as a broad characterization of types associated with various metals when scope and funding allow.

\subsubsection{Soil Samples}

For evaluation of microbial community size and diversity, soil samples from both 4- and 10 - $\mathrm{ft}$ depths were diluted $1 \mathrm{~g} / 10 \mathrm{ml}$ PBS and then serially diluted to give final concentrations of $10^{-4}, 10^{-5}$ and $10^{-6}$ on nutrient agar plates.

Soil samples from the 4-ft depth were diluted into all 4 liquid media types for $10^{-1}, 10^{-2}$, and $10^{-3}$ MPN dilutions. Serial dilutions of $10^{-3}, 10^{-4}$ and $10^{-5}$ from $10-\mathrm{ft}$ soil samples were placed in liquid medium for MPN enumeration of sulfate reducing organisms while types NR, OA, and HET were evaluated for presence only $\left(\geq 1 \mathrm{cell} / \mathrm{cm}^{2}\right)$. 


\subsection{Microbiological Results}

\subsubsection{Coupon Contact Plates}

Microbial growth occurred on all contact plates, both those containing antibiotic and those without. Because there was no clear visible difference between antibiotic and non-antibiotic types, antibiotic plates were not used at the 10-ft depth. Growth on plates was heterogeneous with numerous easily distinguishable morphological types at each sample depth. Ten representative types from each depth were selected for isolation and purification preparatory to molecular analysis. Representative photographs of these plates are shown in Figure 6-3 and 6-4. An in-depth analysis would undoubtedly reveal considerable overlap among types observed at the two sample depths in this study. No distinction could be made between types seen on beryllium coupons and adjoining identifier rings.

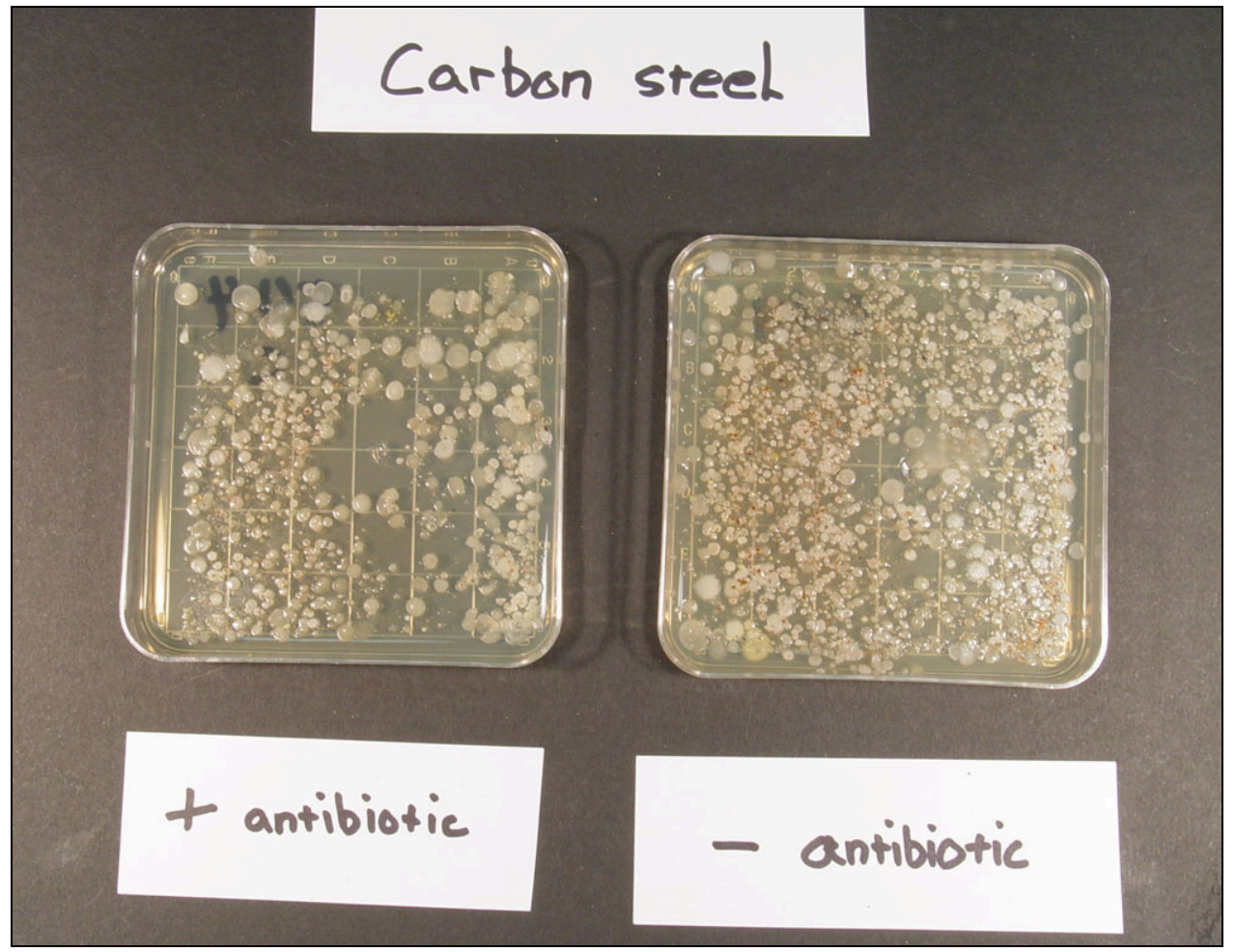

Figure 6-3. Microbial growth on contact plates imprinted from carbon steel coupons. 


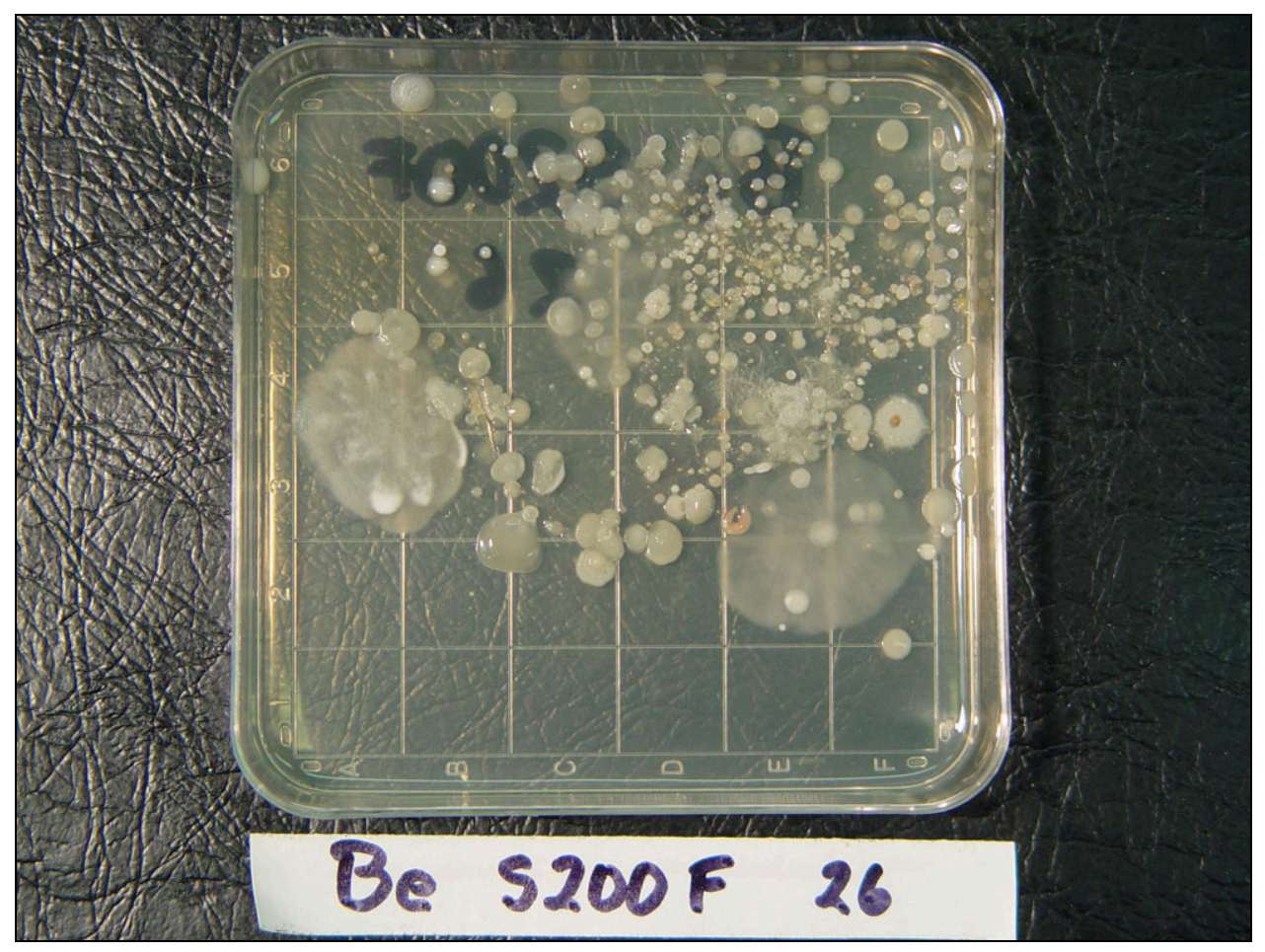

Figure 6-4. Microbial growth on contact plates imprinted from a beryllium coupon.

\subsubsection{Liquid Enrichments}

A total of 240 liquid media vials were inoculated from coupons for each sample depth: 4 media types from each of 36 coupon plus 3 dilution tubes of the 4 media types from each of 4 beryllium and 4 carbon steel coupons. Stated another way, 60 vials of each media type were inoculated at both sample depths.

Essentially all vials for HET and OA media showed positive; the only exceptions were negatives at higher dilutions in the extinction dilution series from the 10-ft sample depth (1 in HET and 6 in OA). (See Table J-1 in Appendix J for additional detail.) Response to NR medium was slightly less robust with 47 of 60 positive at $4 \mathrm{ft}$ and 52 of 60 positive at $10 \mathrm{ft}$. Negative response was again in higher dilution enrichments. In all but SRB enrichments, all metal types at both sample depths had positive response, but not all replicates of each metal at $4 \mathrm{ft}$ depth were positive (5 negative of the 36 coupons). Response in SRB medium was mixed with one-fifth of all vials at either depth positive and no response at one or the other depth from 5 coupon types. (See Table J-2 in Appendix J for additional detail.)

\subsubsection{MPN Enumerations}

Results of serial dilutions of inoculum from $1 \mathrm{~cm}^{2}$ of each beryllium and carbon steel coupon into the 4 media types are shown in Table 6-1. Series were scored according to the highest positive dilution. For example, a series in which the $10^{-1}$ and $10^{-2}$ tubes but not the $10^{-3}$ tube were positive was recorded as having at least 100 cells per $\mathrm{cm}^{2}$. Because dilutions were not replicated, no statistical significance for this number can be given. The values are rough approximations and are intended as relative comparisons, not actual numbers. There is a noticeable trend of decreasing activity with depth that is not visible in the data from all metal types (see Appendix J, Table J-2). 
Table 6-1. MPN estimates for 6-yr exposed beryllium and carbon steel coupons.

\begin{tabular}{|c|c|c|c|c|c|}
\hline Material Type & $\begin{array}{c}\text { Depth } \\
(\mathrm{ft})\end{array}$ & $\begin{array}{c}\text { Sulfate } \\
\text { Reducers }\end{array}$ & $\begin{array}{c}\text { Nitrate } \\
\text { Reducers }\end{array}$ & $\begin{array}{l}\text { Org. Acid } \\
\text { Producers }\end{array}$ & Heterotroph \\
\hline \multirow{8}{*}{ Beryllium } & \multirow[t]{4}{*}{4} & $\geq 1,<10$ & $\geq 100,<1000$ & $\geq 1000$ & $\geq 1000$ \\
\hline & & 0 & $\geq 100,<1000$ & $\geq 1000$ & $\geq 1000$ \\
\hline & & 0 & $\geq 100,<1000$ & $\geq 1000$ & $\geq 1000$ \\
\hline & & 0 & $\geq 1000$ & $\geq 1000$ & $\geq 1000$ \\
\hline & \multirow[t]{4}{*}{10} & $\geq 1,<10$ & $\geq 10,<100$ & $\geq 10,<100$ & $\geq 100,<1000$ \\
\hline & & 0 & $\geq 10,<100$ & $\geq 10,<100$ & $\geq 1000$ \\
\hline & & 0 & $\geq 100,<1000$ & $\geq 10,<100$ & $\geq 1000$ \\
\hline & & 0 & $\geq 100,<1000$ & $\geq 1000$ & $\geq 1000$ \\
\hline \multirow{8}{*}{ Carbon steel } & \multirow[t]{4}{*}{4} & $\geq 1,<10$ & $\geq 10,<100$ & $\geq 1000$ & $\geq 1000$ \\
\hline & & $\geq 1,<10$ & $\geq 10,<100$ & $\geq 1000$ & $\geq 1000$ \\
\hline & & $\geq 1,<10$ & $\geq 100,<1000$ & $\geq 1000$ & $\geq 1000$ \\
\hline & & 0 & $\geq 100,<1000$ & $\geq 1000$ & $\geq 1000$ \\
\hline & \multirow[t]{4}{*}{10} & 1 & $\geq 100,<1000$ & $\geq 1000$ & $\geq 1000$ \\
\hline & & $\geq 1,<10$ & $\geq 100,<1000$ & $\geq 1000$ & $\geq 1000$ \\
\hline & & 1 & $\geq 100,<1000$ & $\geq 1000$ & $\geq 1000$ \\
\hline & & 0 & $\geq 1000$ & $\geq 1000$ & $\geq 1000$ \\
\hline
\end{tabular}

\subsection{Evaluation of Trends}

Comparison of microbiological results from years 1,3 , and 6 reveals a trend toward increasing microbial activity over time at both 4- and 10-ft intervals (see Appendix J). This trend is evident in all 4 physiological types studied and is particularly noticeable in the sulfate- and nitrate-reducing types, which had practically no response in previous years.

Numbers of CFUs on spread plates from 4-ft soil samples ranged from 1.45 to $2.56 \times 10^{6}$ per gram of soil. This is 2 or 3 times higher than samples from $10-\mathrm{ft}\left(6.3\right.$ to $9.05 \times 10^{5}$ CFU/gram). These numbers are similar to previous years but do not range as high $\left(1.1 \times 10^{6}\right.$ to $4.4 \times 10^{8} \mathrm{CFU} / \mathrm{g}$ in the year 2000). This difference may be related to differences in soil moisture between years. Although based on observation of a relatively small segment of potential types of soil organisms (moderate temperature fast growing aerobes), these types are likely to be the common and predominant "weedy" types, and the decrease in numbers with depth may be a typical soil pattern.

All liquid media dilution of soils from 4-ft and all but SRB dilutions from 10-ft were positive; these types are present and robust. Samples for SRB extinction dilution in soil from 10$\mathrm{ft}$ were more dilute and had only one positive response at $10^{-3}$ (the lowest dilution). No coupons from this depth showed SRB activity at any dilution higher than $10^{-1}$. Although only 1 pair of data points, the observation supports the idea that SRB's may be more numerous in soil than on coupons. 


\subsubsection{Microbial Trend Discussion}

These results indicate microbial communities are present in association with coupons, and the numbers and pattern of their occurrence are slowly changing. Microbe-metal interactions are complex and involve feedback loops related to production of organic acids and extra cellular complexing agents. The level of microbial metabolism determines soil oxidation/reduction potential and is thus central to estimation of the rate of metal corrosion. The fact that microbial numbers are changing may be a reflection of microbe-metal interactions.

Soil populations are influenced by complex interactions of moisture, temperature, and available nutrients. Observed patterns could be the result of readjustment of soil populations after excavation and reburial with coupons. The general increase in activity suggested by the data in Appendix J could be the result of such effects. On the other hand, the decrease in activity suggested by the dilution enumeration (Table 6-1), performed on the most active metal types, may reflect influence of the introduced metals to local electrochemistry and changes in cation balance; greater and more annual constancy of moisture at the deeper sample location may provide greater ion mobility over time. 


\section{FIELD MONITORING}

The test plan calls for field monitoring at the berm to collect data on precipitation, soil moisture, soil-water chemistry, soil-gas composition, and soil temperature. All field monitoring called out by the test plan is necessary to correlate the corrosion rate data with the SDA environment. Soil moisture and soil chemistry are potentially the strongest influencing factors in underground corrosion at the test location. Field monitoring data have been collected sporadically during the test, depending on the levels of support funding. With the installation of the probe arrays, additional support instrumentation is now available for monitoring. See Figure 7-1 for the arrangement of arrays and sampling ports at the corrosion test berm.

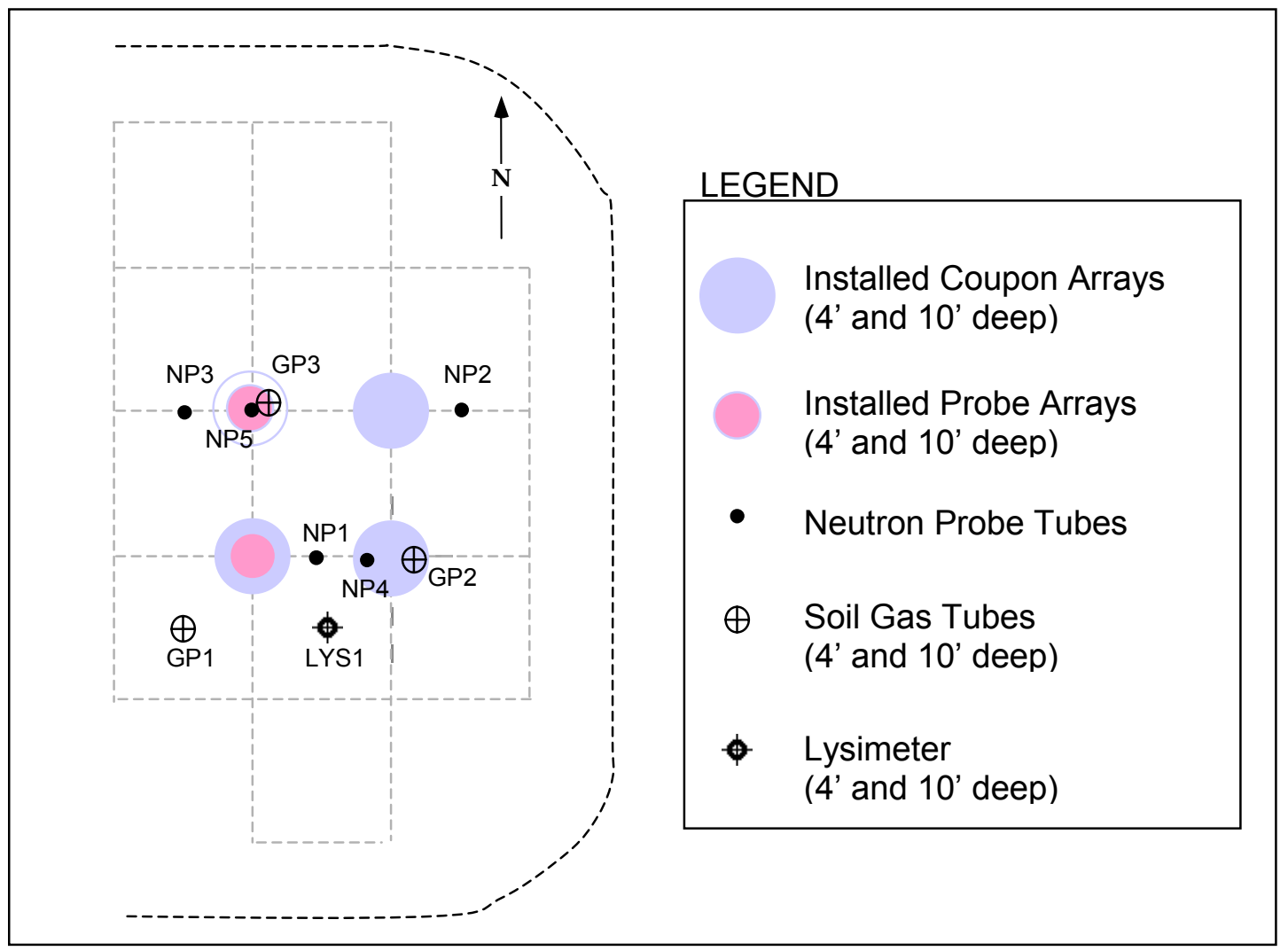

Figure 7-1. Arrangement of coupon arrays, probe arrays and support instrumentation.

\subsection{Precipitation Monitoring}

On average, the region where the berm is located receives $21.97 \mathrm{~cm}(8.65 \mathrm{in}$.) of precipitation a year (National Oceanic and Atmospheric Administration records). Table 7-1 shows the precipitation amounts for the RWMC area over the last 6 years. Spring and summer rainstorms generally supply most of the precipitation, but soil moisture and total infiltration are impacted greatest by moisture supplied by snowmelt. Snowmelt at the berm generally occurs in February and March, at a time that the water is free to infiltrate into the ground with little opportunity for evapotranspiration. The impact of snowmelt on infiltration is increased in areas where the water collects and is lessened in areas where the water runs off. Figure 7-2, precipitation by month over the last 6 years, illustrates the variations in seasonal precipitation. 
Table 7-1. Precipitation totals for RWMC.

\begin{tabular}{ccc}
\hline Year & $\begin{array}{c}\text { Total Annual Precipitation } \\
\text { (inch) }\end{array}$ & $\begin{array}{c}\text { Months with precipitation } \\
\text { totaling } \mathbf{1} \text { inch or more }\end{array}$ \\
\hline 1997 & 8.8 & $3(1>1.5$ in $)$ \\
1998 & 9.5 & $4(2>1.5$ in. $)$ \\
1999 & 5.56 & $2(1>2$ in. $)$ \\
2000 & 5.67 & 1 \\
2001 & 4.53 & 0 \\
2002 & 4.12 & 0 \\
2003 & 4.40 & $1(>1.5$ in. $)$ \\
$2004(1 / 2$ year $)$ & 2.85 & 0 \\
\hline
\end{tabular}

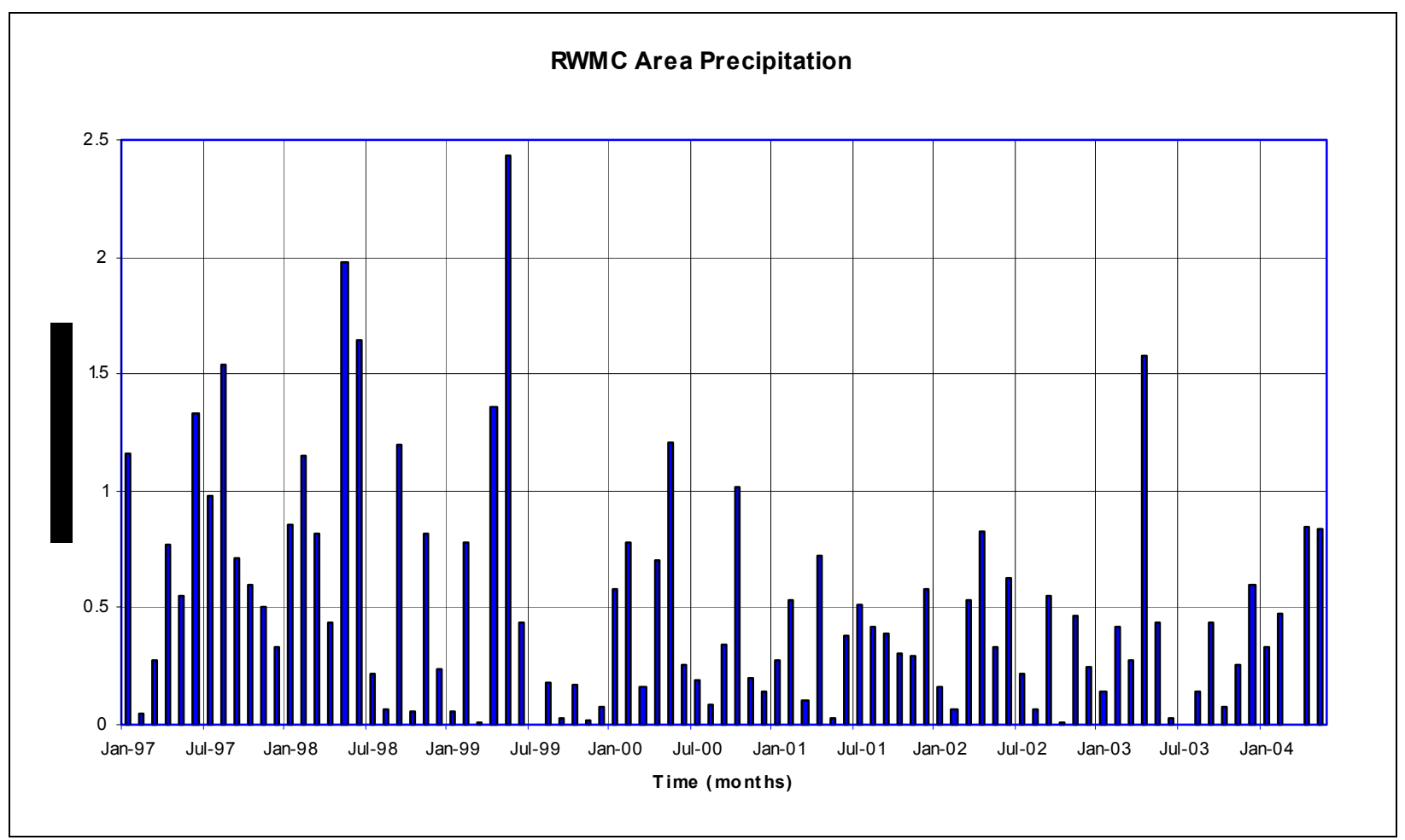

Figure 7-2. Graph showing monthly precipitation totals for the years 1997 through May 2004.

\subsection{Soil Moisture}

Soil moisture in the corrosion test berm is monitored using two methods: neutron probe and time domain reflectometery (TDR) also known as a water content reflectometer. The neutron probe method allows a vertical moisture profile of berm at selected locations while the TDR provides volumetric water content at a point location. 


\subsubsection{Neutron Probe}

\subsubsection{Neutron Probe Operation}

Three 10-ft neutron probe access tubes (NP1, NP2, and NP3) were installed in the corrosion test berm near the coupon burial sites, and a fourth and fifth were installed inside two of the augered holes (NP4 and NP5). (Refer to Figure 7-1 showing the neutron access tube locations.) NP1, NP2, and NP3 were installed before placing the coupon arrays by drilling a 2-in. auger hole, placing a 1.9-in (outer diameter) stainless steel tube (casing) downhole, and filling the annular space with sieved berm material. The backfill was packed into the annular space to ensure that the neutron access tube did not become a conduit for moisture movement into the test berm. The installation locations for these were outside the 6$\mathrm{ft}$ diameter holes. NP4 (installed in the fall of 1998) and NP5 (installed in the fall of 2003), however, are located inside 6-ft diameter holes. The casing for NP4 and NP5 was placed inside the hole and soil was backfilled around the tubes.

A CPN 503DR hydroprobe neutron moisture gauge with an Am/Be source is used to collect the moisture data (see Figure 7-3). The gauge operates by emitting fast neutrons that are thermalized or slowed when they collide with hydrogen atoms. The probe detector counts the thermalized (slowed) neutrons, and the neutron counts are calibrated to the specific soil to provide volumetric moisture content measurements.

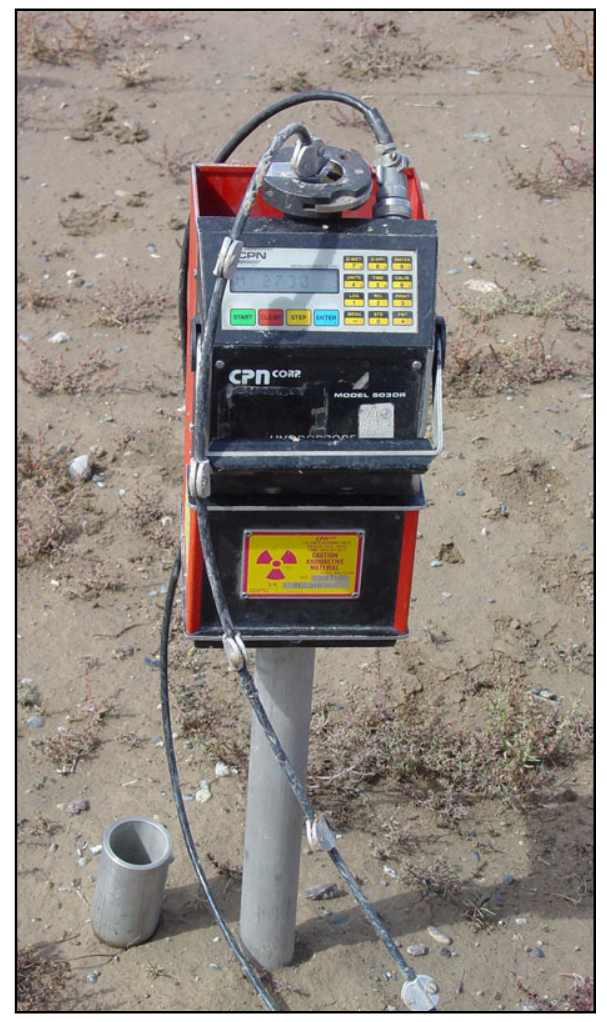

Figure 7-3. CPN 503DR hydroprobe neutron moisture gauge.

Logging is initiated by lowering the source to the bottom of the hole where the first 16-second count is taken. The source is pulled up 6 inches and another count is taken. The process is repeated in 6inch increments until the entire hole is logged. The source housing, which includes the source, detector, and electrical circuit boards, is about 12 inches long and must be in the subsurface for counts to be safely 
taken; thus, the moisture level in the top $1.5 \mathrm{ft}$ of soil is not measured nor is the bottom 6 inches. When the following discussion refers to surface moisture conditions, it is referring to the soil that is located 1.5 $\mathrm{ft}$ below the surface. Likewise, the bottom of the hole is the count taken at $9.5 \mathrm{ft}$.

\subsubsection{Neutron Probe Monitoring}

Moisture levels in the corrosion berm have been monitored on a limited basis. Although moisture levels were monitored frequently during the first year of the corrosion test, subsequent monitoring has been less frequent. Data collection has taken place since January 13, 1998 for some of the probe locations and as additional probe tubes have been installed, additional measurements have taken place. Soil moisture profiles along with the measurement schedule are reported in Appendix K.

\subsubsection{Neutron Probe Monitoring Results}

Highest infiltration rates at the corrosion test berm were measured in 1998 corresponding to the year with the greatest precipitation. Since that time, precipitation is fallen off to less than half the longterm average for the INEEL. The berm area along with much of southeastern Idaho has sustained drought conditions for the past 4 or 5 years. This is translated to limited snowfall and consequently, limited infiltration from snowmelt. When a year of normal or above normal snowfall occurs, the moisture patterns for each of the NPs is likely to vary greatly.

Moisture monitoring has been sporadic, especially between the years of 1999 and 2002. A more frequent and consistent monitoring program has been adopted and needs to be sustained at the corrosion berm to understand the role of moisture on subsurface corrosion especially in years with substantial snow accumulation and summer rainstorms. Understanding the specific relationship between soil moisture and corrosion is difficult without data collected on a more frequent basis and during times of high infiltration.

Figure 7-4 summarizes data collected on March 15, 2004 for each of the five NP locations. The moisture profiles appear to fall into two groups: first, NP1, NP2, and NP5 and second, NP3 and NP4. NP1, NP2, and NP5 have wetter profiles than NP3 and NP4. NP4 and NP5 are the neutron access tubes that are installed inside the 6-ft diameter holes. Table 7-2 compares the NP5 data at the 4- and 10-ft level to excavation samples taken during the recovery in the fall of 2003.

Table 7-2. NP5 and excavation samples, moisture comparison.

\begin{tabular}{cc|ccc}
\hline & NP5 & \multicolumn{3}{|c}{ Bulk Samples from Recovery/Installation } \\
Depth (Ft) & Moisture content \% & Sample & Depth $(\mathrm{Ft})$ & Moisture content \% \\
\hline 4 & 19 & D55 & 4 & 10.6 \\
10 & 23 & D36 & 10 & 17.4 \\
& D29 & 10 & 16.07 \\
& D37 & 4 & 17.96 \\
& D8 & 4 & 12.79 \\
\hline
\end{tabular}




\section{Moisture Content Comparison}

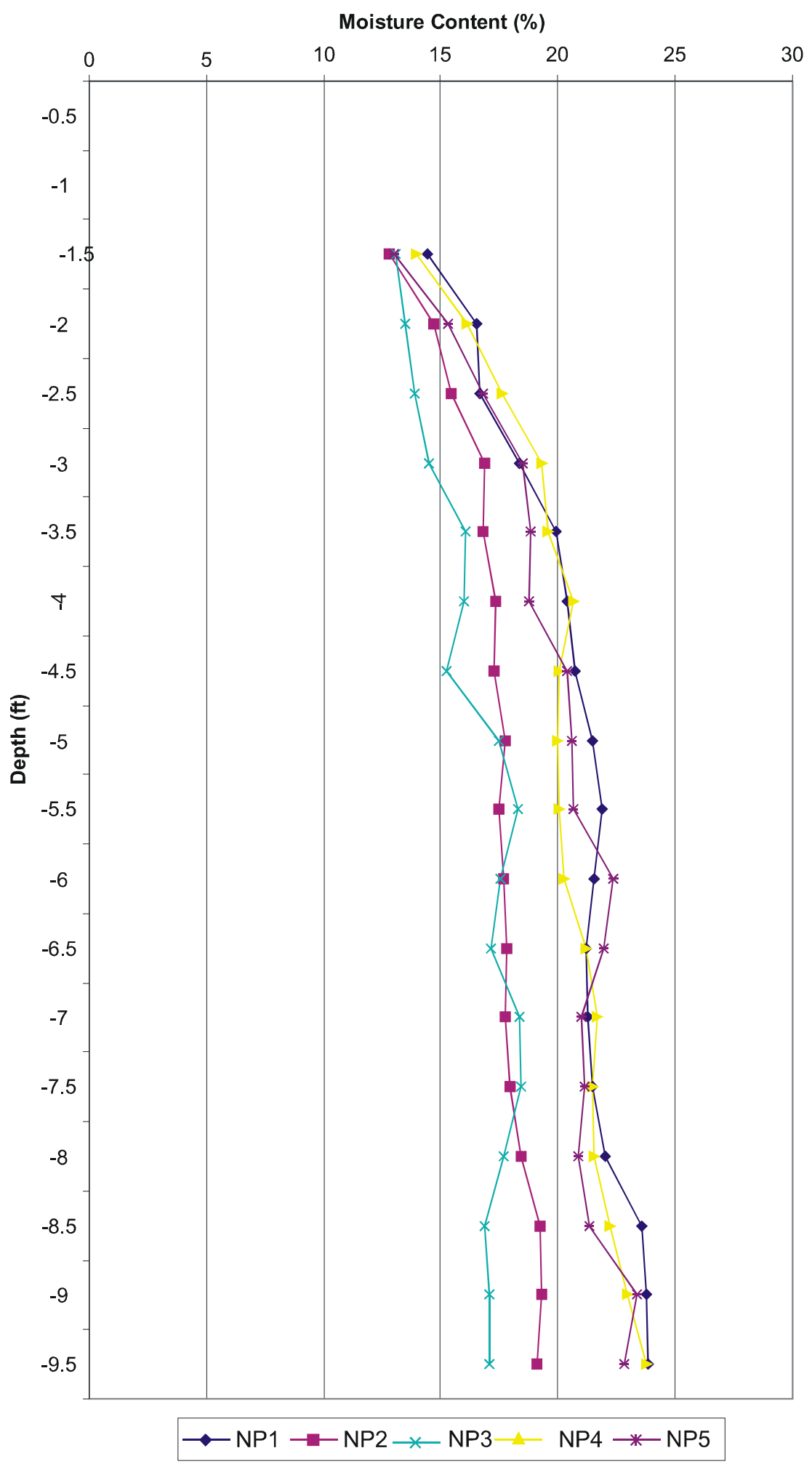

Figure 7-4. Comparison of March 15, 2004 moisture profiles. 


\subsubsection{TDR Probes}

\subsubsection{TDR Operation}

The TDR or water content reflectometer provides a point measurement of the volumetric water content of the soil. The water content information is derived from the effect of changing dielectric constant on electromagnetic waves propagating along the two wave-guides.

\subsubsection{TDR Monitoring}

Neither TDR has been connected to the data logger; therefore, continuous moisture readings from 2000 to 2003 are not available. Data were collected for a short time period on July 24, 2003, when the TDRs were temporarily connected to a programmed data logger. Data have not been collected subsequently.

Two TDR probes were installed during the October 2000 electrical resistance probe array installation. One is installed at each of the installation levels: 4 and $10 \mathrm{ft}$. Four additional TDR probes were installed during November 2003 when additional probe arrays were installed. During the 2003 installation, two TDR probes were installed at each of the installation levels: 4 and $10 \mathrm{ft}$. The TDR probes from both installations were connected to a datalogger in May 2004. Limited data has been collected; however, additional data, with seasonal variations, are required to adequately correlate the TDR probe data with the moisture profiles collected via the neutron probe.

\subsubsection{TDR Results}

For a short time period on July 24, 2003, the TDRs were monitored from the location II at depths of 4 and $10 \mathrm{ft}$. Moisture measurements obtained were 19\% at the $4-\mathrm{ft}$ level and $26 \%$ at the $10-\mathrm{ft}$ level. Because these measurements were taken in II, and are within the augered hole area, one would expect the readings to compare favorably to NP4-also in an augered hole area. Soils in both holes are packed less densely than the berm, but more importantly, about one gallon of water was added to II soils (at the $7 \mathrm{ft}$ $10 \mathrm{in}$. level in October 2000) to obtain compaction. The $19 \%$ at the $4 \mathrm{ft}$ level is slightly wetter than the $17 \%$ measured by the neutron probe in NP4. However, the $26 \%$ at the 10 -ft level is significantly moister than the 17 to $19 \%$ measured in NP4. The TDR measurements actually compare more favorably with measurements taken in the berm (e.g., NP3). The water that was added to obtain compaction can likely explain the difference between the TDR and neutron probe measurements at the bottom of the NP4. To a lesser extent the differences in moisture content may be influenced by instrument error due to different measurement techniques or compaction differences between the two.

\subsection{Soil Water Chemistry}

The lysimeter, a soil water sampler, was placed in the corrosion test berm at the start of testing. Soil water chemistry differs from soil chemistry in that the soluble ions will transport with the available water through the subsurface. Transport of soluble ions will, over time, changes the chemistry of the soil. During the first year attempts were made to apply a vacuum to the lysimeters at the 4- and 10-ft levels without success. There is not enough soil water to retrieve a sample from the lysimeter. No subsequent attempts have been made. Soil moisture is monitored, and if moisture is adequate for a water chemistry sample in the future, then collection will be recommended and attempted. 


\subsection{Soil Gas Chemistry}

Three sets of soil gas sampling tubes have been inserted for the corrosion test. The objective is to determine if any difference in subsurface gas mixtures occur near the corrosion coupons as compared with the gas mixture from a control hole. Corollary to this is that microbial activities produce signature gases as well as alter the gas mixture concentration that would not be present if there is a lack of microbial activity. The gases of interest are the following: oxygen, carbon dioxide, methane, and hydrogen sulfide.

In general, the soil atmosphere recovered from near the coupons at the 4-ft and 10-ft depths collaborated the occurrence of microbial activity at depth (see Appendix L). The $\mathrm{O}_{2}$ concentrations were not statistically different, but the elevated $\mathrm{CO}_{2}$ data does indicate microbial activity. These data were consistent with those of other soil atmosphere studies. Alexander (1961) showed that it was common for $\mathrm{CO}_{2}$ concentrations to exceed the atmospheric level by at least a factor of 10 to 100 while at the same time $\mathrm{O}_{2}$ was less plentiful than atmospheric concentrations. The difference in the composition of the above ground and below ground atmospheres arises from the respiration of microbes and plant roots living organisms consuming $\mathrm{O}_{2}$ and releasing $\mathrm{CO}_{2}$. The increased $\mathrm{CO}_{2}$ concentration at the 10 - $\mathrm{ft}$ level was likely not the result of root activity since connected roots were not found at this depth. Because of the balance of both the $\mathrm{N}_{2}$ and $\mathrm{O}_{2}$ at both depths, it was assumed that microbial activity was responsible, though it was not determined at which depth greater numbers occurred. The average $\mathrm{CH}_{4}$ concentration for both locations at both depths has increased significantly over time.

Diffusion of the gases tends to balance somewhat the concentration gradient so that the content of $\mathrm{O}_{2}$ and $\mathrm{CO}_{2}$ is governed by both the diffusion rate and by the rate of respiration. As a rule, the $\mathrm{O}_{2}$ content declines and the $\mathrm{CO}_{2}$ level in the gas phase increases with depth. Changes in the soil atmosphere alter the size and functions of the microflora as both $\mathrm{CO}_{2}$ and $\mathrm{O}_{2}$ are necessary for growth. A soil that is sufficiently well aerated for the growth of higher plants does not necessarily contain an optimum concentration of $\mathrm{O}_{2}$ for the microflora.

Nitrogen was included in the analysis because not only is it the most abundant gas in the atmosphere, it is also the most abundant inert gas (biologically non reactive except for nitrogen fixation which was not considered as a major sink in the berm soil). It provides an indication whether or not the soil was permeable enough to allow atmosphere gas transfers, which from these data appears to be true. The $\mathrm{N}_{2}$ concentration at both depths is within about $1-2 \%$ of the known atmospheric concentration.

\subsection{Soil Temperature}

Soil temperature monitoring capabilities are now available with the addition of the probe arrays. Temperatures will automatically be logged along with the time domain reflectometery reading. Data collected will assist in correlating any seasonal variations or correlations with other monitored data. Another comparison that can be made is to compare corrosion test data with existing subsurface temperature data such as the general INEEL subsoil temperatures previously recorded from November 1956 through August 1963 up to a depth of $7 \mathrm{ft}$ (K. L. Clawson, et al. 1989. 
(This page intentionally left blank.) 


\section{CONCLUSIONS AND RECOMMENDATIONS}

\subsection{Summary of Six-Year Corrosion Results}

The austenitic stainless steels (Type 304L and 316L), nickel-based alloy (Inconel-718), aluminum 6061, and Ferrallium 255 all had small but measurable corrosion rates after 6 years of underground exposure. Zircaloy-4 had, for most samples, non-measurable corrosion rates after a 6-year test period. Of the materials tested, Beryllium S200F, carbon steel 1018, and aluminum 6061 were pitted, and corrosion showed definite affects of soil depth.

Based on the test results from the 1-, 3-, and 6-year retrievals, the conclusion by Nagata and Banaee (1996) continues to be reinforced and that the corrosion rates being used in the SDA performance assessment, composite analysis and CERCLA risk asssessment may be considerably higher than actual corrosion rates in SDA soils and thus should be conservative when used in calculating radionuclide release rates from buried activated metals. Continued work retrieving coupons, obtaining additional supporting environmental data, and correlating the data from the corrosion test with SDA monitoring should be actively pursued to reduce uncertainties in the source term being used in the SDA performance assessment as well as the RWMC Remedial Investigation and Feasibility Study.

Testing thus far is still considered early-stage testing and, as such, the test would benefit from further comparison to other reported underground corrosion rates. Other ongoing, long-term testing does exist for stainless steel and efforts need to be pursued to obtain the data from the long-term tests to compare with the results from the INEEL test.

\subsection{Possible Long-Term Trends}

Comparisons between the 1-, 3- and 6-year corrosion rates for the beryllium, and carbon steel indicate trends of more rapid mass losses from the coupons at the 10-ft level. For the 10-ft level, the beryllium is following the trend for carbon steel with significant mass losses after the first year and steadily increasing with time. The 4 - $\mathrm{ft}$ level is not as dramatic for beryllium, although the mass loss is significant; the amounts have stayed at or around the levels detected after 1 and 3 years.

The aluminum has also shown significant pitting corrosion, only at the 4-ft level though. As the program is interested in total mass loss rather than specific mechanisms, only limited attempts have been made to include additional information on pit characterization using the vertical scanning-interferometry. So, rather than deteriming a "pit factor" (the ratio of the depth of the deepest pit to the average depth of general corrosion) mass loss has been used to make a determination of the rate with "total metal wastage" for comparative purposes.

\subsection{Beryllium}

After 6 years, the single most interesting material with respect to underground corrosion rates is the beryllium metal. This test represents the first time underground beryllium corrosion has been investigated and since the results are significant and can be directly applied to buried irradiated beryllium components, continued beryllium corrosion study is warranted.

While examining the beryllium coupons from the archived samples with the SEM, the observation of silver chloride on the 1-year exposed coupons - particularly in the pitted areas - adds to the importance of pursuing a standardized method for beryllium-cleaning. (See Appendix F) Subsequent recoveries, the 3- and 6-year exposed coupons, were cleaned with a different procedure with what appears to be better 
results (less resides from cleaning solutions). The 1-year coupons should be reexamined to determine if the residue from the silver chloride adds mass to the coupons and is therefore erroneously limiting the corrosion rates from the 1-year exposure.

Continued analytical effort was performed with soil adhering to the beryllium coupons with the results being similar from the 3- and 6-year coupons. Although the soil adhering to the beryllium contains significant beryllium, there also is background beryllium in the soil. Beryllium compounds found in the adhering soils are bonded primarily with the silicon forming an insoluble substance. Other analysis tools could be applied to detail surface corrosion effects and corrosion products and define corrosion initiation and propagation. One difficulty with analyzing for beryllium components has been the fact that beryllium is such a light metal and is nearly "invisible" to detection with some processes and methods.

The SDA has 7 trenches and 1 soil vault with activated beryllium (Josten, 2004). Of particular concern are the long-lived C-14 and the highly mobile, but shorter-lived tritium in the activated beryllium. Of interest is the ongoing monitoring of one disposal location (1993) of beryllium blocks in

the SDA. A progress report of the monitoring has been published (Ritter \& McElroy, 1999) and describes the findings of soil gas and above ground air monitoring between 1994 and 1999. In the summer of 2004, beryllium disposal locations were injected with a wax-based grout under high pressure. The grouting is an attempt at reducing the moisture from reaching the beryllium metal and thereby limiting the corrosion concerns. Ongoing testing and study of both the disposed beryllium and underground corrosion of beryllium should be pursued to determine what effects the grouting may have on the long-term beryllium corrosion.

\subsection{Soil Characteristics}

Soil characteristics have been documented for samples collected and analyzed to date. Additional monitoring and investigations need to continue to support the understanding of the soil effects on the corrosion rates. Additional studies should compare soil moisture contents of the berm and the SDA, additional soil resistivity measurements should be taken on the test berm at different times of the year to account for different soil moisture contents, soil characteristics such as $\mathrm{pH}$ and composition need further investigation, comparisons and documentation. Additional testing implementing the E/R probes at the test location need to be done to compare variable soil moistures within the SDA.

\subsection{Microbiological Factors}

The microbiological study found evidence of microorganisms on the surface of all the examined coupons. There is an increasing presence of organic acid-producing microbial species colonizing the coupon surfaces together with SRB colonization of carbon steel, aluminum, and in particular beryllium. The environment is suitable for the promotion of microbially induced corrosion (MIC). By inference then, MIC should be expected at the SDA. The results of the microbial study represent a beginning point from which additional investigations should continue to be performed in conjunction with future coupon recoveries and examinations. Special care was taken to preserve specimens from the 6-year retrieval to continue studies, funding permitting. Further microbial investigations to pursue should include: continued soil gas analysis should be performed biannually at the berm and compared to SDA soil gas analyses, examine coupon surfaces upon recovery for biofilm using mechanical and biomolecular techniques, identification of microorganism genus and species, conduct bacterial counts for SRB and other microbes of interest for comparison with MIC criteria specified in the literature and make a comparison of SDA and berm microbial characteristics. 


\section{REFERENCES}

10 CFR 61, "Licensing Requirements for Land Disposal of Radioactive Waste.

Adler Flitton, M.K., C.W. Bishop, R.E. Mizia, J.H. Wolfram, and P.K. Nagata, 2001, Long Term Corrosion/Degradation Test, Test Plan, INEEL/INT-97-00276, Rev. 1.

Adler Flitton, M.K., et al., 2001, Long Term Corrosion/Degradation Test Three Year Results, INEEL/EXT-01-00036.

A-E Construction Specification, 1996, Long Term Corrosion/Degradation Test Berm, A-ECS40902.

Alexander, M., 1961, Introduction to Soil Microbiology, John Wiley and Sons, Publishers.

ASTM Method G1, "Practice for Preparing, Cleaning, and Evaluating Corrosion Test Specimens," American Society for Testing and Materials.

ASTM Method G4, "Standard Guide for Conducting Corrosion Coupon Tests in Field Applications," American Society for Testing and Materials.

ASTM Method G15, "Standard Terminology Relating to Corrosion and Corrosion Testing," American Society for Testing and Materials.

ASTM Method G30, "Standard Practice for Making and Using U-Bend Stress-Corrosion Test Specimens," American Society for Testing and Materials.

ASTM Method G46, "Standard Guide for Examination and Evaluation of Pitting Corrosion," American Society for Testing and Materials.

ASTM Method G16, "Standard Guide for Applying Statistics to Analysis of Corrosion Data," American Society for Testing and Materials.

ASTM Method G51, "Standard Test Method for Measuring pH of Soil for Use in Corrosion Testing," American Society for Testing and Materials.

ASTM Method G57, "Standard Test Method for Field Measurement of Soil Resistivity Using the Wenner Four-Electrode Method," American Society for Testing and Materials.

ASTM Method G96, "Standard Guide for On-Line Monitoring of Corrosion in Plant Equipment (Electrical and Electrochemical Methods)," Standard Guide for American Society for Testing and Materials.

Bishop, C.W., 1998, Soil Moisture Monitoring Results at the Radiological Waste Management Complex of the INEEL, FY 1996, FY 1995, and FY 1994, INEEL/EXT98-00941.

Black, C.A., et al. (eds.), 1965, Methods of Soil Analysis, Part 1, Number 9, Series Agronomy, American Society of Agronomy, Madison, Wisconsin.

Bunnel, L.R., L.A. Doremus, and J. B. Topping, 1994, Task E Container Corrosion Studies: Annual Report, WHC-EP-0769, Westinghouse Hanford Company, Rev. 1. 
Case, M.J. et al., 2000, Technical Revision of the Radioactive Waste Management Complex LowLevel Waste Radiological Performance Assessment for Calendar Year 2000, INEEL/EXT2000-0189.

Chaker, V., 1995, "Soils," in Corrosion Testing and Standards, Application and Interpretation, R. Baboian, ed., American Society for Testing and Materials.

Clawson, K.L., G.E. Start and N. R. Ricks, 1989, Climatography of the Idaho National Engineering Laboratory, $2^{\text {nd }}$ Edition, DOE/ID-12118.

DOE, 1999, DOE Order 435.1a, Radioactive Waste Management" U.S. Department of Energy, July.

Durr, C.L. and J.A. Beavers, “Techniques for Assessment of Soil Corrosivity,” Paper 667, Corrosion 98, NACE International, Houston, TX.

Franklin, D.G., 1997, “The Corrosion of Zircaloy-Clad Fuel Assemblies in a Geologic Repository Environment", presented at the Workshop on Alternative Models and Interpretations Waste Form Degradation and Radionuclide Mobilization Expert Elicitation Panel, San Francisco, CA. December, WAPD-T-3193, Bettis Atomic Power Laboratory, West Mifflin, Pa.

Gerhold, W.G., E. Escalante, and B.T. Sanderson, 1981, The Corrosion Behavior of Selected Stainless Steels in Soil Environments, NBSIR 81-2228 (NBS), National Bureau of Standards, Washington, D.C.

Hillner, E., D.G. Franklin, and J.D. Smee, 1994, The Corrosion of Zircaloy-Clad Fuel Assemblies in a Geologic Repository Environment, WAPD-T-3173, Bettis Atomic Power Laboratory, West Mifflin, PA.

Josten, N.E., 2004, Determination of Beryllium Block Disposal Locations for the OU7-13/14 Early Actions Beryllium Encapsulation Project. EDF-4899, Rev. 1.

LMITCO, A-E Construction Specification, 1996, Long Term Corrosion Degradation Test Berm, A-E Construction Specification, A-E-ECS-40902.

Maheras, S.J., A.S. Rood, S.0. Magnuson, M.E. Sussman, and R.N. Bhatt, 1994, Radioactive Waste Management Complex Low-Level Waste Radiological Performance Assessment, EGG-WM-8773, EG\&G Idaho, Inc.

McCarthy, J.M. et al., 2000, Radioactive Waste Management Complex Low-Level Waste Radiological Composite Analysis, INEEL/EXT-97-01113.

Mizia, R.E. et al., 2000, Long Term Corrosion/Degradation Test First Year Results, INEEL/EXT-1999-00678.

Nagata, P.K., and J. Banaee, 1996, Estimation of the Underground Corrosion Rates for LowCarbon Steels; Types 304 and 316 Stainless Steels; and Inconel 600, 601, and 718 Alloys at the Radioactive Waste Management Complex, INEL-96/098, Lockheed Martin Idaho Technologies Company. 
Nagata, P.K., 1997, Literature Search on Underground Corrosion Rates of Austenitic Stainless Steels, Letter Report to John A. Logan, PKN-15-97.

Oztunali, O.I., and G.W. Roles, 1986, Update of Part 61 IMPACTS Analysis Methodology, NUREG/CR-4370, Vols. 1 and 2.

Pfeifer, M.K., 1997, Background Resistivity and Conductivity for the Long Term Corrosion/Degradation Test Project, EDF-RWMC-985.

Palmer, J.D., 1974, "Soil Resistivity-Measurement and Analysis", Materials Performance, National Association of Corrosion Engineers.

Palmer, J.D., 1989, "Environmental Characteristics Controlling the Soil Corrosion of Ferrous Pipe," Effects of Soil Characteristics on Corrosion, ASTM STP 1013, American Society for Testing and Materials.

Piciulo, P.L., C.E. Shea, and R.E. Barietta, 1985, Analyses of Soils from the Low-Level Radioactive Waste Disposal Site at Barnwell, SC, and Richland, WA, NUREG/CR-4083.

Ritter, P. D., and D. L. McElroy, 1999, Progress Report; Tritium and Carbon-14 Sampling at the Radioactive Waste Management Complex, INEEL/EXT-98-00669.

Rood, A.S., and M.K. Adler Flitton, 1997, Identification of Metal Alloys for Inclusion into Corrosion Test, RWMC-EDF-931, INEL/INT-97-00038, Lockheed Martin Idaho Technologies Company.

Technical Procedure. “Corrosion Coupon Installation,” TPR-1659, Rev. 0, October 12, 2000.

Technical Procedure. “Corrosion Coupon Removal,” TPR-1660, Rev. 1, October 28, 2003.

Tullis, J.A., S.T. Marts, M.C. Pfeifer, and J.B. Sisson, 1993, Corrosive Properties of Backfill Soils at the Radioactive Waste Management Complex, Idaho National Engineering Laboratory, EGG-GEO-10382, EG\&G Idaho, Inc.

Wilkins, S.C., B.C. Norby, and E.C. Hales, 1998, Test Results, Weight Loss Measurements in Coupon Control blank Cleaning for the Long-Term Corrosion/Degradation Test, INEELINT-97-01196, EDF-RWMC-994. 
(This page intentionally left blank.) 


\section{APPENDIX A}

\section{Material Test Report}





\section{Material Test Report}

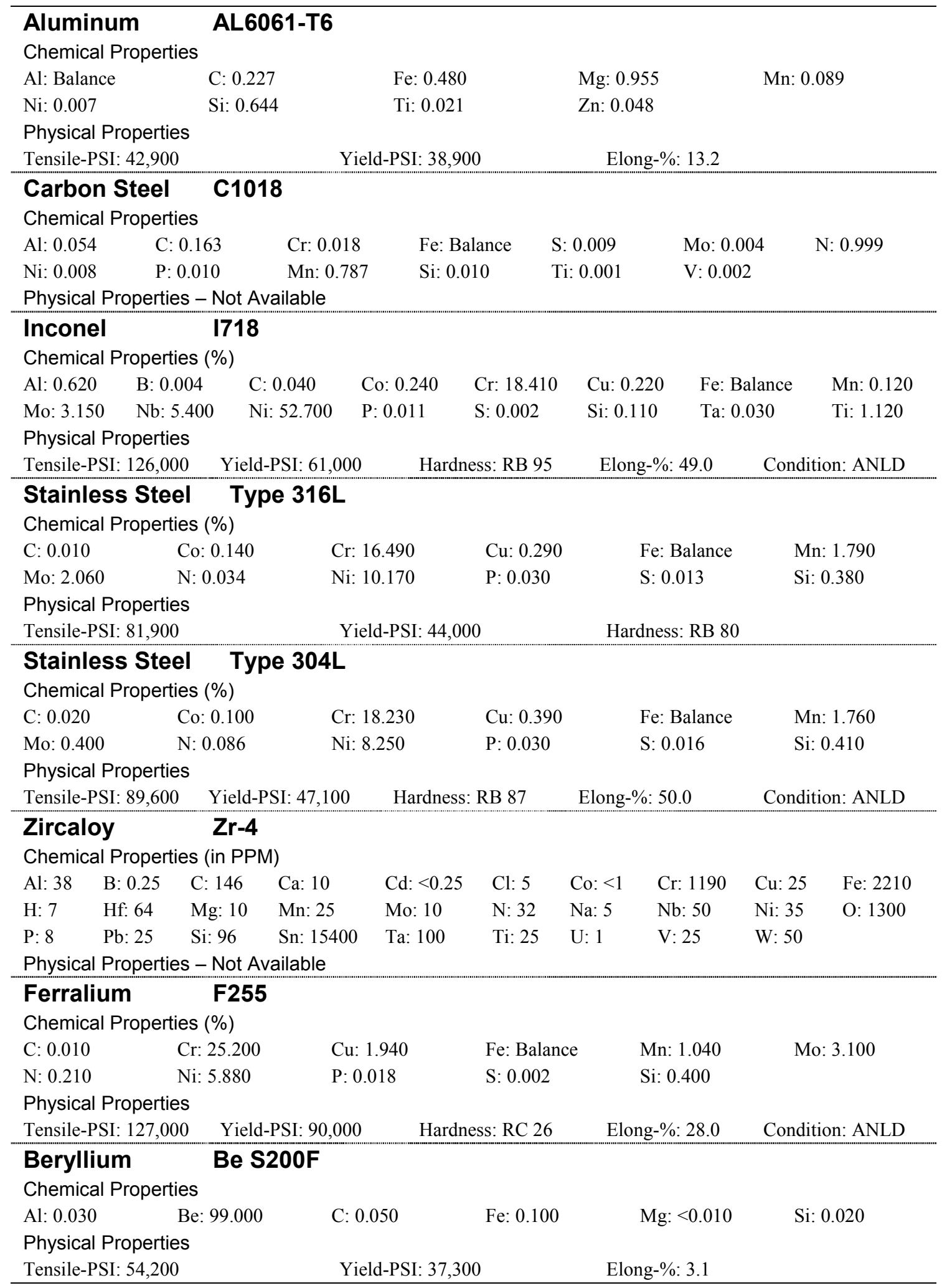


(This page intentionally left blank.) 


\section{APPENDIX B}

\section{Cleaning Curves for Chemical Cleaning}

6-Year Exposed Coupons

- $4 \mathrm{ft}$ Aluminum

- 4 and $10 \mathrm{ft}$ Beryllium

- 4 and $10 \mathrm{ft}$ Carbon Steel 
(This page intentionally left blank.) 


\section{Aluminum Cleaning Curves \\ 6-year exposure at 4 feet}
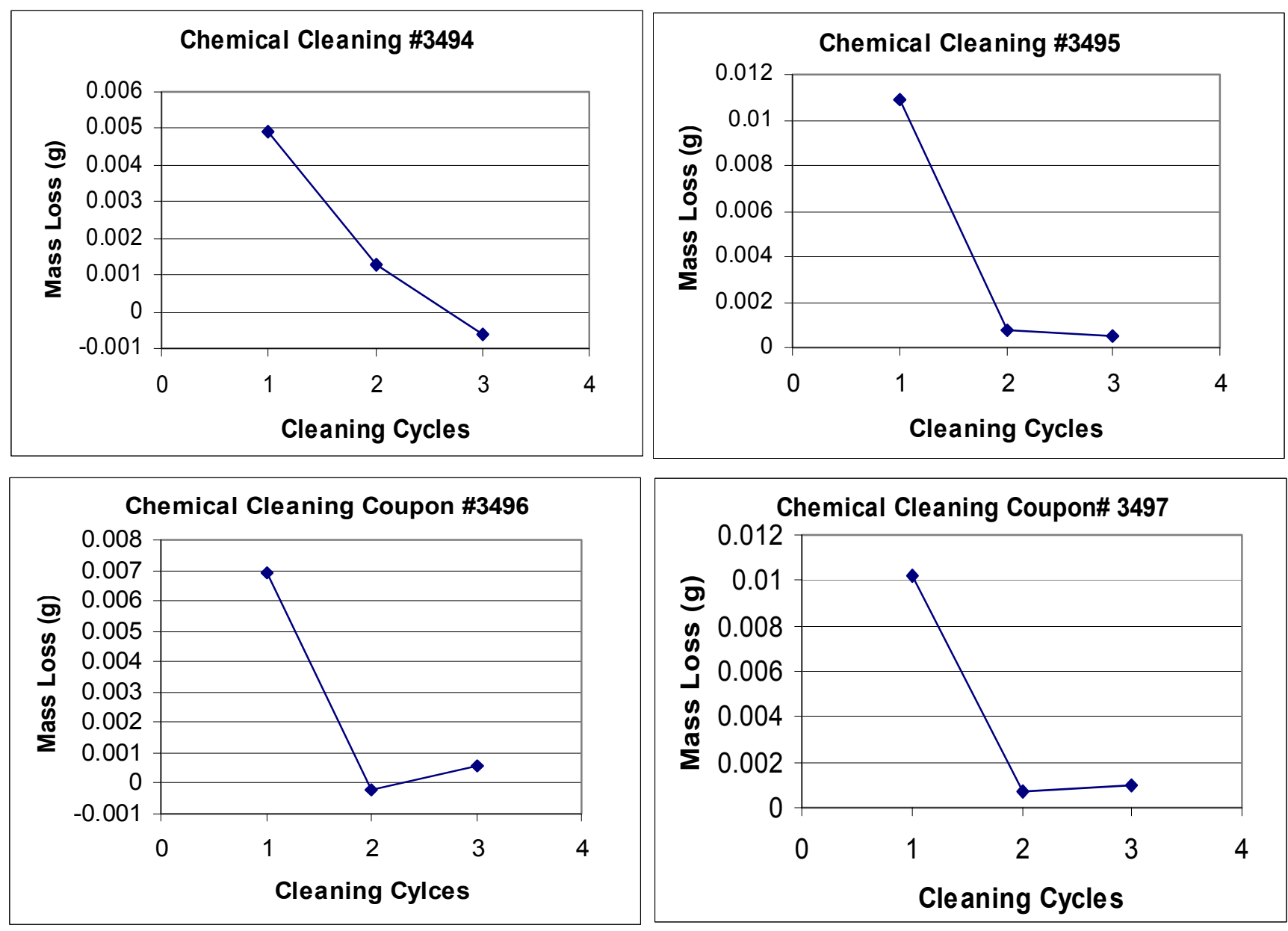

Cleaning Coupon \#3535

\begin{tabular}{|c|c|c|c|}
\hline Cycle & $\begin{array}{c}\text { Initial Mass } \\
(\mathrm{g})\end{array}$ & $\begin{array}{c}\text { Final Mass } \\
(\mathrm{g})\end{array}$ & $\begin{array}{c}\text { Mass Loss } \\
\text { Correction }\end{array}$ \\
\hline 1 & 44.1378 & 44.1373 & 0.0005 \\
2 & 44.1373 & 44.1369 & 0.0004 \\
3 & 44.1369 & 44.1369 & 0.000 \\
\hline \multicolumn{3}{|c|}{ Cleaning Coupon } \\
\hline
\end{tabular}




\section{Beryllium Cleaning Curves \\ 6-year exposure at 4 feet}
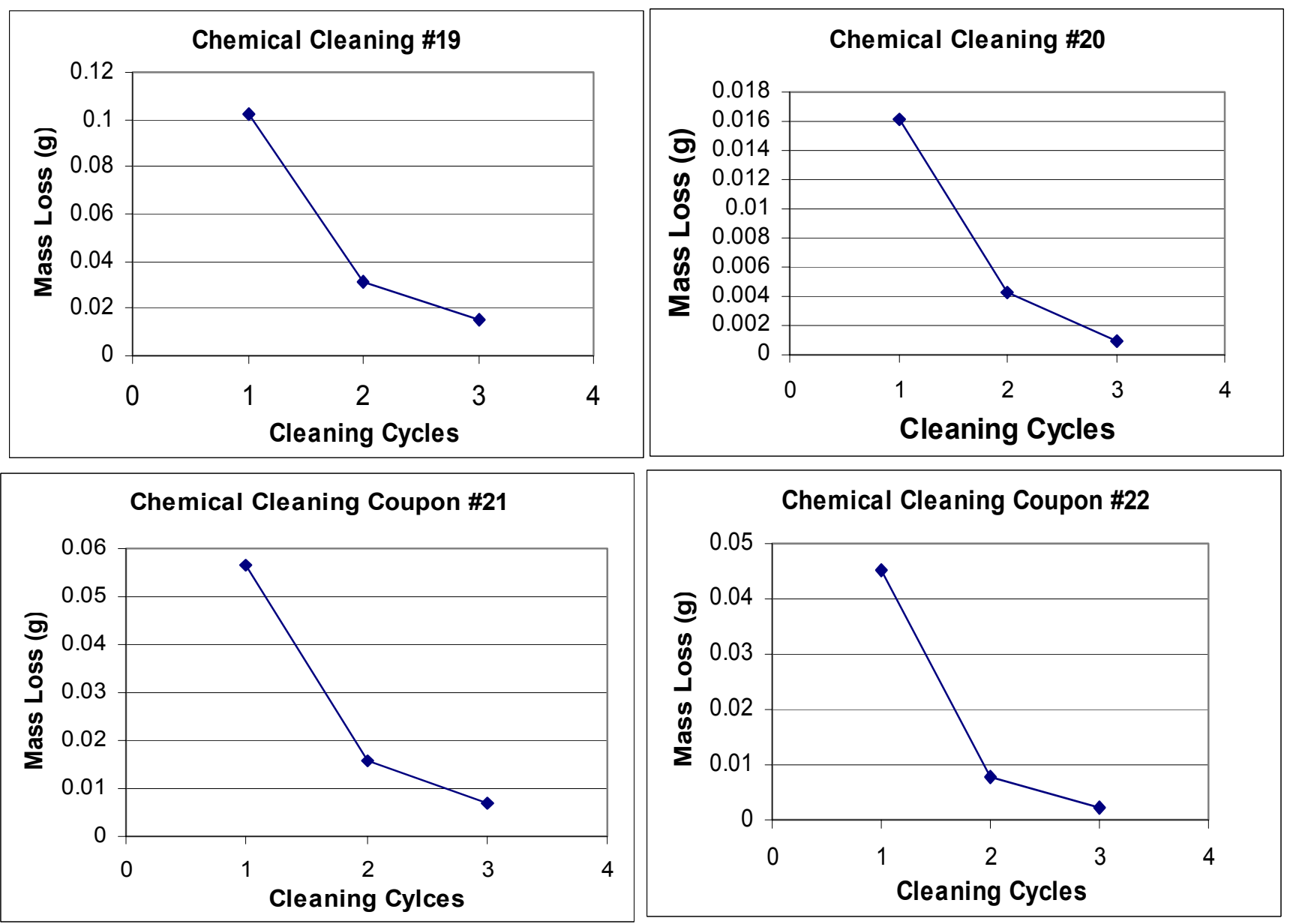

Cleaning Coupon \#53

\begin{tabular}{|c|c|c|c|}
\hline Cycle & $\begin{array}{c}\text { Initial Mass } \\
(\mathrm{g})\end{array}$ & $\begin{array}{c}\text { Final Mass } \\
(\mathrm{g})\end{array}$ & $\begin{array}{c}\text { Mass Loss } \\
\text { Correction }\end{array}$ \\
\hline 1 & 36.5738 & 36.5746 & -0.0008 \\
2 & 36.5746 & 36.5738 & 0.0008 \\
3 & 36.5738 & 36.5745 & -0.0007 \\
4 & 36.5745 & 36.5744 & 0.0001 \\
\hline \multicolumn{3}{|c}{} \\
\hline
\end{tabular}




\section{Beryllium Cleaning Curves}

\section{6-year exposure at 10 feet}
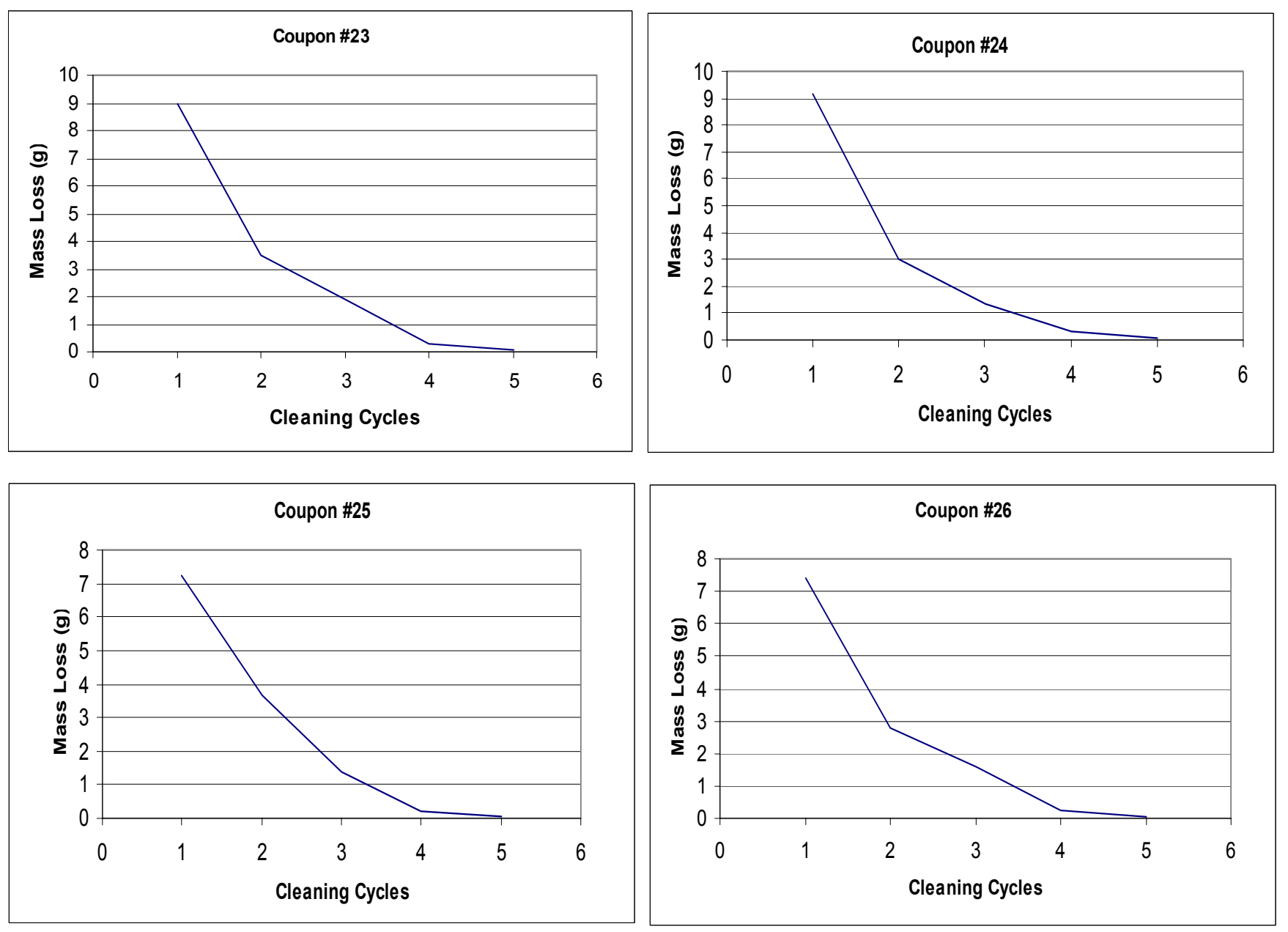

Cleaning Coupon \#53

\begin{tabular}{|c|c|c|c|}
\hline Cycle & $\begin{array}{c}\text { Initial Mass } \\
(\mathrm{g})\end{array}$ & $\begin{array}{c}\text { Final Mass } \\
(\mathrm{g})\end{array}$ & $\begin{array}{c}\text { Mass Loss } \\
\text { Correction }\end{array}$ \\
\hline 1 & 36.5746 & 36.5745 & 0.0001 \\
2 & 36.5745 & 36.5748 & -0.0003 \\
3 & 36.5748 & 36.5735 & 0.0013 \\
4 & 36.5735 & 36.5726 & 0.0009 \\
5 & 36.5726 & 36.5747 & -0.0021 \\
6 & 36.5747 & 36.5744 & 0.0003 \\
\hline \multicolumn{3}{|c|}{ Cleaning Coupon Total mass loss } \\
\hline
\end{tabular}




\section{Carbon Steel Cleaning Curves \\ 6-year exposure at 4 feet}
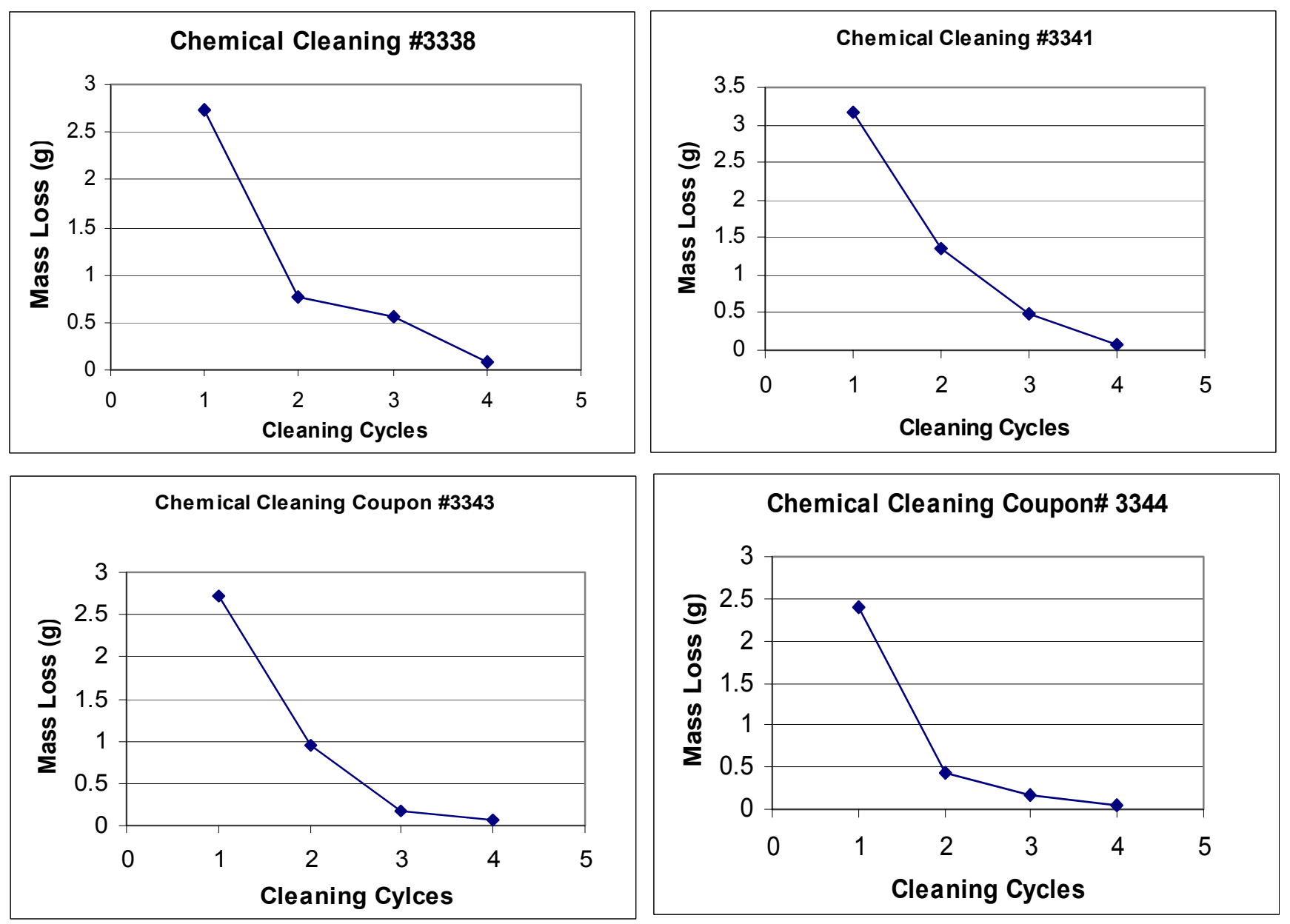

Cleaning Coupon \#3619/MS \#102

\begin{tabular}{|c|c|c|c|}
\hline Cycle & $\begin{array}{c}\text { Initial Mass } \\
(\mathrm{g})\end{array}$ & $\begin{array}{c}\text { Final Mass } \\
(\mathrm{g})\end{array}$ & $\begin{array}{c}\text { Mass Loss } \\
\text { Correction }\end{array}$ \\
\hline 1 & 129.9688 & 129.9152 & 0.0536 \\
2 & 129.9125 & 129.8382 & 0.0770 \\
3 & 129.8382 & 129.6987 & 0.1395 \\
4 & 129.6987 & 129.6517 & 0.0470 \\
\hline \multicolumn{3}{|c}{} \\
\hline
\end{tabular}




\section{Carbon Steel Cleaning Curves \\ 6-year exposure at 10 feet}
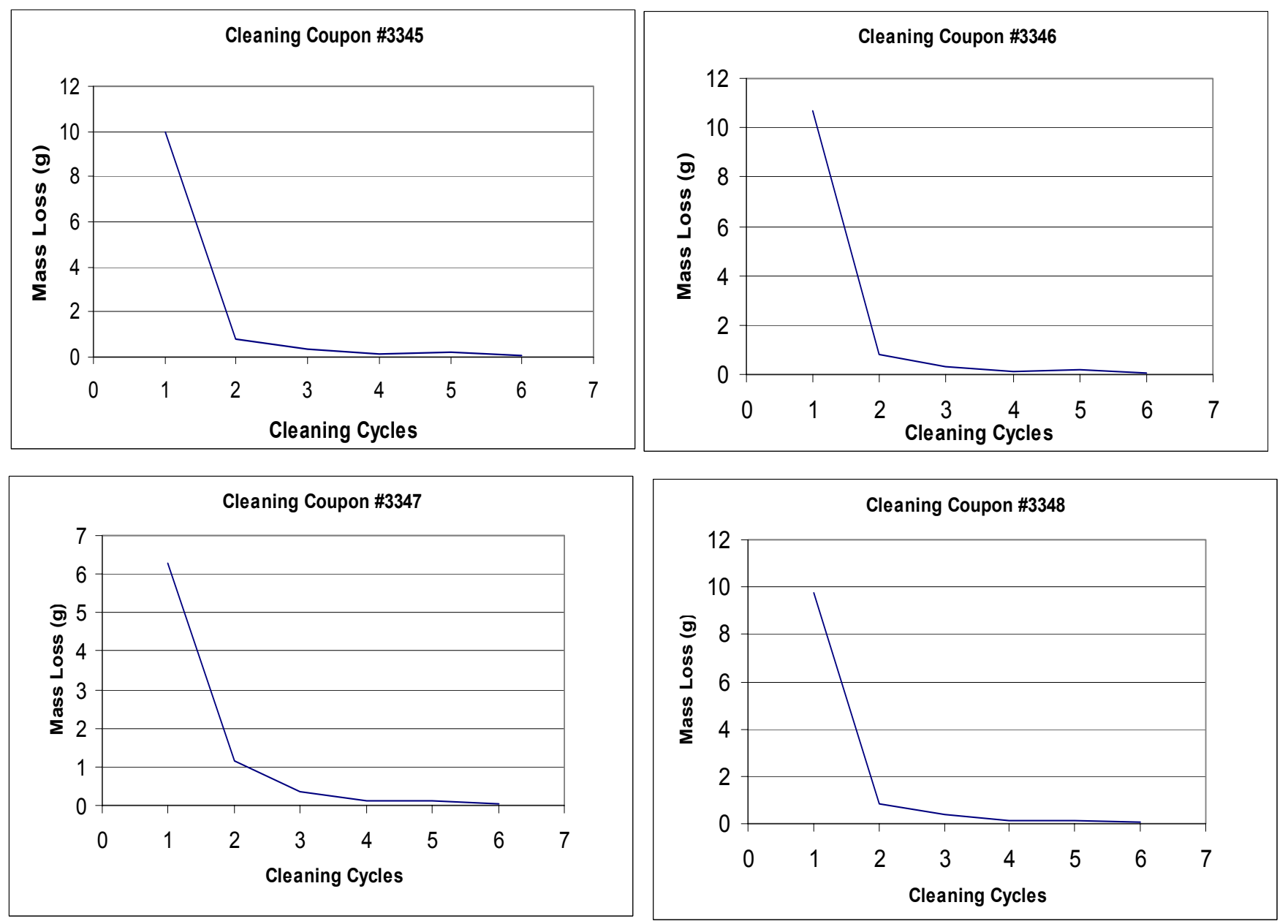

Cleaning Coupon \#3619/MS \#102

\begin{tabular}{|c|c|c|c|}
\hline Cycle & $\begin{array}{c}\text { Initial Mass } \\
(\mathrm{g})\end{array}$ & $\begin{array}{c}\text { Final Mass } \\
(\mathrm{g})\end{array}$ & $\begin{array}{c}\text { Mass Loss } \\
\text { Correction }\end{array}$ \\
\hline 1 & 129.6517 & 129.5771 & 0.0536 \\
2 & 129.5771 & 129.5219 & 0.0770 \\
3 & 129.5219 & 129.4765 & 0.1395 \\
4 & 129.4765 & 129.4348 & 0.0470 \\
5 & 129.4348 & 129.3693 & 0.0655 \\
6 & 129.3693 & 129.3325 & 0.0368 \\
\hline \multicolumn{3}{|c|}{ Cleaning Coupon Total mass loss } \\
\hline
\end{tabular}


(This page intentionally left blank.) 


\section{APPENDIX C}

\section{Mass Loss Tables \\ For 1-, 3-, and 6- Year Exposed Coupons}

The mass losses for the individual coupons, along with the corresponding corrosion rates are presented in this appendix. A notation of "No reportable corrosion" indicates that no weight loss was measured or that the measured weight loss was less than the uncertainties described in Section 2.8 (uncertainties due to variability in the balance scale measurements, in some cases combined with uncertainties due to the wash/brush process). Note, also, that losses of base metal due to chemical cleaning of aluminum, beryllium, and carbon steel, as described in Section 2.8, have already been accounted for in the reported weight losses for coupons of those compositions. 
(This page intentionally left blank.) 
Table C1. Corrosion results after one year for coupons buried at $4 \mathrm{ft}$.

\begin{tabular}{|c|c|c|c|c|}
\hline Coupon location & Composition & Identifier & $\begin{array}{c}\text { Mass loss } \\
(\mathrm{g})\end{array}$ & $\begin{array}{c}\text { Corrosion rate } \\
\text { (MPY) }\end{array}$ \\
\hline CAO1-2-1 & Aluminum & 3478 & 0.0011 & 0.0013 \\
\hline CAO1-3-2 & Aluminum & 3479 & 0.0004 & 0.0005 \\
\hline CAO1-4-1 & Aluminum & 3480 & 0.0024 & 0.0028 \\
\hline CAO1-5-5 & Aluminum & 3481 & 0.0000 & No Reportable Corrosion \\
\hline CAO1-2-5 & Beryllium & $S / N-1$ & 0.0150 & 0.025 \\
\hline CAO1-3-8 & Beryllium & $S / N-2$ & 0.0589 & 0.099 \\
\hline CAO1-4-7 & Beryllium & $\mathrm{S} / \mathrm{N}-3$ & 0.0480 & 0.081 \\
\hline CAO1-5-6 & Beryllium & $\mathrm{S} / \mathrm{N}-4$ & 0.0662 & 0.111 \\
\hline CAO1-1-1 & Carbon Steel & 3322 & 0.3193 & 0.13 \\
\hline CAO1-2-2 & Carbon Steel & 3323 & 0.3501 & 0.14 \\
\hline CAO1-3-5 & Carbon Steel & 3324 & 0.3012 & 0.12 \\
\hline CAO1-4-4 & Carbon Steel & 3325 & 0.2780 & 0.11 \\
\hline CAO1-1-3 & Ferralium 255 & W3732 & $0.0001^{\mathrm{a}}$ & No Reportable Corrosion \\
\hline CAO1-3-1 & Ferralium 255 & W3733 & Weight Gain $0.0002^{a}$ & No Reportable Corrosion \\
\hline CAO1-4-8 & Ferralium 255 & W3734 & 0.0012 & 0.0005 \\
\hline CAO1-6-2 & Ferralium 255 & W3735 & 0.0010 & 0.0004 \\
\hline CAO1-2-3 & Inconel 718 & 3424 & $0.0001^{a}$ & No Reportable Corrosion \\
\hline CAO1-3-4 & Inconel 718 & 3425 & Weight Gain $0.0005^{a}$ & No Reportable Corrosion \\
\hline CAO1-4-6 & Inconel 718 & 3426 & $0.0000^{\mathrm{a}}$ & No Reportable Corrosion \\
\hline CAO1-5-4 & Inconel 718 & 3427 & $0.0000^{\mathrm{a}}$ & No Reportable Corrosion \\
\hline CAO1-2-4 & $304 \mathrm{~L}$ & 3268 & $0.0006^{a}$ & No Reportable Corrosion \\
\hline CAO1-3-6 & $304 \mathrm{~L}$ & 3269 & Weight Gain $0.0001^{a}$ & No Reportable Corrosion \\
\hline CAO1-5-3 & $304 \mathrm{~L}$ & 3270 & $0.0001^{\mathrm{a}}$ & No Reportable Corrosion \\
\hline CAO1-5-1 & $304 \mathrm{~L}$ & 3271 & Weight Gain $0.0003^{a}$ & No Reportable Corrosion \\
\hline CAO1-1-2 & $316 \mathrm{~L}$ & 3364 & $0.0005^{\mathrm{a}}$ & No Reportable Corrosion \\
\hline CAO1-4-3 & $316 \mathrm{~L}$ & 3365 & $0.0004^{\mathrm{a}}$ & No Reportable Corrosion \\
\hline CAO1-5-2 & $316 \mathrm{~L}$ & 3366 & $0.0004^{\mathrm{a}}$ & No Reportable Corrosion \\
\hline CAO1-6-1 & $316 \mathrm{~L}$ & 3367 & $0.0008^{\mathrm{a}}$ & No Reportable Corrosion \\
\hline CAO1-2-6 & 316L Welded & W3672 & Weight Gain $0.0007^{a}$ & No Reportable Corrosion \\
\hline CAO1-3-7 & 316L Welded & W3673 & Weight Gain $0.0004^{a}$ & No Reportable Corrosion \\
\hline CAO1-4-2 & 316L Welded & W3674 & Weight Gain $0.0005^{a}$ & No Reportable Corrosion \\
\hline CAO1-5-7 & 316L Welded & W3675 & Weight Gain $0.0003^{a}$ & No Reportable Corrosion \\
\hline CAO1-2-7 & Zircaloy-4 & 3792 & Weight Gain 0.0010 & No Reportable Corrosion \\
\hline CAO1-3-3 & Zircaloy-4 & 3793 & Weight Gain 0.0013 & No Reportable Corrosion \\
\hline CAO1-4-5 & Zircaloy-4 & 3794 & Weight Gain 0.0007 & No Reportable Corrosion \\
\hline CAO1-6-3 & Zircaloy-4 & 3795 & Weight Gain 0.0009 & No Reportable Corrosion \\
\hline
\end{tabular}


Table C2. Corrosion results after one year for coupons buried at $10 \mathrm{ft}$.

\begin{tabular}{|c|c|c|c|c|}
\hline Coupon location & Composition & Identifier & $\begin{array}{c}\text { Mass Loss } \\
(\mathrm{g})\end{array}$ & $\begin{array}{c}\text { Corrosion Rate } \\
\text { (MPY) }\end{array}$ \\
\hline CAO2-1-2 & Aluminum & 3482 & $0.0000^{*}$ & No Reportable Corrosion \\
\hline CAO2-1-3 & Aluminum & 3483 & $0.0011^{*}$ & 0.0013 \\
\hline CAO2-3-7 & Aluminum & 3484 & $0.0005^{*}$ & No Reportable Corrosion \\
\hline CAO2-4-1 & Aluminum & 3485 & $0.0006^{*}$ & No Reportable Corrosion \\
\hline CAO2-2-5 & Beryllium & $S / N-5$ & 0.0932 & 0.152 \\
\hline CAO2-4-4 & Beryllium & $S / N-10$ & 0.1084 & 0.176 \\
\hline CAO2-4-7 & Beryllium & $S / N-11$ & 0.1138 & 0.185 \\
\hline CAO2-5-7 & Beryllium & $\mathrm{S} / \mathrm{N}-12$ & 0.1239 & 0.202 \\
\hline CAO2-2-3 & Carbon Steel & 3326 & 0.6996 & 0.27 \\
\hline CAO2-3-2 & Carbon Steel & 3327 & 0.5961 & 0.23 \\
\hline CAO2-3-6 & Carbon Steel & 3328 & 0.5661 & 0.22 \\
\hline CAO2-4-3 & Carbon Steel & 3329 & 0.7095 & 0.28 \\
\hline CAO2-2-2 & Ferralium 255 & W3736 & $0.0007^{*}$ & No Reportable Corrosion \\
\hline CAO2-3-4 & Ferralium 255 & W3737 & 0.0010 & 0.0004 \\
\hline CAO2-4-2 & Ferralium 255 & W3738 & 0.0012 & 0.0005 \\
\hline $\mathrm{CAO} 2-5-4$ & Ferralium 255 & W3739 & 0.0011 & 0.0004 \\
\hline CAO2-2-7 & Inconel 718 & 3428 & Weight gain $0.0004^{*}$ & No Reportable Corrosion \\
\hline CAO2-4-6 & Inconel 718 & 3429 & $0.0006^{*}$ & No Reportable Corrosion \\
\hline CAO2-5-2 & Inconel 718 & 3430 & $0.0000^{*}$ & No Reportable Corrosion \\
\hline CAO2-5-3 & Inconel 718 & 3431 & $0.0000^{*}$ & No Reportable Corrosion \\
\hline CAO2-2-4 & $304 \mathrm{~L}$ & 3272 & $0.0004^{*}$ & No Reportable Corrosion \\
\hline CAO2-3-1 & $304 \mathrm{~L}$ & 3273 & $0.0004^{*}$ & No Reportable Corrosion \\
\hline CAO2-4-5 & $304 \mathrm{~L}$ & 3274 & $0.0007^{*}$ & No Reportable Corrosion \\
\hline CAO2-5-6 & $304 \mathrm{~L}$ & 3275 & $0.0003^{*}$ & No Reportable Corrosion \\
\hline CAO2-2-6 & $316 \mathrm{~L}$ & 3368 & $0.0002^{*}$ & No Reportable Corrosion \\
\hline CAO2-3-8 & $316 \mathrm{~L}$ & 3369 & $0.0001^{*}$ & No Reportable Corrosion \\
\hline CAO2-5-1 & $316 \mathrm{~L}$ & 3370 & $0.0007^{*}$ & No Reportable Corrosion \\
\hline $\mathrm{CAO} 2-6-3$ & $316 \mathrm{~L}$ & 3371 & $0.0007^{*}$ & No Reportable Corrosion \\
\hline CAO2-2-1 & 316L Welded & W3676 & Weight gain $0.0007^{*}$ & No Reportable Corrosion \\
\hline CAO2-3-3 & 316L Welded & W3677 & Weight gain $0.0003^{*}$ & No Reportable Corrosion \\
\hline CAO2-3-5 & 316L Welded & W3678 & Weight gain $0.0006^{*}$ & No Reportable Corrosion \\
\hline CAO2-5-5 & 316L Welded & W3679 & Weight gain $0.0007^{*}$ & No Reportable Corrosion \\
\hline CAO2-1-1 & Zircaloy-4 & 3796 & Weight gain 0.0016 & No Reportable Corrosion \\
\hline CAO2-4-8 & Zircaloy-4 & 3797 & Weight gain 0.0011 & No Reportable Corrosion \\
\hline CAO2-6-1 & Zircaloy-4 & 3798 & Weight gain 0.0009 & No Reportable Corrosion \\
\hline CAO2-6-2 & Zircaloy-4 & 3799 & Weight gain 0.0010 & No Reportable Corrosion \\
\hline
\end{tabular}


Table C3. Corrosion results after three years for coupons buried at $4 \mathrm{ft}$.

\begin{tabular}{|c|c|c|c|c|c|}
\hline Coupon location & Composition & Identifier & Weight loss $(\mathrm{g})$ & Weight loss $(\%)$ & Corrosion rate (MPY) \\
\hline CA03-2-4 & Aluminum & 3486 & 0.0043 & 0.0095 & 0.0017 \\
\hline CA03-3-1 & Aluminum & 3487 & 0.0167 & 0.0370 & 0.0067 \\
\hline CA03-3-7 & Aluminum & 3488 & 0.0111 & 0.0246 & 0.0044 \\
\hline CA03-5-7 & Aluminum & 3489 & 0.0072 & 0.0163 & 0.0029 \\
\hline CA03-2-1 & Beryllium & $S / N-6$ & 0.0379 & 0.1102 & 0.0216 \\
\hline CA03-2-6 & Beryllium & $S / N-9$ & 0.016 & 0.0465 & 0.0091 \\
\hline CA03-4-6 & Beryllium & $S / N-13$ & 0.0153 & 0.0435 & 0.0086 \\
\hline CA03-5-2 & Beryllium & $\mathrm{S} / \mathrm{N}-14$ & 0.0591 & 0.1676 & 0.0337 \\
\hline CA03-1-2 & Carbon Steel & 3330 & 0.7831 & & 0.1067 \\
\hline CA03-3-2 & Carbon Steel & 3331 & 1.0298 & & 0.1404 \\
\hline CA03-4-1 & Carbon Steel & 3332 & 0.9728 & & 0.1325 \\
\hline CA03-4-8 & Carbon Steel & 3333 & 0.7787 & & 0.1065 \\
\hline Coupon location & Composition & Identifier & \multicolumn{2}{|c|}{ Weight loss $(\mathrm{g})$} & Corrosion rate (MPY) \\
\hline CA03-2-7 & Ferralium 255 & W3740 & \multicolumn{2}{|c|}{0.0022} & 0.0003 \\
\hline CA03-3-6 & Ferralium 255 & W3741 & \multicolumn{2}{|c|}{0.0017} & 0.0002 \\
\hline CA03-4-5 & Ferralium 255 & W3742 & \multicolumn{2}{|c|}{0.0026} & 0.0004 \\
\hline CA03-5-3 & Ferralium 255 & W3743 & \multicolumn{2}{|c|}{0.0024} & 0.0003 \\
\hline CA03-1-1 & Inconel 718 & 3432 & \multicolumn{2}{|c|}{0.0028} & 0.0004 \\
\hline CA03-3-3 & Inconel 718 & 3433 & \multicolumn{2}{|c|}{0.0021} & 0.0003 \\
\hline CA03-3-5 & Inconel 718 & 3434 & \multicolumn{2}{|c|}{0.0019} & 0.0002 \\
\hline CA03-3-8 & Inconel 718 & 3435 & \multicolumn{2}{|c|}{0.0034} & 0.0004 \\
\hline CA03-4-2 & $304 \mathrm{~L}$ & 3279 & \multicolumn{2}{|c|}{0.0019} & 0.0003 \\
\hline CA03-4-4 & $304 \mathrm{~L}$ & 3321 & \multicolumn{2}{|c|}{0.0017} & 0.0002 \\
\hline CA03-5-4 & $304 \mathrm{~L}$ & 3276 & \multicolumn{2}{|c|}{0.0019} & 0.0003 \\
\hline CA03-6-3 & $304 \mathrm{~L}$ & 3277 & \multicolumn{2}{|c|}{0.0018} & 0.0002 \\
\hline CA03-1-3 & $316 \mathrm{~L}$ & 3372 & \multicolumn{2}{|c|}{0.0023} & 0.0003 \\
\hline CA03-4-3 & $316 \mathrm{~L}$ & 3374 & \multicolumn{2}{|c|}{0.003} & 0.0004 \\
\hline CA03-5-5 & $316 \mathrm{~L}$ & 3373 & \multicolumn{2}{|c|}{0.0023} & 0.0003 \\
\hline CA03-6-1 & $316 \mathrm{~L}$ & 3375 & \multicolumn{2}{|c|}{0.0031} & 0.0004 \\
\hline CA03-2-2 & 316L Welded & W3680 & \multicolumn{2}{|c|}{0.0015} & 0.0002 \\
\hline CA03-2-3 & 316L Welded & W3681 & \multicolumn{2}{|c|}{0.0015} & 0.0002 \\
\hline CA03-4-7 & 316L Welded & W3682 & \multicolumn{2}{|c|}{0.0013} & 0.0002 \\
\hline CA03-6-2 & 316L Welded & W3683 & \multicolumn{2}{|c|}{0.0015} & 0.0002 \\
\hline CA03-2-5 & Zircaloy-4 & 3800 & \multicolumn{2}{|c|}{$0.0002^{a}$} & No Reportable corrosion \\
\hline CA03-3-4 & Zircaloy-4 & 3801 & \multicolumn{2}{|c|}{$0.0003^{a}$} & No Reportable corrosion \\
\hline CA03-5-1 & Zircaloy-4 & 3802 & \multicolumn{2}{|c|}{$0.0000^{\mathrm{a}}$} & No Reportable corrosion \\
\hline CA03-5-6 & Zircaloy-4 & 3803 & \multicolumn{2}{|c|}{$0.0006^{a}$} & No Reportable corrosion \\
\hline
\end{tabular}

a. weight loss or gain (if any) is within the tolerance of the Mettler AE 163 Balance 
Table C4. Corrosion results after three years for coupons buried at $10 \mathrm{ft}$.

\begin{tabular}{|c|c|c|c|c|c|}
\hline Coupon location & Composition & Identifier & Weight Loss (g) & Weight Loss (\%) & Corrosion Rate (MPY) \\
\hline CA04-2-2 & Aluminum & 3490 & 0.0039 & 0.0089 & 0.0015 \\
\hline CA04-2-3 & Aluminum & 3491 & 0.003 & 0.0067 & 0.0012 \\
\hline CA04-3-1 & Aluminum & 3492 & 0.0087 & 0.0195 & 0.0032 \\
\hline CA04-3-2 & Aluminum & 3493 & 0.0047 & 0.0105 & 0.0019 \\
\hline CA04-2-5 & Beryllium & $S / N-15$ & 0.5247 & 1.4886 & 0.2942 \\
\hline CA04-3-3 & Beryllium & $S / N-16$ & 0.5776 & 1.6832 & 0.3267 \\
\hline CA04-4-3 & Beryllium & $\mathrm{S} / \mathrm{N}-17$ & 0.5651 & 1.6358 & 0.3188 \\
\hline CA04-4-7 & Beryllium & $S / N-18$ & 0.3616 & 0.9792 & 0.2017 \\
\hline CA04-1-3 & Carbon Steel & 3334 & 3.2952 & & 0.4467 \\
\hline CA04-2-6 & Carbon Steel & 3335 & 3.4051 & & 0.4598 \\
\hline CA04-4-4 & Carbon Steel & 3336 & 3.1047 & & 0.4207 \\
\hline CA04-6-1 & Carbon Steel & 3337 & 3.4196 & & 0.4545 \\
\hline Coupon location & Composition & Identifier & Weight & Loss $(\mathrm{g})$ & Corrosion Rate (MPY) \\
\hline CA04-1-2 & Ferralium 255 & W3744 & & 016 & 0.0002 \\
\hline CA04-3-8 & Ferralium 255 & W3745 & & 009 & 0.0001 \\
\hline CA04-4-6 & Ferralium 255 & W3746 & & 025 & 0.0003 \\
\hline CA04-5-3 & Ferralium 255 & W3747 & & 021 & 0.0003 \\
\hline CA04-2-4 & Inconel 718 & 3436 & & 039 & 0.0005 \\
\hline CA04-4-2 & Inconel 718 & 3437 & & 035 & 0.0004 \\
\hline CA04-5-2 & Inconel 718 & 3438 & & 035 & 0.0004 \\
\hline CA04-5-4 & Inconel 718 & 3439 & & 034 & 0.0004 \\
\hline CA04-3-7 & $304 \mathrm{~L}$ & 3278 & & 02 & 0.0003 \\
\hline CA04-4-1 & $304 \mathrm{~L}$ & 3280 & & 03 & 0.0004 \\
\hline CA04-4-5 & $304 \mathrm{~L}$ & 3317 & & 025 & 0.0003 \\
\hline CA04-4-8 & $304 \mathrm{~L}$ & 3318 & & 026 & 0.0003 \\
\hline CA04-5-6 & $316 \mathrm{~L}$ & 3376 & & 031 & 0.0004 \\
\hline CA04-5-7 & $316 \mathrm{~L}$ & 3377 & & 032 & 0.0004 \\
\hline CA04-6-2 & $316 \mathrm{~L}$ & 3378 & & 036 & 0.0005 \\
\hline CA04-6-3 & $316 \mathrm{~L}$ & 3379 & & 044 & 0.0006 \\
\hline CA04-1-1 & 316L Welded & W3684 & & 018 & 0.0002 \\
\hline CA04-2-7 & 316L Welded & W3685 & & 025 & 0.0003 \\
\hline CA04-3-4 & 316L Welded & W3686 & & 02 & 0.0003 \\
\hline CA04-3-5 & 316L Welded & W3687 & & 026 & 0.0004 \\
\hline CA04-2-1 & Zircaloy-4 & 3804 & & 001 & 0.0002 \\
\hline CA04-3-6 & Zircaloy-4 & 3805 & 0.0 & $005^{a}$ & No Reportable Corrosion \\
\hline CA04-5-1 & Zircaloy-4 & 3806 & & 014 & 0.0002 \\
\hline CA04-5-5 & Zircaloy-4 & 3807 & & 001 & 0.0002 \\
\hline
\end{tabular}


Table C5. Corrosion results after six years for coupons buried at $4 \mathrm{ft}$.

\begin{tabular}{|c|c|c|c|c|c|}
\hline Coupon location & Composition & Identifier & Mass loss $(\mathrm{g})$ & Mass loss $(\%)$ & Corrosion rate (MPY) \\
\hline CA05-1-3 & Aluminum & 3494 & 0.0035 & 0.0077 & 0.0007 \\
\hline CA05-2-5 & Aluminum & 3495 & 0.0094 & 0.0210 & 0.0019 \\
\hline CA05-4-3 & Aluminum & 3496 & 0.0027 & 0.0060 & 0.0005 \\
\hline CA05-5-2 & Aluminum & 3497 & 0.0149 & 0.0342 & 0.0030 \\
\hline CA05-1-2 & Beryllium & $\mathrm{S} / \mathrm{N}-19$ & 0.0372 & 0.1015 & 0.0105 \\
\hline CA05-2-6 & Beryllium & $S / N-20$ & 0.0152 & 0.0421 & 0.0043 \\
\hline CA05-3-5 & Beryllium & $S / N-21$ & 0.0411 & 0.1139 & 0.0115 \\
\hline CA05-3-6 & Beryllium & $\mathrm{S} / \mathrm{N}-22$ & 0.0277 & 0.0752 & 0.0078 \\
\hline CA05-2-2 & Carbon Steel & 3338 & 2.3053 & 1.7418 & 0.1559 \\
\hline CA05-3-1 & Carbon Steel & 3341 & 2.6791 & 2.0140 & 0.1806 \\
\hline CA05-4-2 & Carbon Steel & 3343 & 2.3045 & 1.8277 & 0.1565 \\
\hline CA05-4-4 & Carbon Steel & 3344 & 1.8962 & 1.4734 & 0.1286 \\
\hline Coupon location & Composition & Identifier & \multicolumn{2}{|c|}{ Mass loss $(\mathrm{g})$} & Corrosion rate (MPY) \\
\hline CA05-2-4 & Ferralium 255 & W3748 & \multicolumn{2}{|c|}{0.0013} & 0.0001 \\
\hline CA05-3-2 & Ferralium 255 & W3749 & \multicolumn{2}{|c|}{0.0012} & 0.0001 \\
\hline CA05-4-5 & Ferralium 255 & W3750 & \multicolumn{2}{|c|}{0.0009} & 0.0001 \\
\hline CA05-6-2 & Ferralium 255 & W3751 & \multicolumn{2}{|c|}{0.0014} & 0.0001 \\
\hline CA05-4-6 & Inconel 718 & 3440 & \multicolumn{2}{|c|}{0.0016} & 0.0001 \\
\hline CA05-5-3 & Inconel 718 & 3441 & \multicolumn{2}{|c|}{0.0024} & 0.0002 \\
\hline CA05-5-4 & Inconel 718 & 3442 & \multicolumn{2}{|c|}{0.0016} & 0.0001 \\
\hline CA05-5-7 & Inconel 718 & 3443 & \multicolumn{2}{|c|}{0.0010} & No Reportable corrosion ${ }^{b}$ \\
\hline CA05-3-4 & $304 \mathrm{~L}$ & 3320 & \multicolumn{2}{|c|}{0.0022} & 0.0001 \\
\hline CA05-4-1 & $304 \mathrm{~L}$ & 3319 & \multicolumn{2}{|c|}{0.0008} & No Reportable corrosion ${ }^{a}$ \\
\hline CA05-4-7 & $304 \mathrm{~L}$ & 3313 & \multicolumn{2}{|c|}{0.0010} & 0.0001 \\
\hline CA05-5-6 & $304 \mathrm{~L}$ & 3314 & \multicolumn{2}{|c|}{0.0022} & 0.0001 \\
\hline CA05-1-1 & $316 \mathrm{~L}$ & 3380 & \multicolumn{2}{|c|}{0.0017} & 0.0001 \\
\hline CA05-3-3 & $316 \mathrm{~L}$ & 3381 & \multicolumn{2}{|c|}{0.0018} & 0.0001 \\
\hline CA05-5-1 & $316 \mathrm{~L}$ & 3382 & \multicolumn{2}{|c|}{0.0016} & 0.0001 \\
\hline CA05-5-5 & $316 \mathrm{~L}$ & 3384 & \multicolumn{2}{|c|}{0.0010} & 0.0001 \\
\hline CA05-2-7 & 316L Welded & W3688 & \multicolumn{2}{|c|}{0.0008} & No Reportable corrosion ${ }^{a}$ \\
\hline CA05-3-8 & 316L Welded & W3689 & \multicolumn{2}{|c|}{0.0009} & 0.0001 \\
\hline CA05-4-8 & 316L Welded & W3690 & \multicolumn{2}{|c|}{0.0004} & No Reportable corrosion ${ }^{\text {a }}$ \\
\hline CA05-6-3 & 316L Welded & W3691 & \multicolumn{2}{|c|}{0.0009} & 0.0001 \\
\hline CA05-2-1 & Zircaloy-4 & 3808 & \multicolumn{2}{|c|}{-0.0006} & No Reportable corrosion ${ }^{a}$ \\
\hline CA05-2-3 & Zircaloy-4 & 3809 & \multicolumn{2}{|c|}{-0.0012} & -0.0001 \\
\hline CA05-3-7 & Zircaloy-4 & 3810 & \multicolumn{2}{|c|}{-0.0004} & No Reportable corrosion ${ }^{a}$ \\
\hline CA05-6-1 & Zircaloy-4 & 3811 & \multicolumn{2}{|c|}{-0.0010} & -0.0001 \\
\hline
\end{tabular}

a. mass loss or gain (if any) is within the tolerance of the Mettler AE 163 Balance

b. mass loss or gain (if any) is within the tolerance of the Mettler AE 163 Balance and cleaning uncertainty combined. 
Table C6. Corrosion results after six years for coupons buried at $10 \mathrm{ft}$.

\begin{tabular}{|c|c|c|c|c|c|}
\hline Coupon location & Composition & Identifier & Mass Loss (g) & Mass Loss $(\%)$ & Corrosion Rate (MPY) \\
\hline CA06-2-1 & Aluminum & 3498 & 0.0029 & 0.0066 & 0.0006 \\
\hline CA06-2-4 & Aluminum & 3499 & 0.0028 & 0.0067 & 0.0006 \\
\hline CA06-4-7 & Aluminum & 3500 & 0.0047 & 0.0105 & 0.0009 \\
\hline CA06-6-1 & Aluminum & 3501 & 0.0024 & 0.0054 & 0.0005 \\
\hline CA06-1-3 & Beryllium & $S / N-23$ & 1.148 & 3.2827 & 0.3282 \\
\hline CA06-3-2 & Beryllium & $S / N-24$ & 0.9451 & 2.5893 & 0.2624 \\
\hline CA06-3-4 & Beryllium & $S / N-25$ & 0.7196 & 2.0409 & 0.2022 \\
\hline CA06-4-5 & Beryllium & $S / N-26$ & 0.9029 & 2.4823 & 0.2518 \\
\hline CA06-2-6 & Carbon Steel & 3345 & 5.3662 & 4.3751 & 0.3639 \\
\hline CA06-4-6 & Carbon Steel & 3346 & 5.3910 & 4.1823 & 0.3643 \\
\hline CA06-5-1 & Carbon Steel & 3347 & 5.1221 & 3.9943 & 0.3461 \\
\hline CA06-6-2 & Carbon Steel & 3348 & 4.3363 & 3.4112 & 0.2924 \\
\hline Coupon location & Composition & Identifier & \multicolumn{2}{|c|}{ Mass Loss $(\mathrm{g})$} & Corrosion Rate (MPY) \\
\hline CA06-2-5 & Ferralium 255 & W3752 & \multicolumn{2}{|c|}{0.0015} & 0.0001 \\
\hline CA06-3-1 & Ferralium 255 & W3753 & \multicolumn{2}{|c|}{0.0016} & 0.0001 \\
\hline CA06-4-8 & Ferralium 255 & W3754 & \multicolumn{2}{|c|}{0.0007} & No Reportable corrosion ${ }^{a}$ \\
\hline CA06-5-5 & Ferralium 255 & W3755 & \multicolumn{2}{|c|}{0.0004} & No Reportable corrosion ${ }^{a}$ \\
\hline CA06-1-2 & Inconel 718 & 3444 & \multicolumn{2}{|c|}{0.0011} & 0.0001 \\
\hline CA06-2-7 & Inconel 718 & 3445 & \multicolumn{2}{|c|}{0.0019} & 0.0001 \\
\hline CA06-3-8 & Inconel 718 & 3446 & \multicolumn{2}{|c|}{0.0020} & 0.0001 \\
\hline CA06-4-2 & Inconel 718 & 3447 & \multicolumn{2}{|c|}{0.0015} & 0.0001 \\
\hline CA06-1-1 & $304 \mathrm{~L}$ & 3315 & \multicolumn{2}{|c|}{0.0000} & No Reportable corrosion ${ }^{a}$ \\
\hline CA06-4-3 & $304 \mathrm{~L}$ & 3316 & \multicolumn{2}{|c|}{0.0006} & No Reportable corrosion ${ }^{a}$ \\
\hline CA06-5-4 & $304 \mathrm{~L}$ & 3308 & \multicolumn{2}{|c|}{0.0017} & 0.0001 \\
\hline CA06-5-6 & $304 \mathrm{~L}$ & 3310 & \multicolumn{2}{|c|}{0.0011} & 0.0001 \\
\hline CA06-2-3 & $316 \mathrm{~L}$ & 3383 & \multicolumn{2}{|c|}{0.0012} & 0.0001 \\
\hline CA06-3-5 & $316 \mathrm{~L}$ & 3386 & \multicolumn{2}{|c|}{0.0015} & 0.0001 \\
\hline CA06-3-7 & $316 \mathrm{~L}$ & 3385 & \multicolumn{2}{|c|}{0.0010} & 0.0001 \\
\hline CA06-4-4 & $316 \mathrm{~L}$ & 3387 & \multicolumn{2}{|c|}{0.0014} & 0.0001 \\
\hline CA06-2-2 & 316L Welded & W3692 & \multicolumn{2}{|c|}{0.0008} & No Reportable corrosion ${ }^{a}$ \\
\hline CA06-3-6 & 316L Welded & W3693 & \multicolumn{2}{|c|}{0.0007} & No Reportable corrosion ${ }^{a}$ \\
\hline CA06-5-2 & 316L Welded & W3694 & \multicolumn{2}{|c|}{0.0009} & 0.0001 \\
\hline CA06-5-7 & 316L Welded & W3695 & \multicolumn{2}{|c|}{0.0006} & No Reportable corrosion ${ }^{a}$ \\
\hline CA06-3-3 & Zircaloy-4 & 3812 & \multicolumn{2}{|c|}{-0.0004} & No Reportable Corrosion ${ }^{a}$ \\
\hline CA06-4-1 & Zircaloy-4 & 3813 & \multicolumn{2}{|c|}{-0.0006} & No Reportable Corrosion ${ }^{a}$ \\
\hline CA06-5-3 & Zircaloy-4 & 3814 & \multicolumn{2}{|c|}{-0.0004} & No Reportable Corrosion ${ }^{a}$ \\
\hline CA06-6-3 & Zircaloy-4 & 3815 & \multicolumn{2}{|c|}{-0.0002} & No Reportable Corrosion ${ }^{a}$ \\
\hline
\end{tabular}

a. weight loss or gain (if any) is within the tolerance of the Mettler AE 163 Balance. 


\section{APPENDIX D}

\section{Vertical Scanning-Interferometry Measurements}


(This page is intentionally left blank.) 
Beryllium \#2, 1-Year Exposure, 4 Ft Level

\section{Veeco}

\section{3-Dimensional Interactive Display}

Surface Stats:

Ra: 22.16 um

Rq: 27.07 um

Rt: 122.29 um

Measurement Info:

Magnification: 2.54

Measurement Mode: VSI

Sampling: $6.61 \mathrm{um}$

Array Size: 368 X 240

Title: Be \#2 -1

Note: 1 yr exposure
Date: 08/04/2004

Time: 06:57:31

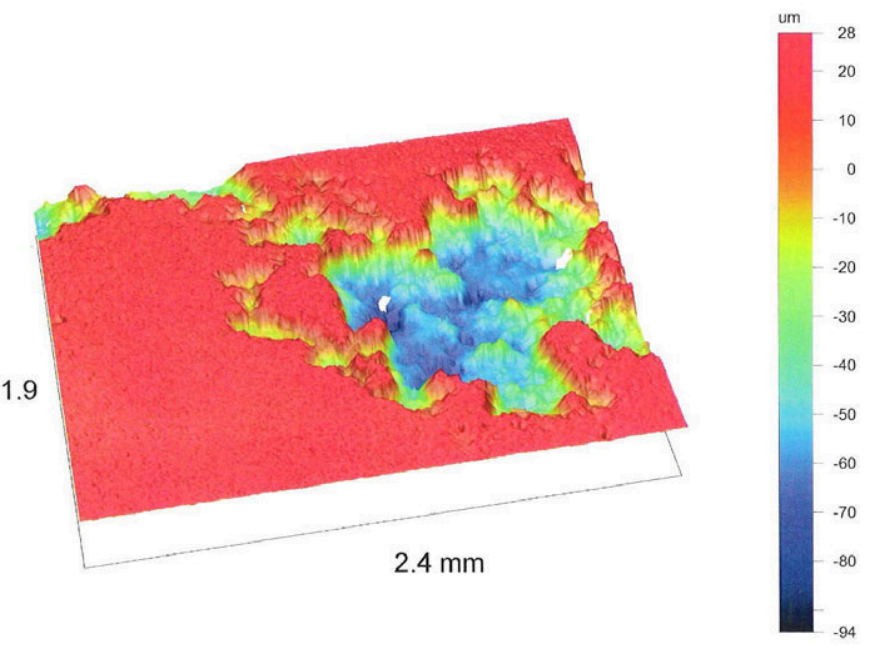

Veeco
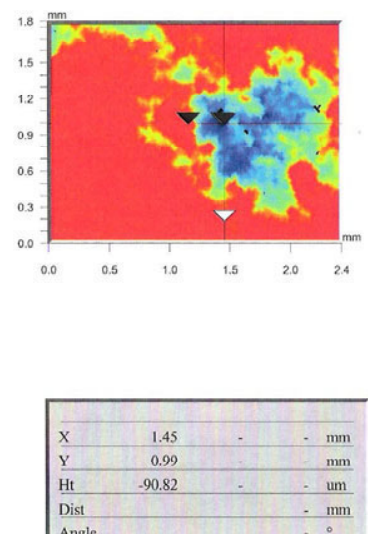

Title: Be \#2 -1

Note: 1 yr exposure
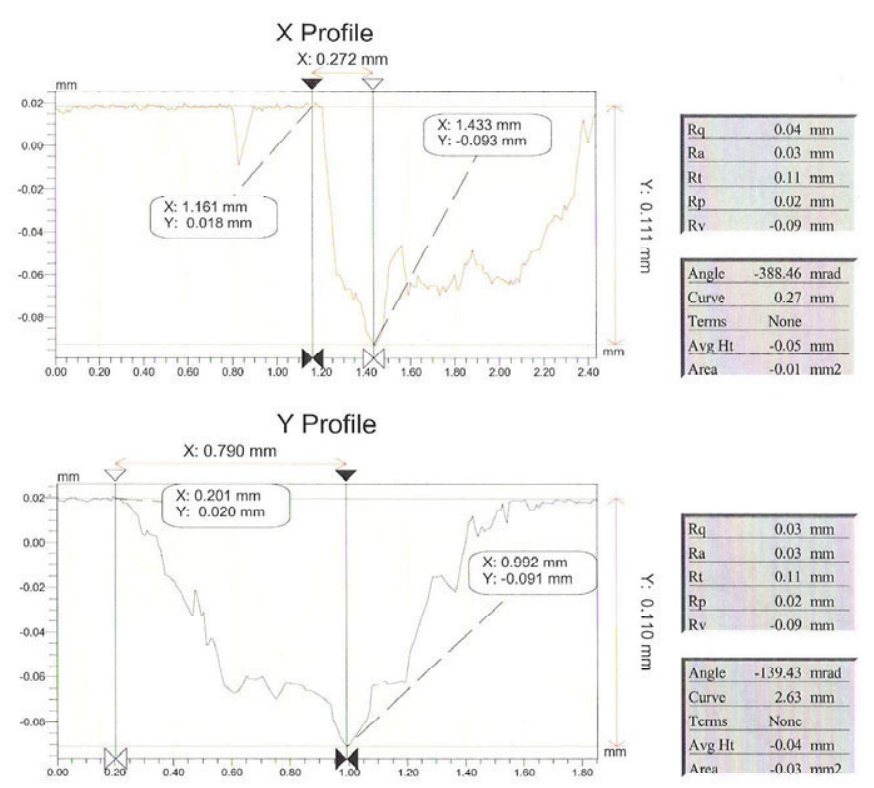
Beryllium \#2, 1-Year Exposure, 4 Ft Level

(Continued)

\section{Veeco}

3-Dimensional Interactive Display

Surface Stats:

Ra: 14.84 um

Rq: $22.21 \mathrm{um}$

Rt: 115.33 um

Measurement Info:

Magnification: 2.54

Measurement Mode: VSI

Sampling: $6.61 \mathrm{um}$

Array Size: 368 X 240

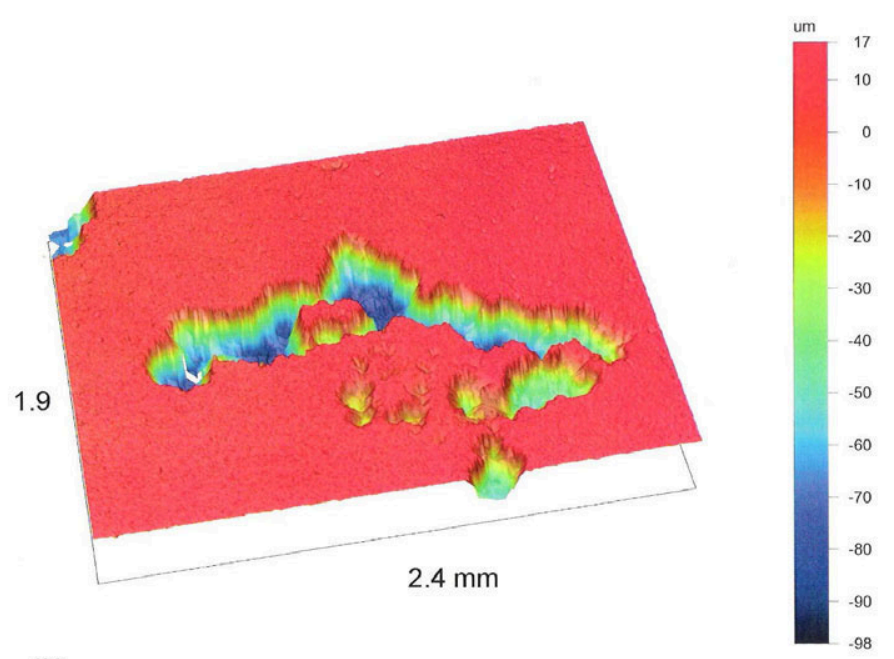

Title: Be \#2 -2 Area \#2

Note: 1 yr exposure
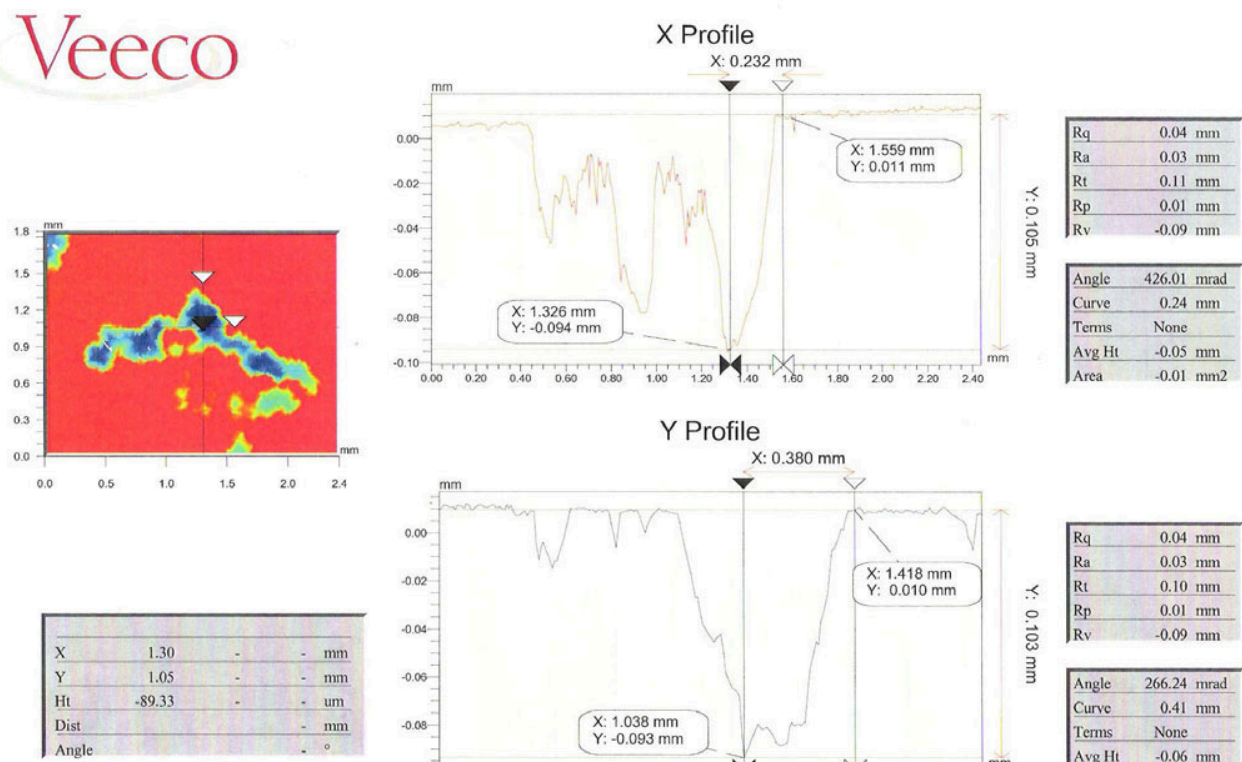

Title: Be \#2 -2 Area \#2

Note: 1 yr exposure

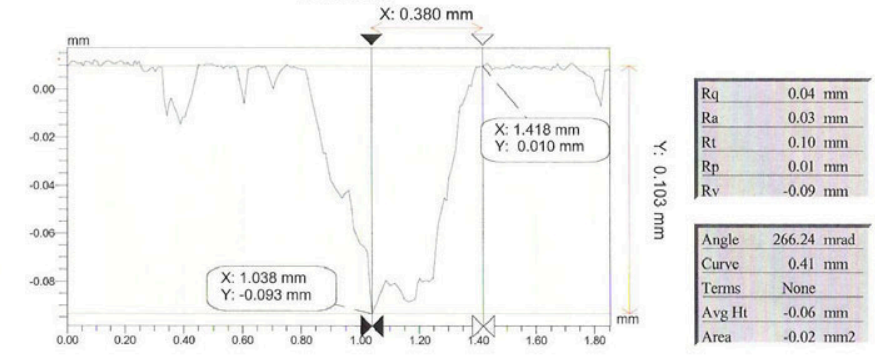




\section{Veeco}

\section{3-Dimensional Interactive Display}

Surface Stats:

Ra: 35.36 um

Rq: $41.55 \mathrm{um}$

Rt: 156.05 um

Measurement Info:

Magnification: 2.54

Measurement Mode: VSI

Sampling: $6.61 \mathrm{um}$

Array Size: 368 X 240

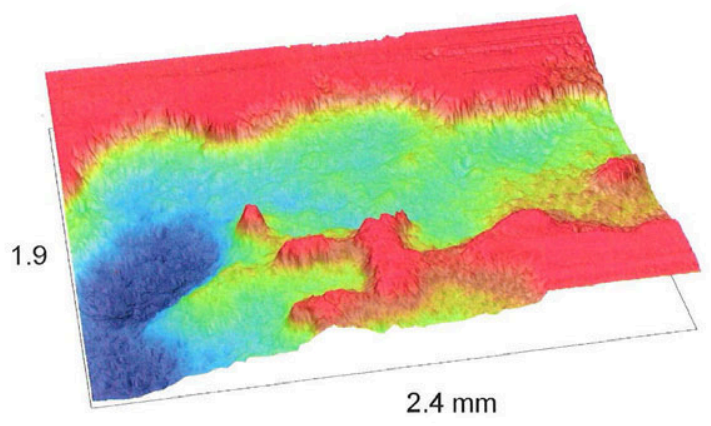

Date: 08/03/2004

Time: 16:01:30

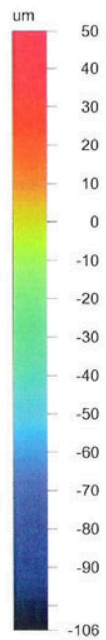

Title: CS \#3323 Area \#1

Note: 1 yr exposure
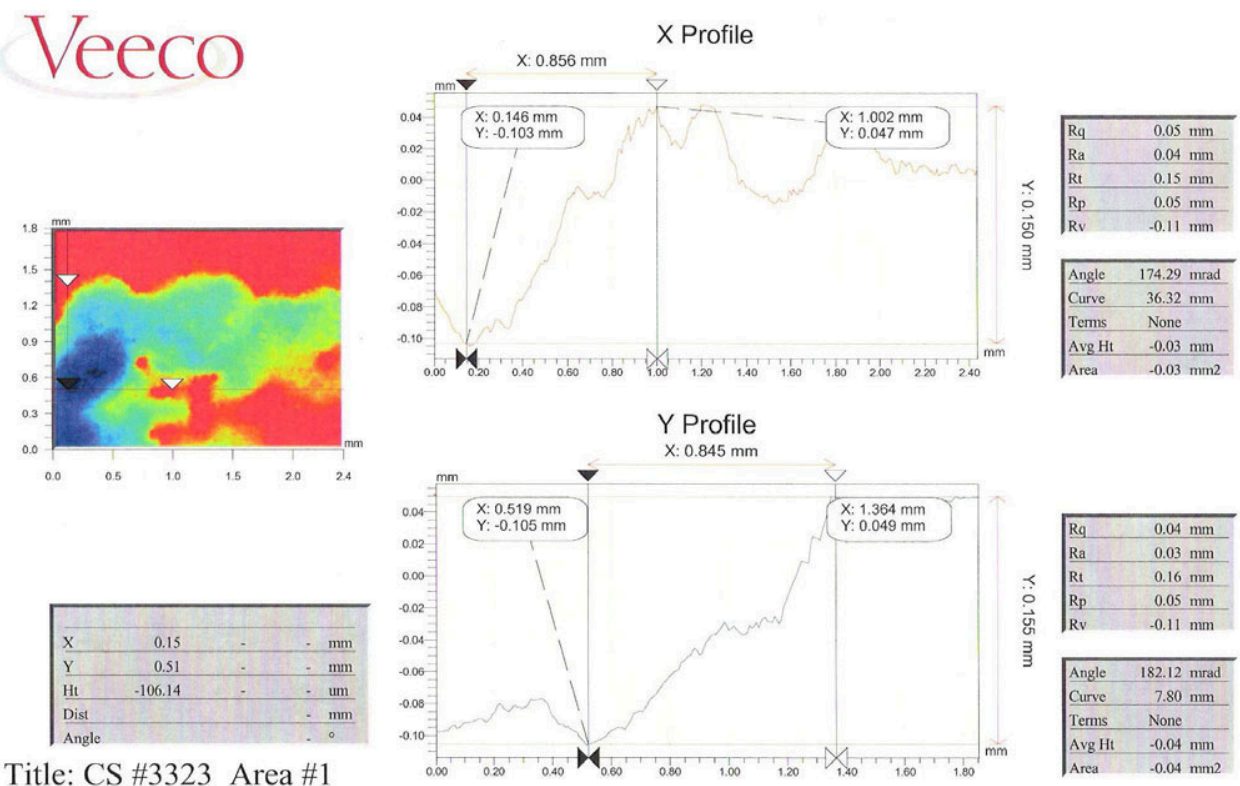

Title: CS \#3323 Area \#1

Note: 1 yr exposure 


\section{Carbon Steel \#3323, 1-Year Exposure, 4 Ft Level}

(Continued)

\section{Veeco}

\section{3-Dimensional Interactive Display}

ate: $08 / 03 / 2004$

Time: 16:08:31

Surface Stats:

Ra: $20.51 \mathrm{um}$

Rq: $23.04 \mathrm{um}$

Rt: 102.14 um

Measurement Info:

Magnification: 2.54

Measurement Mode: VSI

Sampling: $6.61 \mathrm{um}$

Array Size: 368 X 240

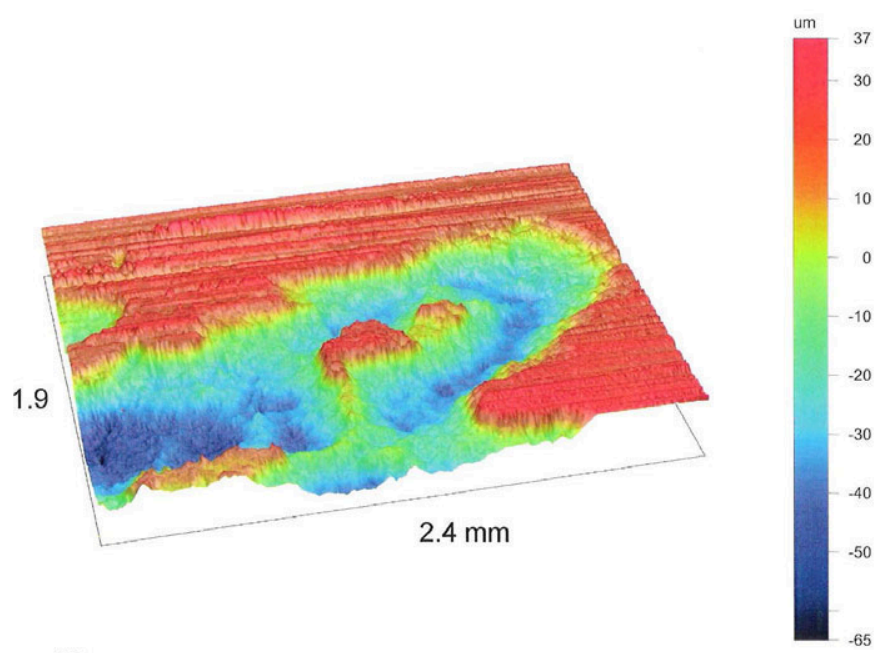

Title: CS \#3323 Area \#2

Note: 1 yr exposure

\section{Veeco}
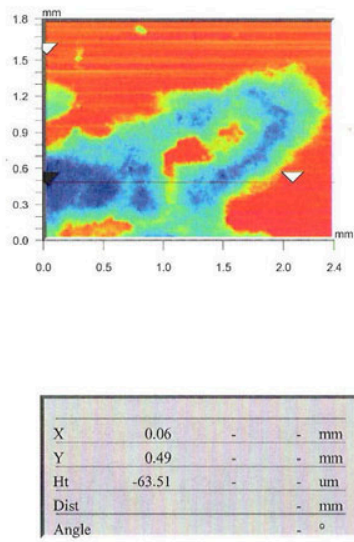

Title: CS \#3323 Area \#2

Note: 1 yr exposure
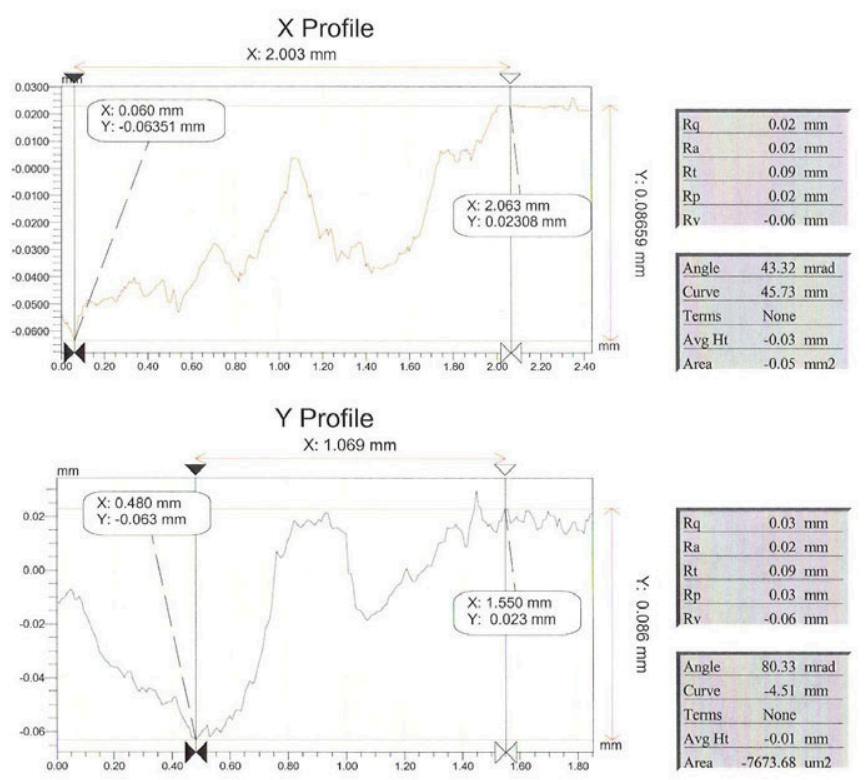
Aluminum \#3492, 3-Year Exposure, 10 Ft Level

\section{VeCCO 3-Dimensional Interactive Display $\begin{aligned} & \text { Date: 08/04/2004 } \\ & \text { Time: 10:01:37 }\end{aligned}$}

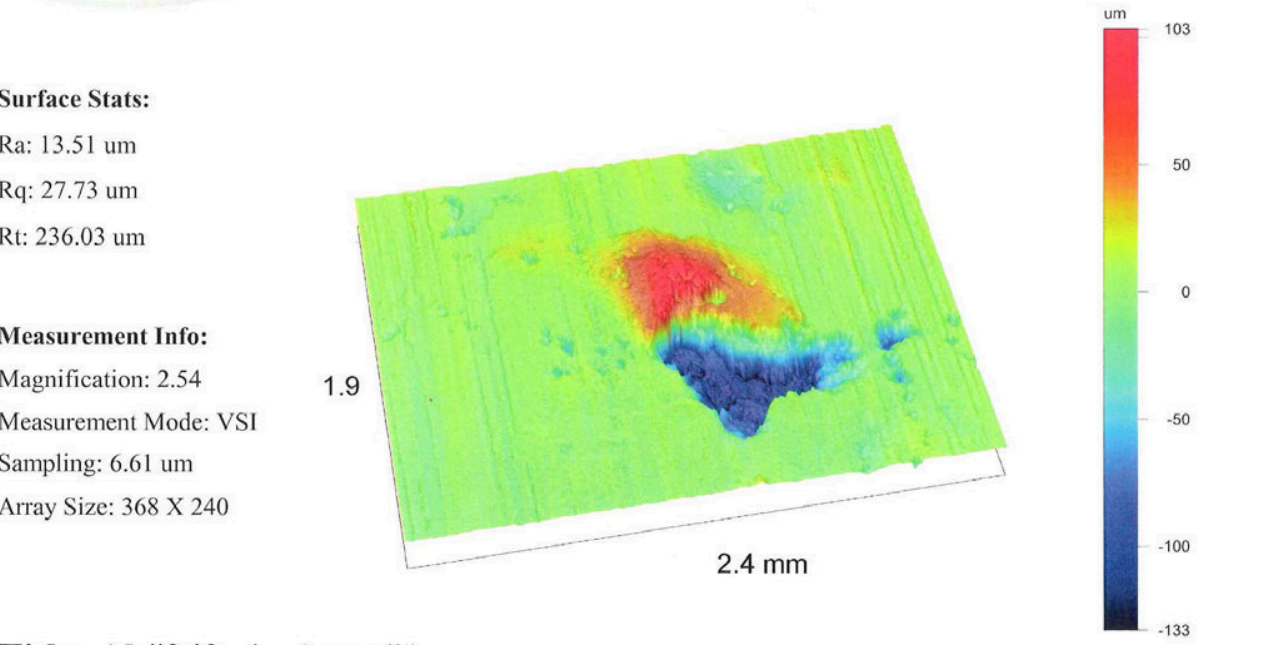

Title: Al \#349 -1 Area \#1

Note: 3 yr exposure

\section{Veeco}
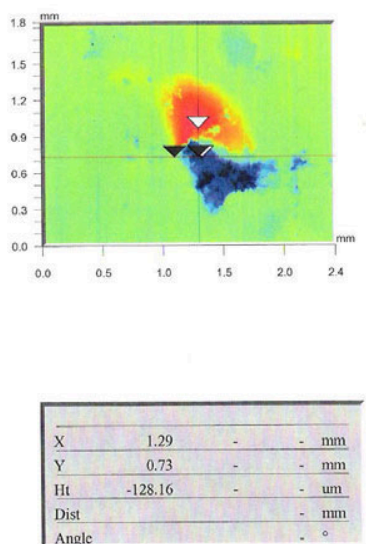

Title: Al \#349-1 Area \#1 Note: 3 yr exposure

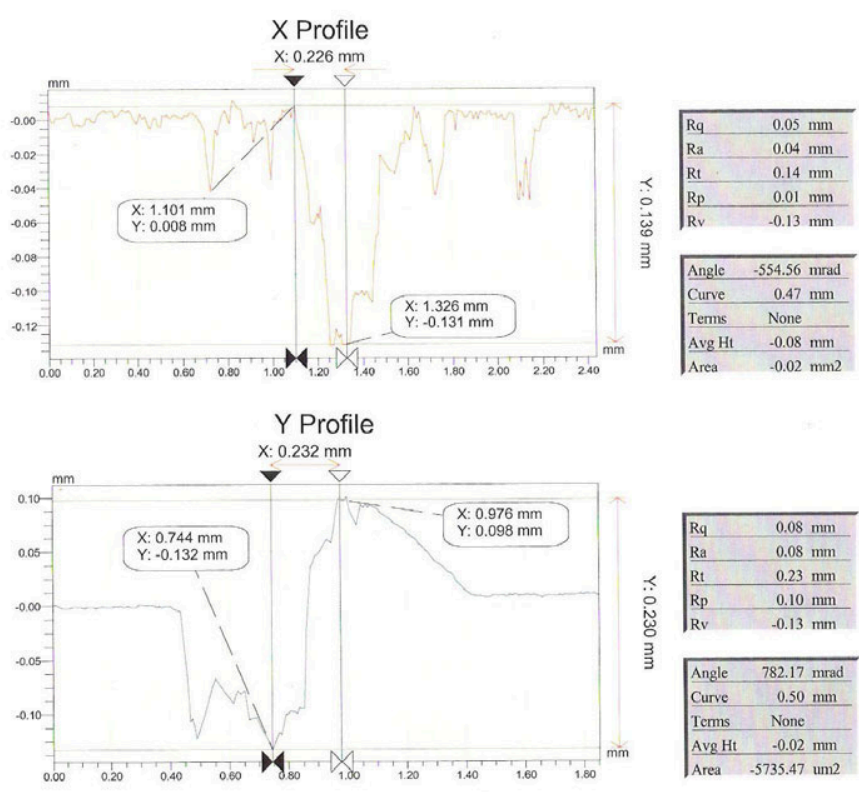


Aluminum \#3492, 3-Year Exposure, 10 Ft Level

(Continued)

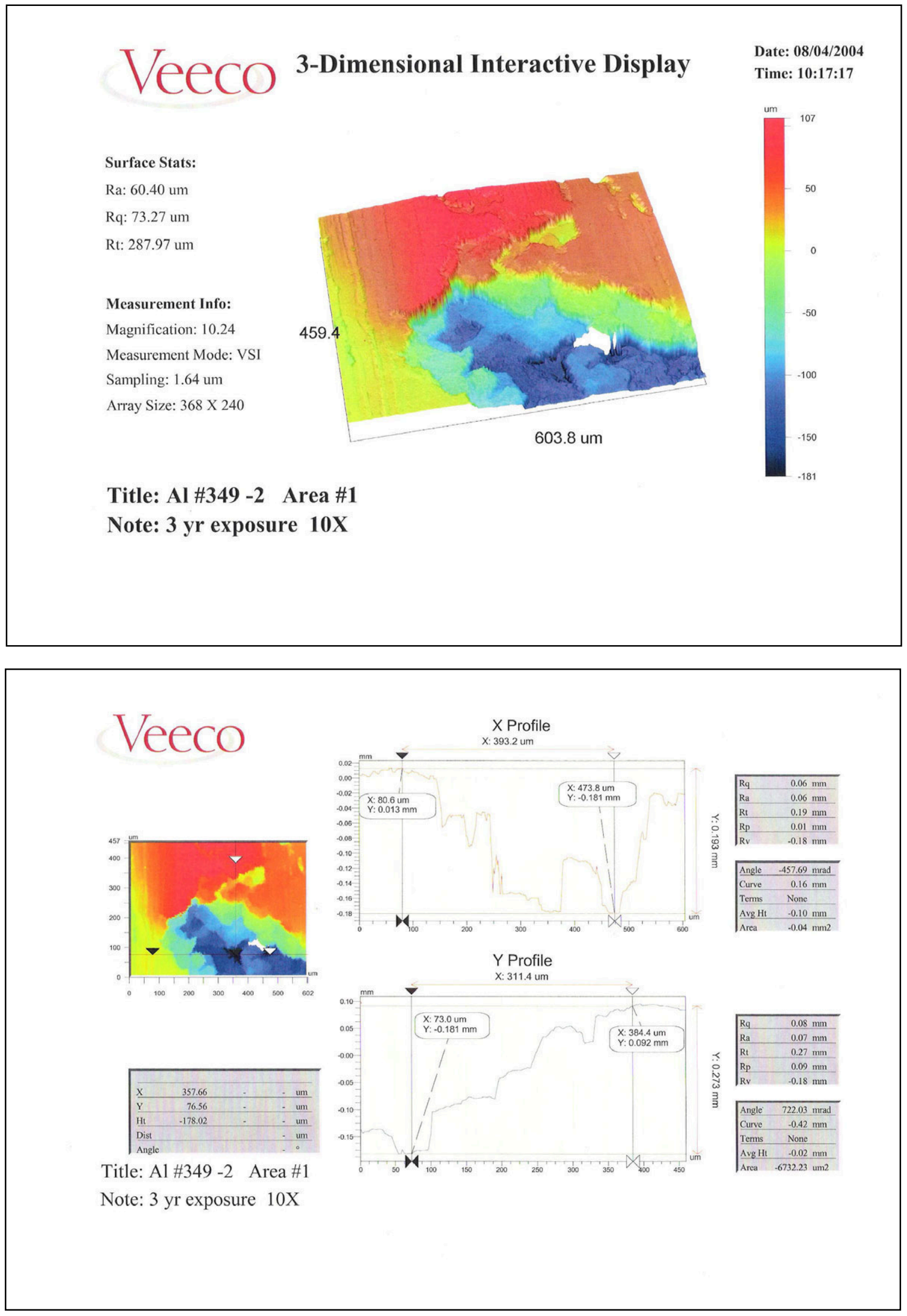


Beryllium \#9, 3-Year Exposure, 4 Ft Level

Veeco

\section{3-Dimensional Interactive Display}

Surface Stats:

Ra: 11.80 um

Rq: $14.80 \mathrm{um}$

Rt: 75.33 um

Measurement Info:

Magnification: 2.54

Measurement Mode: VSI

Sampling: $6.61 \mathrm{um}$

Array Size: $368 \times 240$

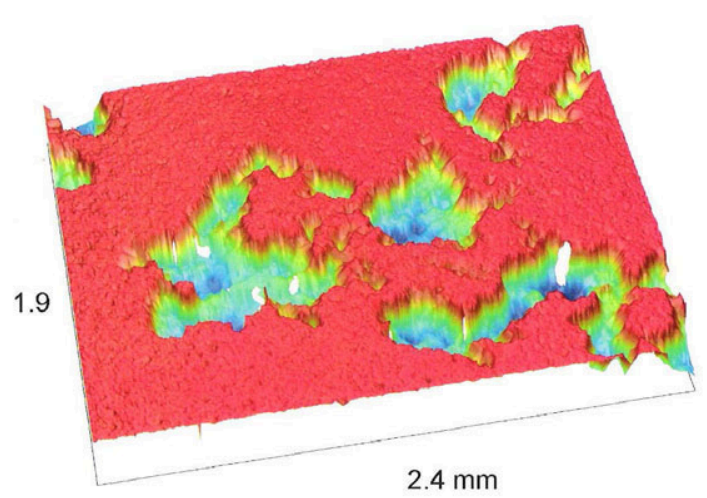

Date: 08/04/2004

Time: 09:44:00

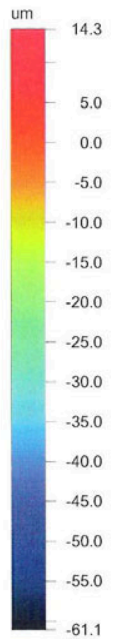

Title: Be \#9 -1 Area \#1

Note: 3 yr exposure

Veeco
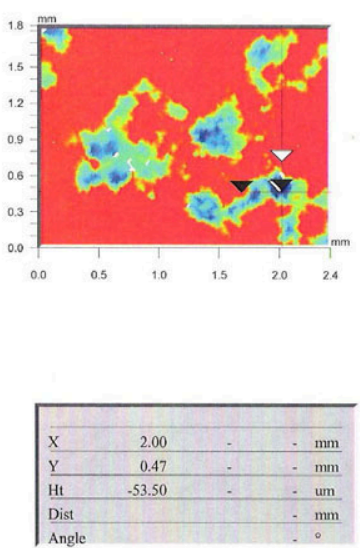

Title: Be \#9-1 Area \#1

Note: 3 yr exposure

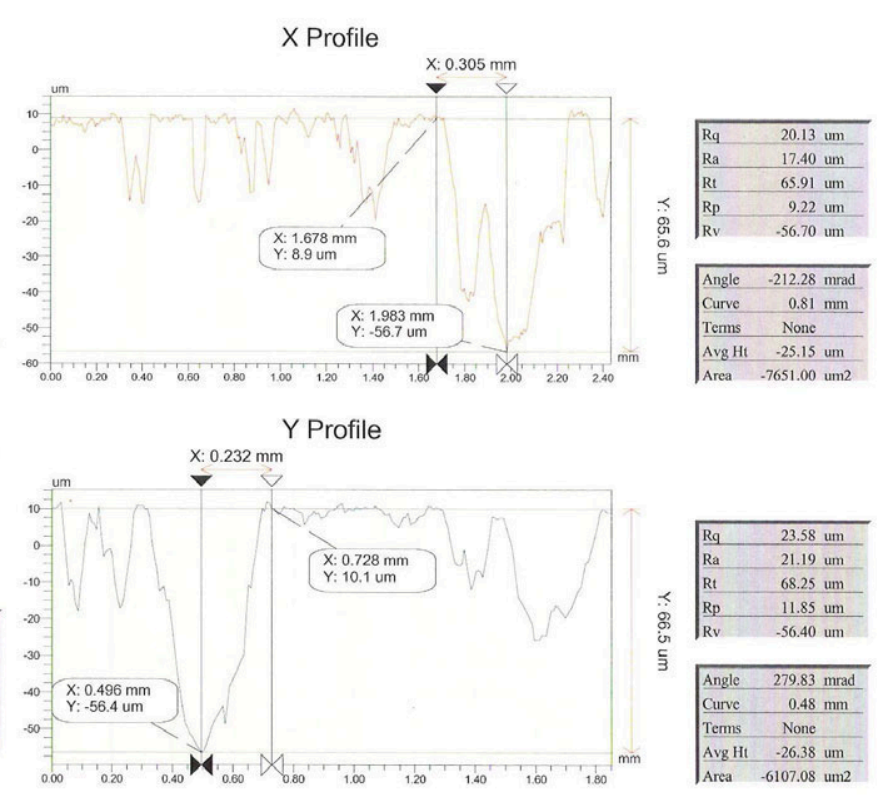


Beryllium \#9, 3-Year Exposure, 4 Ft Level

(Continued)

\section{Veeco}

\section{3-Dimensional Interactive Display}

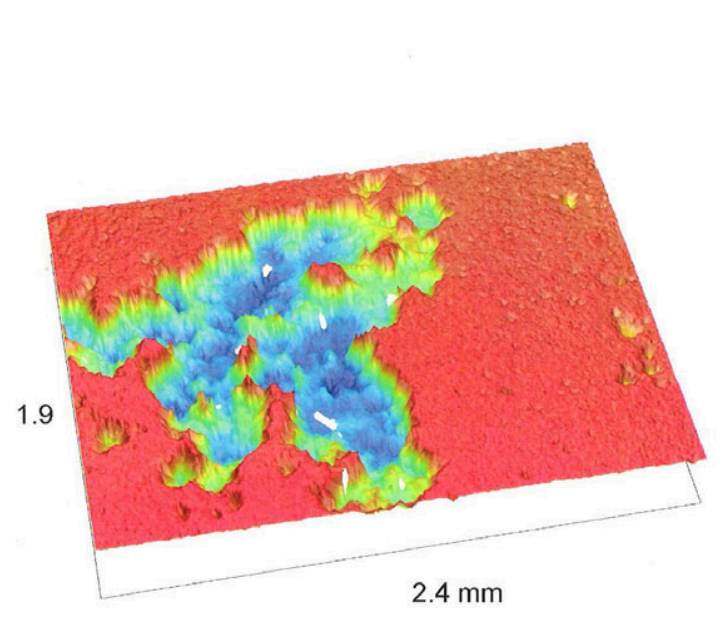

Date: 08/04/2004

Time: 09:48:26

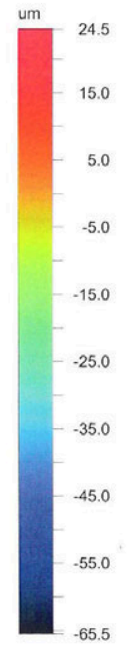

Title: Be \#9 -2 Area \#2

Surface Stats:

Ra: 17.03 um

Rq: 20.22 um

Rt: 89.98 um

Measurement Info:

Magnification: 2.54

Measurement Mode: VSI

Sampling: $6.61 \mathrm{um}$

Array Size: $368 \times 240$

Note: 3 yr exposure

Veeco
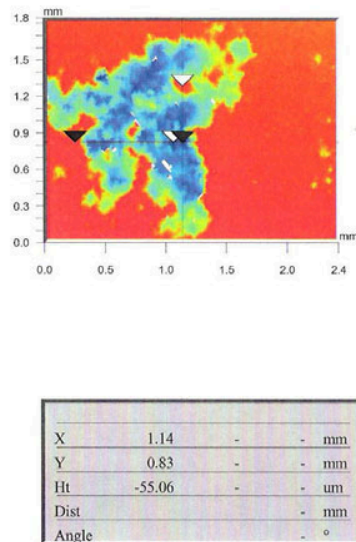

Title: Be \#9-2 Area \#2 Note: 3 yr exposure

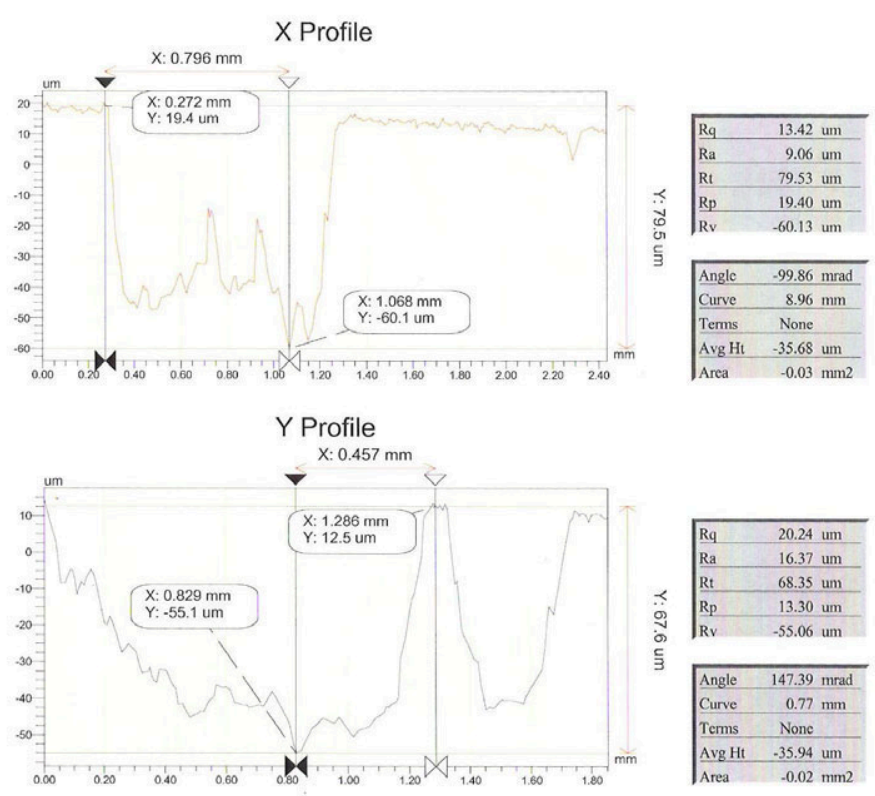


Beryllium \#15, 3-Year Exposure, 10 Ft Level

\section{Veeco}

\section{3-Dimensional Interactive Display}

Surface Stats:

Ra: 30.27 um

Rq: 35.14 um

Rt: 121.05 um

Measurement Info:

Magnification: 2.54

Measurement Mode: VSI

Sampling: $6.61 \mathrm{um}$

Array Size: 368 X 240

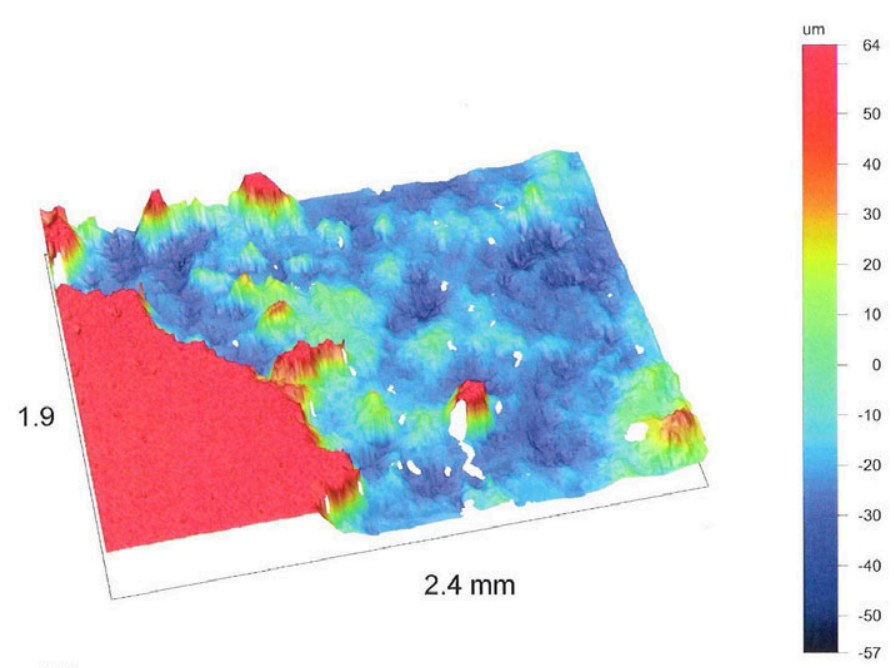

Title: Be \#15 -1 Area \#1

Note: 3 yr exposure

Veeco

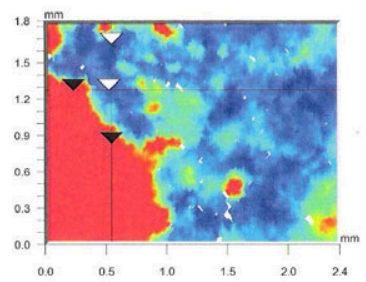

Title: Be \#15 -1 Area \#1

Note: 3 yr exposure

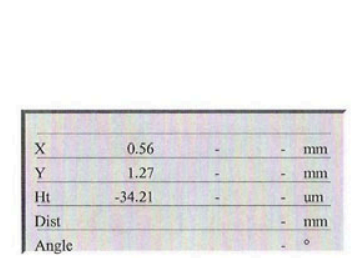

Date: 08/04/2004

Time: 07:40:57

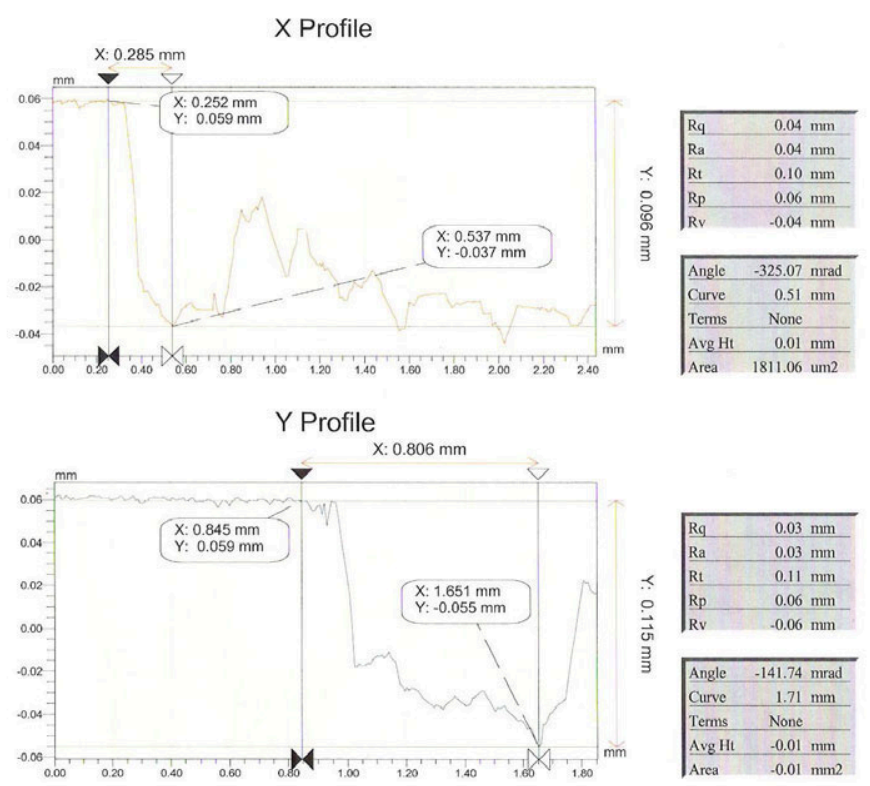


Beryllium \#15, 3-Year Exposure, 10 Ft Level

(Continued)

\section{Veeco}

3-Dimensional Interactive Display

Surface Stats:

Ra: 30.35 um

Rq: 33.52 um

Rt: 115.07 um

Measurement Info:

Magnification: 2.54

Measurement Mode: VSI

Sampling: $6.61 \mathrm{um}$

Array Size: 368 X 240

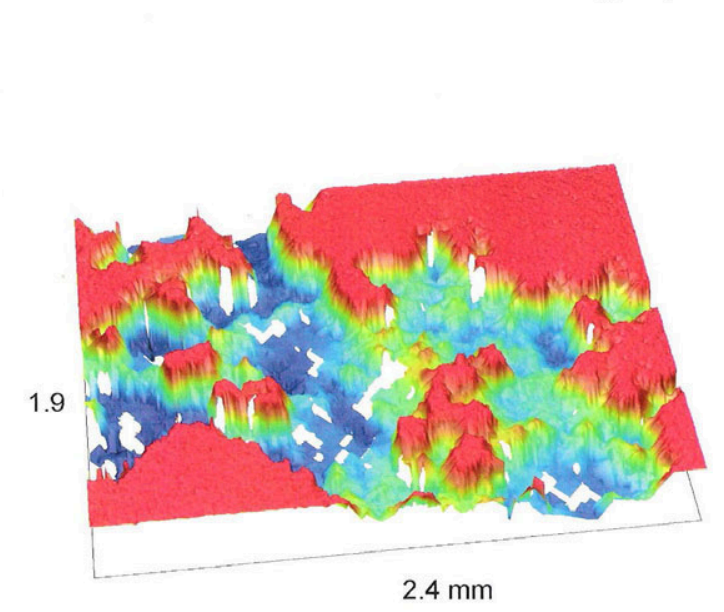

Date: 08/04/2004

Time: 08:52:46

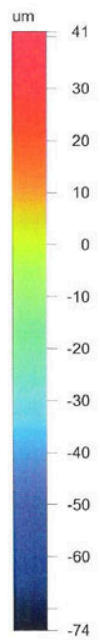

Title: Be \#15 -2 Area \#2

Note: 3 yr exposure

Veeco
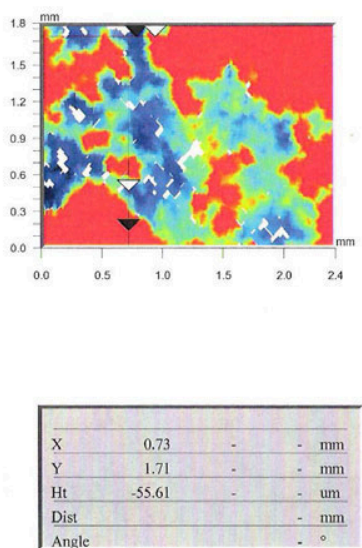

Title: Be \#15 -2 Area \#2

Note: 3 yr exposure

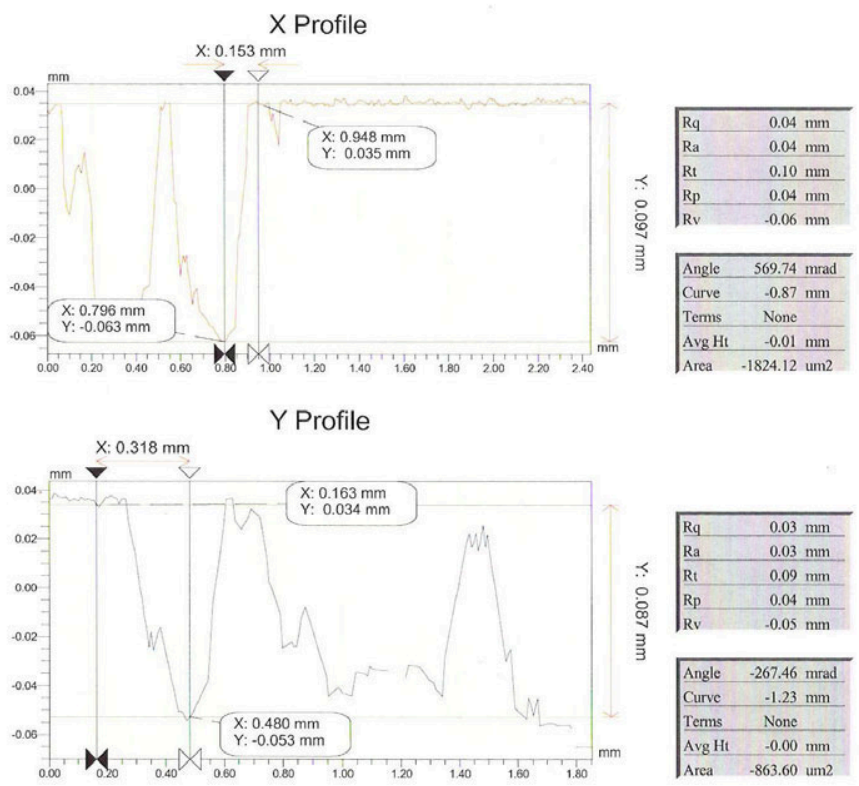

D-10 


\section{Veeco}

\section{3-Dimensional Interactive Display}

Surface Stats:

Ra: 11.65 um

Rq: 15.40 um

Rt: 109.42 um

Measurement Info:

Magnification: 2.54

Measurement Mode: VSI

Sampling: $6.61 \mathrm{um}$

Array Size: $368 \times 240$

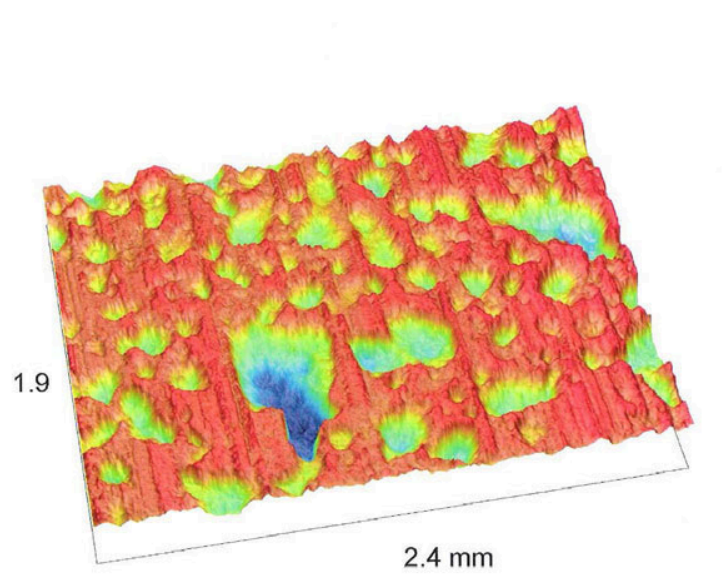

Date: 08/04/2004

Time: 10:34:57

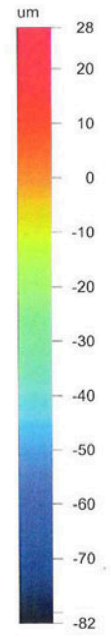

Title: CS \#3330-1 Area \#1

Note: 3 yr exposure

Veeco
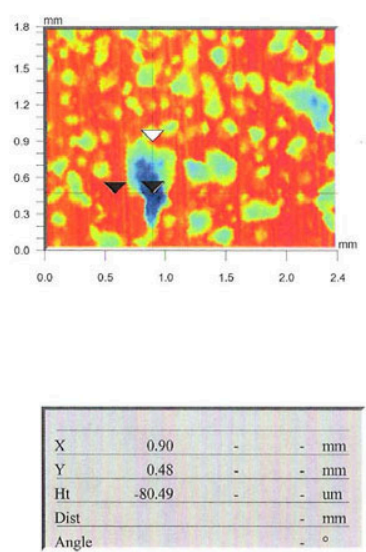

Title: CS \#3330-1 Area \#1

Note: 3 yr exposure

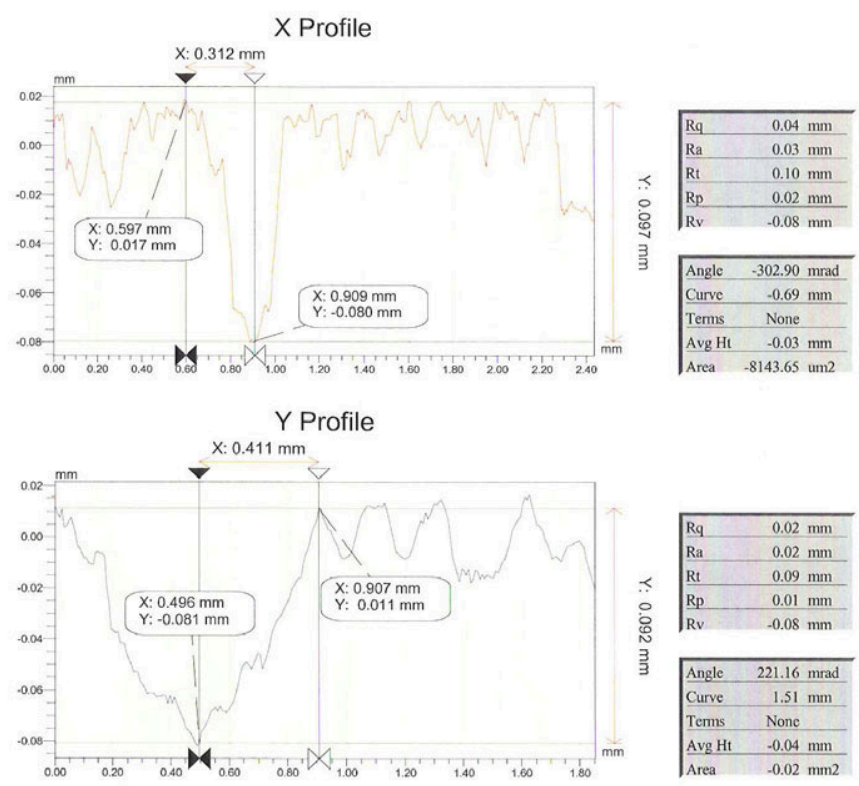




\section{Carbon Steel \#3330, 3-Year Exposure, 4 Ft Level}

(Continued)

\section{Veeco 3-Dimensional Interactive Display}

Date: 08/04/2004

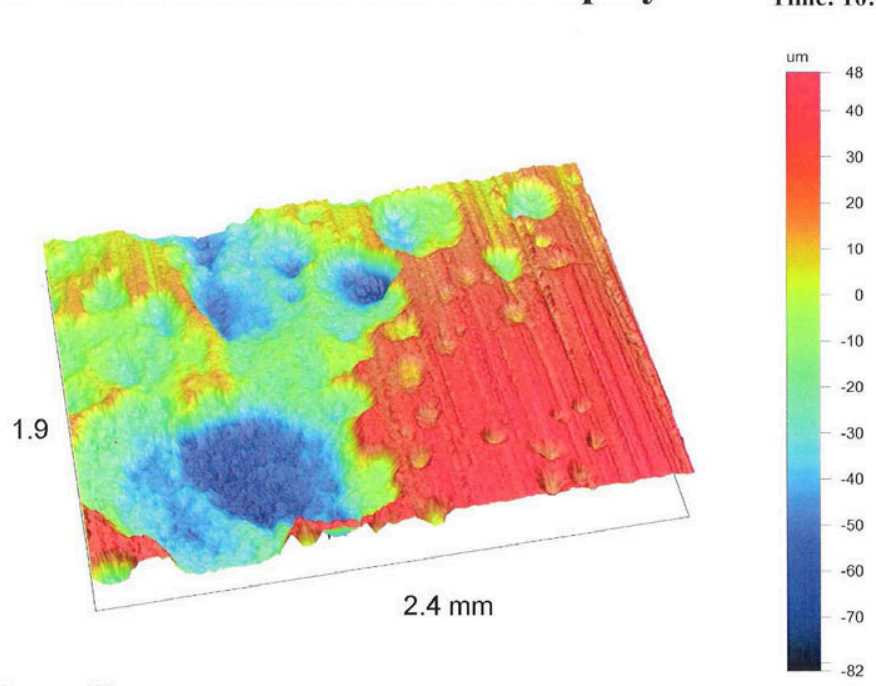

Title: CS \#3330-2 Area \#2

Surface Stats:

Ra: 25.11 um

Rq: 29.42 um

Rt: 130.00 um

Measurement Info:

Magnification: 2.54

Measurement Mode: VSI

Sampling: $6.61 \mathrm{um}$

Array Size: $368 \times 240$

Note: 3 yr exposure

Veeco
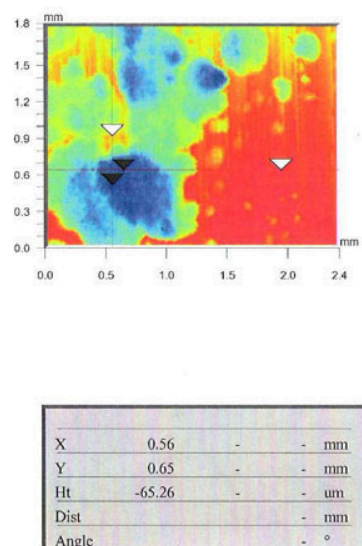

Title: CS \#3330-2 Area \#2 Note: 3 yr exposure
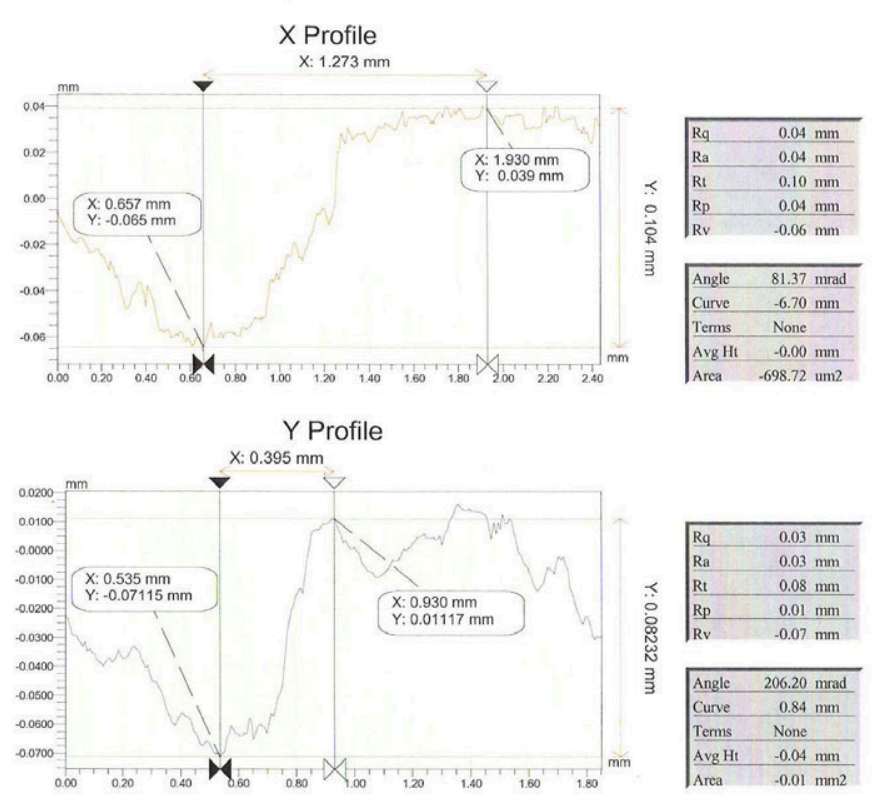


\section{Veeco}

3-Dimensional Interactive Display

Surface Stats:

Ra: 50.69 um

Rq: $59.25 \mathrm{um}$

Rt: 247.57 um

Measurement Info:

Magnification: 2.54

Measurement Mode: VSI

Sampling: $6.61 \mathrm{um}$

Array Size: 368 X 240

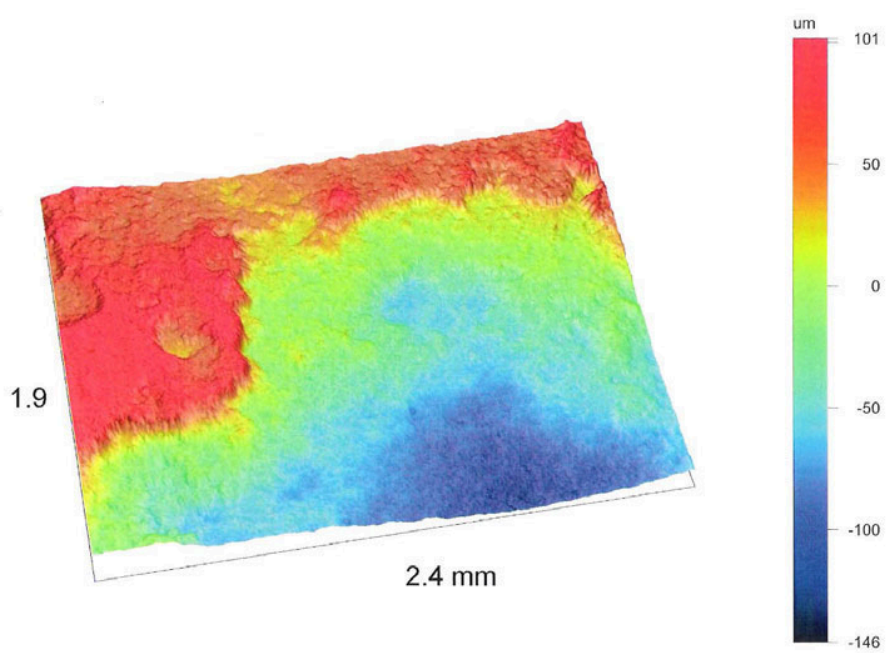

Title: CS \#3336-2 Area \#2

Note: 3 yr exposure
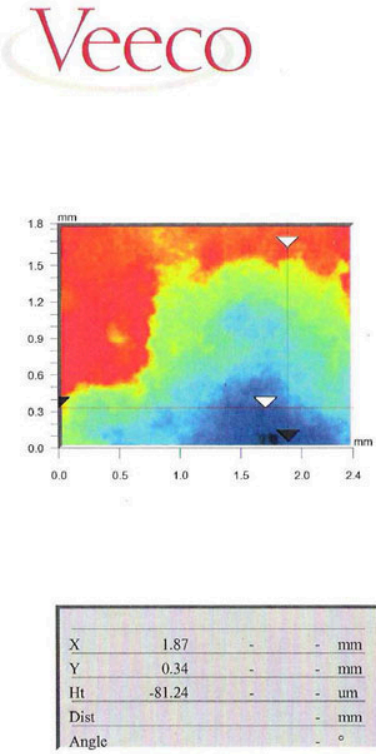

Title: CS \#3336-2 Area \#2

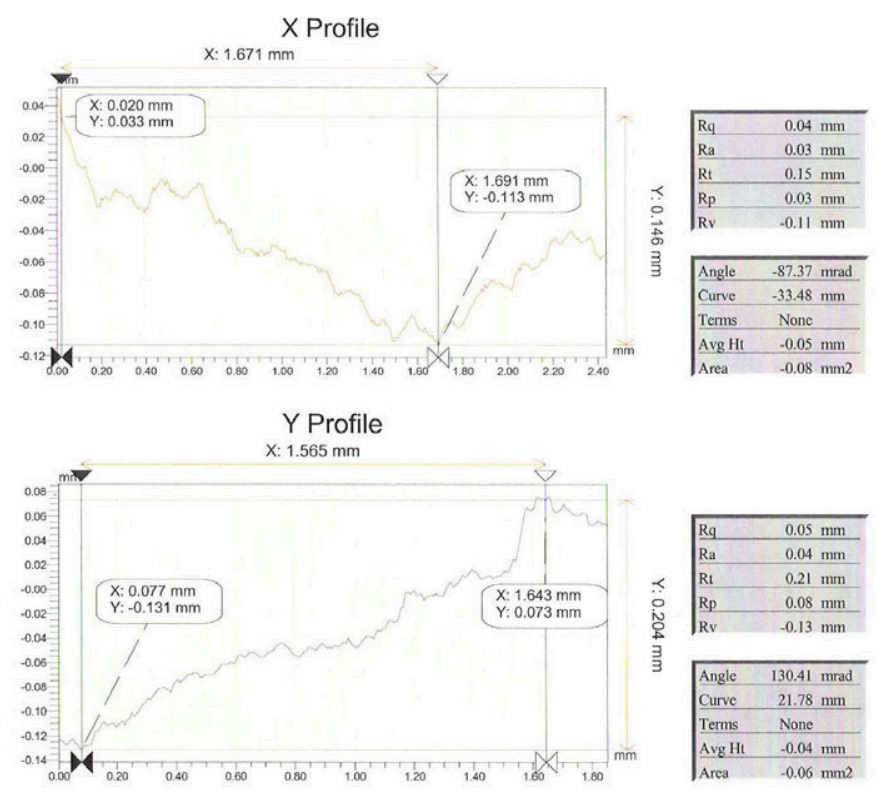

Note: 3 yr exposure 


\section{Carbon Steel \#3336, 3-Year Exposure, 10 Ft Level}

(Continued)
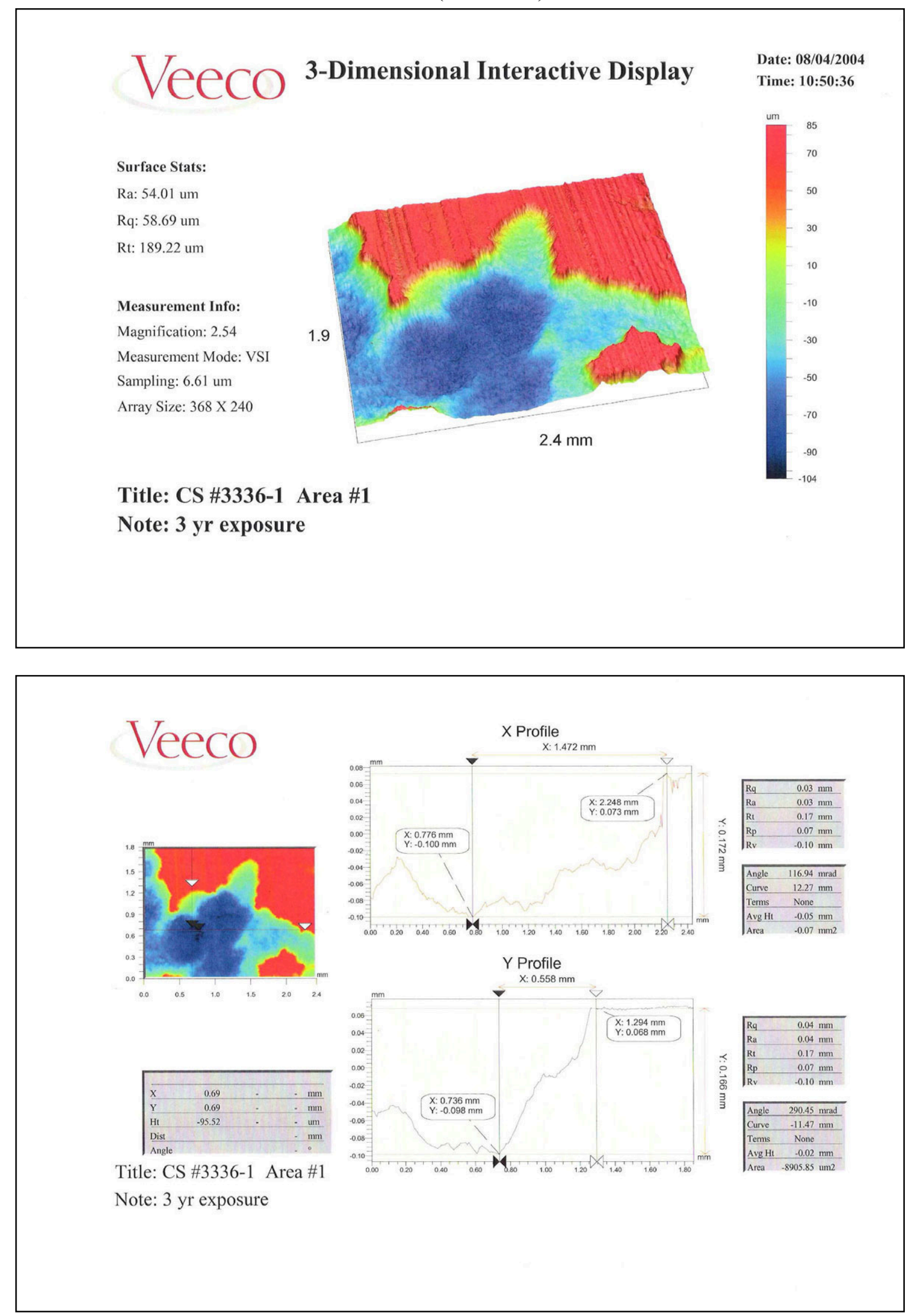


\section{3-Dimensional Interactive Display}

Surface Stats:

Ra: 19.97 um

Rq: 31.38 um

Rt: 196.29 um

Measurement Info:

Magnification: 2.54

Measurement Mode: VSI

Sampling: $6.61 \mathrm{um}$

Array Size: 368 X 240

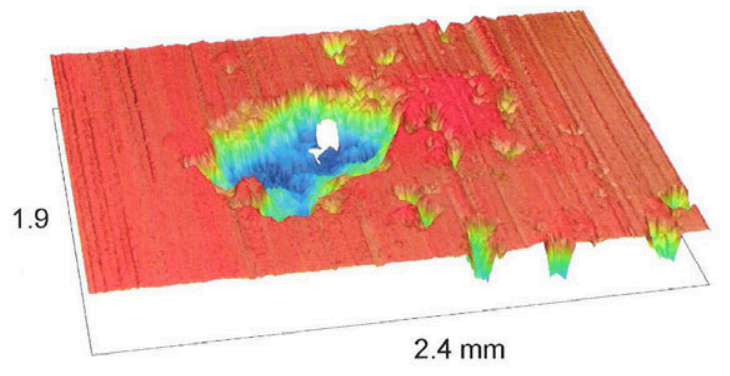

Date: $08 / 05 / 2004$

Time: 08:35:09

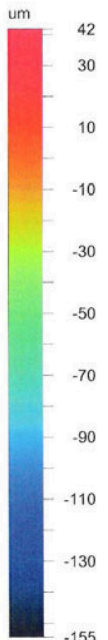

Title: Al \#3494-2

Note: 6 yr exposure 4' level
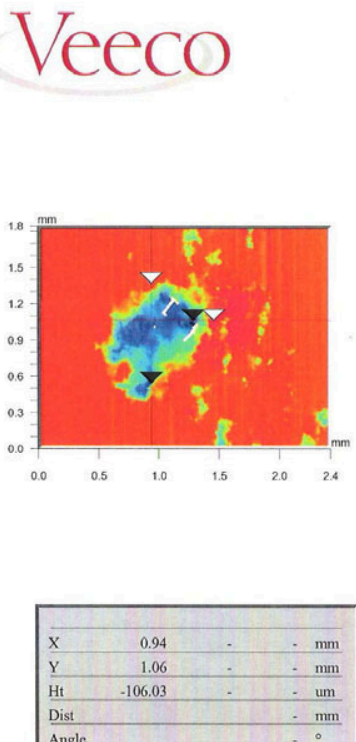

Title: Al \#3494-2

Note: 6 yr exposure 4' level

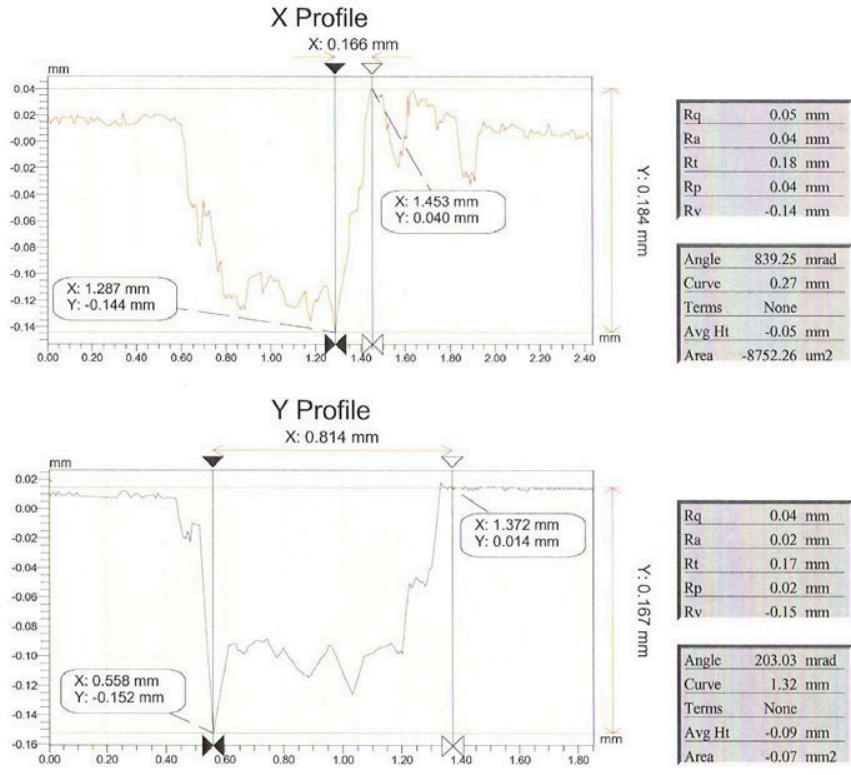

D-15 


\section{Veeco}

\section{3-Dimensional Interactive Display}

Date: 08/05/2004

Time: 08:09:21

Surface Stats:

Ra: 15.52 um

Rq: $22.01 \mathrm{um}$

Rt: 177.60 um

Measurement Info:

Magnification: 2.54

Measurement Mode: VSI

Sampling: $6.61 \mathrm{um}$

Array Size: 368 X 240
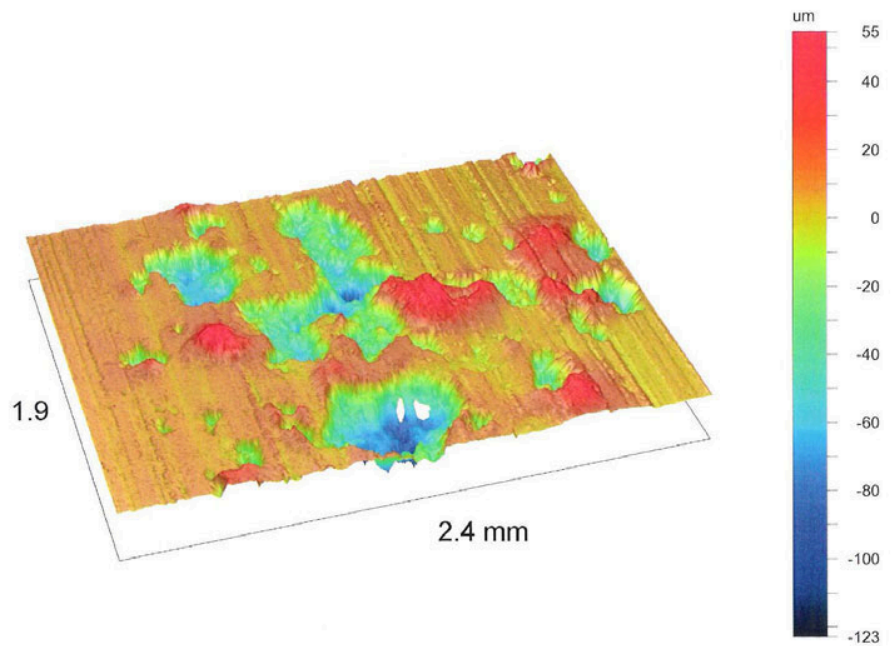

Title: Al \#3494-1

Note: 6 yr exposure 4 ' level

Veeco
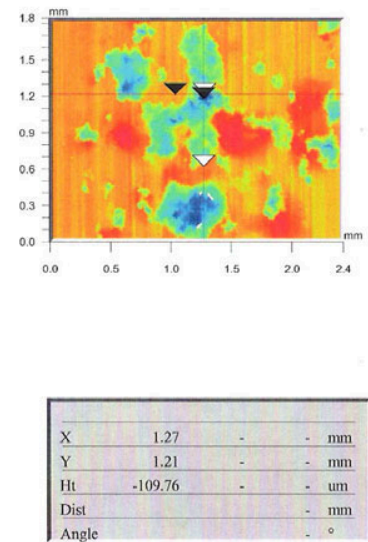

Title: Al \#3494-1

Note: 6 yr exposure 4 ' level

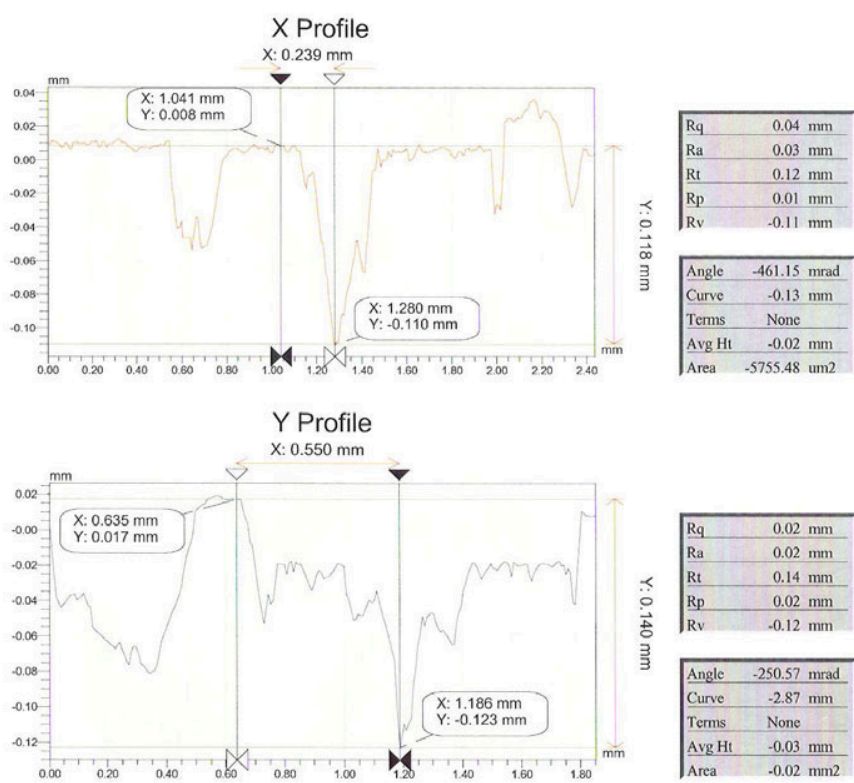

D-16 
Aluminum \#3497, 6-Year Exposure, 4 Ft Level

\section{Veeco}

\section{3-Dimensional Interactive Display}

Surface Stats:

Ra: 13.97 um

Rq: $22.82 \mathrm{um}$

Rt: 233.35 um

Measurement Info:

Magnification: 2.54

Measurement Mode: VSI

Sampling: $6.61 \mathrm{um}$

Array Size: 368 X 240

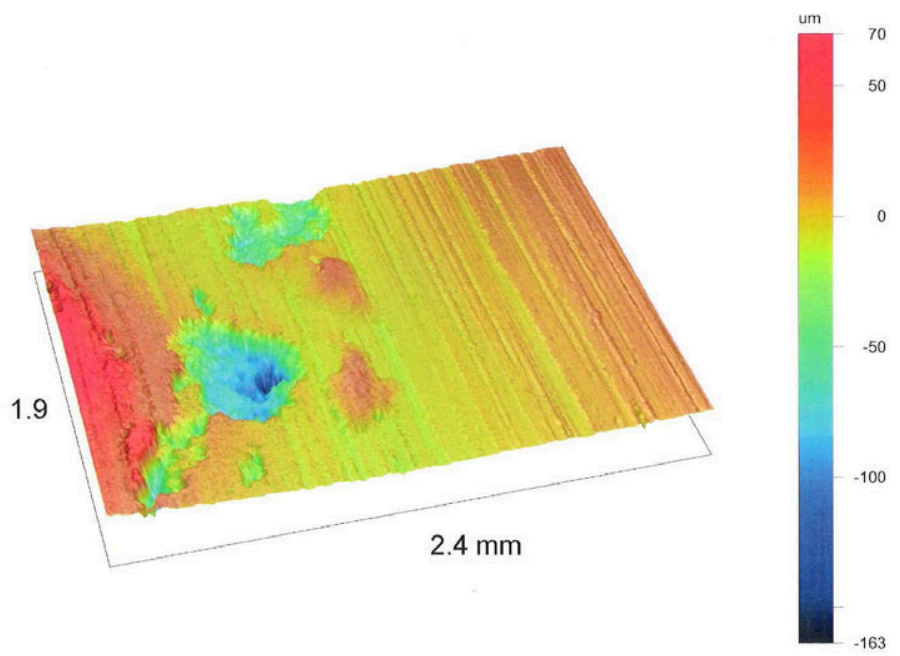

Title: Al \#3497-1

Note: 6 yr exposure 4 ' level
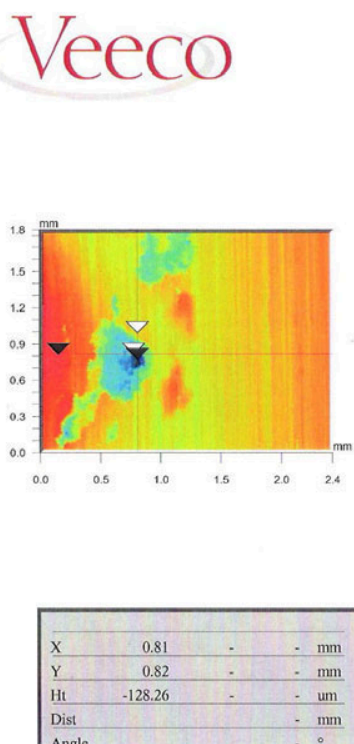

Title: Al \#3497-1

Note: 6 yr exposure 4 ' level
Date: 08/05/2004

Time: 08:54:12 


\section{Veeco}

3-Dimensional Interactive Display

Date: 08/05/2004

Time: 09:59:43

Surface Stats:

Ra: 6.49 um

Rq: $14.06 \mathrm{um}$

Rt: 238.88 um

Measurement Info:

Magnification: 1.31

Measurement Mode: VSI

Sampling: $12.87 \mathrm{um}$

Array Size: 644 X 652
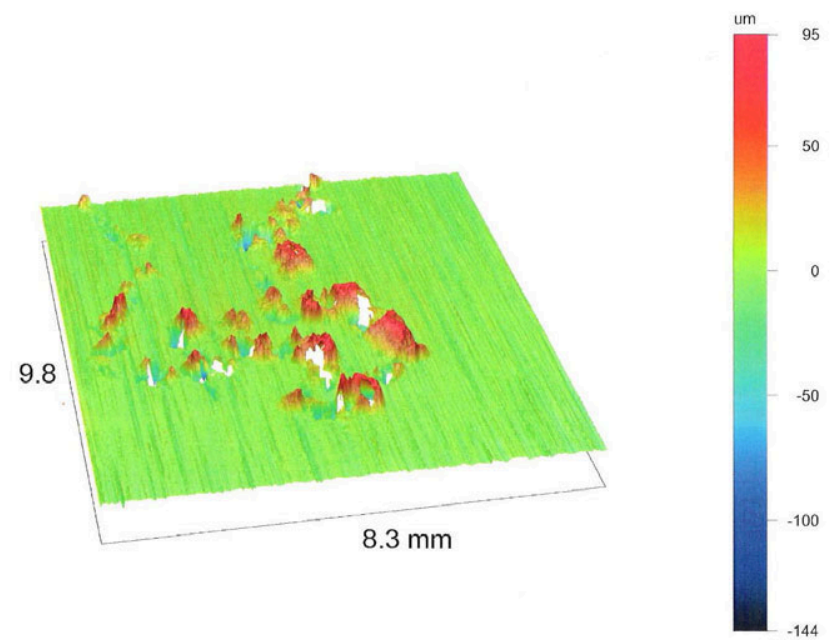

Title: Al \#3497-2 Backside

Note: 6 yr exposure 4' level

\section{Veeco}
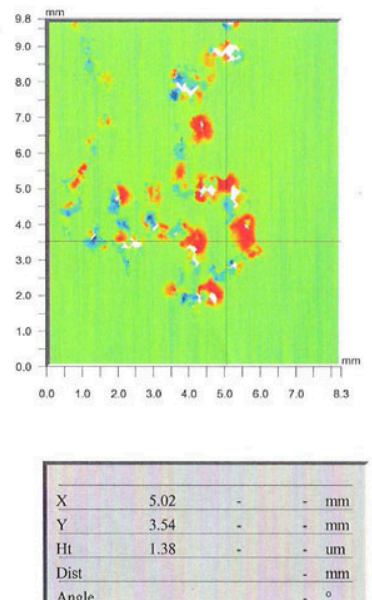

Title: Al \#3497-2 Backside
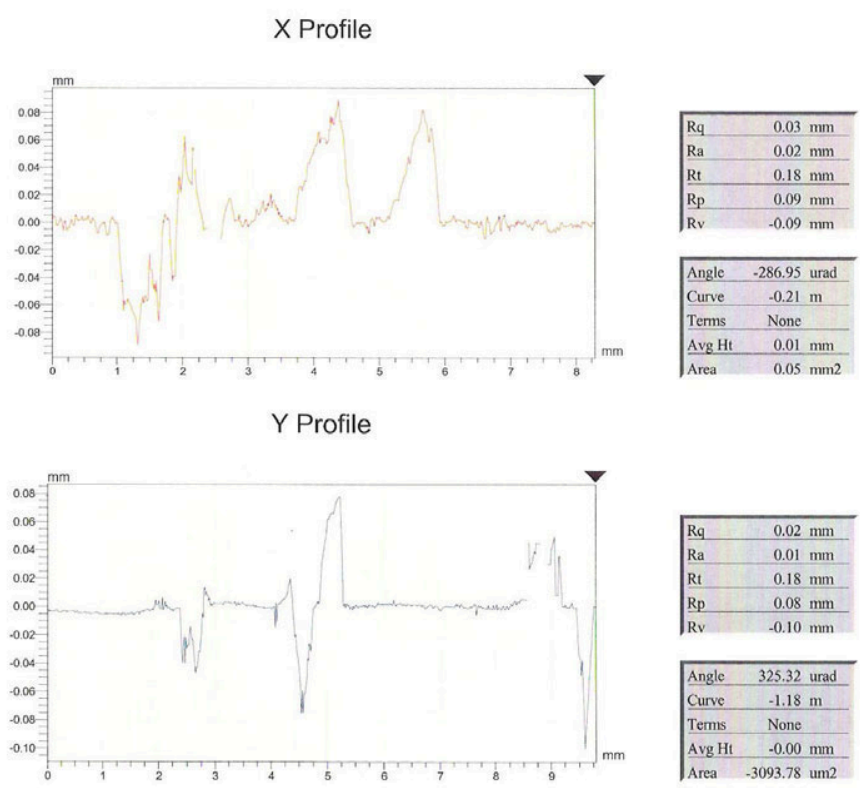

Note: 6 yr exposure 4' level 


\section{Veeco}

\section{3-Dimensional Interactive Display}

Surface Stats:

Ra: 2.27 um

Rq: $2.95 \mathrm{um}$

Rt: 39.71 um

Measurement Info:

Magnification: 2.54

Measurement Mode: VSI

Sampling: $6.61 \mathrm{um}$

Array Size: 368 X 240

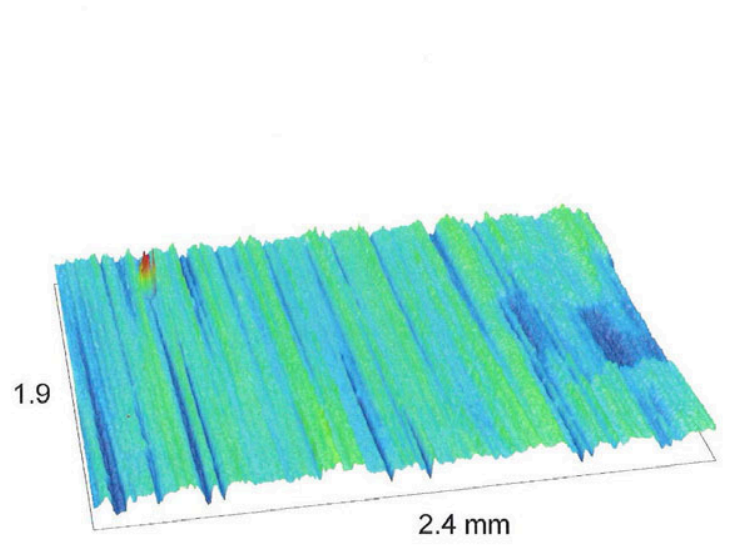

Date: 08/12/2004

Time: 14:22:26

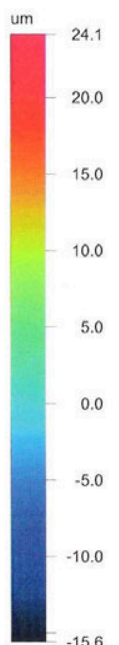

Title: Al 3498-1

Note: 6 yr exposure 10 ' level

\section{Veeco}
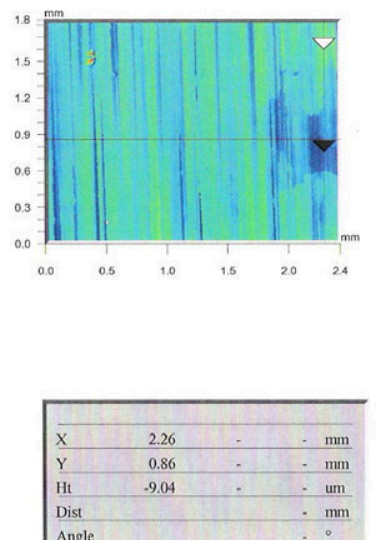

Title: Al 3498-1
X Profile
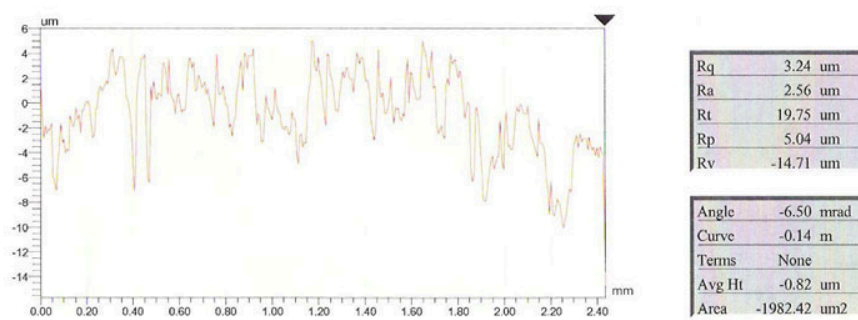

Ra $\quad 2.56 \mathrm{um}$

Rt $\quad 19.75 \mathrm{um}$

$\mathrm{Rp} \quad 5.04 \mathrm{um}$

\begin{tabular}{l} 
Angle $\quad-6.50 \mathrm{mrad}$ \\
\hline
\end{tabular}

Curve $\quad-0.14 \mathrm{~m}$

Terms None

\begin{tabular}{lr} 
Avg Ht $\quad-0.82$ um \\
\hline Arca & -1982.42
\end{tabular}

Y Profile

$\mathrm{x}: 0.829 \mathrm{~mm}$
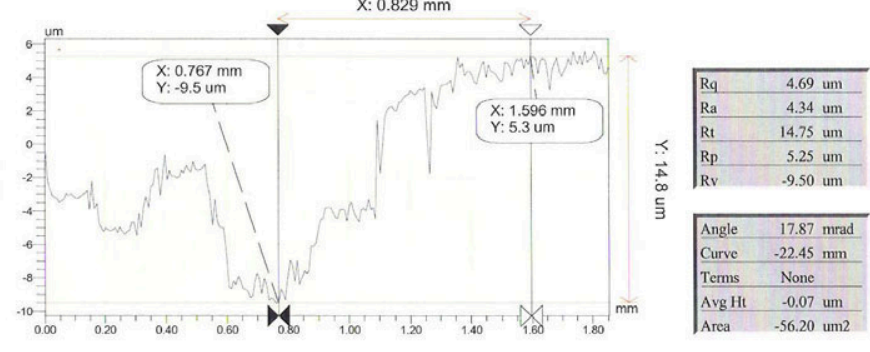

Note: 6 yr exposure 10' level 
Aluminum \#3498, 6-Year Exposure, 10 Ft Level

(Continued)

\section{Veeco}

\section{3-Dimensional Interactive Display}

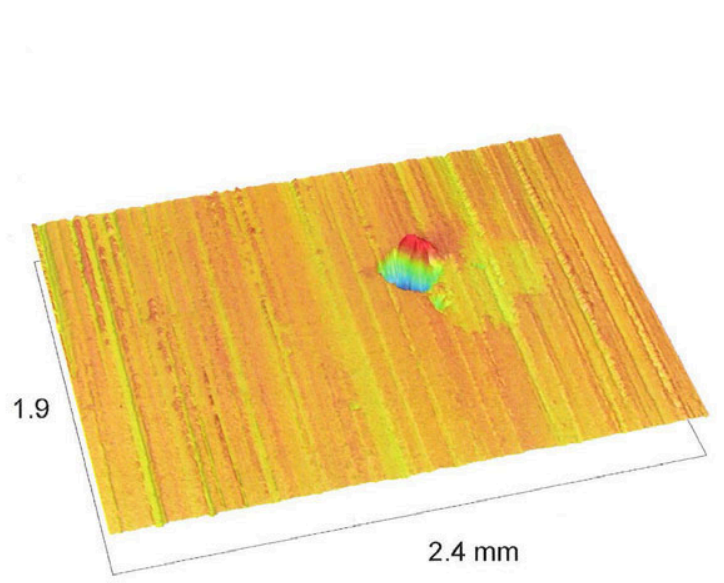

Surface Stats:

Ra: 3.27 um

Rq: $8.30 \mathrm{um}$

Rt: 202.12 um

Measurement Info:

Magnification: 2.54

Measurement Mode: VSI

Sampling: $6.61 \mathrm{um}$

Array Size: $368 \times 240$
Date: $08 / 12 / 2004$

Time: 14:28:23

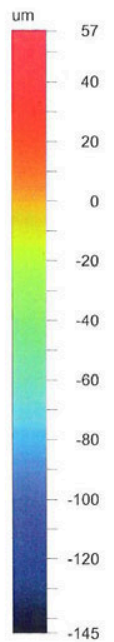

Title: Al 3498-2

Note: 6 yr exposure $10^{\prime}$ level
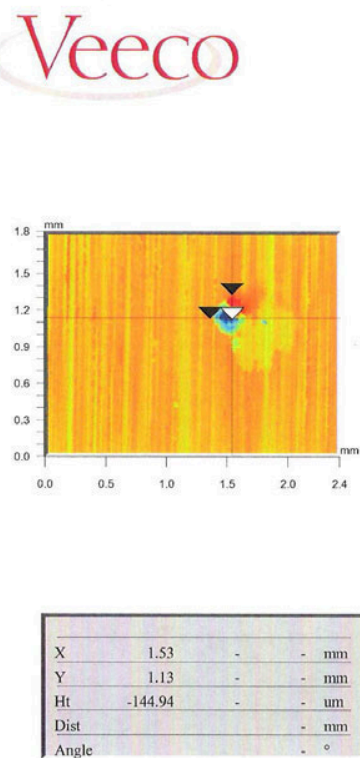

Title: Al 3498-2
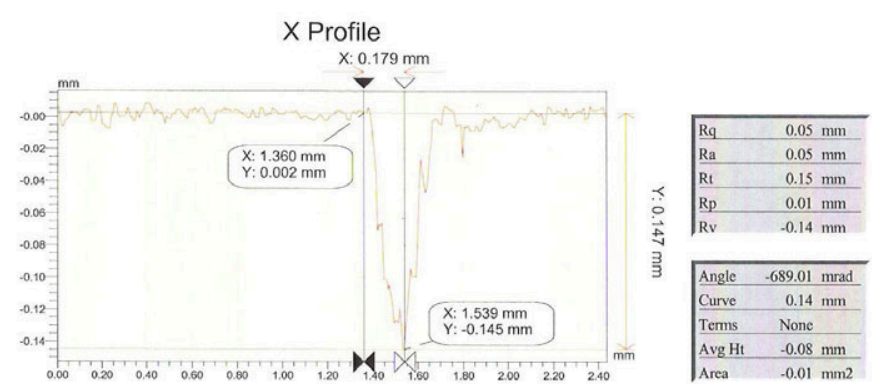

Y Profile

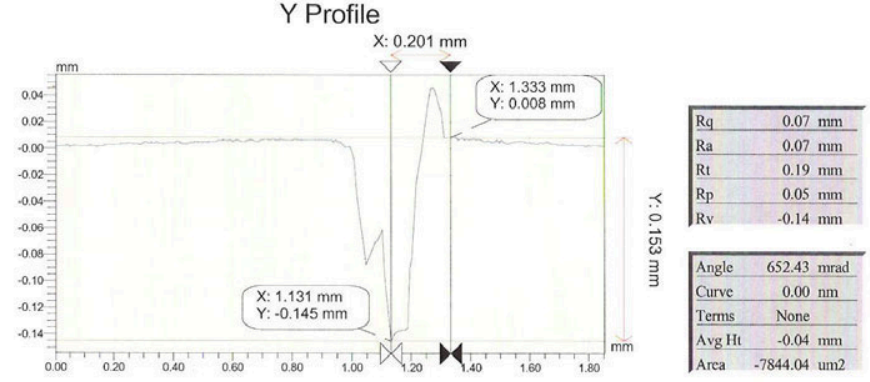

Note: 6 yr exposure $10^{\prime}$ level 


\section{Veeco}

\section{3-Dimensional Interactive Display}

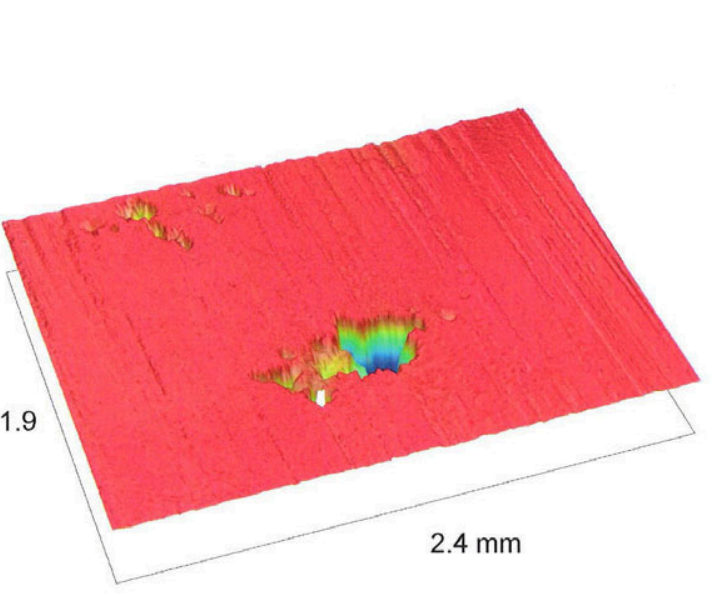

Surface Stats:

Ra: 7.47 um

Rq: $19.78 \mathrm{um}$

Rt: 223.50 um

Measurement Info:

Magnification: 2.54

Measurement Mode: VSI

Sampling: $6.61 \mathrm{um}$

Array Size: 368 X 240
Date: $08 / 12 / 2004$

Time: 14:50:45

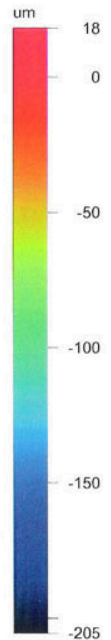

Title: Al 3500-1 backside

Note: 6 yr exposure 10' level

\section{Veeco}
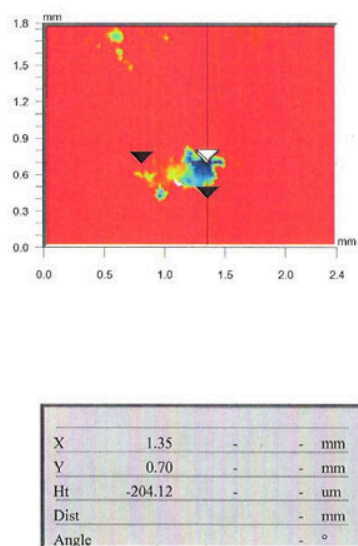

Title: Al 3500-1 backside

Note: 6 yr exposure 10' level

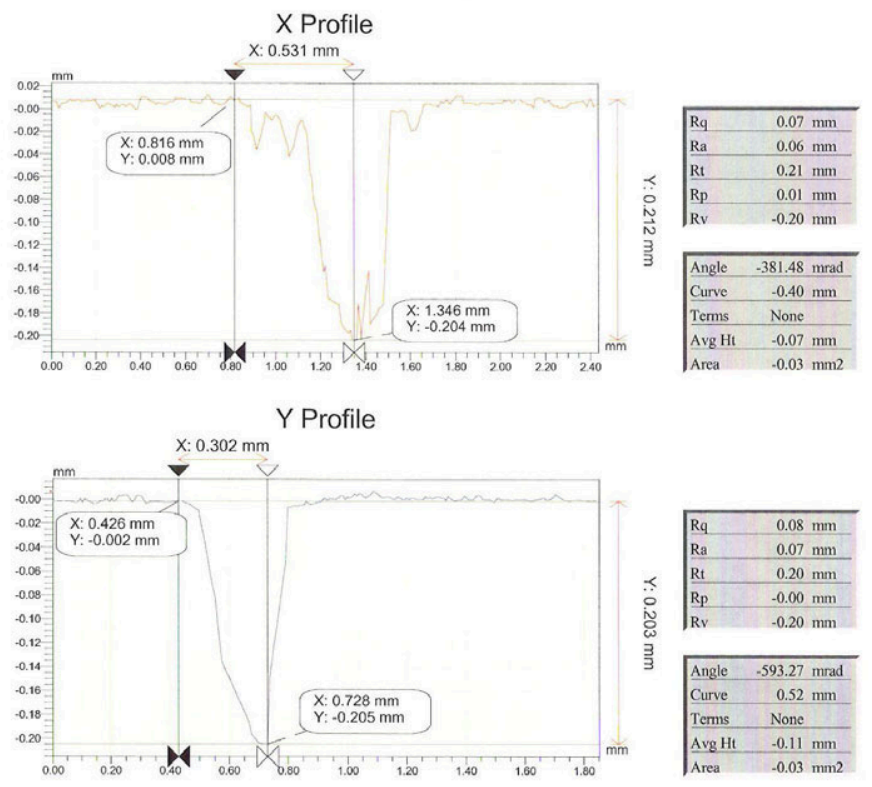

D-21 


\section{Veeco}

\section{3-Dimensional Interactive Display}

Date: 08/12/2004

Time: 15:04:10

Surface Stats:

Ra: 35.23 um

Rq: $42.67 \mathrm{um}$

Rt: 214.41 um

Measurement Info:

Magnification: 2.54

Measurement Mode: VSI

Sampling: $6.61 \mathrm{um}$

Array Size: 368 X 240
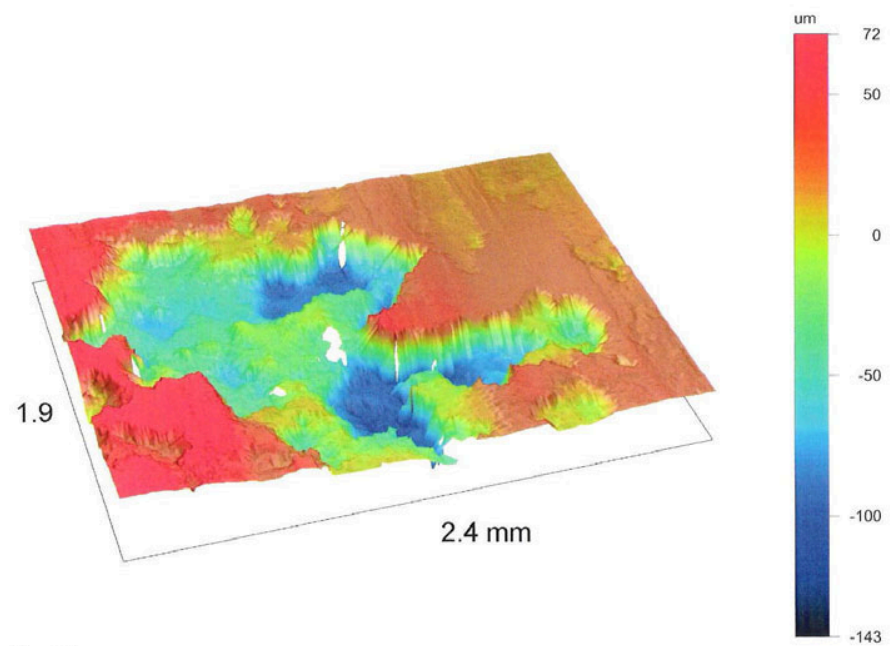

Title: Al 3500-2 backside

Note: 6 yr exposure 10' level

\section{Veeco}
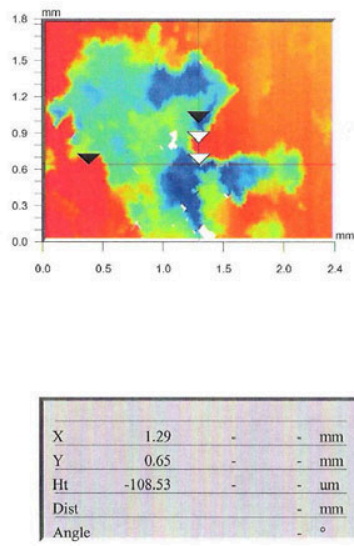

Title: Al 3500-2 backside Note: 6 yr exposure 10' level

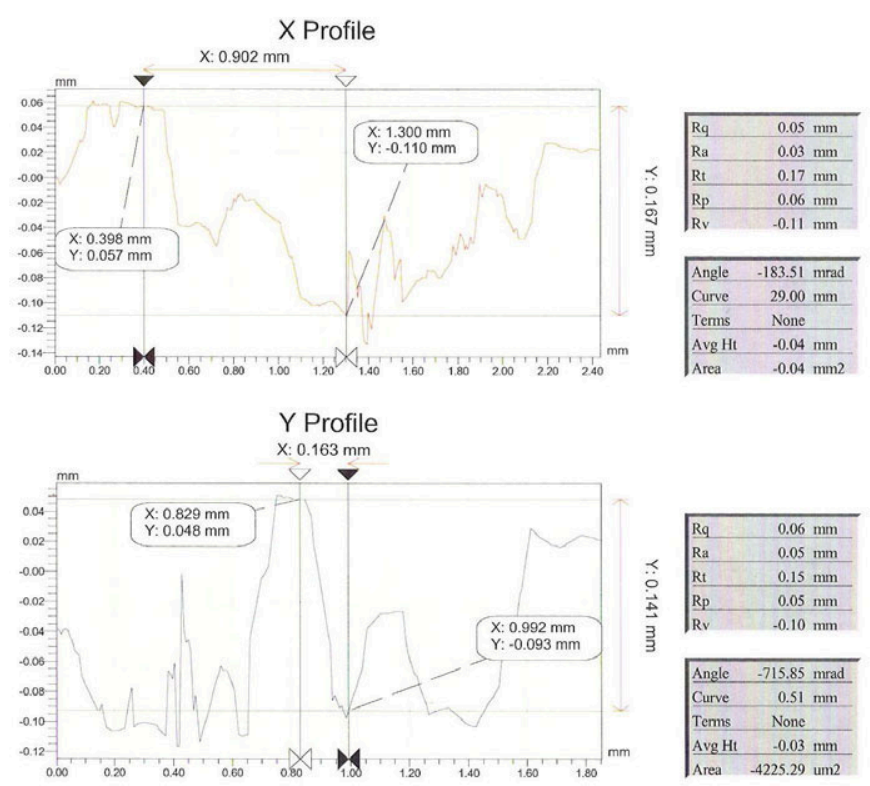


Aluminum \#3535, Unexposed Blank

\section{Veeco}

\section{3-Dimensional Interactive Display}

Date: $08 / 05 / 2004$

Time: 07:41:48

Surface Stats:

Ra: 1.76 um

Rq: 2.39 um

Rt: 26.92 um

Measurement Info:

Magnification: 2.54

Measurement Mode: VSI

Sampling: 6.61 um

Array Size: 368 X 240

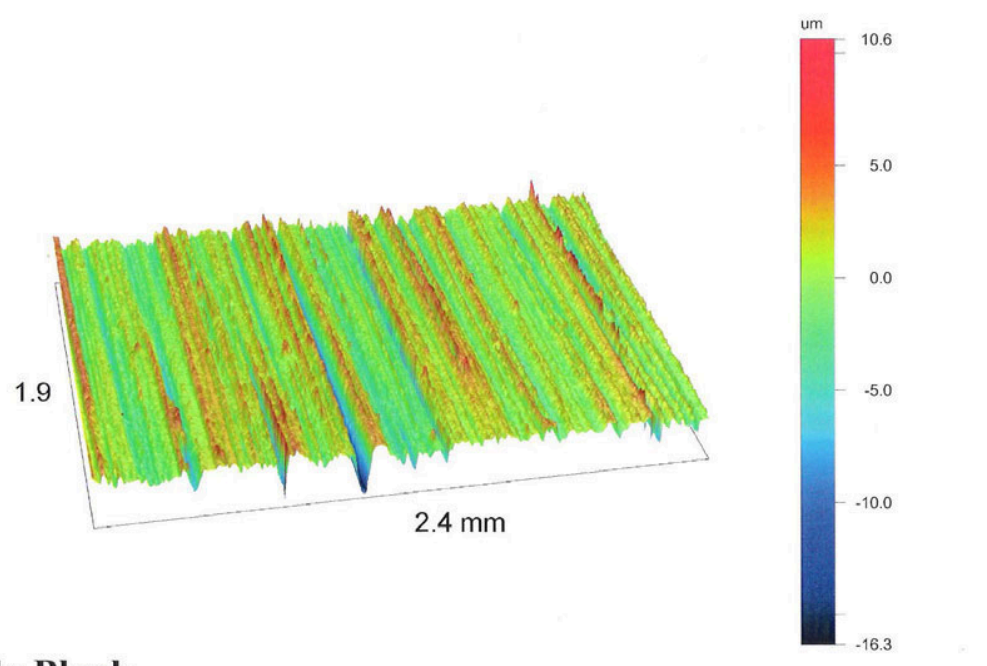

Title: Al \#3535 Cln Blank

Note: 6 yr exposure

Veeco
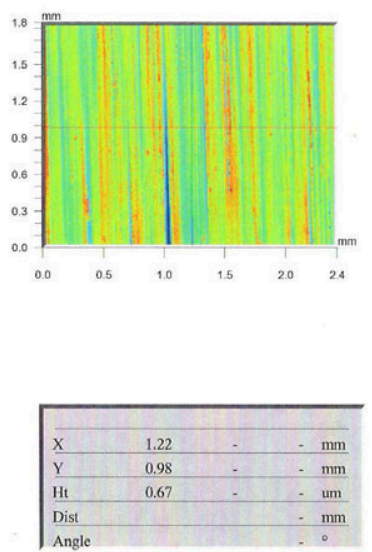

Title: Al \#3535 Cln Blank Note: 6 yr exposure
X Profile

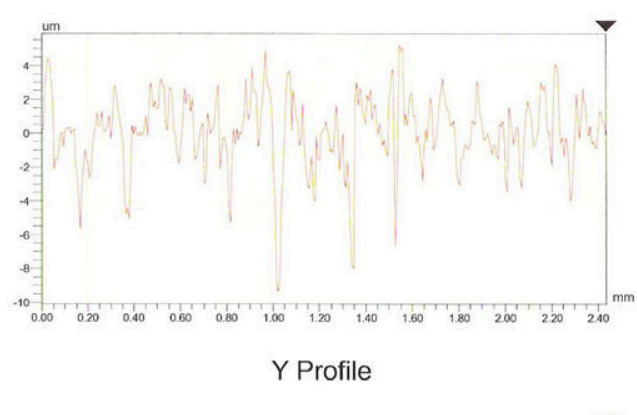

$\mathrm{Rq} \quad 2.22 \mathrm{um}$

$\mathrm{Ra} \quad 1.61 \mathrm{um}$

Rt $14.55 \mathrm{um}$

$\begin{array}{lr}\mathrm{Rp} & 5.18 \mathrm{um} \\ \mathrm{Rv} & -9.37 \mathrm{um}\end{array}$

Angle -152.68 urad

Terms None

Avg $\mathrm{Ht} \quad 0.07 \mathrm{~mm}$

Avg Ht $\quad 0.07$ um

$168.84 \mathrm{um} 2$

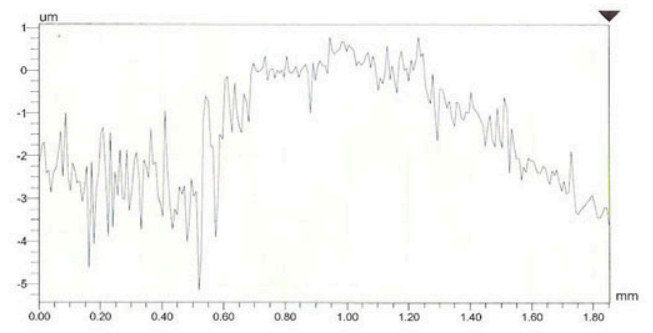


3-Dimensional Interactive Display

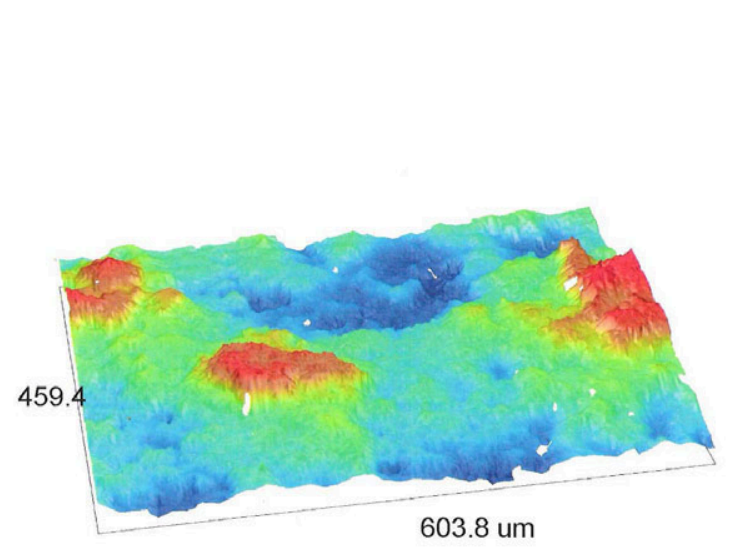

Date: 07/19/2004

Time: 07:07:19

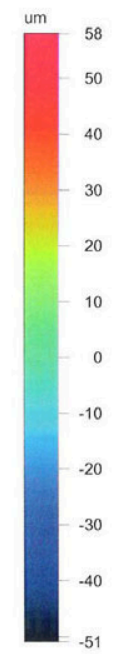

Title: Be\#19 - 1

Note: 6 yr exposure 4 ' level

\section{Veeco}
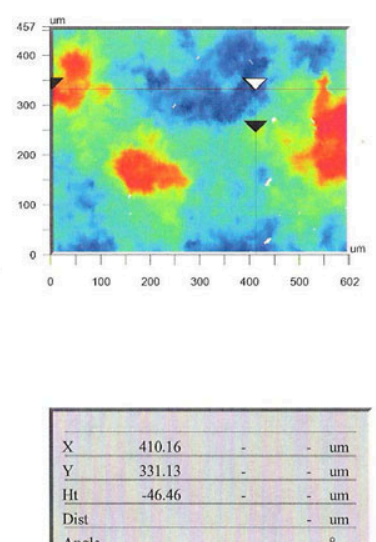

Title: Be\#19 - 1

Note: 6 yr exposure 4 ' level

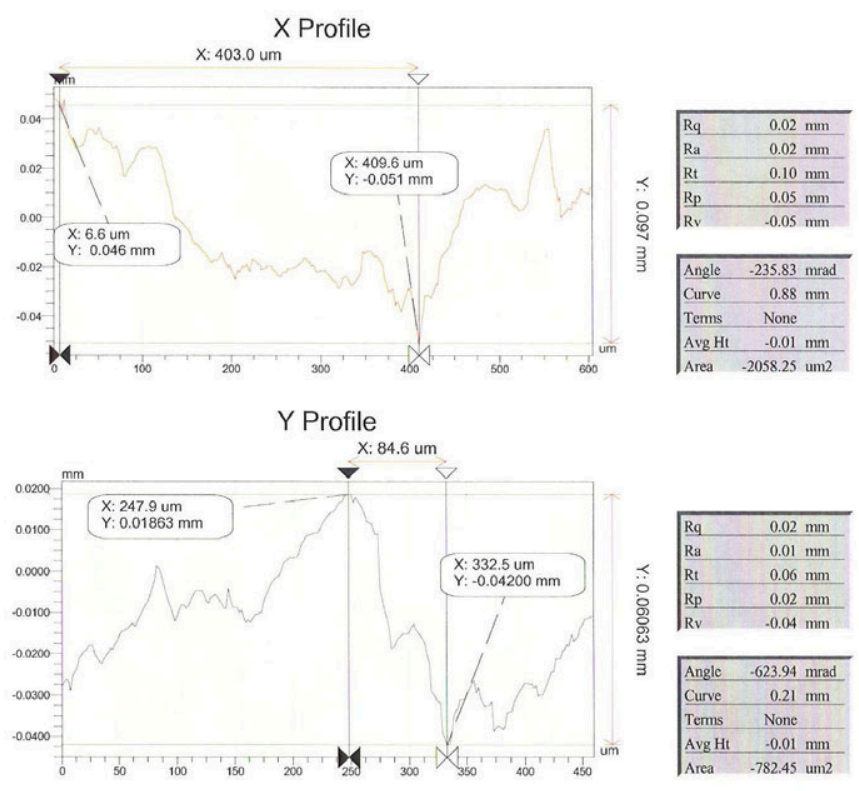


Beryllium \#19, 6-Year Exposure, 4 Ft Level

(Continued)

\section{Veeco}

\section{3-Dimensional Interactive Display}

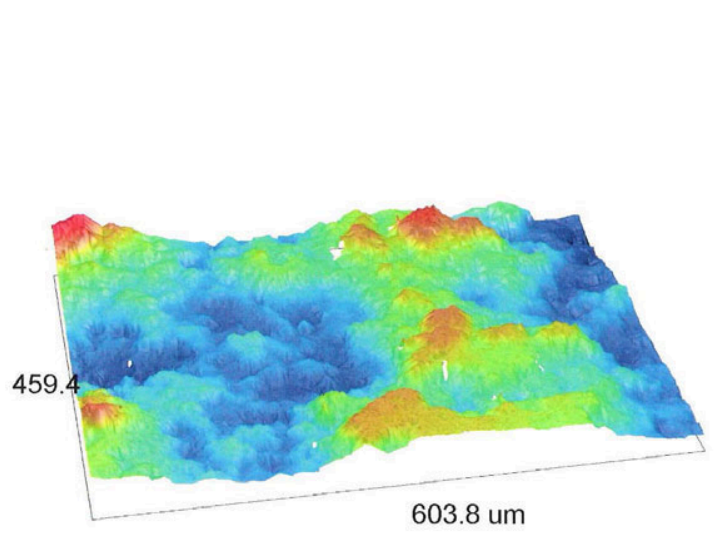

Date: 07/19/2004

Time: 07:12:29

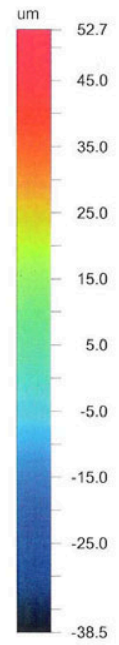

Title: Be\#19 - 2

Surface Stats:

Ra: 12.77 um

Rq: $15.26 \mathrm{um}$

Rt: 91.16 um

Measurement Info:

Magnification: 10.24

Measurement Mode: VSI

Sampling: $1.64 \mathrm{um}$

Array Size: 368 X 240

Note: 6 yr exposure 4' level

\section{Veeco}
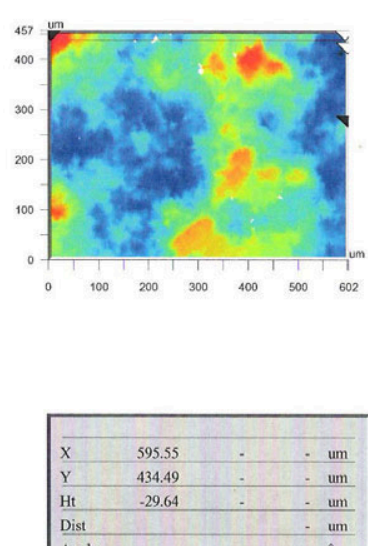

Title: Be\#19 - 2

Note: 6 yr exposure 4' level

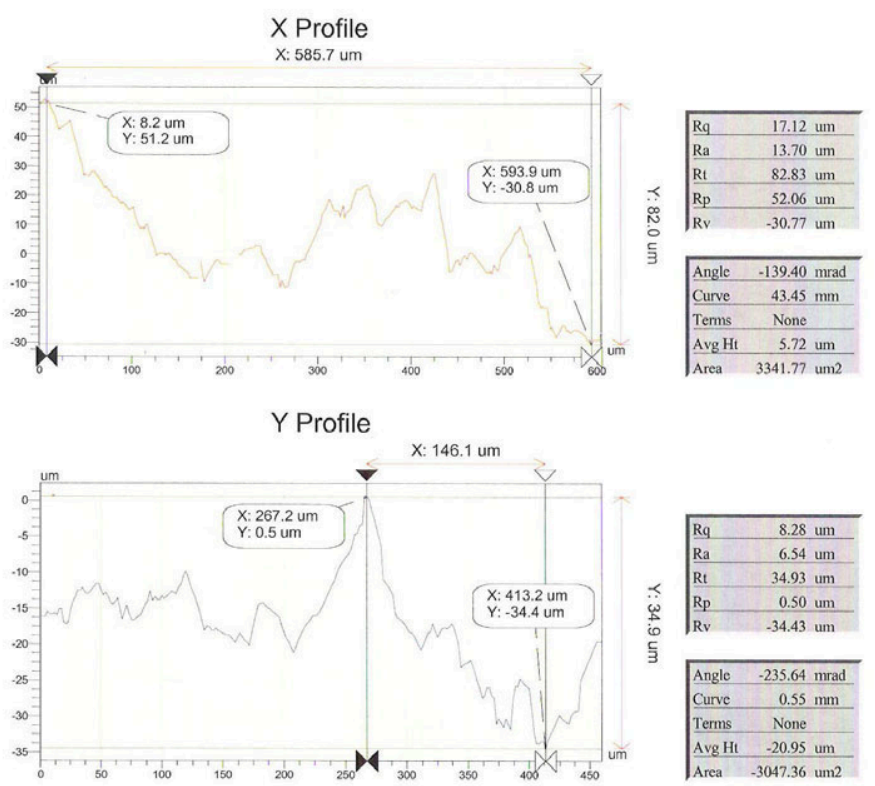




\section{Veeco}

\section{3-Dimensional Interactive Display}

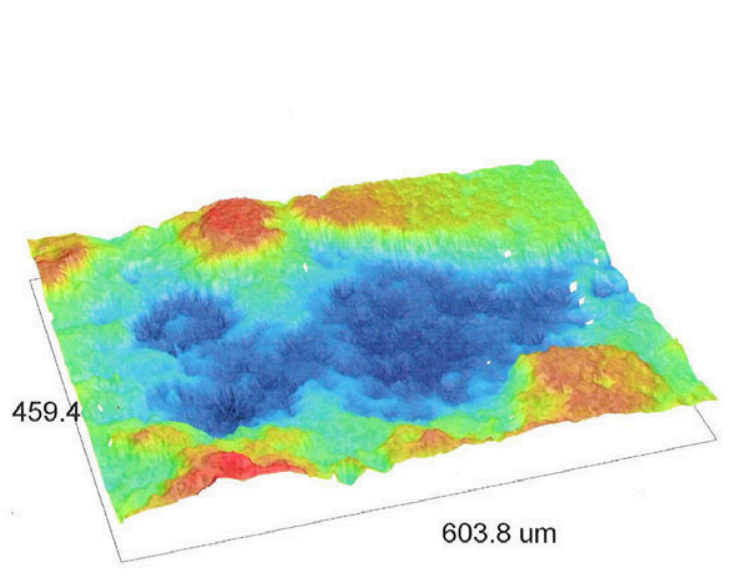

Surface Stats:

Ra: 19.19 um

Rq: $22.02 \mathrm{um}$

Rt: 108.78 um

Measurement Info:

Magnification: 10.24

Measurement Mode: VSI

Sampling: $1.64 \mathrm{um}$

Array Size: 368 X 240
Date: 07/19/2004

Time: 07:18:33

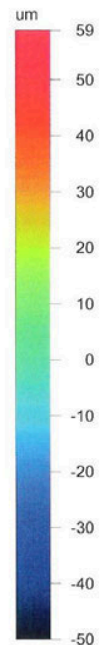

Title: Be\#20 - 1

Note: 6 yr exposure 4 ' level

Veeco
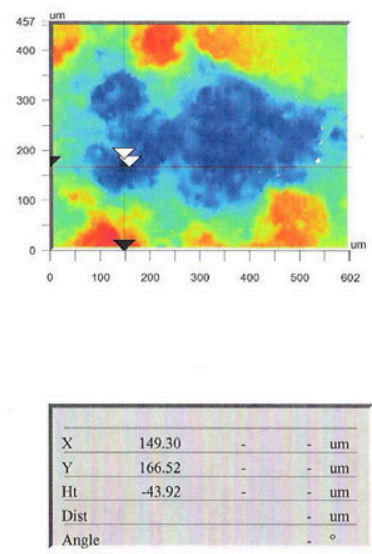

Title: Be\#20 - 1

Note: 6 yr exposure 4' level

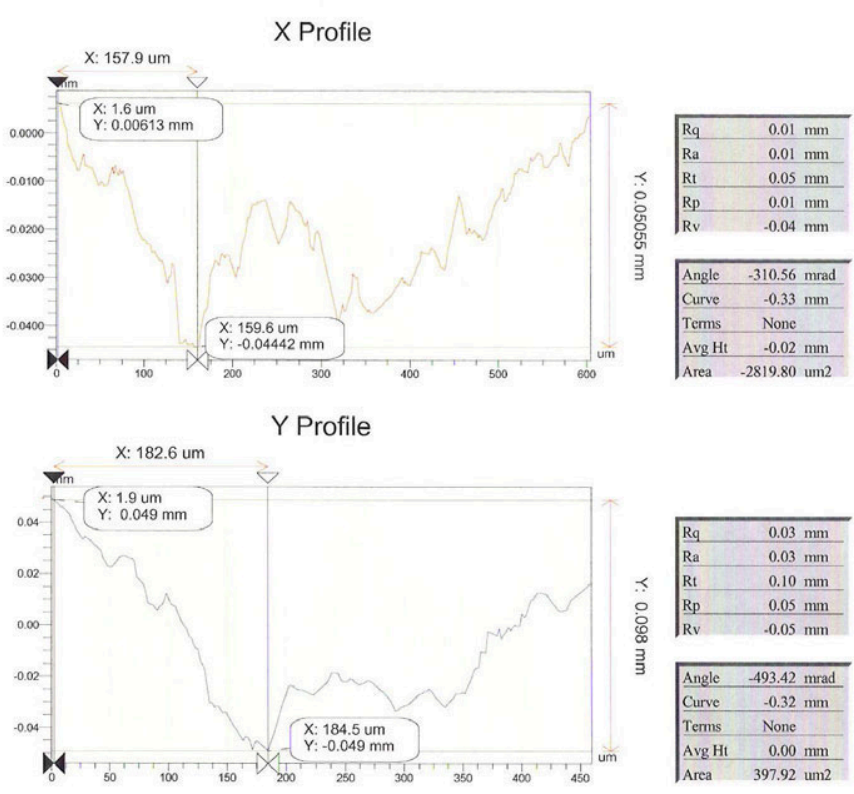

D-26 
Beryllium \#21, 6-Year Exposure, 4 Ft Level
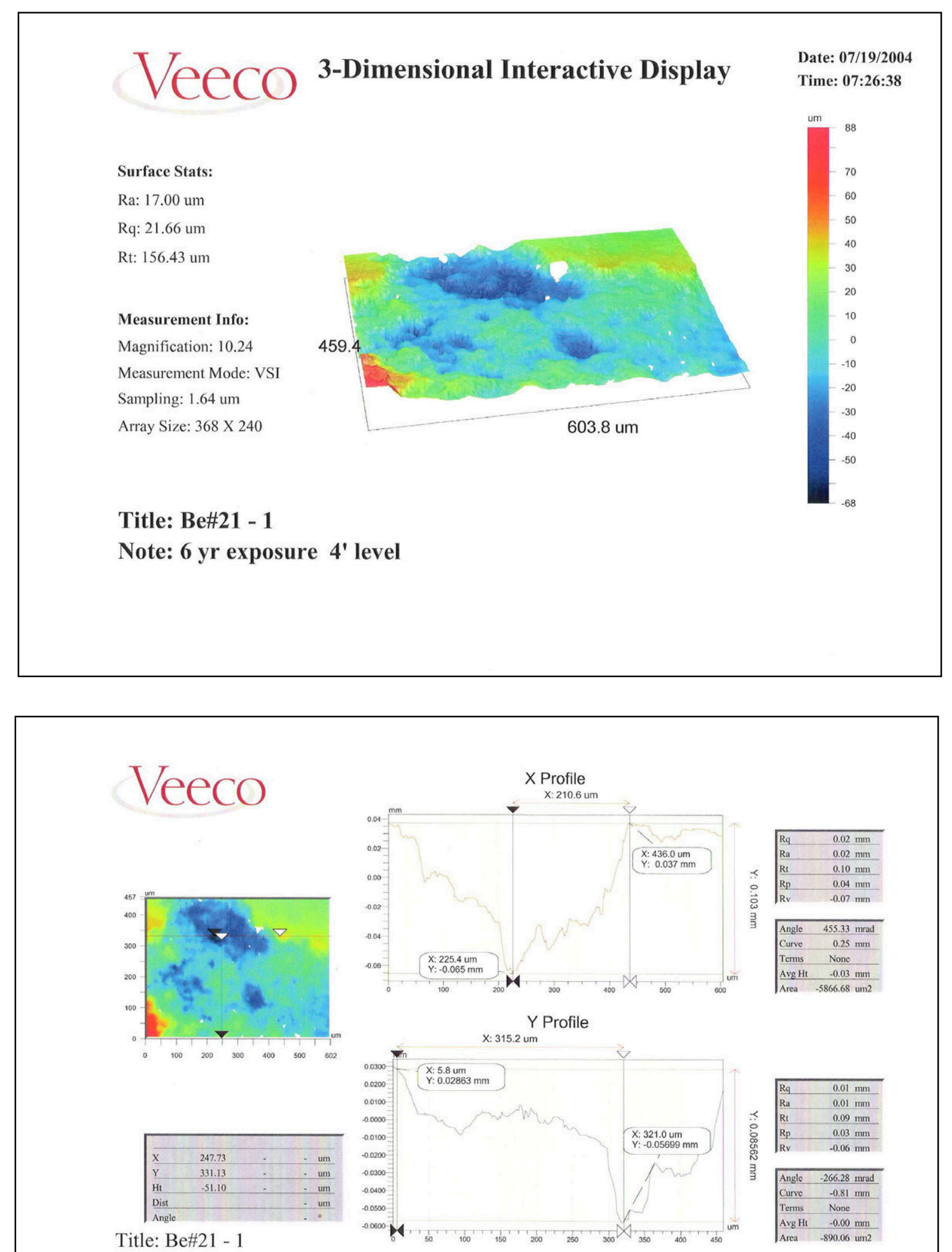

Title: Be\#21 - 1

Note: 6 yr exposure 4' level 
Beryllium \#22, 6-Year Exposure, 4 Ft Level
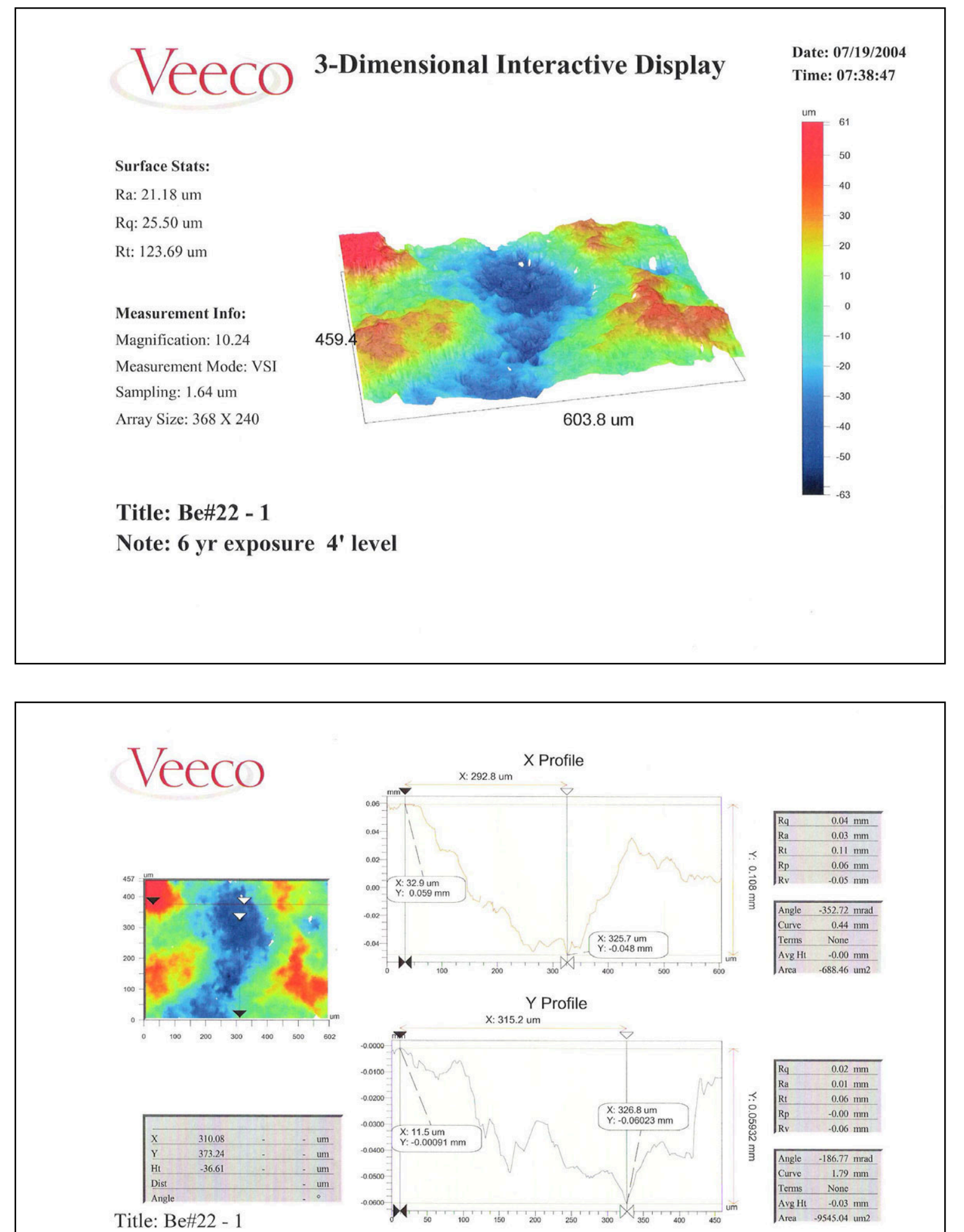

Title: Be\#22 - 1

Note: 6 yr exposure 4' level 
Beryllium \#22, 6-Year Exposure, 4 Ft Level

(Continued)

\section{Veeco}

3-Dimensional Interactive Display

Surface Stats:

Ra: 9.50 um

Rq: $11.93 \mathrm{um}$

Rt: 83.30 um

Measurement Info:

Magnification: 10.24

Measurement Mode: VSI

Sampling: $1.64 \mathrm{um}$

Array Size: 368 X 240

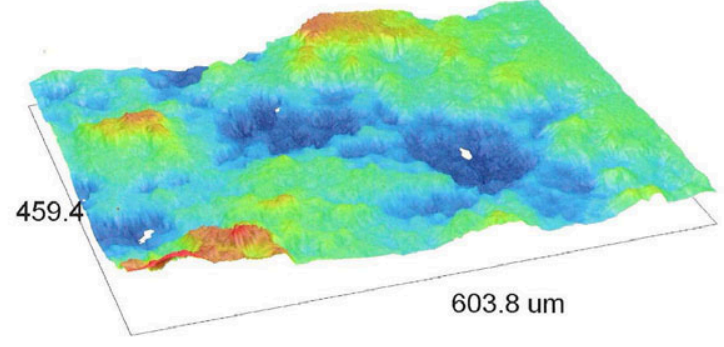

Date: 07/19/2004

Time: 07:43:17

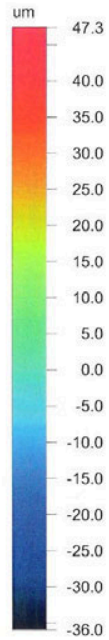

Title: Be\#22 - 2

Note: 6 yr exposure 4 ' level

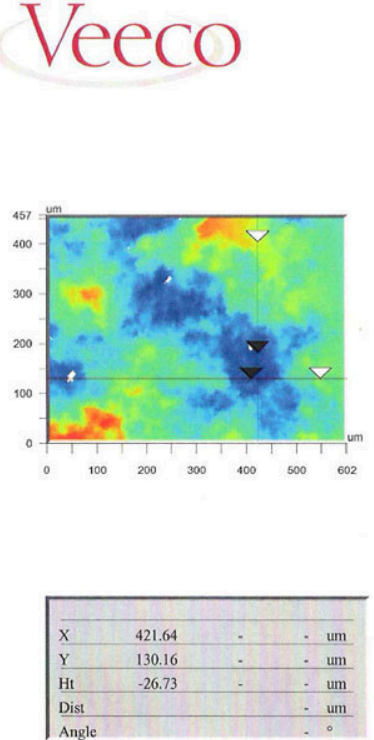

Title: Be\#22 - 2

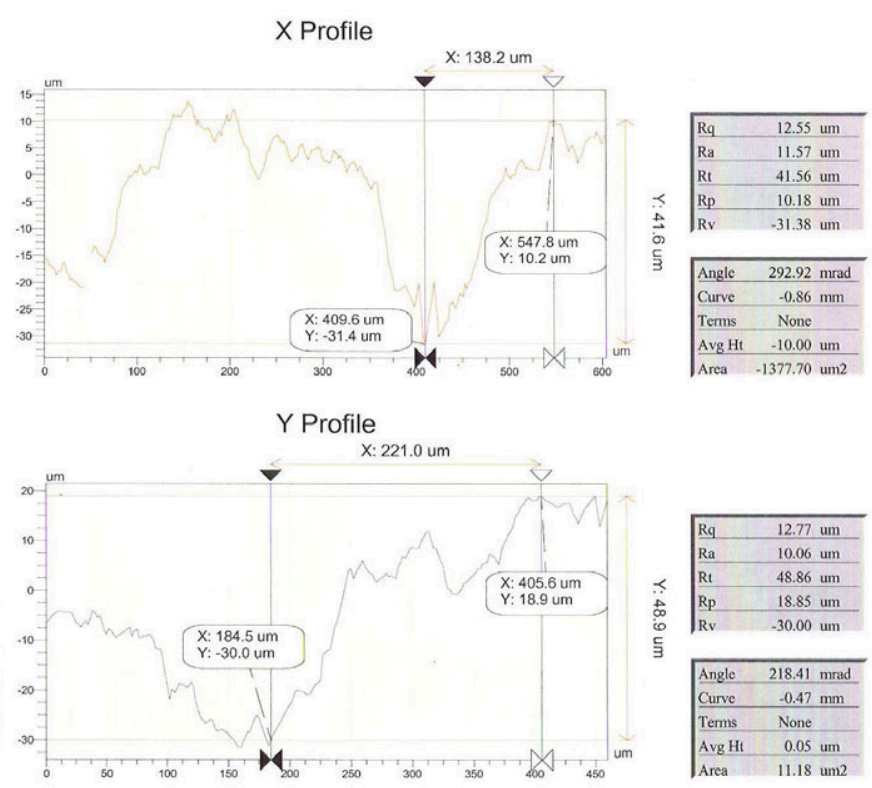

Note: 6 yr exposure 4' level 


\section{VeeCO 3-Dimensional Interactive Display}

Surface Stats:

Ra: 5.60 um

Rq: 7.24 um

Rt: 75.69 um

Measurement Info:

Magnification: 10.24

Measurement Mode: VSI

Sampling: 1.64 um

Array Size: 368 X 240

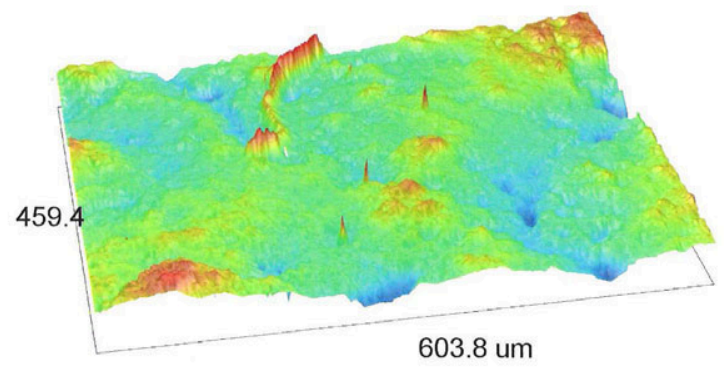

Date: 07/19/2004

Time: 10:11:17

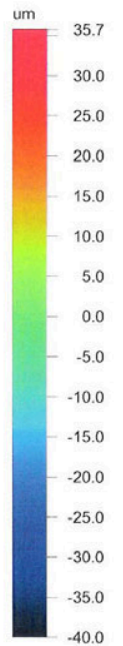

Title: Be\#23 - 2

Note: 6 yr exposure $10^{\prime}$ level
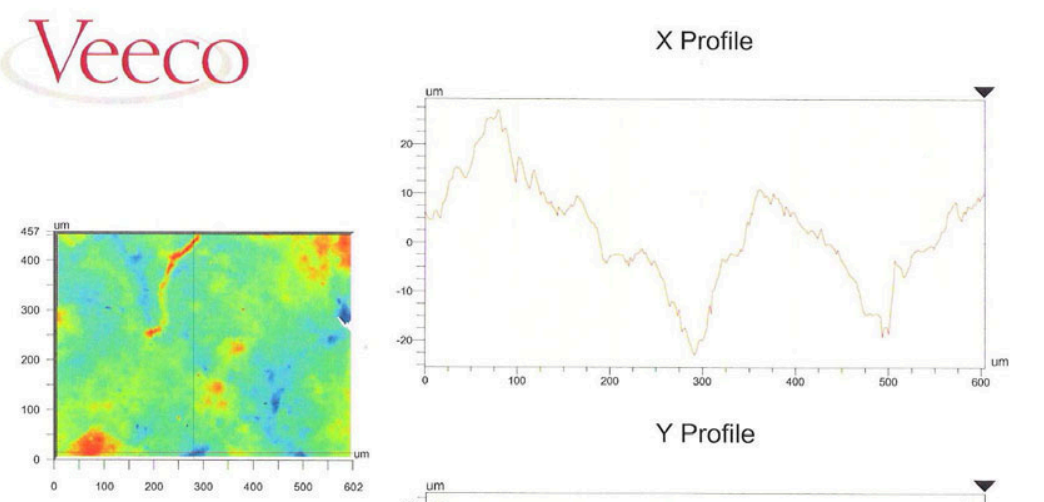

Rq $\quad 10.64 \mathrm{um}$

Y Profile
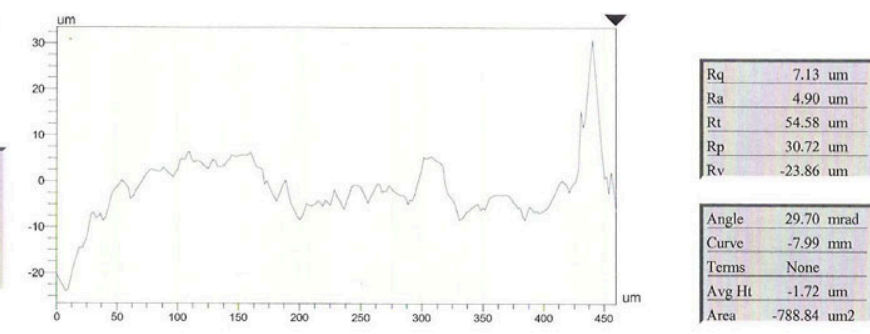

Title: Be\#23 - 2

Note: 6 yr exposure 10 level 


\section{Veeco}

\section{3-Dimensional Interactive Display}

Surface Stats:

Ra: 22.22 um

Rq: $28.21 \mathrm{um}$

Rt: 177.27 um

Measurement Info:

Magnification: 2.54

Measurement Mode: VSI

Sampling: $6.61 \mathrm{um}$

Array Size: 368 X 240

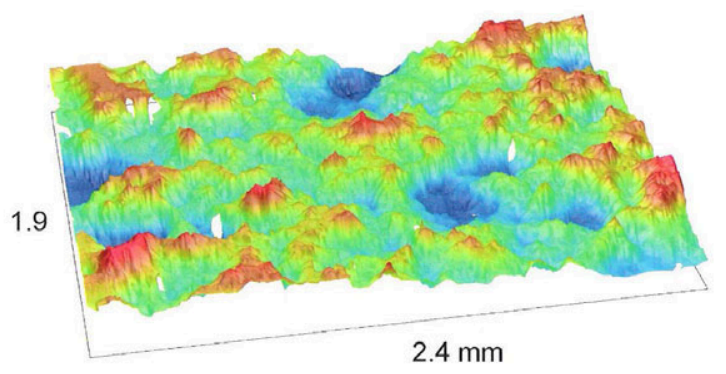

Date: $07 / 19 / 2004$

Time: 09:19:07

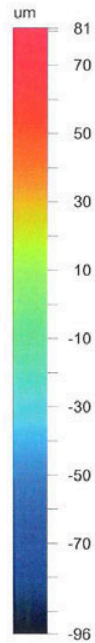

Title: Be\#24 - 1

Note: 6 yr exposure $10^{\prime}$ level

Veeco
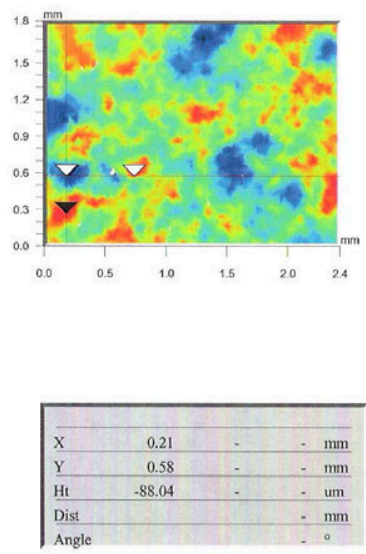

Title: Be\#24 - 1

Note: 6 yr exposure 10' level

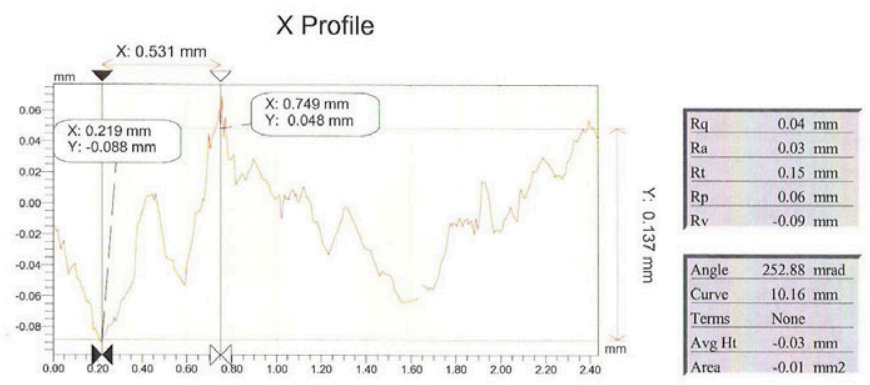

Y Profile

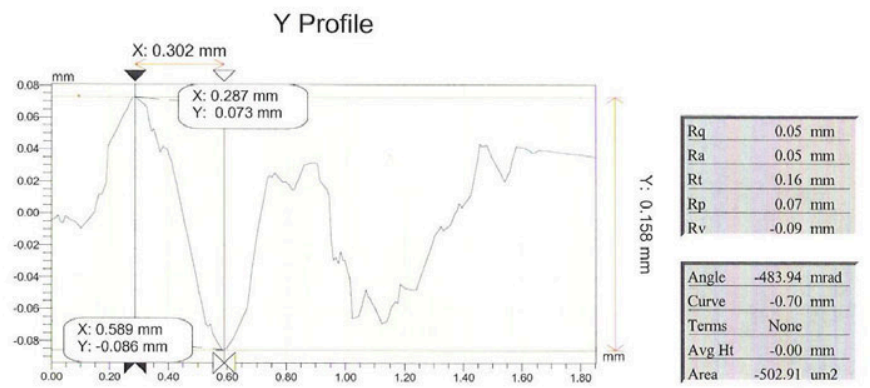




\section{Veeco}

\section{3-Dimensional Interactive Display}

Date: 07/19/2004

Time: 10:29:12

Surface Stats:

Ra: 28.69 um

Rq: 33.27 um

Rt: 154.34 um

Measurement Info:

Magnification: 10.24

Measurement Mode: VSI

Sampling: $1.64 \mathrm{um}$

Array Size: $368 \times 240$
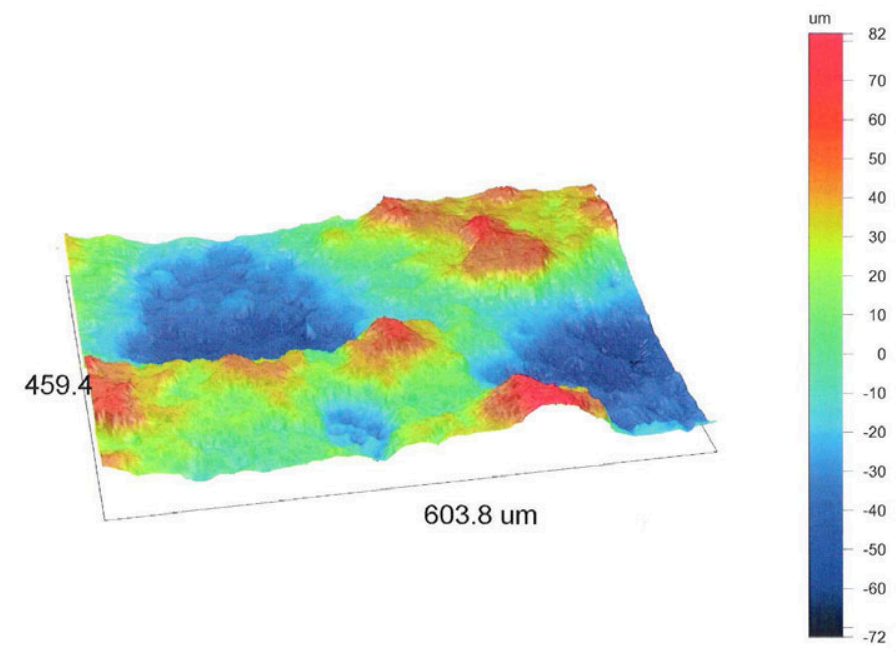

Title: Be\#25 - 2

Note: 6 yr exposure 10 ' level

\section{Veeco}
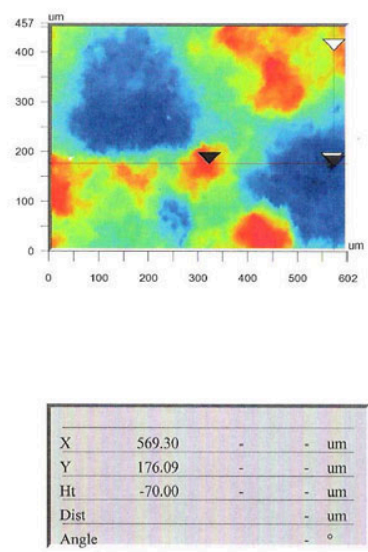

Title: Be\#25 - 2

Note: 6 yr exposure 10' level

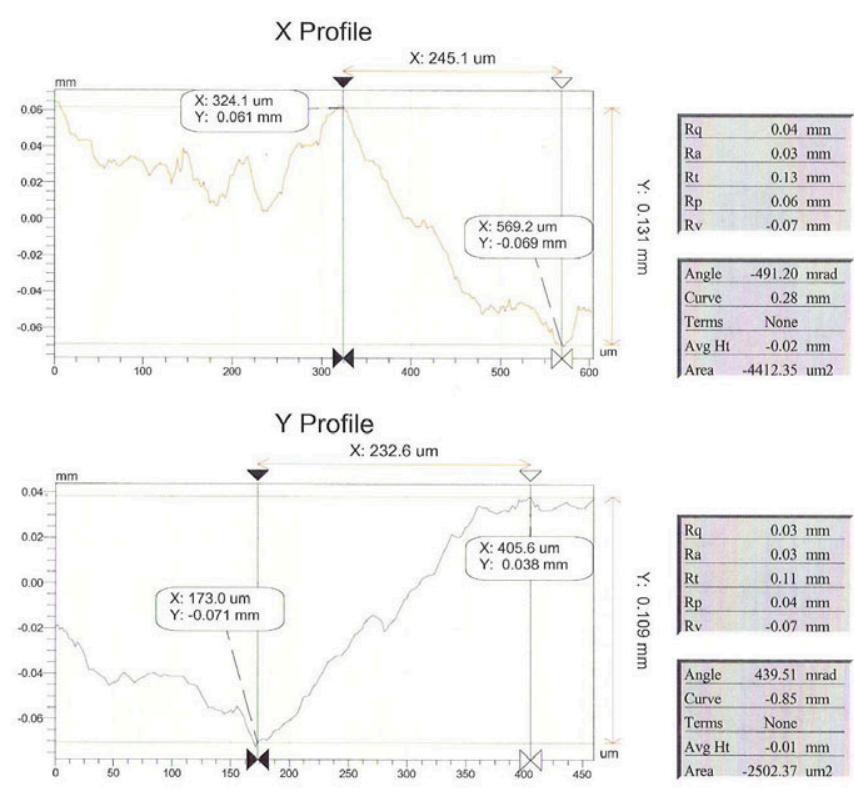




\section{Veeco}

3-Dimensional Interactive Display

Surface Stats:

Ra: 9.45 um

Rq: $11.73 \mathrm{um}$

Rt: 92.40 um

Measurement Info:

Magnification: 10.24

Measurement Mode: VSI

Sampling: 1.64 um

Array Size: 368 X 240

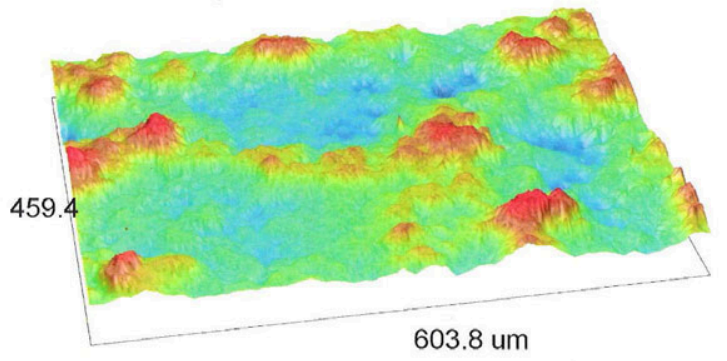

Date: 07/19/2004

Time: 10:38:31

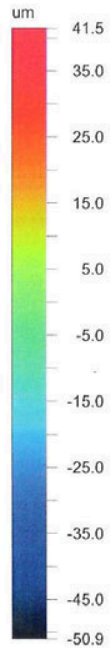

Title: Be\#26 - 1

Note: 6 yr exposure 10 ' level
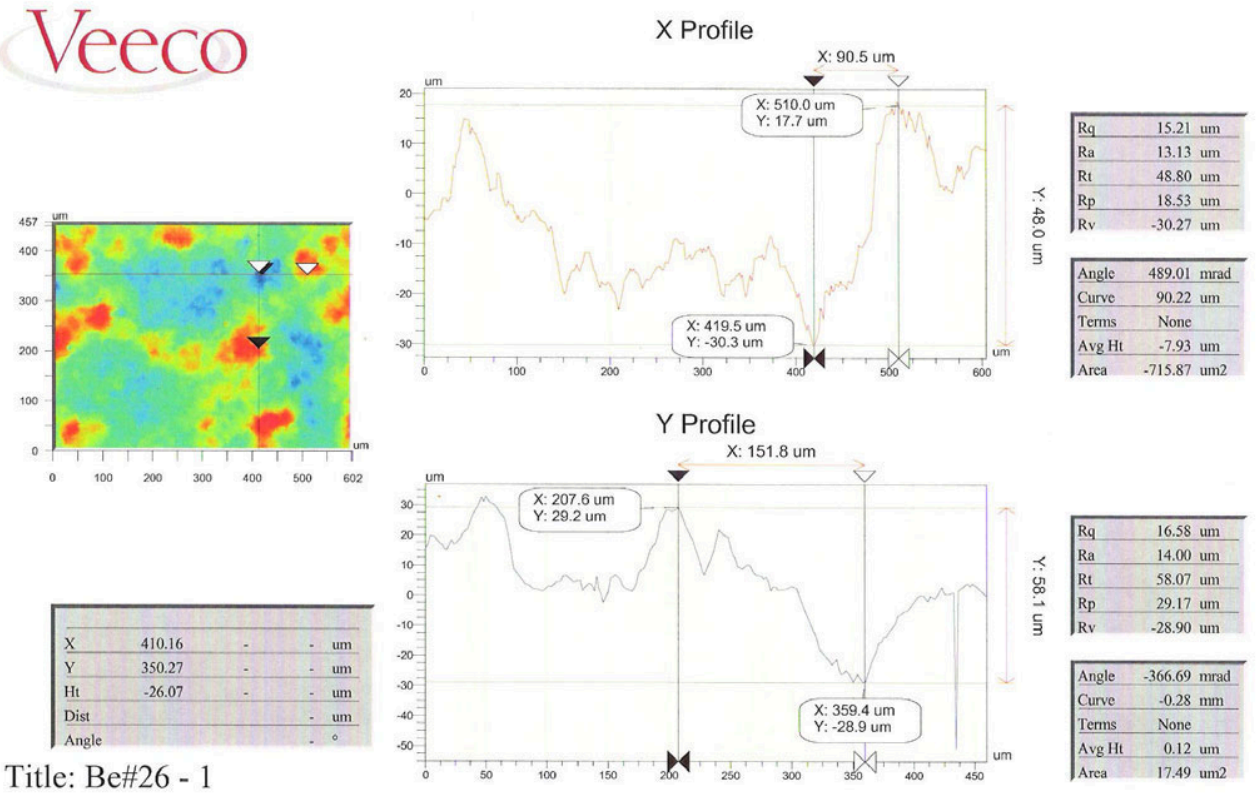

Title: Be\#26 - 1

Note: 6 yr exposure $10^{\prime}$ level 
Beryllium \#26, 6-Year Exposure, 10 Ft Level

(Continued)

\section{VeeCo 3-Dimensional Interactive Display}

Date: 07/19/2004

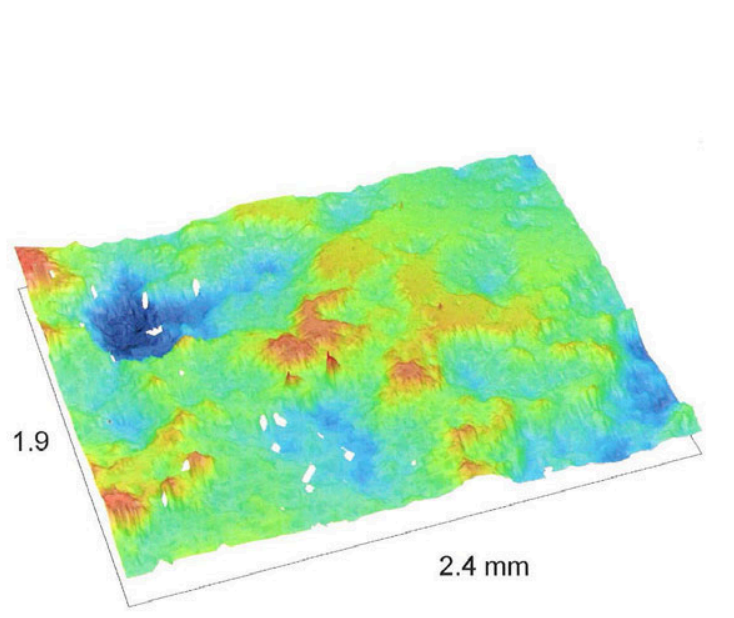

Time: 10:50:16

Surface Stats:

Ra: 24.34 um

Rq: $31.52 \mathrm{um}$

Rt: 252.51 um

Measurement Info:

Magnification: 2.54

Measurement Mode: VSI

Sampling: $6.61 \mathrm{um}$

Array Size: 368 X 240

Title: Be\#26 - 3

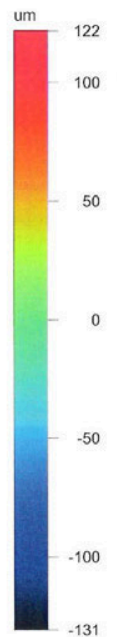

Note: 6 yr exposure $10^{\prime}$ level

Veeco
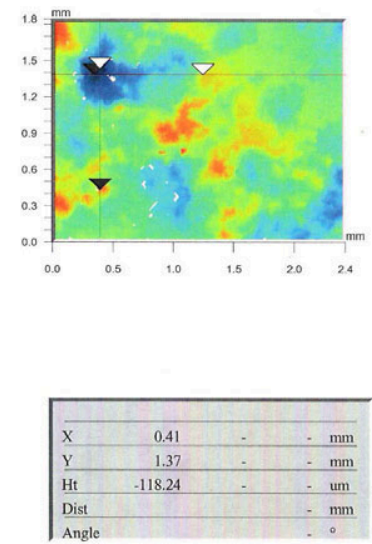

Title: Be\#26 - 3

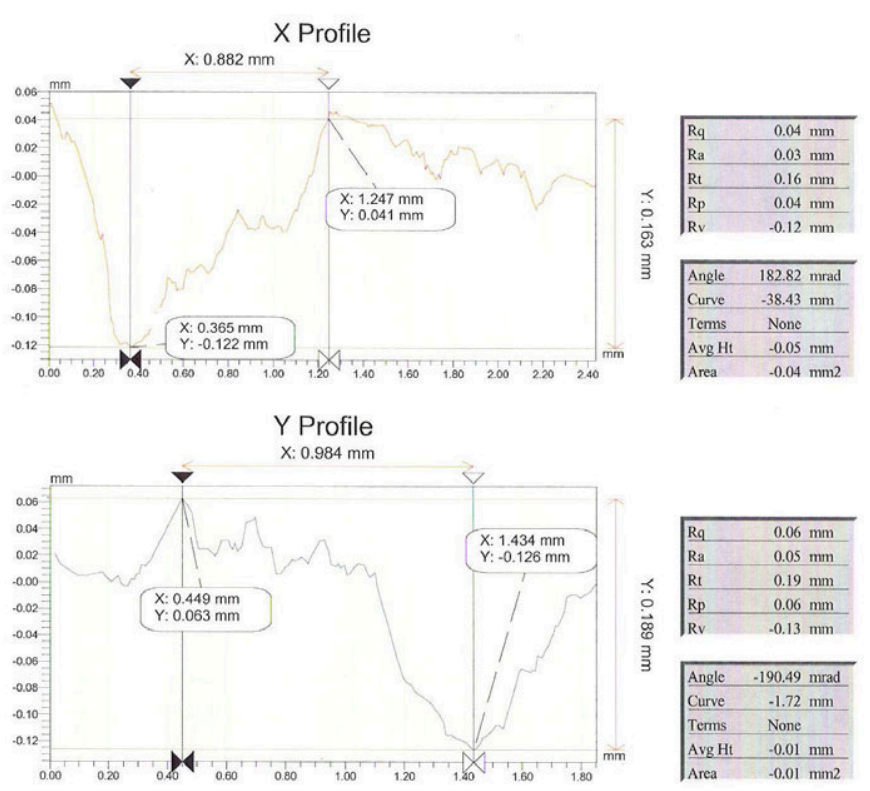




\section{Carbon Steel \#3343, 6-Year Exposure, 4 Ft Level}

Veeco

\section{3-Dimensional Interactive Display}

Surface Stats:

Ra: 89.48 um

Rq: 116.63 um Rt: 552.05 um

Measurement Info:

Magnification: 2.54

Measurement Mode: VSI

Sampling: $6.61 \mathrm{um}$

Array Size: 368 X 240

Title: CS\#3343-1

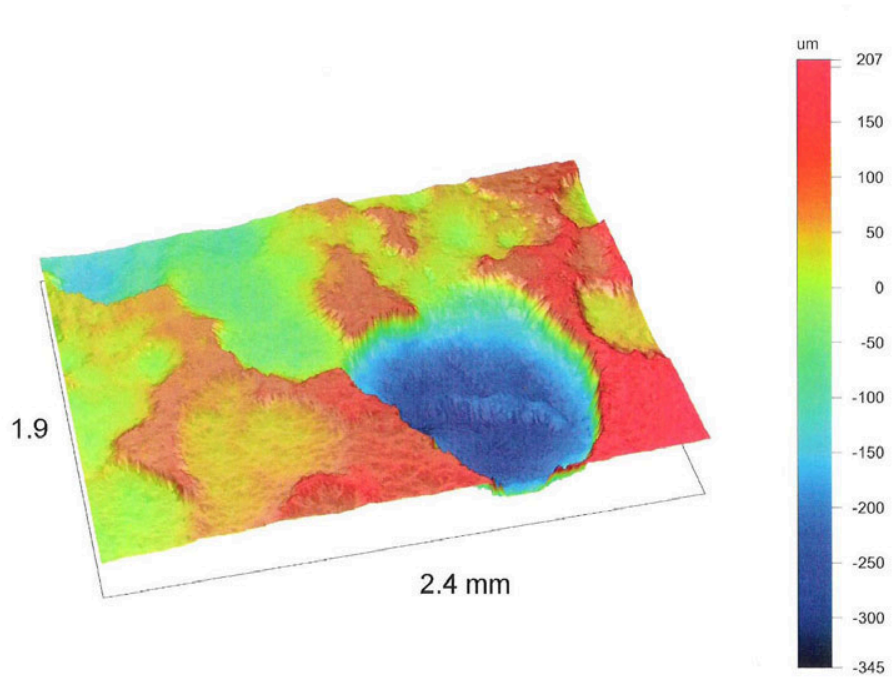

Date: 08/04/2004

Time: 12:36:07

Note: 6 yr exposure 4' level
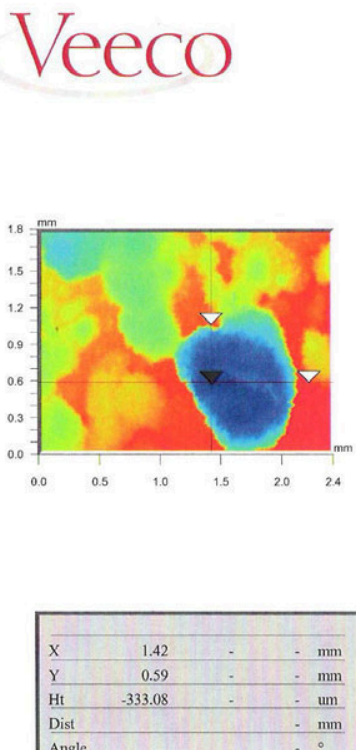

Title: CS\#3343-1

Note: 6 yr exposure 4' level

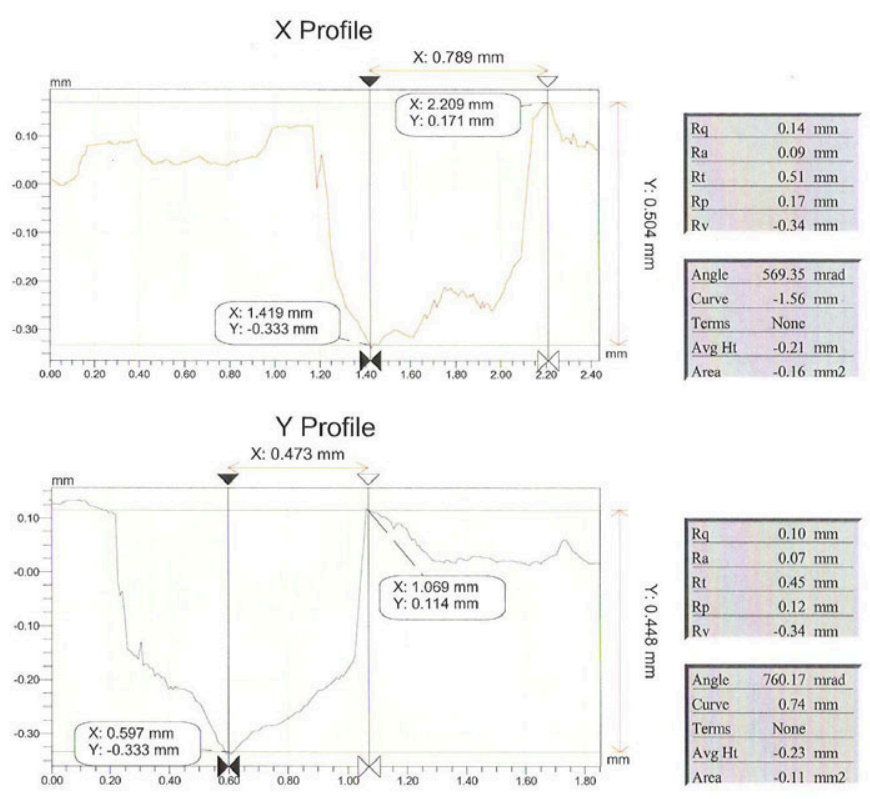




\section{Carbon Steel \#3343, 6-Year Exposure, 4 Ft Level}

(Continued)

\section{Veeco}

\section{3-Dimensional Interactive Display}

Surface Stats:

Ra: 24.87 um

Rq: 30.94 um

Rt: 205.14 um

Measurement Info:

Magnification: 2.54

Measurement Mode: VSI

Sampling: $6.61 \mathrm{um}$

Array Size: 368 X 240

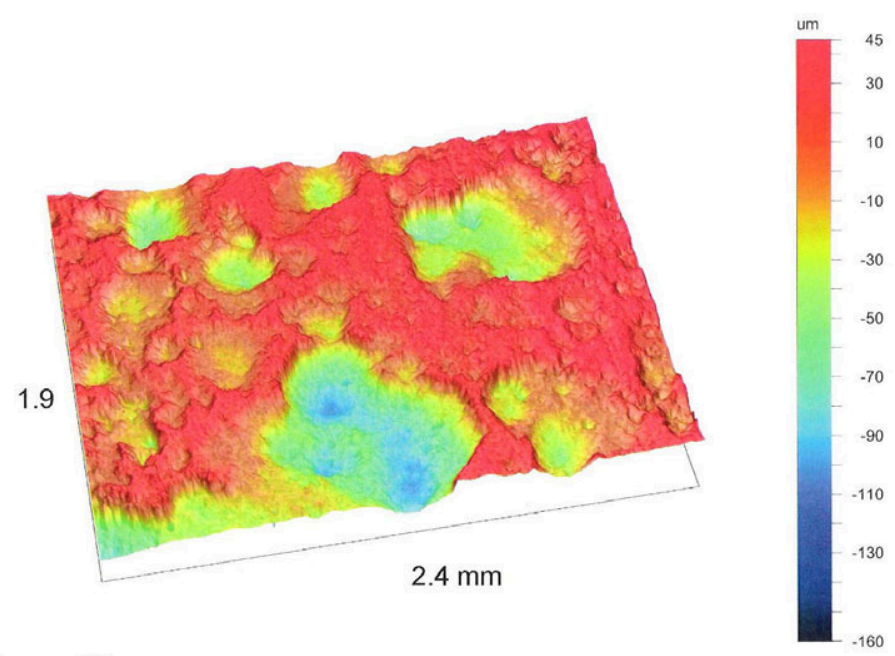

Title: CS\#3343-2 Area \#2

Note: 6 yr exposure
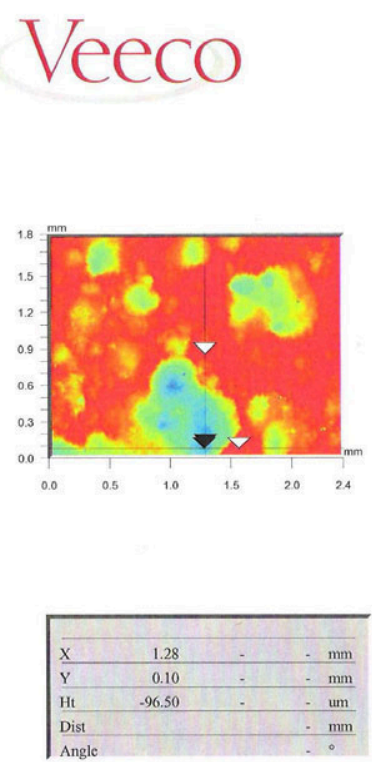

Title: CS\#3343-2 Area \#2

Note: 6 yr exposure
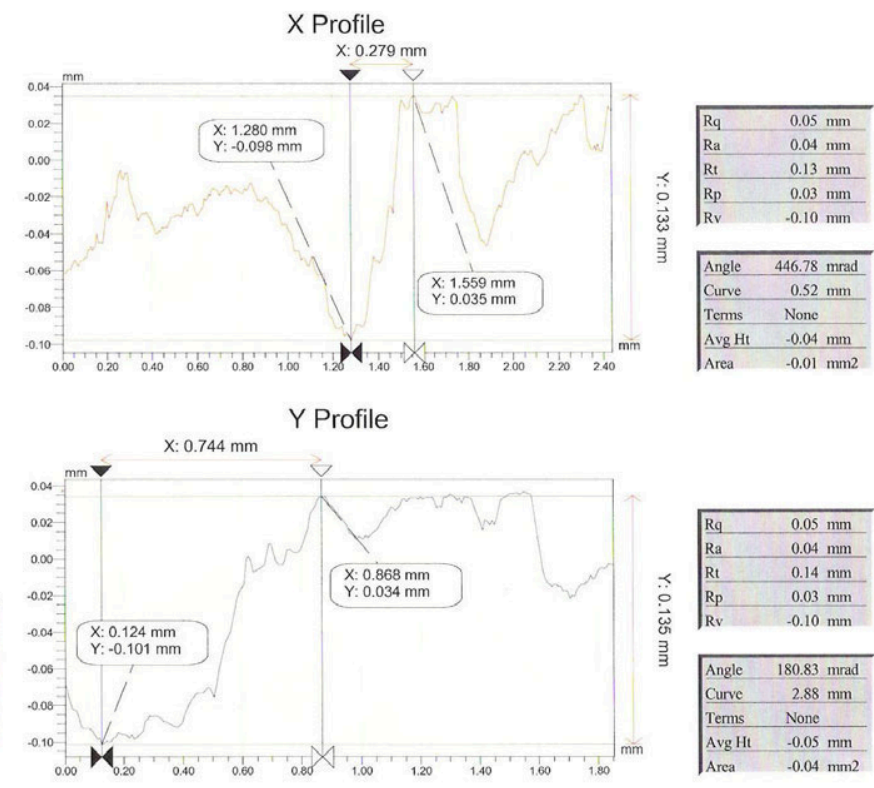


\section{Veeco}

3-Dimensional Interactive Display

Surface Stats:

Ra: 26.28 um

Rq: 33.35 um

Rt: 175.91 um

Measurement Info:

Magnification: 2.54

Measurement Mode: VSI

Sampling: $6.61 \mathrm{um}$

Array Size: 368 X 240

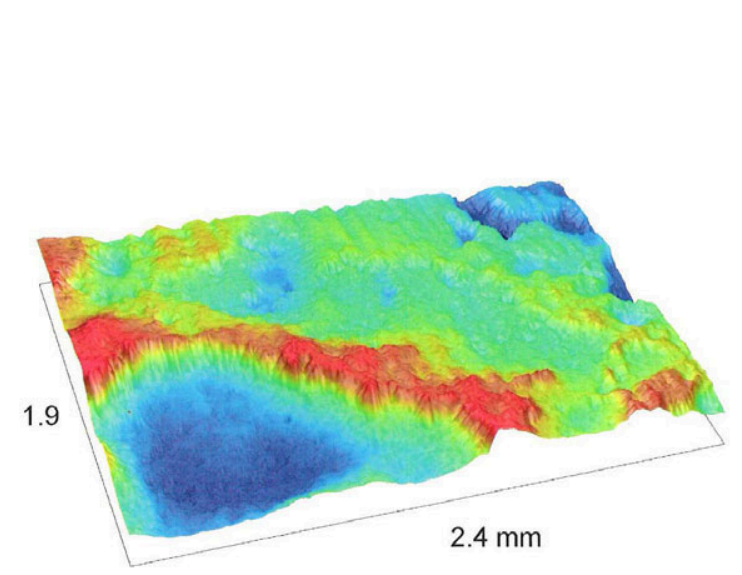

Date: 08/04/2004

Time: 13:08:34

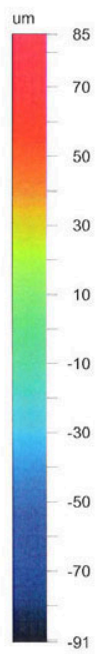

Title: CS\#3344-1

Note: 6 yr exposure $4^{\prime}$ level

\section{Veeco}
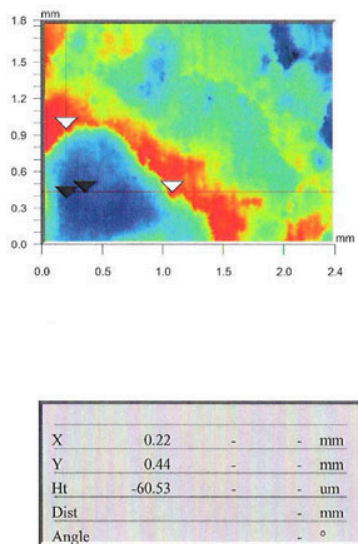

Title: CS\#3344-1

Note: 6 yr exposure 4' level
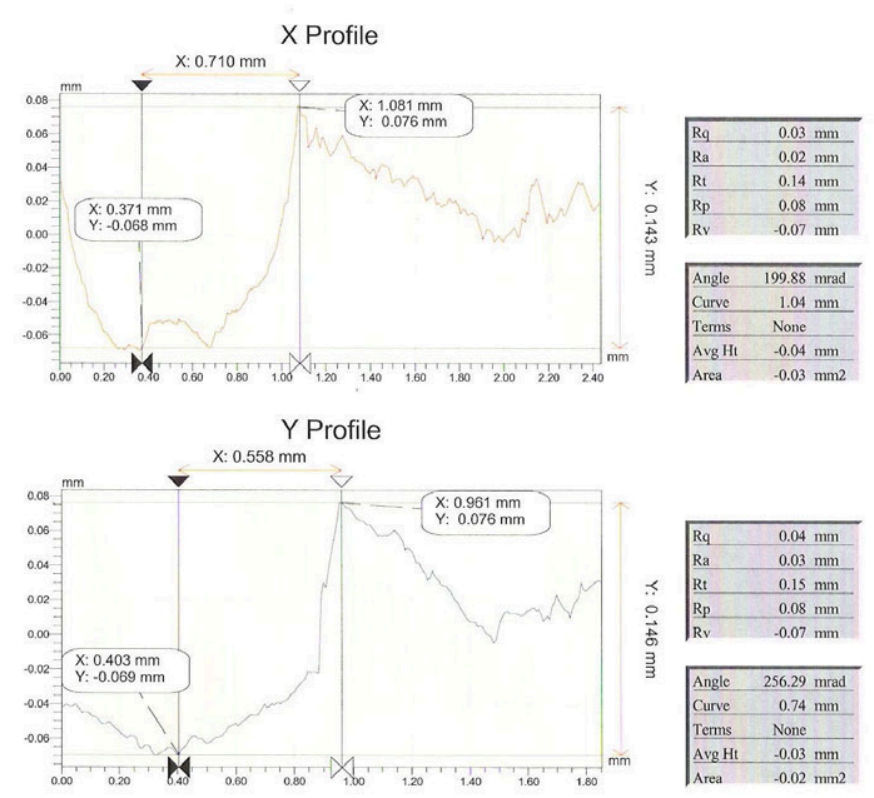
Carbon Steel \#3344, 6Year Exposure, 4 Ft Level

(Continued)

\section{Veeco}

3-Dimensional Interactive Display

Surface Stats:

Ra: 33.64 um

Rq: 38.12 um

Rt: 167.74 um

Measurement Info:

Magnification: 2.54

Measurement Mode: VSI

Sampling: $6.61 \mathrm{um}$

Array Size: 368 X 240

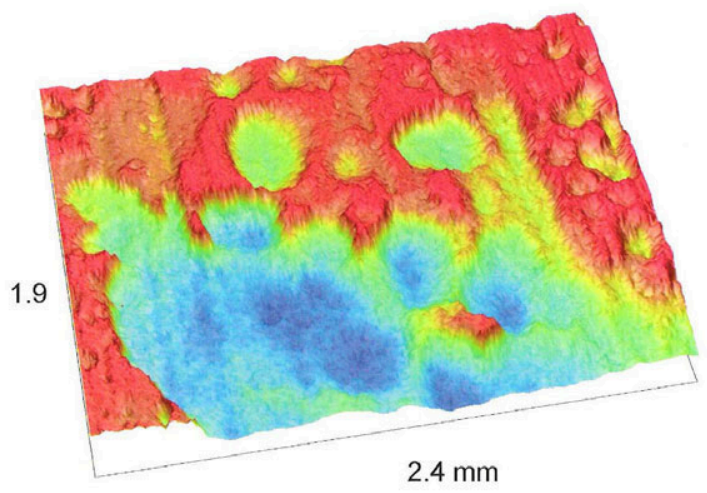

Date: 08/04/2004

Time: 13:17:03

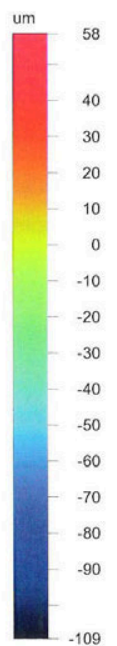

Title: CS\#3344-2 Area \#2

Note: 6 yr exposure

Veeco
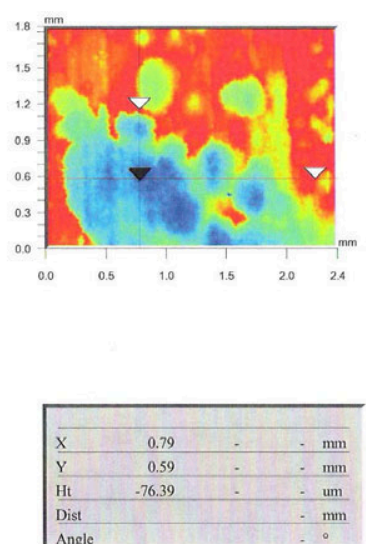

Title: CS\#3344-2 Area \#2 Note: 6 yr exposure
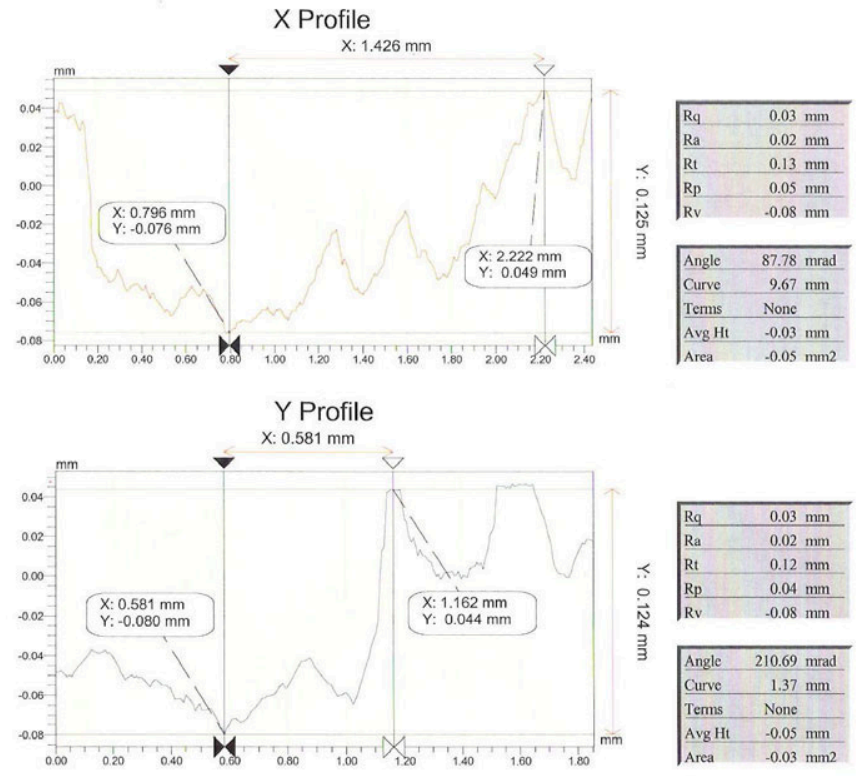


\section{Veeco}

3-Dimensional Interactive Display

Surface Stats:

Ra: 73.42 um

Rq: 84.49 um

Rt: 387.87 um

Measurement Info:

Magnification: 2.54

Measurement Mode: VSI

Sampling: $6.61 \mathrm{um}$

Array Size: 368 X 240

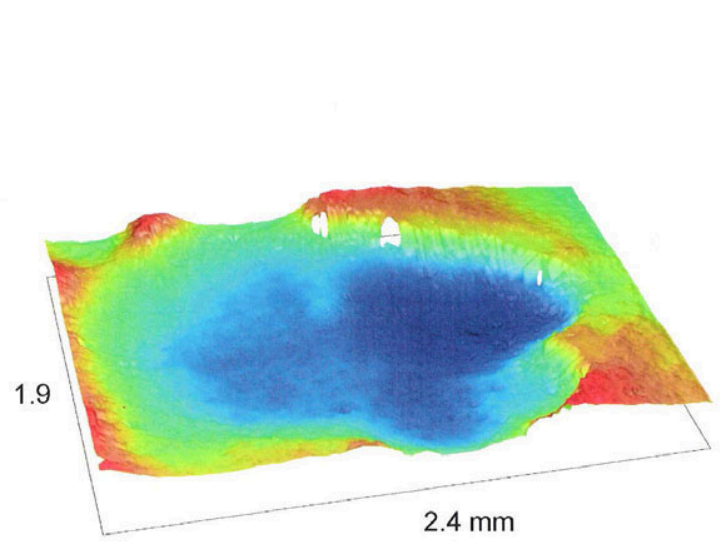

Date: 08/04/2004

Time: 13:30:22

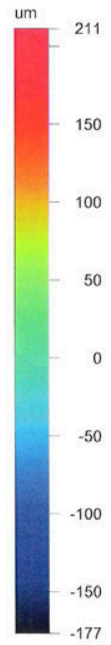

Title: CS\#3347-1

Note: 6 yr exposure 10' level
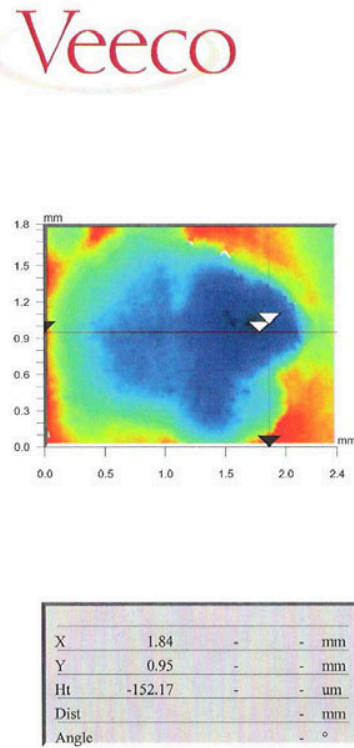

Title: CS\#3347-1

Note: 6 yr exposure 10' level

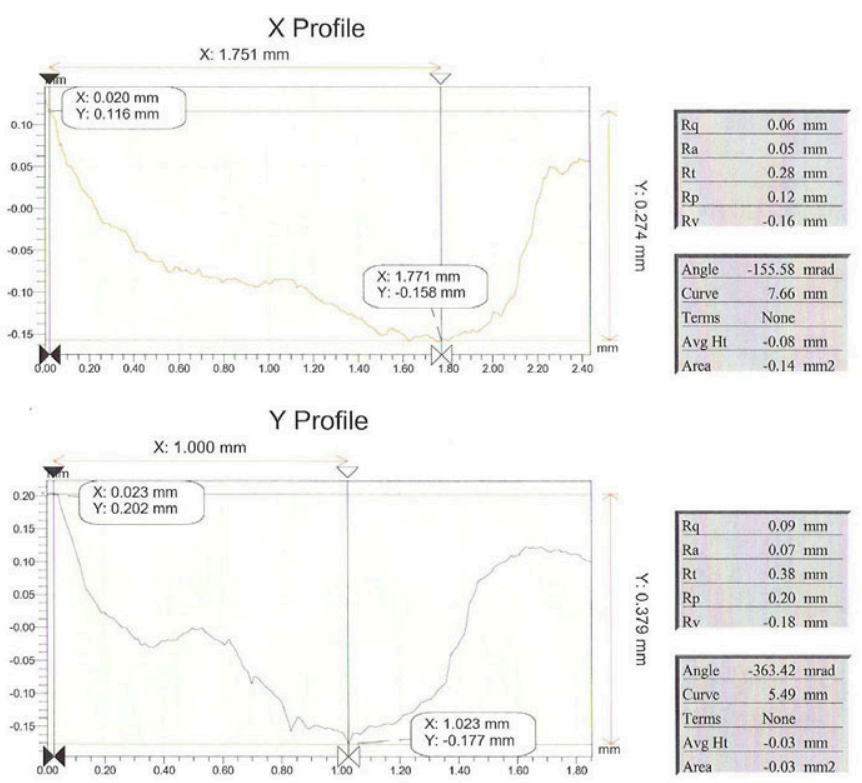




\section{Carbon Steel \#3347, 6-Year Exposure, 10 Ft Level}

(Continued)

\section{Veeco}

\section{3-Dimensional Interactive Display}

Time: 13:38:46

Surface Stats:

Ra: 23.82 um

Rq: 28.75 um

Rt: $151.11 \mathrm{um}$

Measurement Info:

Magnification: 2.54

Measurement Mode: VSI

Sampling: $6.61 \mathrm{um}$

Array Size: 368 X 240

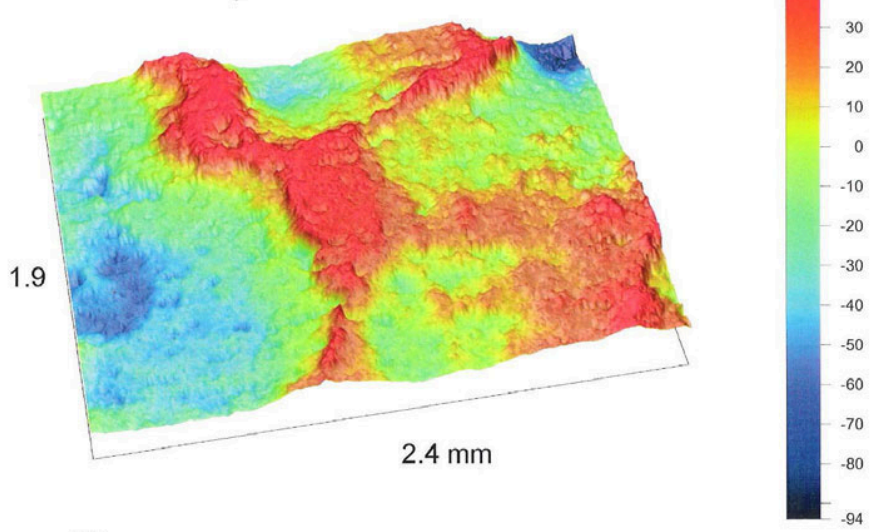

Title: CS\#3347-2 Area \#2

Note: 6 yr exposure
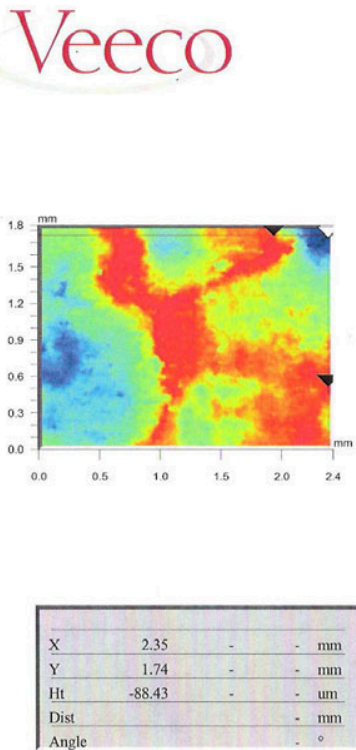

Title: CS\#3347-2 Area \#2

Note: 6 yr exposure

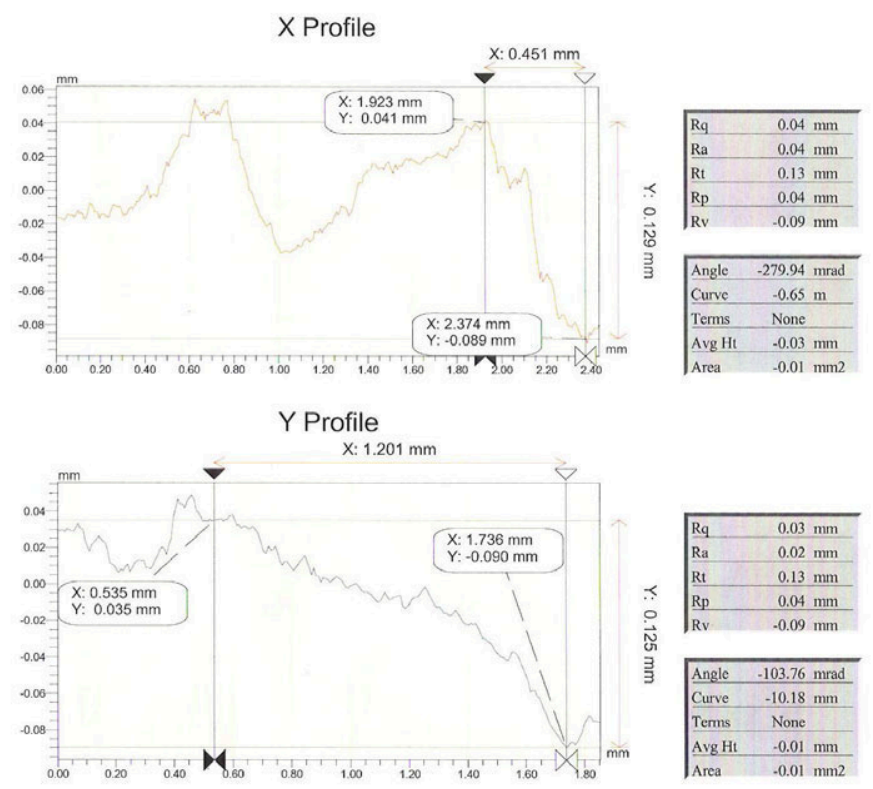




\section{VeeCo 3-Dimensional Interactive Display}

Surface Stats:

Ra: 50.55 um

Rq: 61.58 um

Rt: 339.93 um

Measurement Info:

Magnification: 2.54

Measurement Mode: VSI

Sampling: $6.61 \mathrm{um}$

Array Size: 368 X 240

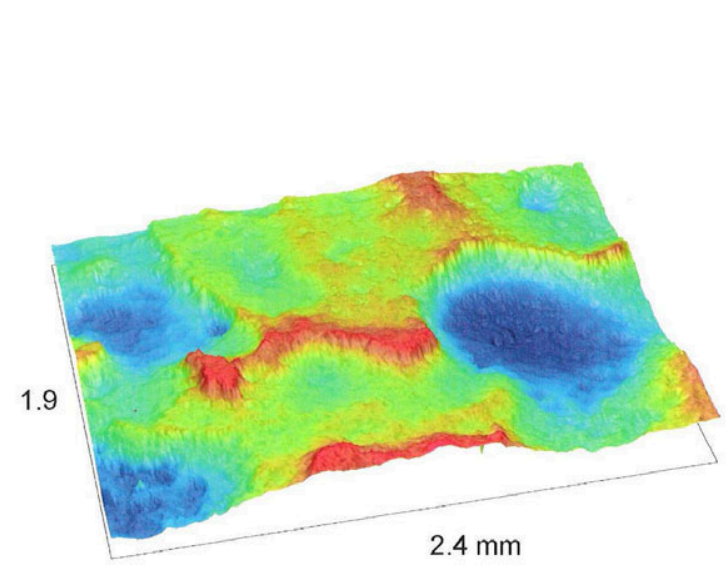

Date: 08/04/2004

Time: 13:55:05

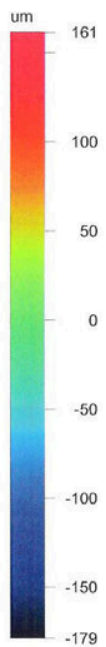

161

$-50$

$-150$

Title: CS\#3348-1

Note: 6 yr exposure $10^{\prime}$ level
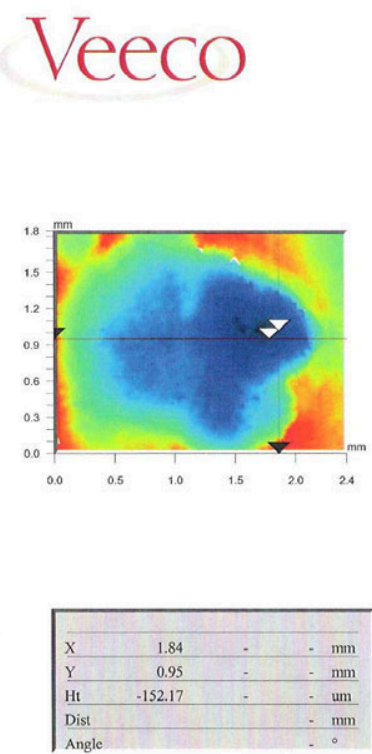

Title: CS\#3347-1
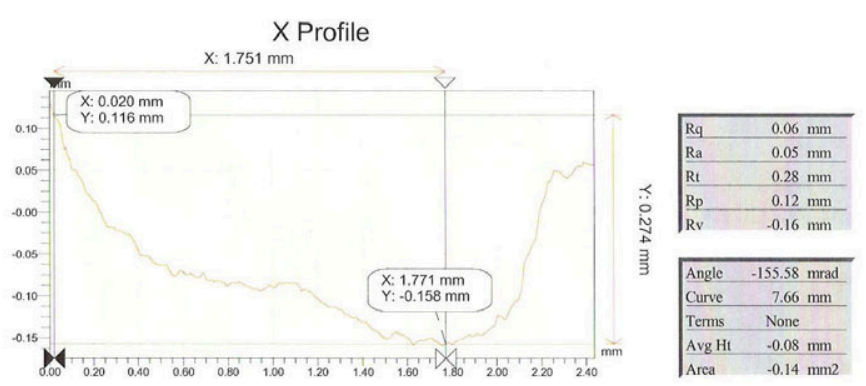

Y Profile

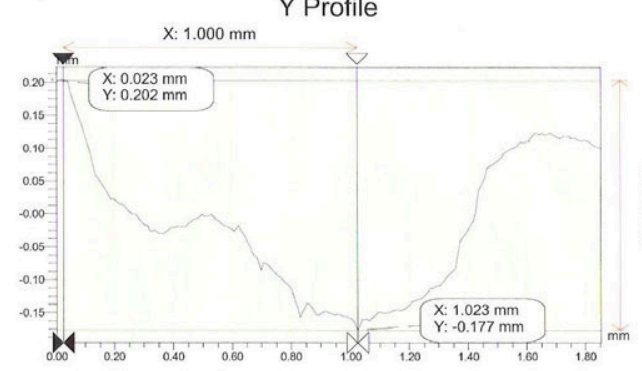

Note: 6 yr exposure $10^{\prime}$ level 
Carbon Steel \#3348, 6-Year Exposure, 10 Ft Level

(Continued)

\section{Veeco}

\section{3-Dimensional Interactive Display}

Surface Stats:

Ra: 61.14 um

Rq: $74.11 \mathrm{um}$

Rt: 388.90 um

Measurement Info:

Magnification: 2.54

Measurement Mode: VSI

Sampling: $6.61 \mathrm{um}$

Array Size: 368 X 240

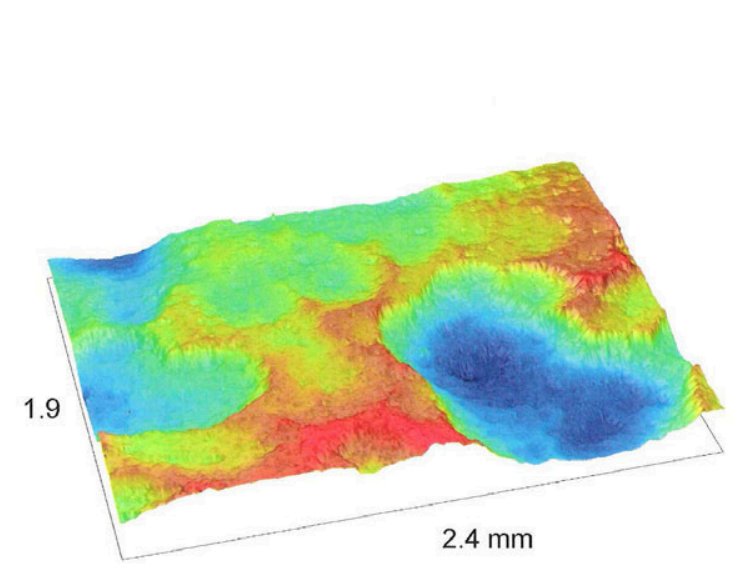

Date: $08 / 04 / 2004$

Time: 14:39:08

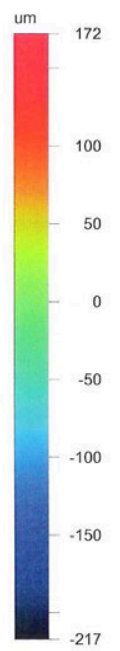

Title: CS\#3348-2

Note: 6 yr exposure 10 ' level

\section{Veeco}
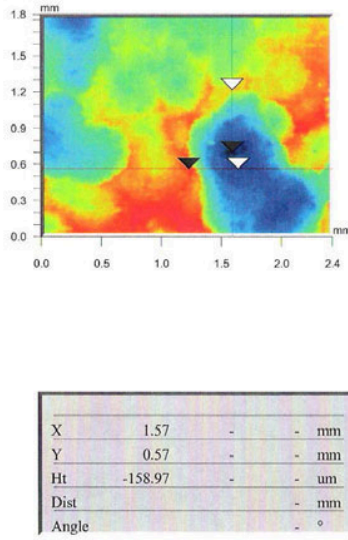

Title: CS\#3348-2

Note: 6 yr exposure 10' level

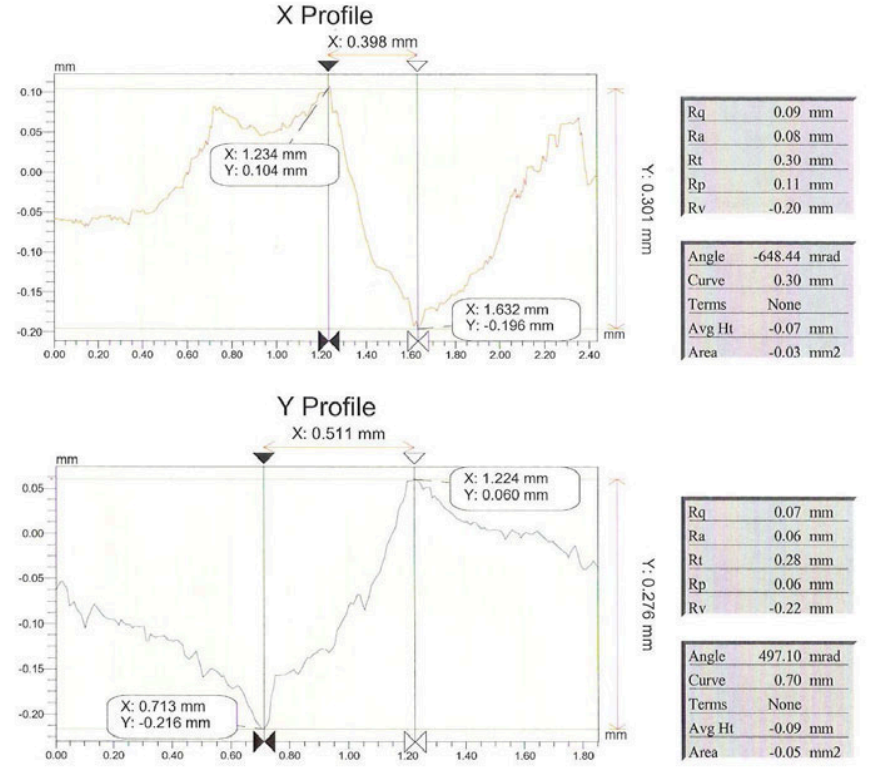

D-42 


\section{Veeco}

3-Dimensional Interactive Display

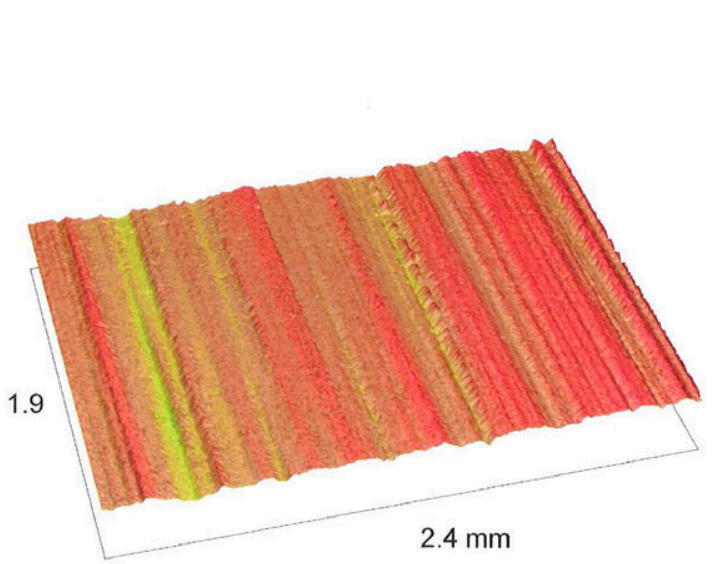

Date: 08/04/2004

Time: 14:46:46

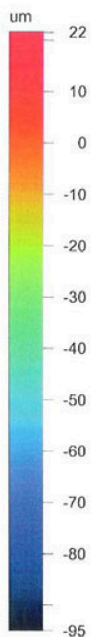

Title: CS\#3619 CIn Blank

Surface Stats:

Ra: 4.67 um

Rq: $5.85 \mathrm{um}$

Rt: 116.53 um

Measurement Info:

Magnification: 2.54

Measurement Mode: VSI

Sampling: $6.61 \mathrm{um}$

Array Size: 368 X 240

Note: 6 yr exposure

Veeco
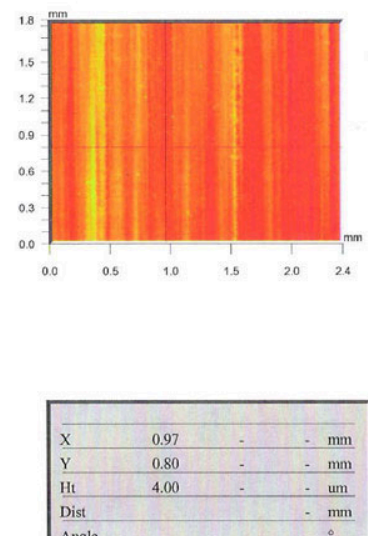

Title: CS\#3619 Cln Blank Note: 6 yr exposure

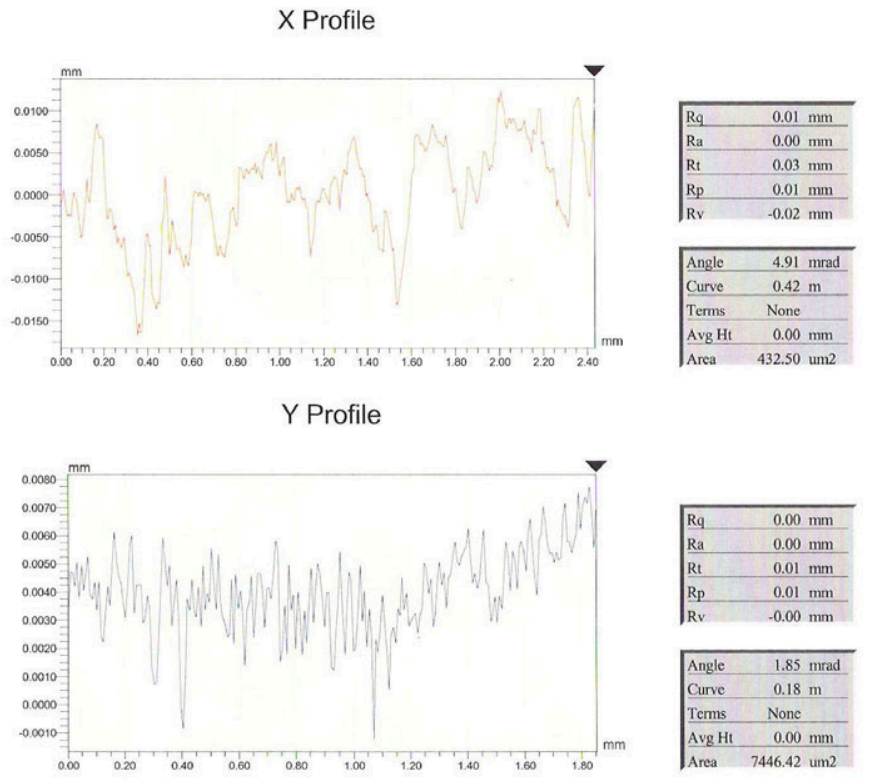

D-43 
(This page intentionally left blank.) 


\section{APPENDIX E}

\section{Beryllium Adhering Soil}

Soil adhering to the four 6-year exposed beryllium coupons from the 10-ft depth was collected for analysis. The samples were analyzed at the INEEL analytical laboratory for suspected corrosion products. Corrosion product analysis results, as reported by the analytical chemistry laboratory, follow in the first section of this appendix, 6-year adhering soil results.

Soil adhering to two of the four beryllium coupons exposed for 3 years from the $10-\mathrm{ft}$ depth was collected for analysis. The samples were analyzed at the INEEL analytical laboratory for suspected corrosion products. Corrosion product analysis results, as reported by the analytical chemistry laboratory, are in the second section of this appendix, 3-year adhering soil results.

Soil collected from the location of the 6-year removal at $10 \mathrm{ft}$ was also collected for analysis. The sample was analyzed at the INEEL analytical laboratory for background values for comparative purposes. Also, in the soil properties appendix (Appendix I), additional background corrosion berm sample results are available. The soil background was a core sample drilled at the berm and analyzed at Southwestern Research Institute. 
(This page intentionally left blank.) 


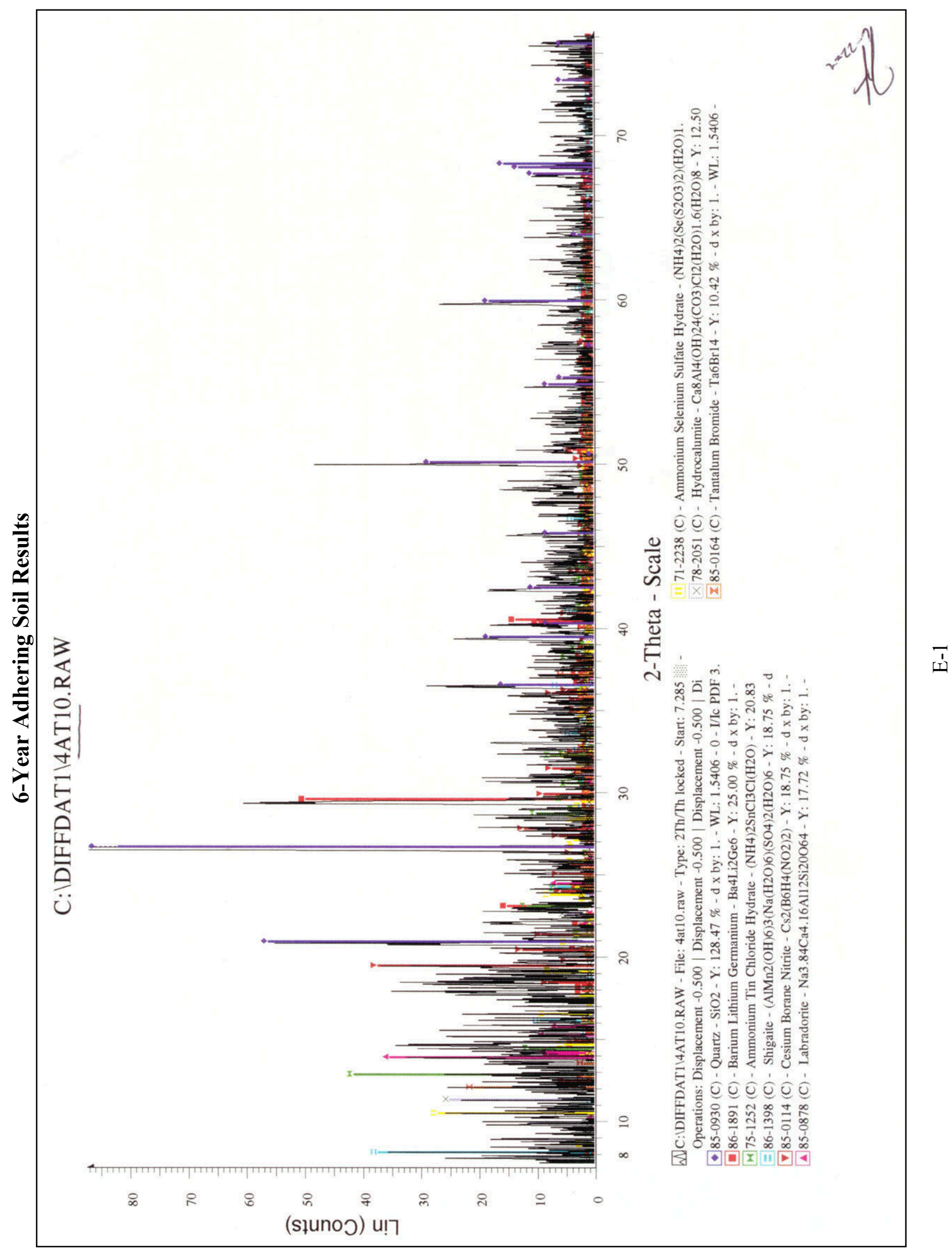




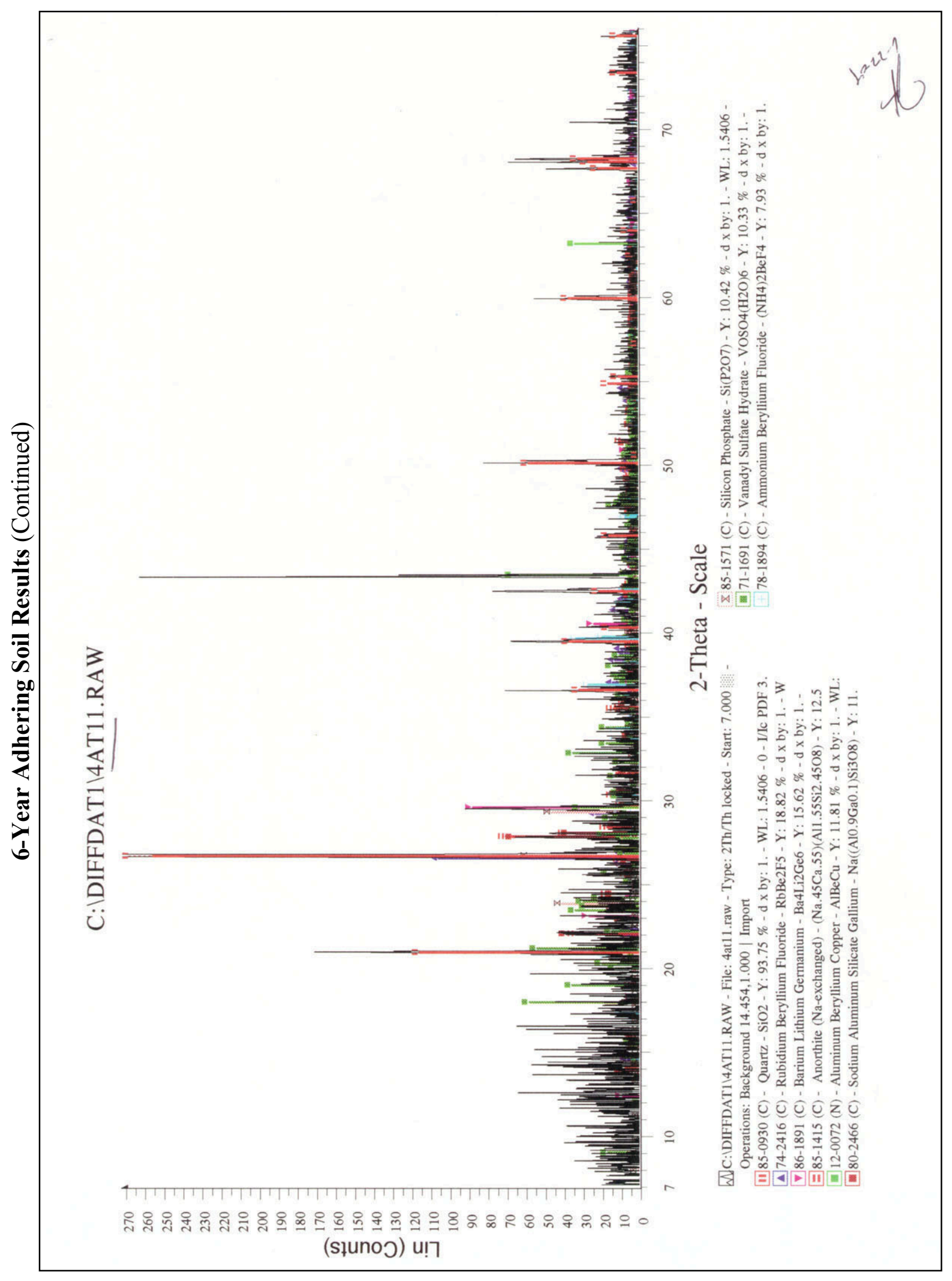

I
I 
6-Year Adhering Soil Results (Continued)

\author{
Bechtel BWXT Idaho, LIC \\ ANALYTICAI CHEMISTRY \\ SPECTROCHEMICAL ANALYSIS
}

Record No.
Analyzed By
Approved By
Sample Activity
Method

Log No. $\quad 0403227$

Project BE Dirt 2004

Charge No. 100665240

Requested BY TIM YODER

Page Number $\frac{1 \text { of } 1}{1}$
Sample Name

$4 \mathrm{AT} 10$

4 AT11

\section{$\underline{X-r a y ~ D i f f r a c t i o n ~ R e s u l t s ~}$}

$\mathbf{S i O}_{2}$-(Quartz) is the major crystalline component.

$\mathbf{B a}_{4} \mathbf{I i}_{2} \mathbf{G e}_{6}-$ (Barium Lithium Germanium), $\left(\mathrm{NH}_{4}\right)_{2} \mathrm{SnCl}_{3} \mathrm{Cl}\left(\mathrm{H}_{2} \mathrm{O}\right)$ - (Ammonium Tin Chloride Hydrate), $\left(\mathrm{AlMn}_{2}(\mathrm{OH})_{6}\right)_{3}\left(\mathrm{Na}\left(\mathrm{H}_{2} \mathrm{O}\right)_{6}\right)\left(\mathrm{SO}_{4}\right)_{2}\left(\mathrm{H}_{2} \mathrm{O}\right)_{6}-$ (Shigaite), $\mathbf{C s}_{\mathbf{2}}\left(\mathbf{B}_{6} \mathbf{H}_{\mathbf{4}}\left(\mathbf{N O}_{2}\right)_{\mathbf{2}}\right)-(\mathrm{Cesium}$ Borane Nitrite), $\mathbf{N a}_{3.84} \mathbf{C a}_{4.16} \mathbf{A l}_{12} \mathbf{S i}_{20} \mathbf{O}_{64}$ (Labradorite), $\left(\mathbf{N H}_{4}\right)_{2}\left(\mathrm{Se}\left(\mathbf{S}_{2} \mathrm{O}_{3}\right)_{2}\left(\mathrm{H}_{2} \mathrm{O}\right)_{1}\right.$ (Ammonium Selenium Sulfate Hydrate, $\mathrm{Ca}_{8} \mathrm{Al}_{4}(\mathrm{OH})_{24}\left(\mathrm{CO}_{3}\right) \mathrm{Cl}_{2}\left(\mathrm{H}_{2} \mathrm{O}\right)_{1.6}\left(\mathrm{H}_{2} \mathrm{O}\right)_{8}-$ (Hydrocalumite), and $\mathbf{T} \mathbf{a}_{\mathbf{6}} \mathbf{B} \mathbf{r}_{\mathbf{1 4}}$-(Tantalum Bromide) are possibly present as minor components. Minor unidentified crystalline material is also possibly present.

$\mathbf{S i O}_{2}-($ Quartz) is the major crystalline component.

$\mathbf{R b B e}_{\mathbf{2}} \mathbf{F}_{\mathbf{5}}$ - (Rubidium Beryllium Fluoride), $\mathbf{B a}_{4} \mathbf{L i}_{2} \mathbf{G e}_{6}$ (Barium Lithium Germanium), ( $\left.\mathrm{Na} .{ }_{45} \mathrm{Ca} .55\right)\left(\mathrm{Al}_{1.55} \mathrm{Si}_{2.45} \mathrm{O}_{8}\right.$ ) - (Anorthite$\mathrm{Na}$-exchanged), AlBeCu-(Aluminum Beryllium Copper), $\mathbf{N a}\left(\left(\mathbf{A l}_{0.9} \mathbf{G a}_{0.1}\right) \mathbf{S i}_{3} \mathrm{O}_{8}\right)-$ (Sodium Aluminum Silicate Gallium), Si $\left(\mathbf{P}_{\mathbf{2}} \mathbf{O}_{7}\right)$ - (Silicon Phosphate), voso $_{4}\left(\mathrm{H}_{2} \mathrm{O}_{6}-(\right.$ Vanadyl Sulfate Hydrate), and $\left(\mathrm{NH}_{4}\right)_{2} \mathrm{BeF}_{\mathbf{4}}-$ (Ammonium Berylitum Fluoride) are possibly present as minor components. Minor unidentified crystalline material is also possibly present.

Composite soil sample from adhering soils, beryllium coupons exposed 6 years at the $10-\mathrm{ft}$ level. 


\section{6-Year Adhering Soil Results (Continued)}

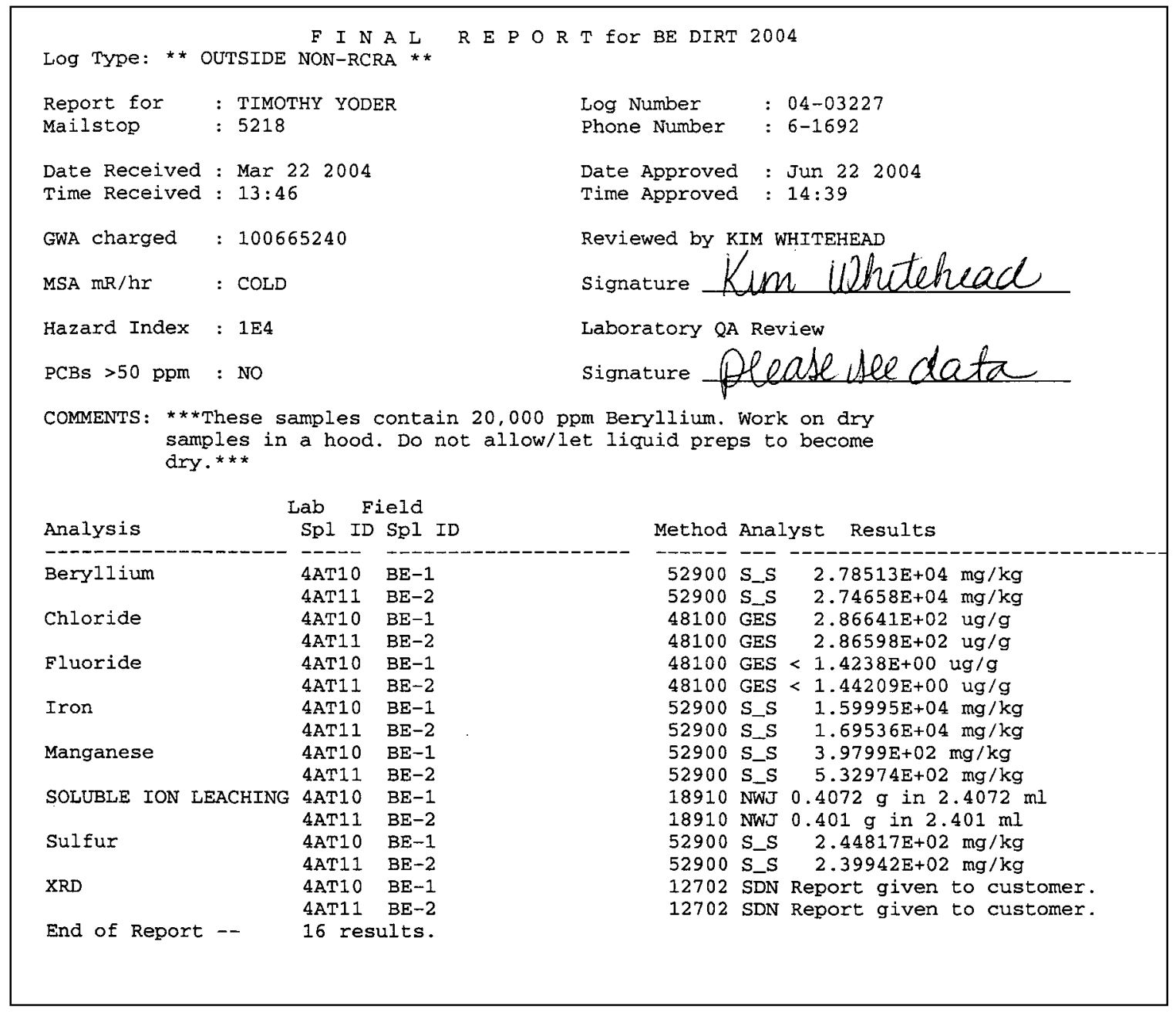




\section{3-Year Adhering Soil Results}

Analytical chemistry spectrochemical analysis.

\begin{tabular}{|c|c|c|c|}
\hline Record No. & $\underline{01-\mathrm{D}-3}$ & Log No. & $\underline{0102204}$ \\
\hline Analyzed by & $\underline{\mathrm{BRB}}$ & Project & $\underline{\text { Be Soil }}$ \\
\hline Sample activity & $\underline{\text { none }}$ & Method & $12702 \mathrm{XRD}$ \\
\hline Sample Name & & \multicolumn{2}{|l|}{ X-ray Diffraction Results } \\
\hline Be Dirt & & \multicolumn{2}{|c|}{$\begin{array}{l}\mathrm{SiO}_{2}(\mathrm{Quartz}) \text { is the major crystalline component of this sample. } \\
\mathrm{CaCO}_{3}(\mathrm{Calcite}) \text { and } \mathrm{Na}\left(\mathrm{AlSi}_{3} \mathrm{O}_{8}\right) \text { (Albite) are present as } \\
\text { minors. The following compounds are possibly present: } \mathrm{SiO}_{2} \text {, } \\
\left.\left(\mathrm{Na}_{0.75} \mathrm{~K}_{0.25}\right)\left(\mathrm{AlSi}_{3} \mathrm{O}_{8}\right) \text { Anorthoclase }\right), \mathrm{CaMgSi}_{2} \mathrm{O}_{6}(\mathrm{Diopside} \text {, } \\
\mathrm{Na}_{2} \mathrm{BeSi}_{2} \mathrm{O}_{6}(\mathrm{Chkalovite}) \text { and } \mathrm{Cu}_{0.6} \mathrm{Fe}_{1.4} \mathrm{Ni}_{0.65} \mathrm{Zn}_{0.35} \mathrm{O}_{4} \text {. Minor } \\
\text { unidentified components are present. Amorphous material is } \\
\text { present. }\end{array}$} \\
\hline
\end{tabular}

Analytical chemistry analysis final report for Be-dirt.

\begin{tabular}{|c|c|c|c|c|c|}
\hline Log Number & $\underline{01-02204}$ & Date Received & February 20,2001 & \multicolumn{2}{|c|}{ Date Approved April 18,2001 } \\
\hline MSA mR/hr & COLD & Hazard Index & $\underline{1 \mathrm{E} 4}$ & \multicolumn{2}{|c|}{$\mathrm{PCBs}>50 \mathrm{ppm} \underline{\mathrm{NO}}$} \\
\hline Analysis & Lab Spl ID & Field Spl ID & Method & Analyst & Results \\
\hline Beryllium & $1 \mathrm{AI} 26$ & DIRT SN-15, SN-16 & 42900 & RHH & $1.95766 \mathrm{E}+04 \mathrm{mg} / \mathrm{kg}$ \\
\hline Chloride & $1 \mathrm{AI} 26$ & DIRT SN-15, SN-16 & 28202 & NWJ & $3.51713 \mathrm{E}+01 \mathrm{ug} / \mathrm{ml}$ \\
\hline Flouride & 1AI26 & DIRT SN-15, SN-16 & 28201 & NWJ & $1.26405 \mathrm{E}-01 \mathrm{ug} / \mathrm{ml}$ \\
\hline Iron & $1 \mathrm{AI} 26$ & DIRT SN-15, SN-16 & 42900 & RHH & $1.94574 \mathrm{E}+04 \mathrm{mg} / \mathrm{kg}$ \\
\hline Manganese & $1 \mathrm{AI} 26$ & DIRT SN-15, SN-16 & 42900 & $\mathrm{RHH}$ & $4.38343 \mathrm{E}+02 \mathrm{mg} / \mathrm{kg}$ \\
\hline Sulfur & 1AI26 & DIRT SN-15, SN-16 & 42900 & $\mathrm{RHH}$ & $2.28941 \mathrm{E}+02 \mathrm{mg} / \mathrm{kg}$ \\
\hline
\end{tabular}




\section{Blank Soil Results}

\begin{tabular}{|c|c|c|c|c|c|}
\hline \multicolumn{6}{|c|}{ I N T E R I M R E P O R T for DIRT BLANK 2004} \\
\hline \multicolumn{6}{|c|}{ Log Type: ** OUTSIDE NON-RCRA ** } \\
\hline \multirow{2}{*}{\multicolumn{3}{|c|}{$\begin{array}{ll}\text { Report for } & : \text { SEE COMMENT } \\
\text { Mailstop } & : 4129\end{array}$}} & \multicolumn{3}{|c|}{ Log Number : 04-08102 } \\
\hline & & & Phone Nur & ber : 6- & \\
\hline \multicolumn{6}{|c|}{ Date Received : Aug 102004} \\
\hline \multicolumn{6}{|c|}{ Time Received : 10:07 } \\
\hline \multicolumn{6}{|c|}{ MSA mR/hr : COLD } \\
\hline \multicolumn{6}{|c|}{ COMMENTS: Send report to Timothy Yoder, MS 5218 and Kay Alder Flitton MS 3790.} \\
\hline Analysis & Lab Spl ID & Field Spl ID & Method & Analyst & Results \\
\hline Beryllium & $4 \mathrm{BZ45}$ & DIRT BLANK 2004 & 52900 & S S & $9.30752 \mathrm{E}-02 \mathrm{mg} / \mathrm{kg}$ \\
\hline Chloride & $4 \mathrm{BZ} 45$ & DIRT BLANK 2004 & 28100 & $\overline{C L D}$ & $<2.02646 \mathrm{E}-03 \mathrm{mg} / \mathrm{g}$ \\
\hline Fluoride & $4 \mathrm{BZ} 45$ & DIRT BLANK 2004 & 28100 & CLD & $<1.01679 \mathrm{E}-03 \mathrm{mg} / \mathrm{g}$ \\
\hline Iron & $4 \mathrm{BZ} 45$ & DIRT BLANK 2004 & 52900 & S_S & $9.1402 \mathrm{E}+03 \mathrm{mg} / \mathrm{kg}$ \\
\hline Manganese & $4 \mathrm{BZ} 45$ & DIRT BLANK 2004 & 52900 & $\mathrm{~S} S \mathrm{~S}$ & $1.89183 \mathrm{E}+01 \mathrm{mg} / \mathrm{kg}$ \\
\hline Sulfur & 4BZ45 & DIRT BLANK 2004 & 52900 & S_S & $6.65488 \mathrm{E}+01 \mathrm{mg} / \mathrm{kg}$ \\
\hline \multicolumn{6}{|c|}{ End of Report -- $\quad 6$ results. } \\
\hline
\end{tabular}




\section{APPENDIX F}

\section{Scanning Electron Microscope Images Of Beryllium Coupons}

As the corrosion test has progressed, the corrosion of beryllium has become more interesting. When this test started, corrosion data for beryllium was limited to aqueous and atmospheric environments. Corrosion of beryllium in soil had never been conducted. To help understand the corrosion products, as well as the corroded surface chemical and physical properties, the scanning electron microscope was used. Six-year exposed beryllium coupons were examined along with archived 1-and 3-year samples and beryllium coupons that had never been in the soil environment. This appendix consists of scanning electron microscope images, spectra of some of the images and details from the spectrums. Some of the images are reduced and placed together for ease of visual comparison. 
(This page intentionally left blank.) 
Archived Beryllium Coupon Blank (No Exposure)
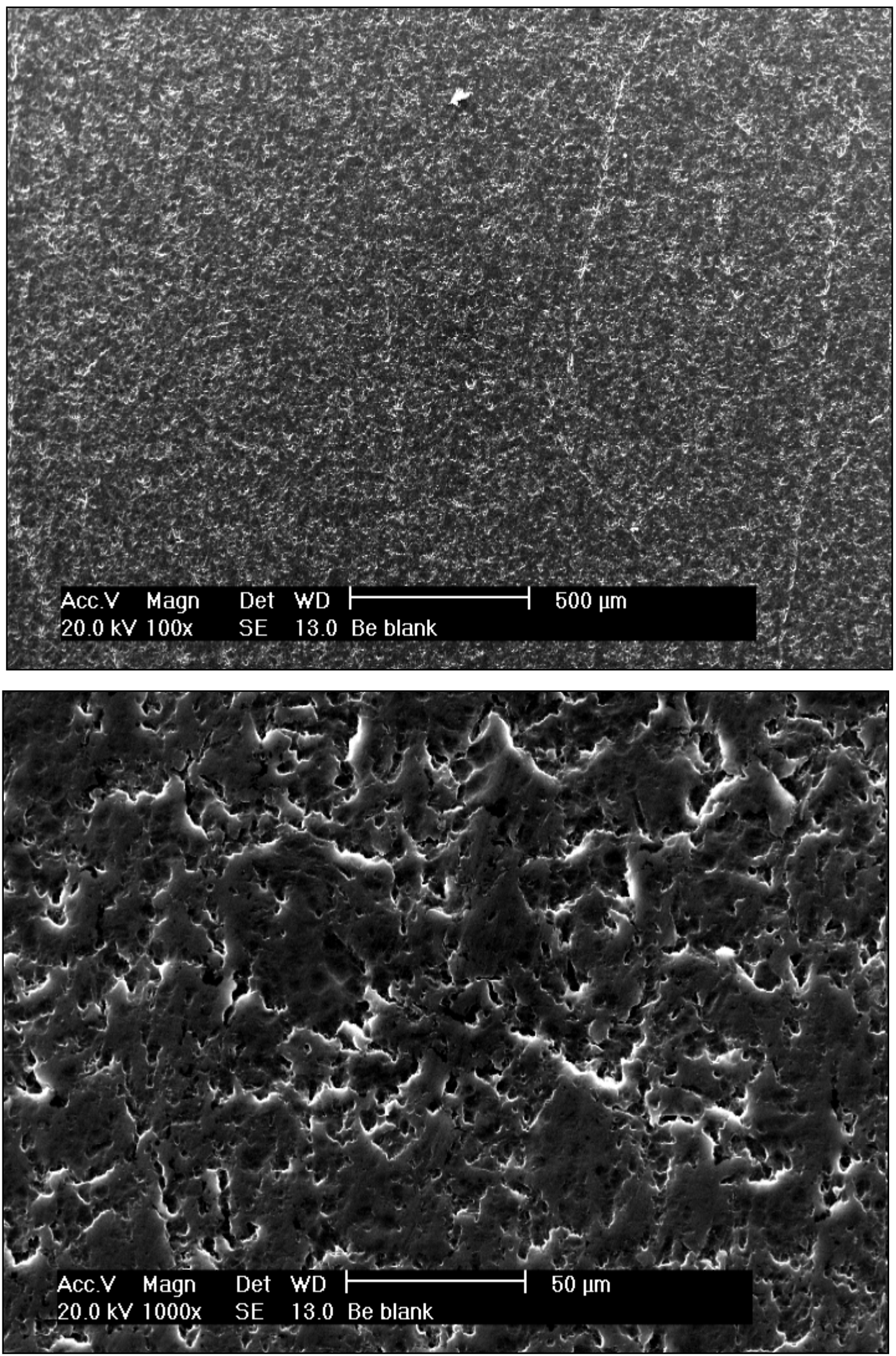


\section{Archived Beryllium Coupon Blank (No Exposure) \\ (Continued)}

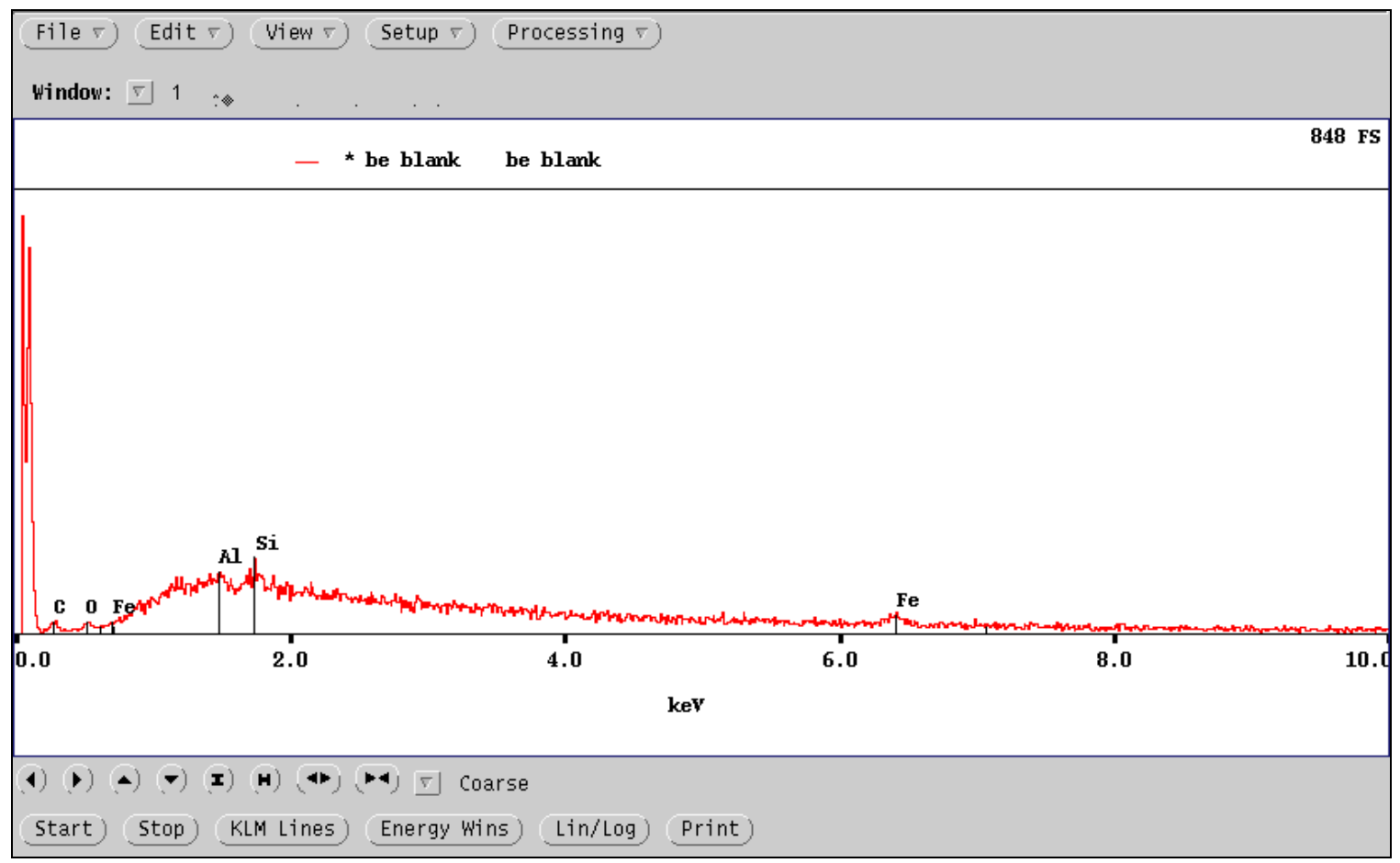

PGT Bulk sample analysis Wed Jul 28 16:04:41 2004

ZAF Method, variable-width filter

Sample /xd1/window1/\#1,/be blank.spt

Accelerating Voltage: $\quad 15.00 \mathrm{keV}$

Takeoff Angle: $\quad 32.00$ degrees

Library for system standards: /imix/quant/rhodonite efficiency

\begin{tabular}{|c|c|c|c|c|c|c|c|c|}
\hline Elm & Rel. K & $\mathrm{Z}$ & $\mathrm{A}$ & $\mathrm{F}$ & Norm wt \% & Atomic $\%$ & Method used & Line \\
\hline $\mathrm{Si}$ & 0.0355 & 1.017 & 1.403 & 1.000 & 5.07 & 3.39 & From spectrum & $\mathrm{K}$ line \\
\hline $\mathrm{C}$ & 0.0460 & 0.947 & 3.352 & 0.999 & 14.59 & 22.81 & From spectrum & $\mathrm{K}$ line \\
\hline$\overline{\mathrm{Al}}$ & 0.0230 & 1.043 & 1.599 & 0.998 & 3.83 & 2.68 & From spectrum & $\mathrm{K}$ line \\
\hline $\mathrm{Fe}$ & 0.1913 & 1.165 & 0.992 & 1.000 & 22.11 & 7.42 & From spectrum & $\mathrm{K}$ line \\
\hline $\mathrm{O}$ & 0.0000 & 0.000 & 0.000 & 0.000 & 54.40 & 63.72 & Stoichiometry & $\mathrm{K}$ line \\
\hline \multicolumn{5}{|l|}{ Total } & 100.00 & 100.02 & & \\
\hline $\begin{array}{l}\text { oxyge } \\
\text { Goodr } \\
\text { WAR } \\
\text { WAR } \\
\text { WAR }\end{array}$ & $\begin{array}{l}\text { nalyzed by } \\
\text { of fit } \\
\text { JG: Resid } \\
\text { JG: Resid } \\
\text { JG: Resid }\end{array}$ & $\begin{array}{l}\text { oichion } \\
1 \\
\text { peak a } \\
\text { peak a } \\
\text { peak a }\end{array}$ & $\begin{array}{l}\text { ry } \\
\text { oproxim } \\
\text { oproxim } \\
\text { oproxim }\end{array}$ & $\begin{array}{lc}\text { ely } & 88 \\
\text { ely } & 116 \\
\text { ely } & 427\end{array}$ & & & & \\
\hline
\end{tabular}




\section{Beryllium Coupon Images - Blanks}
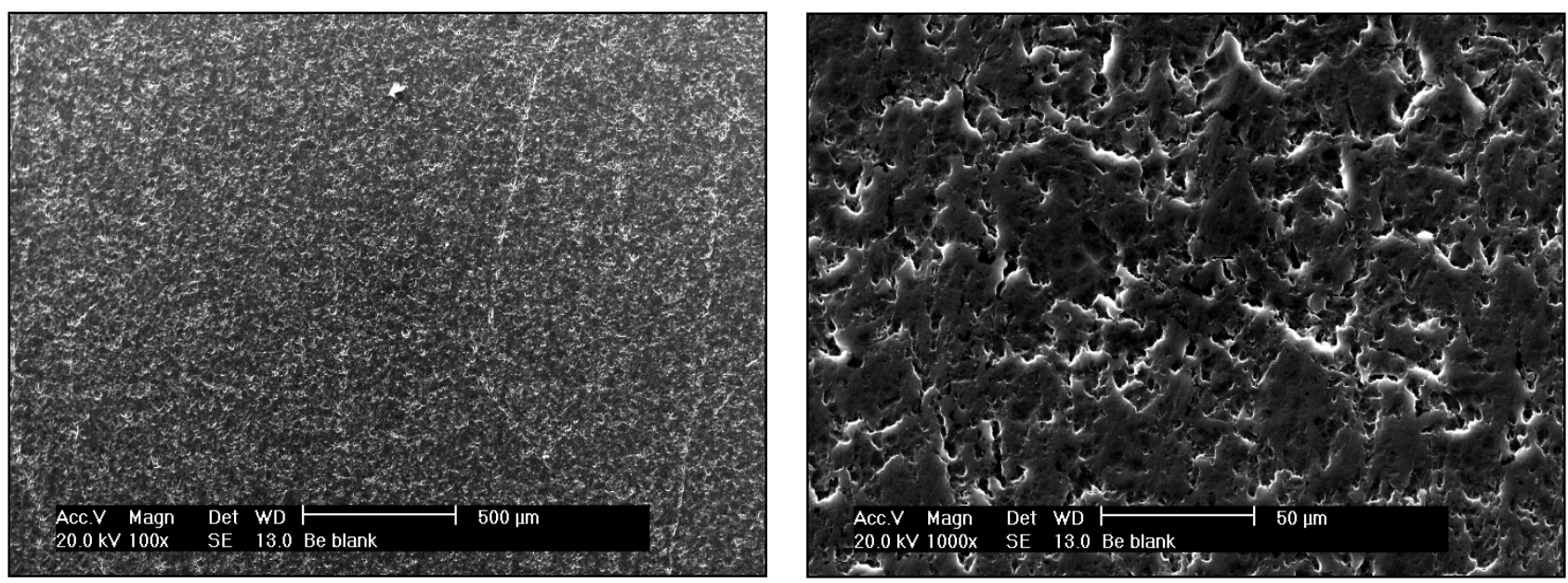

Beryllium coupons in an as received state.
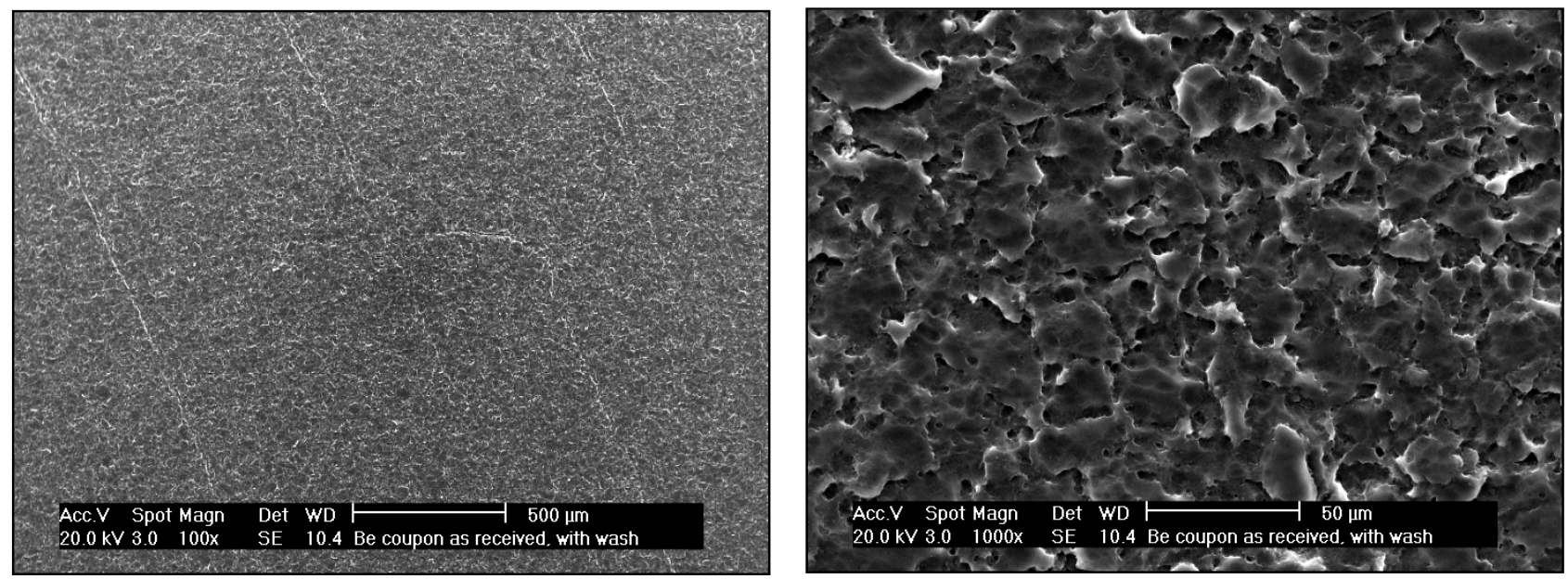

Beryllium coupons that have been washed after receiving.

The beryllium coupons, in an as received state, have a 125 Root Mean Square (RMS) finish. This is the same surface finish as specified for the Advanced Test Reactor beryllium reflectors some of which are disposed at the SDA. The coupons in the corrosion test berm are placed "as received." When the "as received" images are compared with the as received with wash, the angularity of the surface edges is noticeably softened. 


\section{Beryllium Coupon - As Received}

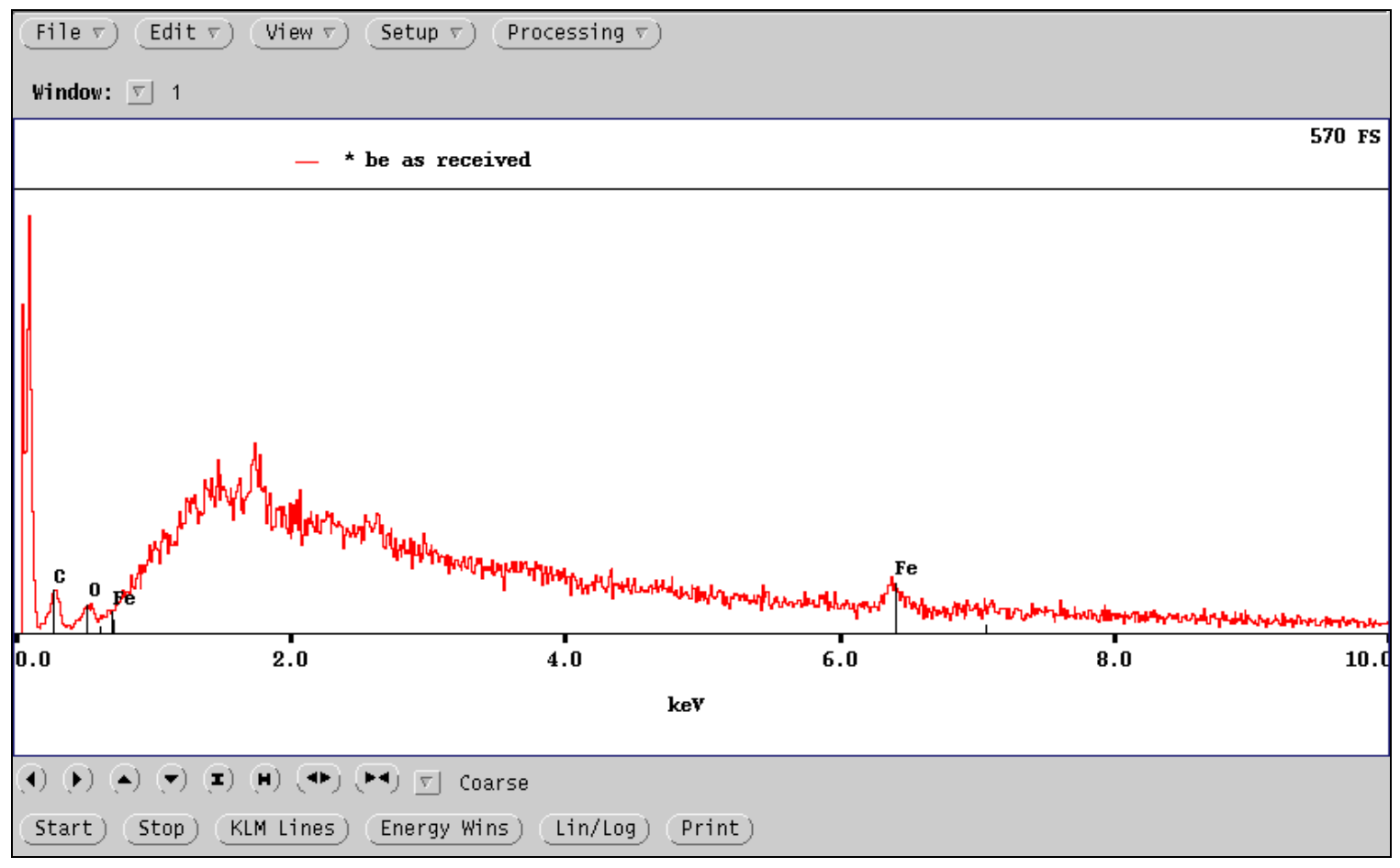

PGT Bulk sample analysis Tue Aug 24 21:32:27 2004

ZAF Method, variable-width filter

Sample /xd1/window1/\#1, /be as received.spt

Accelerating Voltage: $\quad 15.00 \mathrm{keV}$

Takeoff Angle: $\quad 32.00$ degrees

Library for system standards: /imix/quant/rhodonite efficiency

\begin{tabular}{|l|c|c|c|c|c|c|l|l|}
\hline \multicolumn{1}{|c|}{ Elm } & Rel. K & $\mathrm{Z}$ & $\mathrm{A}$ & $\mathrm{F}$ & Norm wt\% & Atomic $\%$ & Method used & Line \\
\hline $\mathrm{C}$ & 0.0681 & 0.940 & 2.574 & 0.999 & 16.46 & 26.22 & From spectrum & K line \\
\hline $\mathrm{Fe}$ & 0.2696 & 1.154 & 0.991 & 1.000 & 30.84 & 10.59 & From spectrum & K line \\
\hline $\mathrm{O}$ & 0.0000 & 0.000 & 0.000 & 0.000 & 52.70 & 63.06 & Stoichiometry & K line \\
\hline Total & \multicolumn{10}{|c|}{100.00} & 99.875 & & \\
\hline \\
Oxygen analyzed by stoichiometry \\
Goodness of fit 1.22 \\
WARNING: Residual peak at approximately $1281 \mathrm{ev}$ \\
WARNING: Residual peak at approximately $1739 \mathrm{ev}$ \\
\hline
\end{tabular}




\section{Beryllium \#2, 1-yr Exposure - 4 ft. (archived for 5 years)}
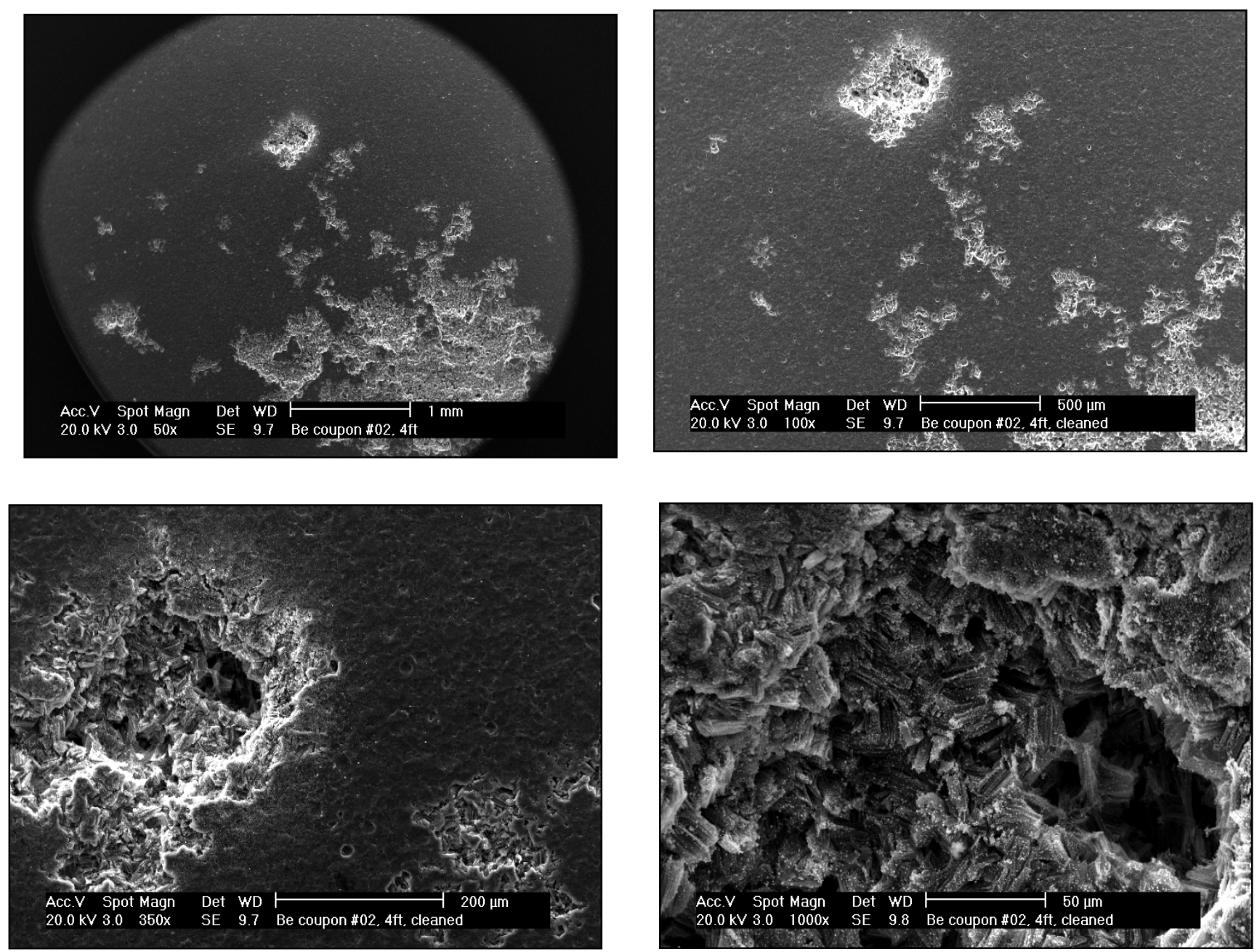

In these four images, one pit has been singled out and enhanced. Of note is the pronounced presence of a white material in the pitted area of the coupon. This white material is not present on the images from the 3-or 6-year exposed coupons. 


\title{
Beryllium \#2, 1-yr Exposure - 4 ft. (archived for 5 years)
}

\author{
(Continued)
}

Area of the corrosion pit with the white material.

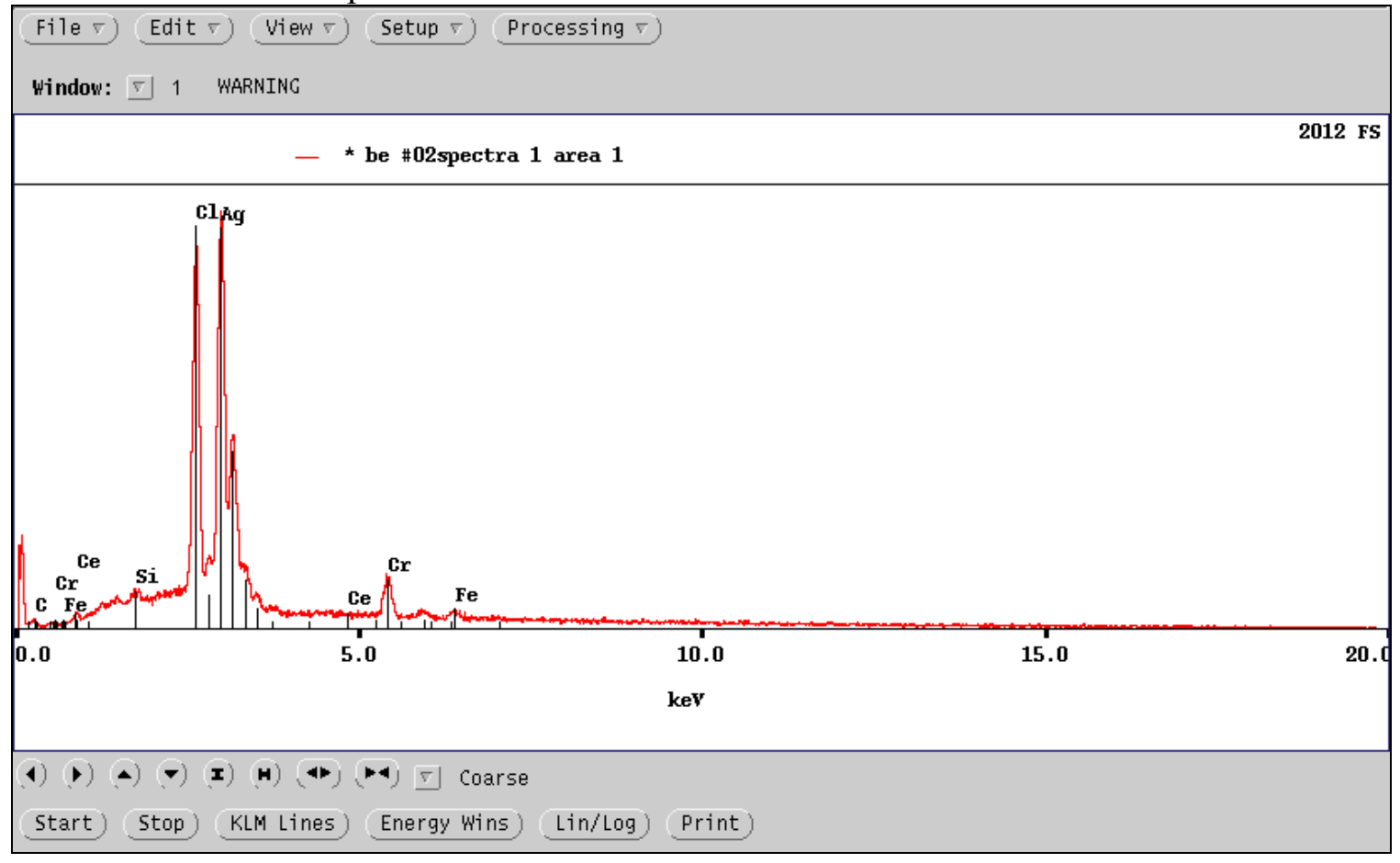

\begin{tabular}{|c|c|c|c|c|c|c|c|c|}
\hline PGT E & alk sampl & analys & $\mathrm{s} \quad \mathrm{Tu}$ & Aug 24 & $21: 45: 48200$ & & & \\
\hline ZAF N & ethod, var & iable-w & idth filte & & & & & \\
\hline Sampl & /xd1/win & low1/\#1 & , be \#02 & pectra 1 & area $1 . s p t$ & & & \\
\hline Accele & ating Vol & age: & 15.00 & $\mathrm{keV}$ & & & & \\
\hline Takeo & f Angle: & & $32.00 \mathrm{~d}$ & grees & & & & \\
\hline Librar & for systel & n stande & rds: /im & /quant/r & hodonite effic & ency & & \\
\hline Elm & Rel. K & $\mathrm{Z}$ & A & $\mathrm{F}$ & Norm $w t \%$ & Atomic \% & Method used & Line \\
\hline $\mathrm{C}$ & 0.0027 & 0.780 & 3.456 & 1.000 & 0.73 & 4.42 & From spectrum & $\mathrm{K}$ line \\
\hline $\mathrm{Cr}$ & 0.0634 & 0.931 & 1.134 & 0.999 & 6.68 & 9.30 & From spectrum & $\mathrm{K}$ line \\
\hline $\mathrm{Fe}$ & 0.0202 & 0.926 & 1.081 & 1.000 & 2.02 & 2.62 & From spectrum & $\mathrm{K}$ line \\
\hline $\mathrm{Ce}$ & 0.0000 & 1.135 & 1.130 & 0.999 & 0.00 & 0.00 & From spectrum & L line? \\
\hline $\mathrm{Si}$ & 0.0022 & 0.810 & 1.527 & 0.989 & 0.27 & 0.72 & From spectrum & $\mathrm{K}$ line \\
\hline $\mathrm{Cl}$ & 0.1714 & 0.876 & 1.144 & 0.953 & 16.38 & 33.43 & From spectrum & $\mathrm{K}$ line \\
\hline $\mathrm{Ag}$ & 0.6662 & 1.052 & 1.056 & 0.999 & 73.92 & 49.57 & From spectrum & L line \\
\hline Total & & & & & 100.00 & 100.06 & & \\
\hline Goodn & sss of fit & 5.35 & & & & & & \\
\hline & & & $\mathrm{Or}_{\mathrm{nr}}$ & & & & & \\
\hline WARI & ING: Res & dual $\mathrm{p}$ & k at ap & pximate & у $1479 \mathrm{ev}$ & & & \\
\hline WARI & ING: Res & & & & y $1791 \mathrm{ev}$ & & & \\
\hline WARI & ING: Res & dual $p$ & $\mathrm{k}$ at ap & oximat & y $1916 \mathrm{ev}$ & & & \\
\hline WARI & ING: Res & idual pe & ak at app & oximate & y $2062 \mathrm{ev}$ & & & \\
\hline
\end{tabular}




\section{Beryllium \#2, 1-yr Exposure - 4 ft. (archived for 5 years)}

\section{(Continued)}

Area of the coupon not affected by corrosion.

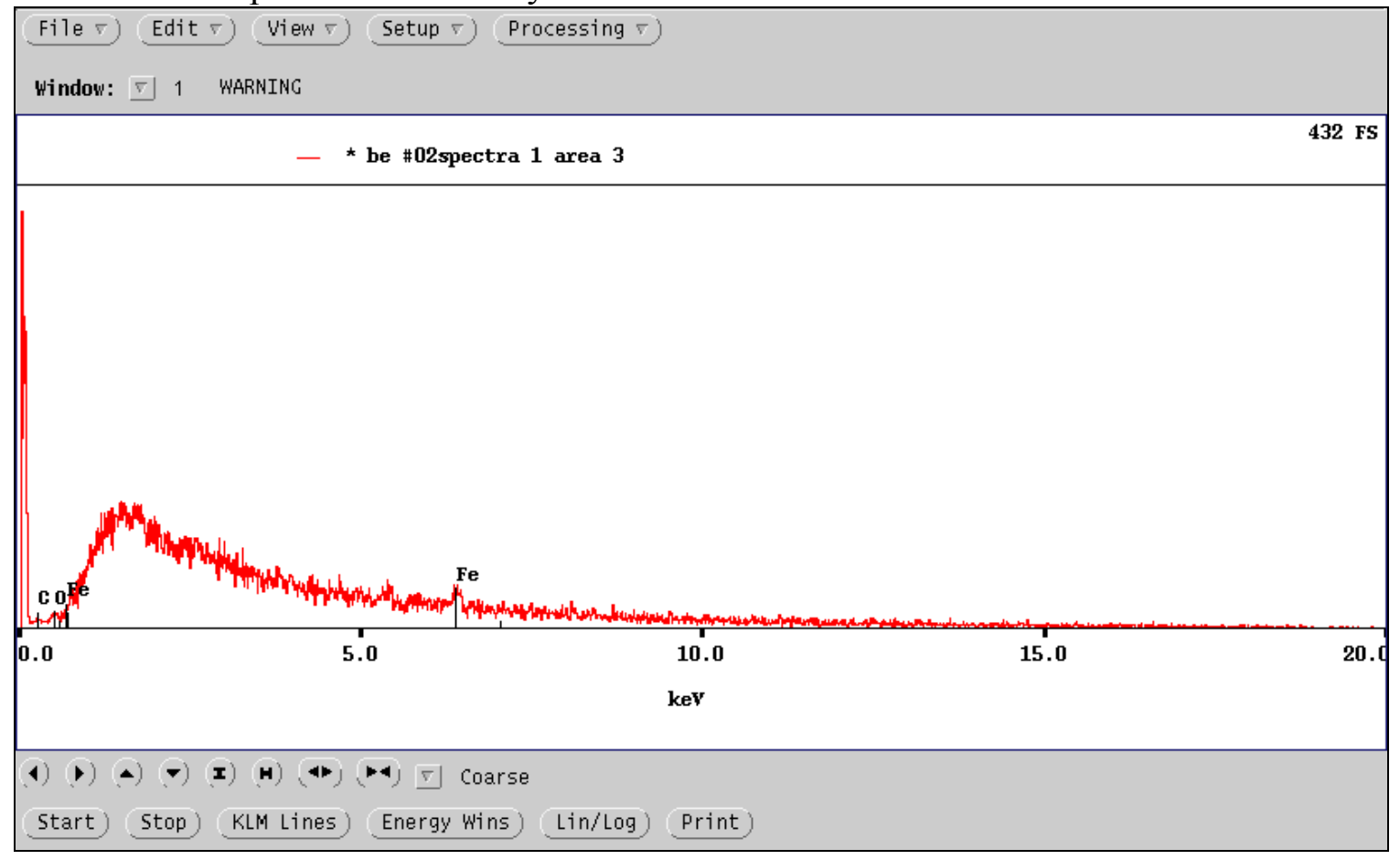

PGT Bulk sample analysis Tue Aug 24 21:41:30 2004

ZAF Method, variable-width filter

Sample /xd1/window1/\#1, /be \#02spectra 1 area 3. spt

Accelerating Voltage: $\quad 15.00 \mathrm{keV}$

Takeoff Angle: $\quad 32.00$ degrees

Library for system standards: /imix/quant/rhodonite efficiency

\begin{tabular}{|c|c|c|c|c|c|c|c|c|}
\hline Elm & Rel. K & $\mathrm{Z}$ & A & $\mathrm{F}$ & Norm wt $\%$ & Atomic $\%$ & Method used & Line \\
\hline $\mathrm{C}$ & 0.0363 & 0.912 & 2.997 & 0.999 & 9.91 & 19.40 & From spectrum & $\mathrm{K}$ line \\
\hline $\mathrm{Fe}$ & .4470 & 1.114 & 0.994 & 1.00 & 49.50 & 20.86 & From spectrum & $\mathrm{K}$ line \\
\hline $\mathrm{O}$ & 0.0000 & 0.000 & 0.000 & 0.000 & 40.59 & 59.57 & Stoichiometry & $\mathrm{K}$ line \\
\hline \multicolumn{5}{|l|}{ Total } & 100.00 & 99.83 & & \\
\hline
\end{tabular}

oxygen analyzed by stoichiometry

Goodness of fit 0.80

? Marks elements with poor precision.

WARNING: Residual peak at approximately $2177 \mathrm{ev}$

WARNING: Residual peak at approximately $2604 \mathrm{ev}$

WARNING: Residual peak at approximately $3812 \mathrm{ev}$ 


\section{Beryllium \#2, 1-yr Exposure - 4 ft. (archived for 5 years)}

(Continued)
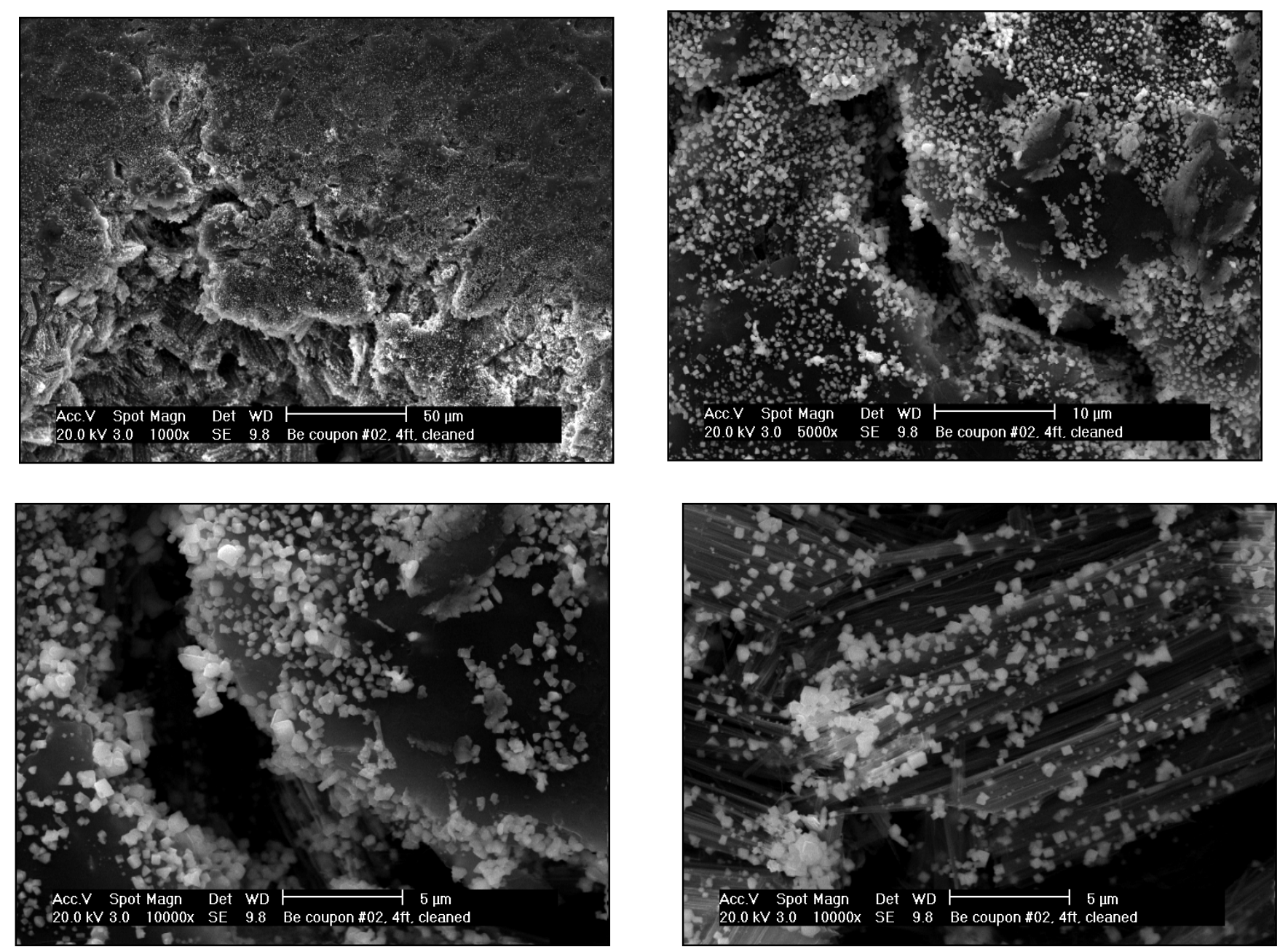

Higher magnification of the pitted area of the beryllium coupon shows the white material to be a cubic crystalline structure. The 1-year exposed coupons were cleaned using ASTM G 1, C.5.1. The beryllium vendor recommended the cleaning procedure for magnesium or aluminum be used to clean the corrosion products from the beryllium. The magnesium (C.5.1) cleaning procedure uses a silver salt, silver chromate $\left(\mathrm{Ag}_{2} \mathrm{CrO}_{4}\right)$, to precipitate chloride. The spectrum of this area shows prominent peaks of both silver and chloride. The white cubic crystals are consistent in color and formation to be silver chloride. Also, silver chloride is not soluble in water, so pitted areas of the coupon may indeed have silver chloride precipitate as residual while more shallow corroded areas of the same coupon may not show significant presence of the silver chloride residue. 


\section{Beryllium \#2, 1-yr Exposure - 4 ft. (archived for 5 years)}

(Continued)
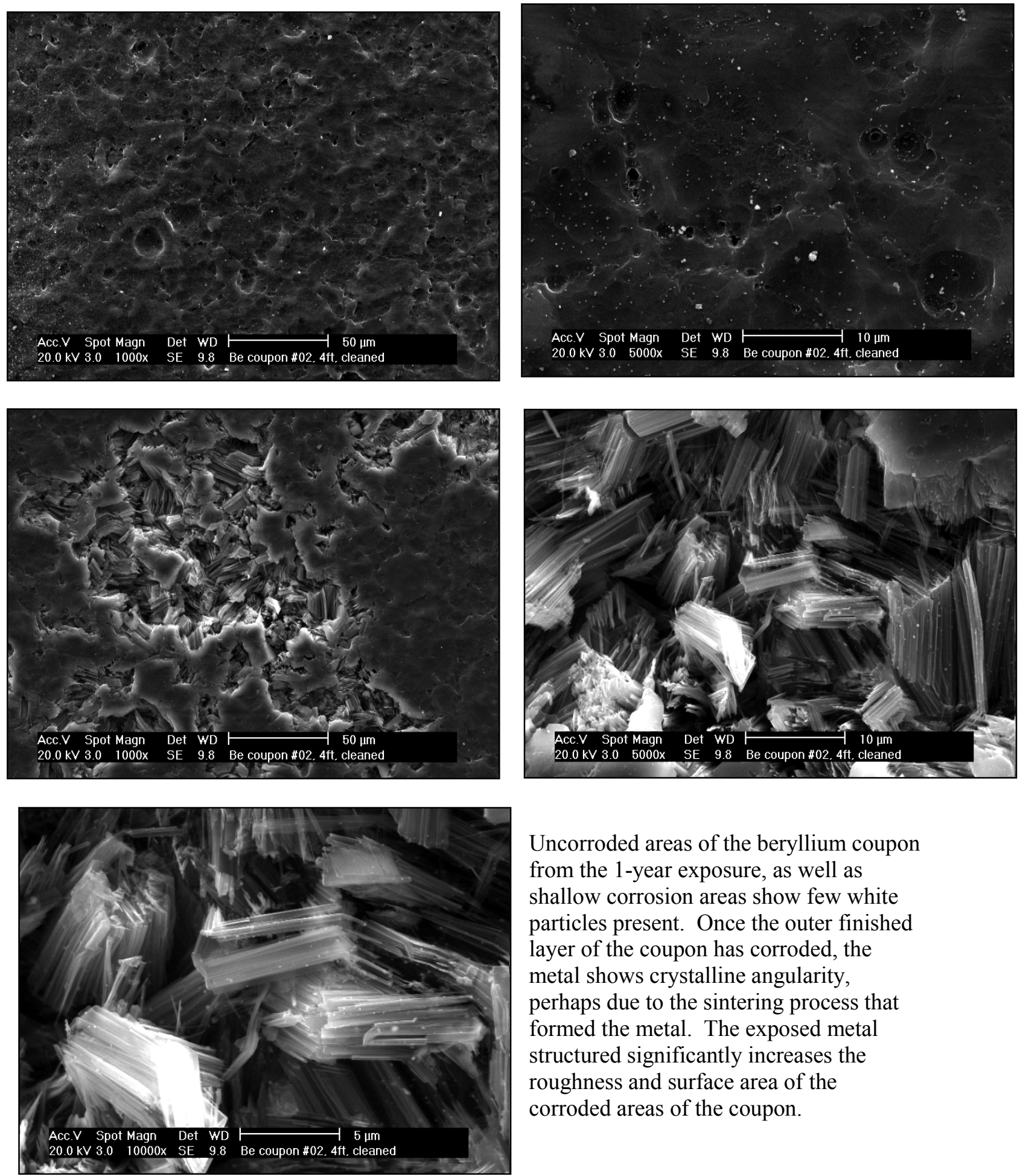

Uncorroded areas of the beryllium coupon from the 1-year exposure, as well as shallow corrosion areas show few white particles present. Once the outer finished layer of the coupon has corroded, the metal shows crystalline angularity, perhaps due to the sintering process that formed the metal. The exposed metal structured significantly increases the roughness and surface area of the corroded areas of the coupon. 
Beryllium\#17, 3-yr Exposure - 10 ft. (archived for 5 years)
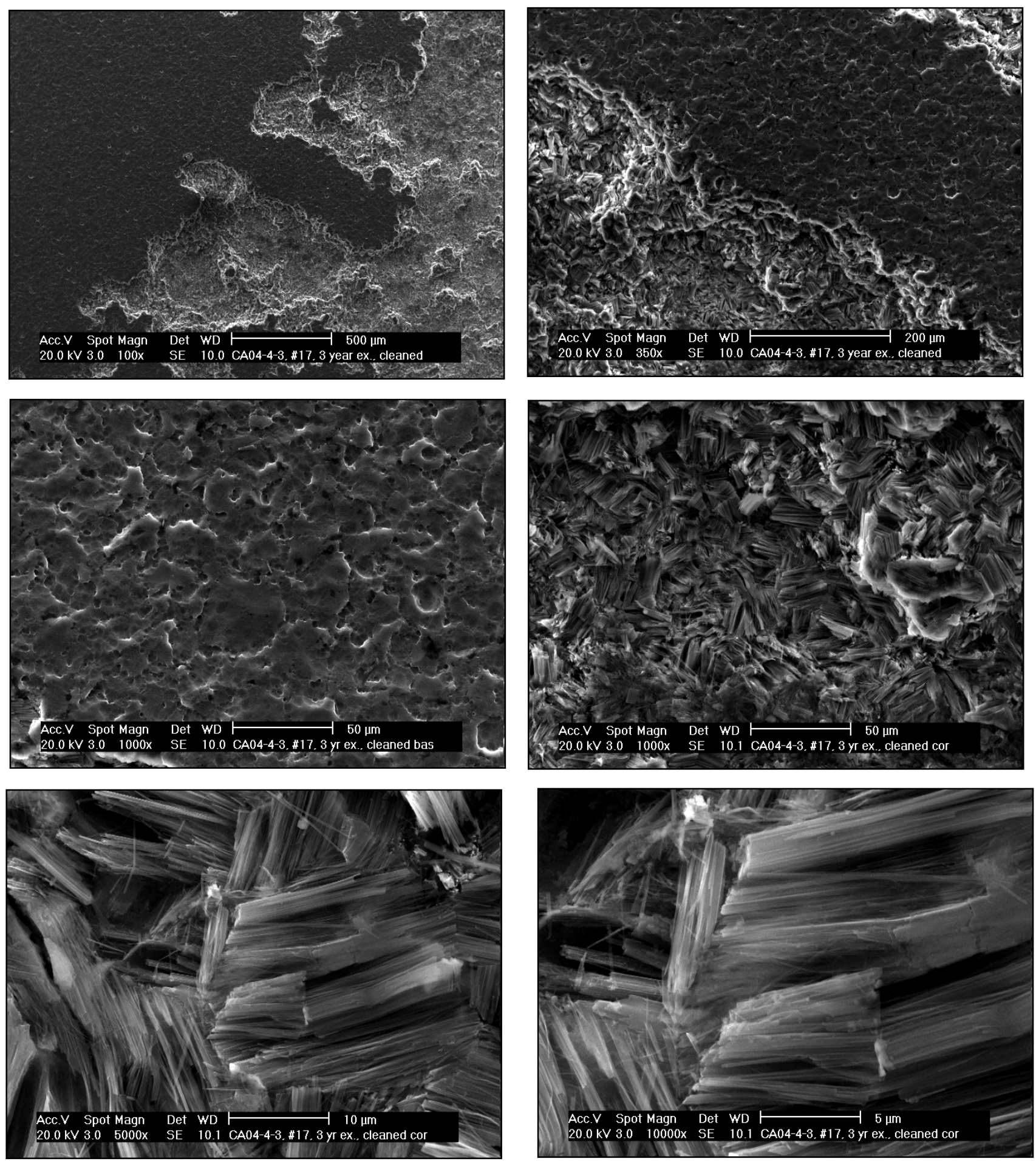


\section{Beryllium \#17, 3-yr Exposure - 10 ft. (archived for 5 years) (Continued)}

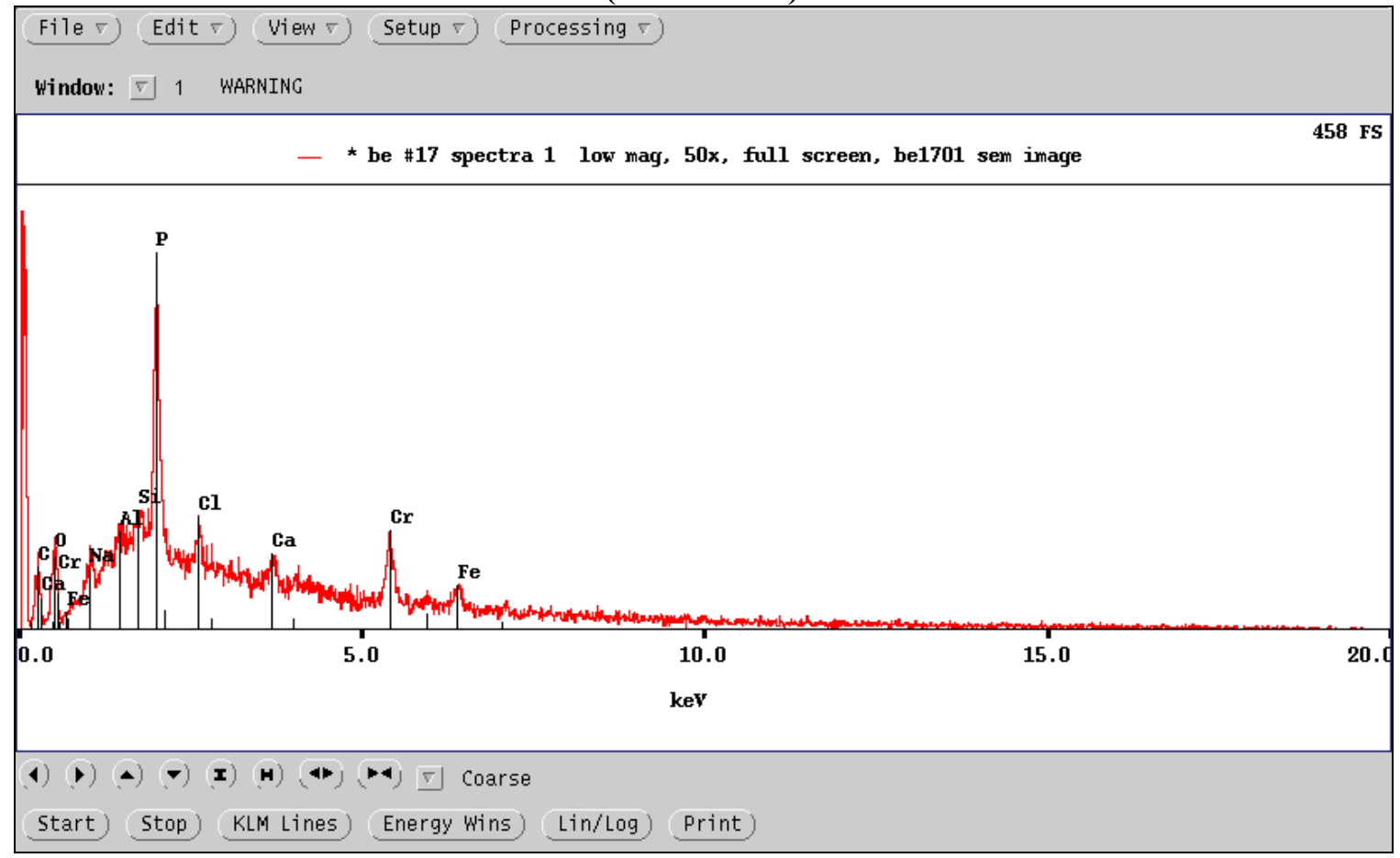

PGT Bulk sample analysis Tue Aug 24 21:50:19 2004

ZAF Method, variable-width filter

Sample /xd1/window1/\#1,/be \#17 spectra 1.spt

Accelerating Voltage: $\quad 15.00 \mathrm{keV}$

Takeoff Angle: $\quad 32.00$ degrees

Library for system standards: /imix/quant/rhodonite efficiency

\begin{tabular}{|c|c|c|c|c|c|c|c|c|}
\hline Elm & Rel. K & $\mathrm{Z}$ & A & $\mathrm{F}$ & Norm wt $\%$ & Atomic $\%$ & Method used & Line \\
\hline $\mathrm{C}$ & 0.0229 & 0.944 & 4.731 & 0.999 & 1.37 & 1.15 & From spectrum & $\mathrm{K}$ line \\
\hline $\mathrm{Al}$ & 0.0065 & 1.039 & 1.508 & 0.995 & 1.02 & 0.75 & From spectrum & $\mathrm{K}$ line ? \\
\hline $\mathrm{Na}$ & 0.0051 & 1.031 & 2.619 & 0.999 & 1.37 & 1.15 & From spectrum & $\mathrm{K}$ line \\
\hline $\mathrm{P}$ & 0.1022 & 1.050 & 1.185 & 0.998 & 12.68 & 7.99 & From spectrum & $\mathrm{K}$ line \\
\hline $\mathrm{Cl}$ & 0.0194 & 1.071 & 1.140 & 0.997 & 2.36 & 1.29 & From spectrum & $\mathrm{K}$ line \\
\hline $\mathrm{Ca}$ & 0.0150 & 1.045 & 1.039 & 0.988 & 1.61 & 0.78 & From spectrum & $\mathrm{K}$ line \\
\hline $\mathrm{Cr}$ & 0.0941 & 1.156 & 1.001 & 0.983 & 10.71 & 4.02 & From spectrum & $\mathrm{K}$ line \\
\hline $\mathrm{Fe}$ & 0.0521 & 1.160 & 1.011 & 1.000 & 6.11 & 2.12 & From spectrum & $\mathrm{K}$ line \\
\hline $\mathrm{Si}$ & 0.0038 & 1.013 & 1.308 & 0.991 & 0.50 & 0.36 & From spectrum & $\mathrm{K}$ line \\
\hline $\mathrm{O}$ & 0.0000 & 0.000 & 0.000 & 0.000 & 53.42 & 64.99 & Stoichiometry & $\mathrm{K}$ line \\
\hline \multicolumn{5}{|l|}{ Total } & 100.00 & 99.99 & & \\
\hline
\end{tabular}

oxygen analyzed by stoichiometry

Goodness of fit 0.91

? Marks elements with poor precision.

WARNING: Residual peak at approximately $1072 \mathrm{ev}$

WARNING: Residual peak at approximately $1281 \mathrm{ev}$

WARNING: Residual peak at approximately $1791 \mathrm{ev}$ 


\section{Beryllium \#17, 3-yr Exposure - 10 ft. (archived for 5 years) (Continued)}

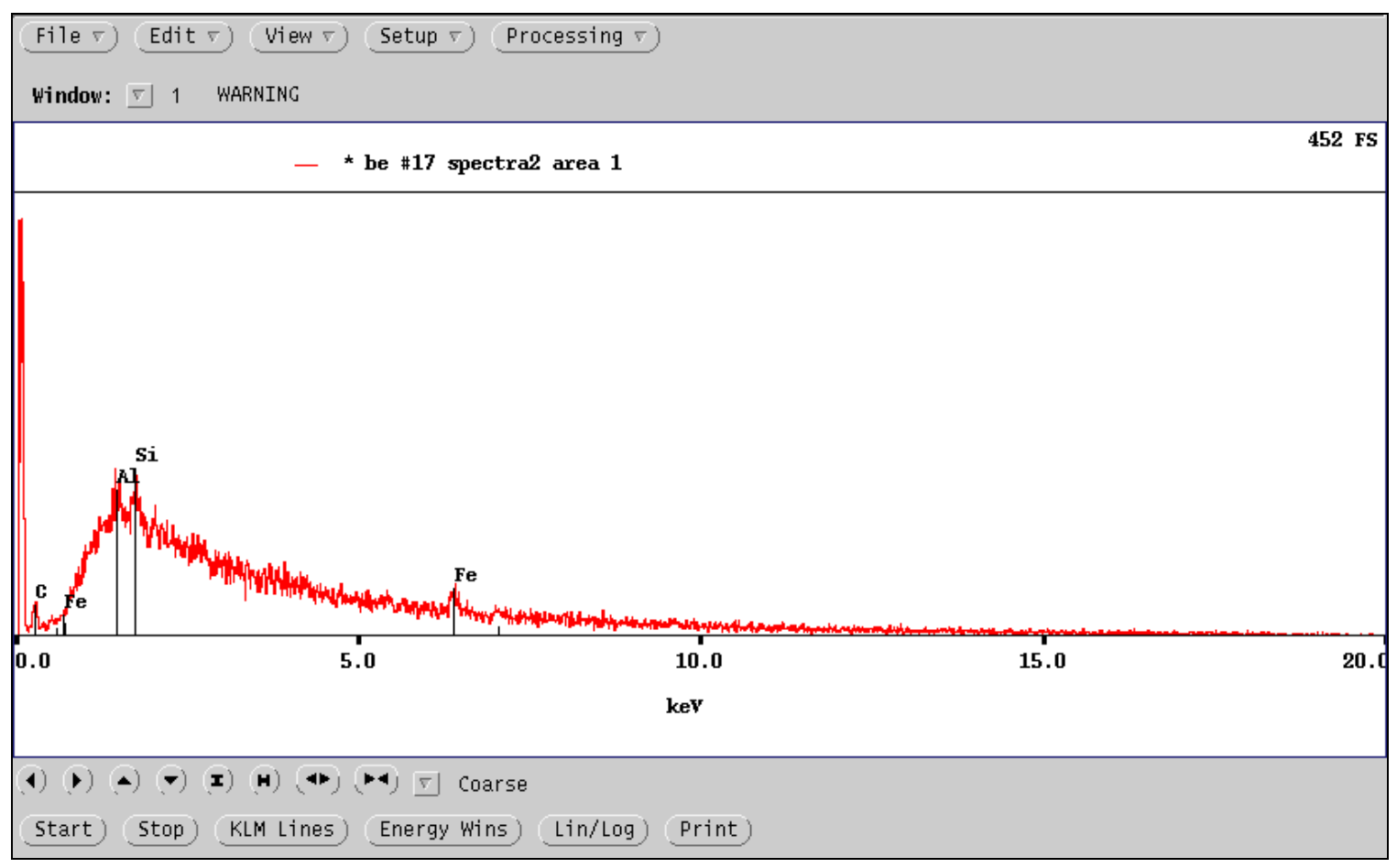

PGT Bulk sample analysis Tue Aug 24 21:48:46 2004

ZAF Method, variable-width filter

Sample /xd1/window1/\#1, be \#17 spectra2 area 1.spt

Accelerating Voltage: $\quad 15.00 \mathrm{keV}$

Takeoff Angle: $\quad 32.00$ degrees

Library for system standards: /imix/quant/rhodonite efficiency

\begin{tabular}{|c|c|c|c|c|c|c|c|c|}
\hline Elm & Rel. K & $\mathrm{Z}$ & A & $\mathrm{F}$ & Norm $w t \%$ & Atomic $\%$ & Method used & Line \\
\hline $\mathrm{C}$ & 0.0905 & 0.912 & 4.420 & 1.000 & 36.45 & 67.93 & From spectrum & $\mathrm{K}$ line \\
\hline $\mathrm{Al}$ & 0.0523 & 1.002 & 1.697 & 0.997 & 8.87 & 7.38 & From spectrum & $\mathrm{K}$ line \\
\hline $\mathrm{Si}$ & 0.0529 & 0.974 & 1.535 & 1.000 & 7.90 & 6.42 & From spectrum & $\mathrm{K}$ line \\
\hline $\mathrm{Fe}$ & 0.4213 & 1.115 & 0.996 & 1.000 & 46.78 & 18.68 & From spectrum & $\mathrm{K}$ line \\
\hline \multicolumn{5}{|c|}{ Total } & 100.00 & 100.41 & & \\
\hline $\begin{array}{l}\text { Good } \\
\text { WAR } \\
\text { WAR } \\
\text { WAR } \\
\text { WAR } \\
\text { WAR }\end{array}$ & $\begin{array}{l}\text { ss of fit } \\
\text { ING: Re } \\
\text { ING: Re } \\
\text { ING: Re } \\
\text { ING: Re } \\
\text { ING: Re }\end{array}$ & $\begin{array}{l}0.85 \\
\text { dual pe } \\
\text { dual pe } \\
\text { dual pe } \\
\text { dual pe } \\
\text { dual pe }\end{array}$ & $\begin{array}{l}\mathrm{k} \text { at ap } \\
\mathrm{k} \text { at apt } \\
\mathrm{k} \text { at apt } \\
\mathrm{k} \text { at app } \\
\mathrm{k} \text { at apt }\end{array}$ & $\begin{array}{l}\text { oximate } \\
\text { oximate } \\
\text { oximate } \\
\text { oximate } \\
\text { oximate }\end{array}$ & $\begin{array}{ll}\text { y } & 885 \mathrm{ev} \\
\text { y } 2020 \mathrm{ev} \\
\text { y } 2770 \mathrm{ev} \\
\text { y } 2927 \mathrm{ev} \\
\text { y } & 4250 \mathrm{ev}\end{array}$ & & & \\
\hline
\end{tabular}


Beryllium \#19, 6-yr Exposure - 4 ft. (Scan \#1)
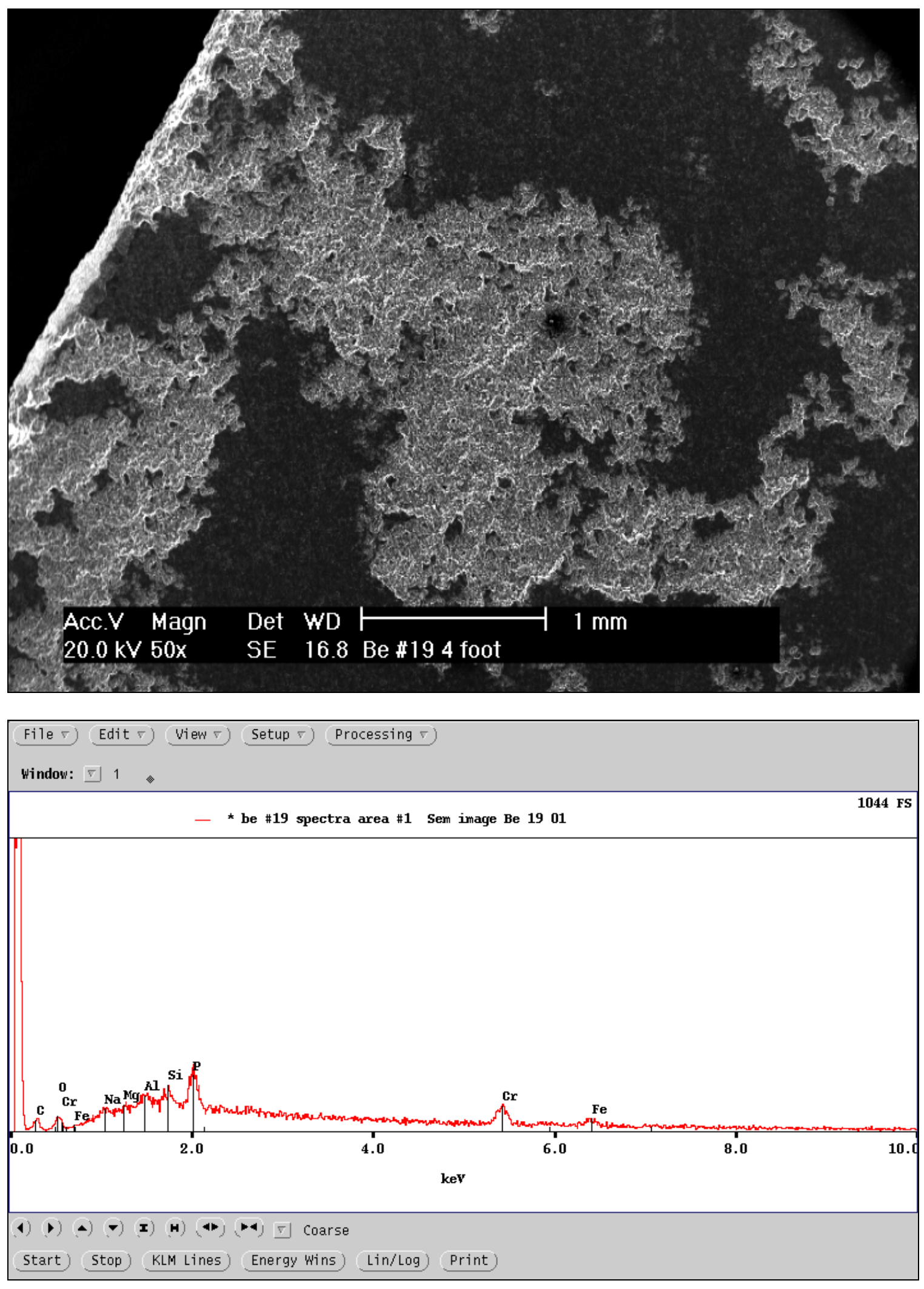


\section{Beryllium \#19, 6-yr Exposure - 4 ft. (Scan \#1) \\ (Continued)}

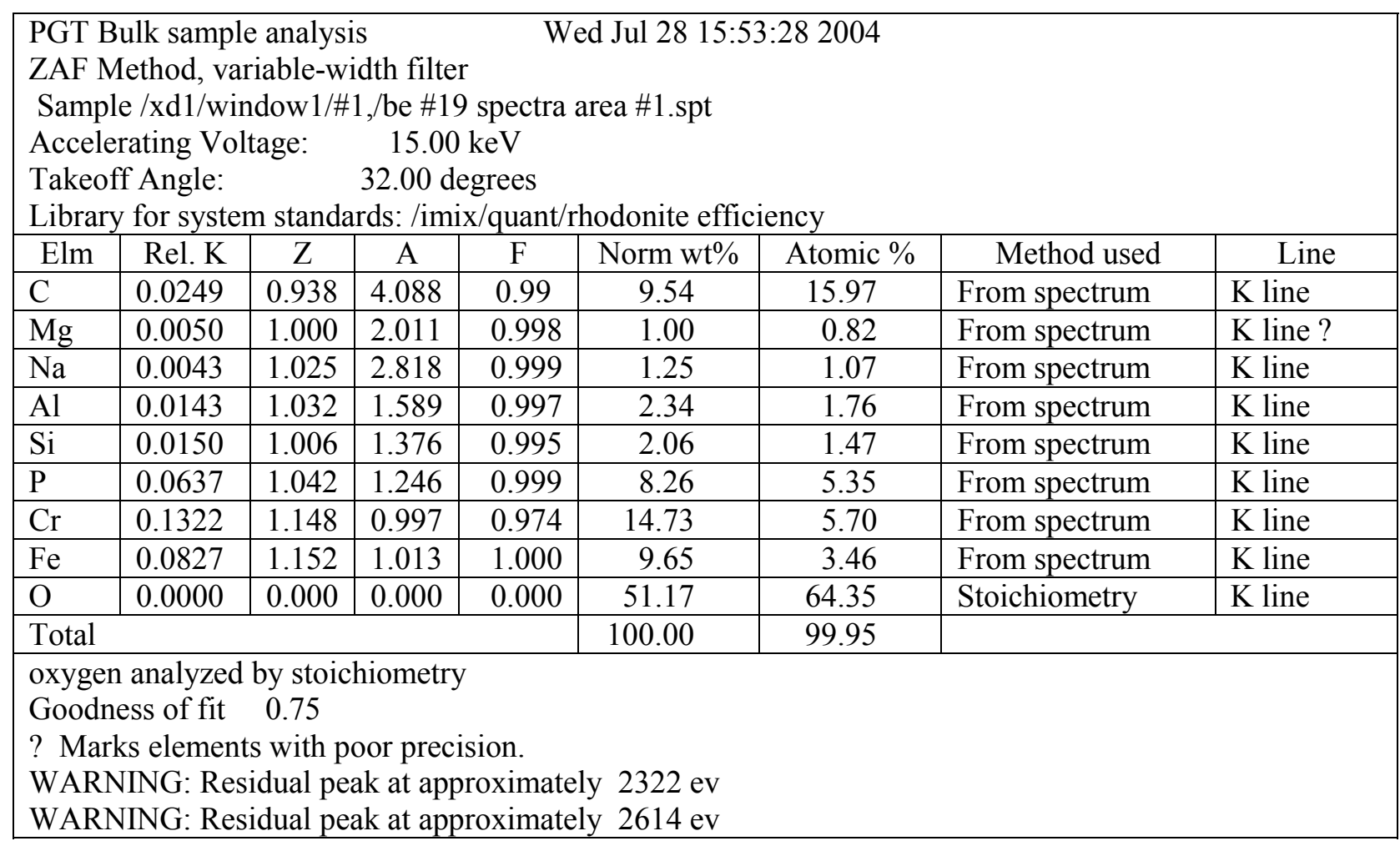


Beryllium\#19, 6-yr Exposure - 4 ft. (Scan \#2)

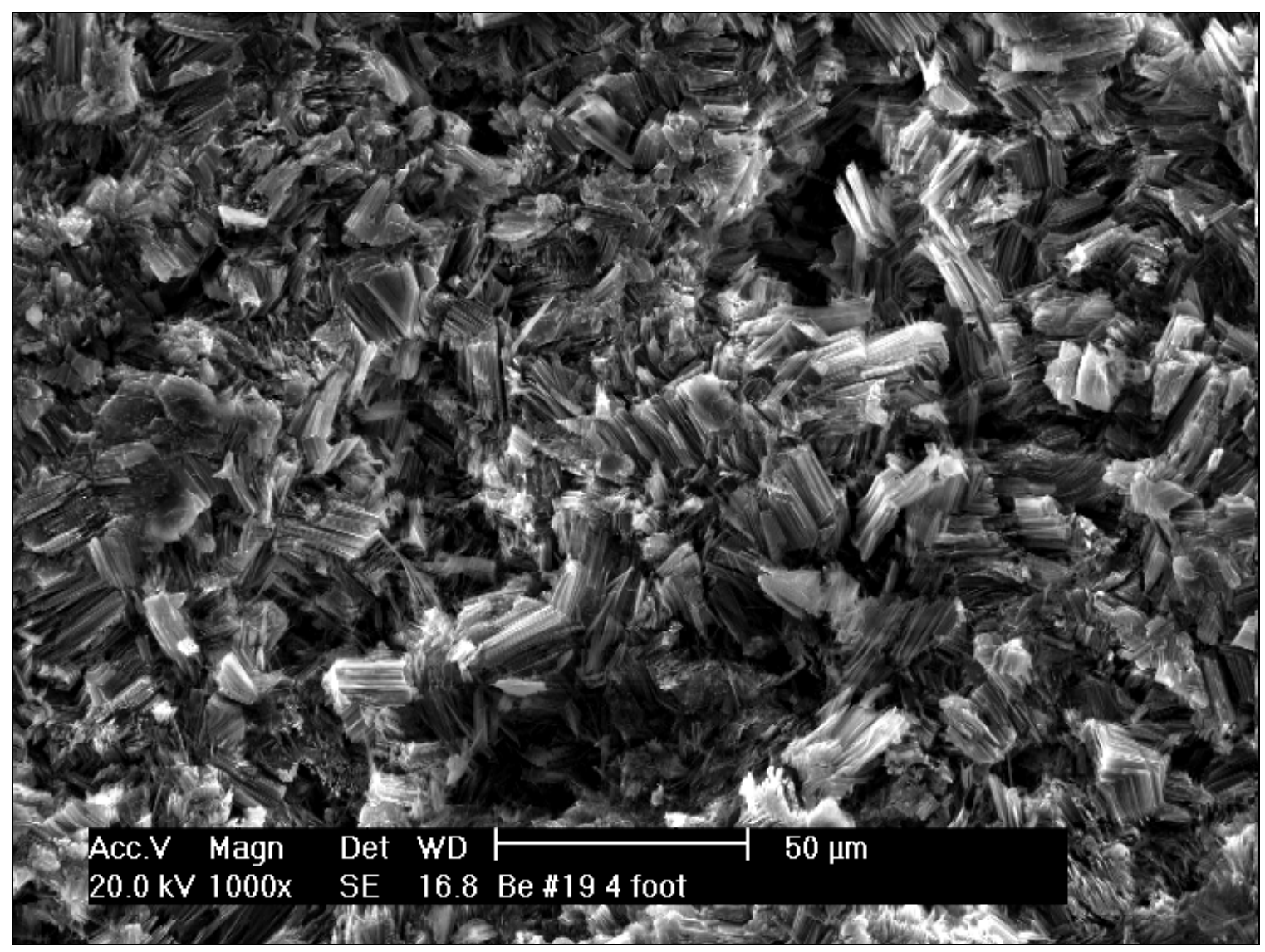

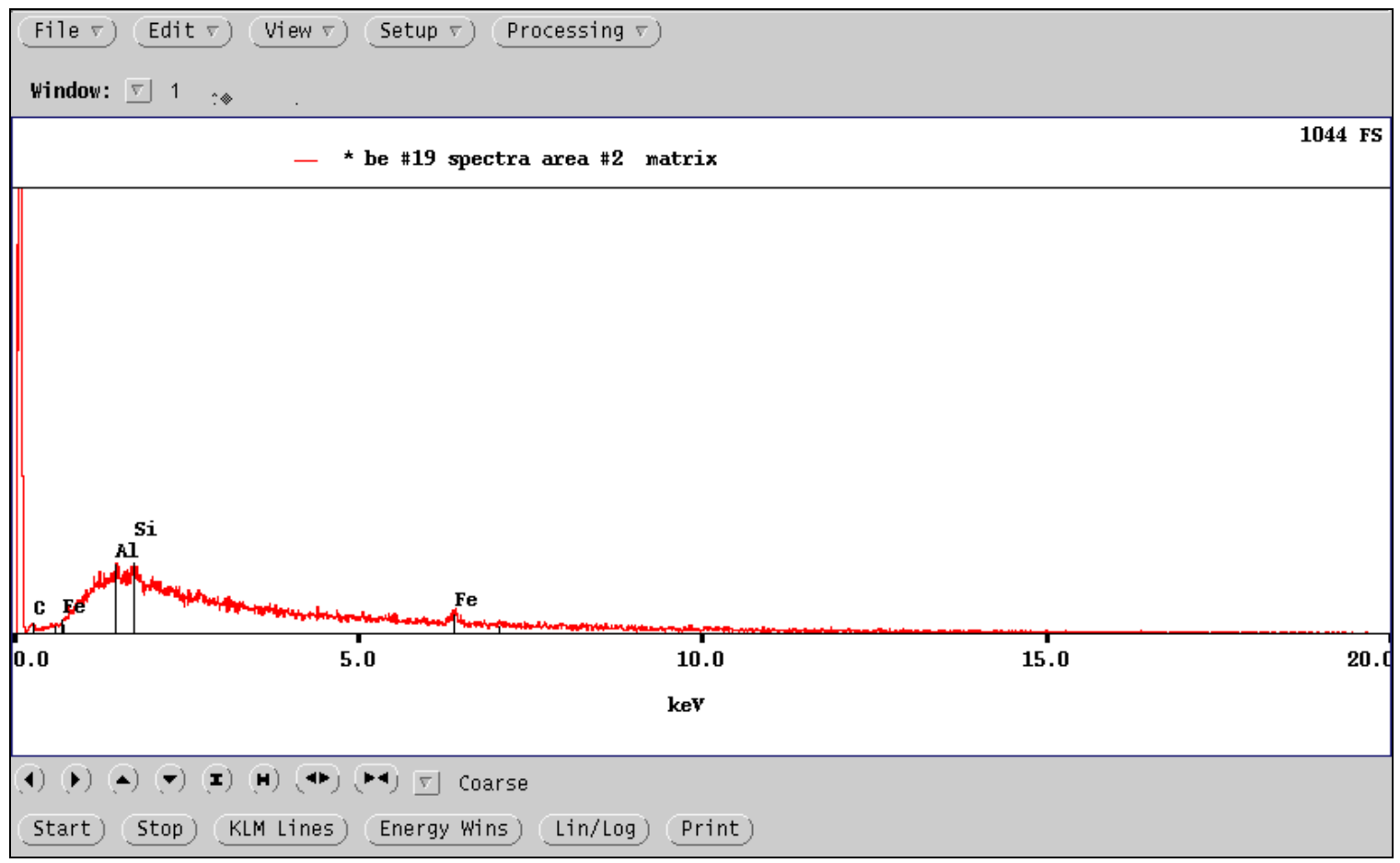




\section{Beryllium \#19, 6-yr Exposure - 4 ft. (Scan \#2) \\ (Continued)}

\begin{tabular}{|c|c|c|c|c|c|c|c|c|}
\hline \multicolumn{9}{|c|}{ PGT Bulk sample analysis $\quad$ Wed J } \\
\hline \multicolumn{9}{|c|}{ ZAF Method, variable-width filter } \\
\hline \multicolumn{9}{|c|}{ Sample /xd1/window1/\#1, be \#19 spectra area \#2.spt } \\
\hline \multicolumn{9}{|c|}{ Accelerating Voltage: $\quad 15.00 \mathrm{keV}$} \\
\hline \multicolumn{9}{|c|}{ Takeoff Angle: $\quad 32.00$ degrees } \\
\hline \multicolumn{9}{|c|}{ Library for system standards: /imix/quant/rhodonite efficiency } \\
\hline Elm & Rel. K & Z & A & $\mathrm{F}$ & Norm wt $\%$ & Atomic $\%$ & Method used & Line \\
\hline $\mathrm{Fe}$ & 0.4826 & 1.097 & 0.997 & 1.000 & 52.81 & 23.16 & From spectrum & $\mathrm{K}$ line \\
\hline $\mathrm{Si}$ & 0.0286 & 0.958 & 1.637 & 1.000 & 4.49 & 3.87 & From spectrum & $\mathrm{K}$ line ? \\
\hline $\mathrm{Al}$ & 0.0725 & 0.987 & 1.772 & 0.998 & 12.67 & 11.65 & From spectrum & $\mathrm{K}$ line? \\
\hline $\mathrm{C}$ & 0.0733 & 0.899 & 4.557 & 1.000 & 30.03 & 61.41 & From spectrum & $\mathrm{K}$ line \\
\hline \multicolumn{5}{|c|}{ Total } & 100.00 & 100.09 & & \\
\hline $\begin{array}{l}\text { Goodi } \\
\text { ? Ma } \\
\text { WAR } \\
\text { WAR } \\
\text { WAR } \\
\text { WAR }\end{array}$ & $\begin{array}{l}\text { ess of fit } \\
\text { ss elemen } \\
\text { IING: Re } \\
\text { IING: Re } \\
\text { IING: Re } \\
\text { IING: Re }\end{array}$ & $\begin{array}{l}0.83 \\
\text { with p } \\
\text { dual pe } \\
\text { dual pe } \\
\text { dual pe } \\
\text { dual pe }\end{array}$ & $\begin{array}{l}\text { or prec } \\
\text { k at ap } \\
\text { k at ap } \\
\text { k at ap } \\
\text { k at ap }\end{array}$ & $\begin{array}{l}\text { ion. } \\
\text { oximate } \\
\text { oximat } \\
\text { oximate } \\
\text { oximate }\end{array}$ & $\begin{array}{l}1156 \mathrm{ev} \\
2010 \mathrm{ev} \\
2291 \mathrm{ev} \\
2718 \mathrm{ev}\end{array}$ & & & \\
\hline
\end{tabular}




\section{Beryllium \#19, 6-yr Exposure - 4 ft. (Scan \#3)}

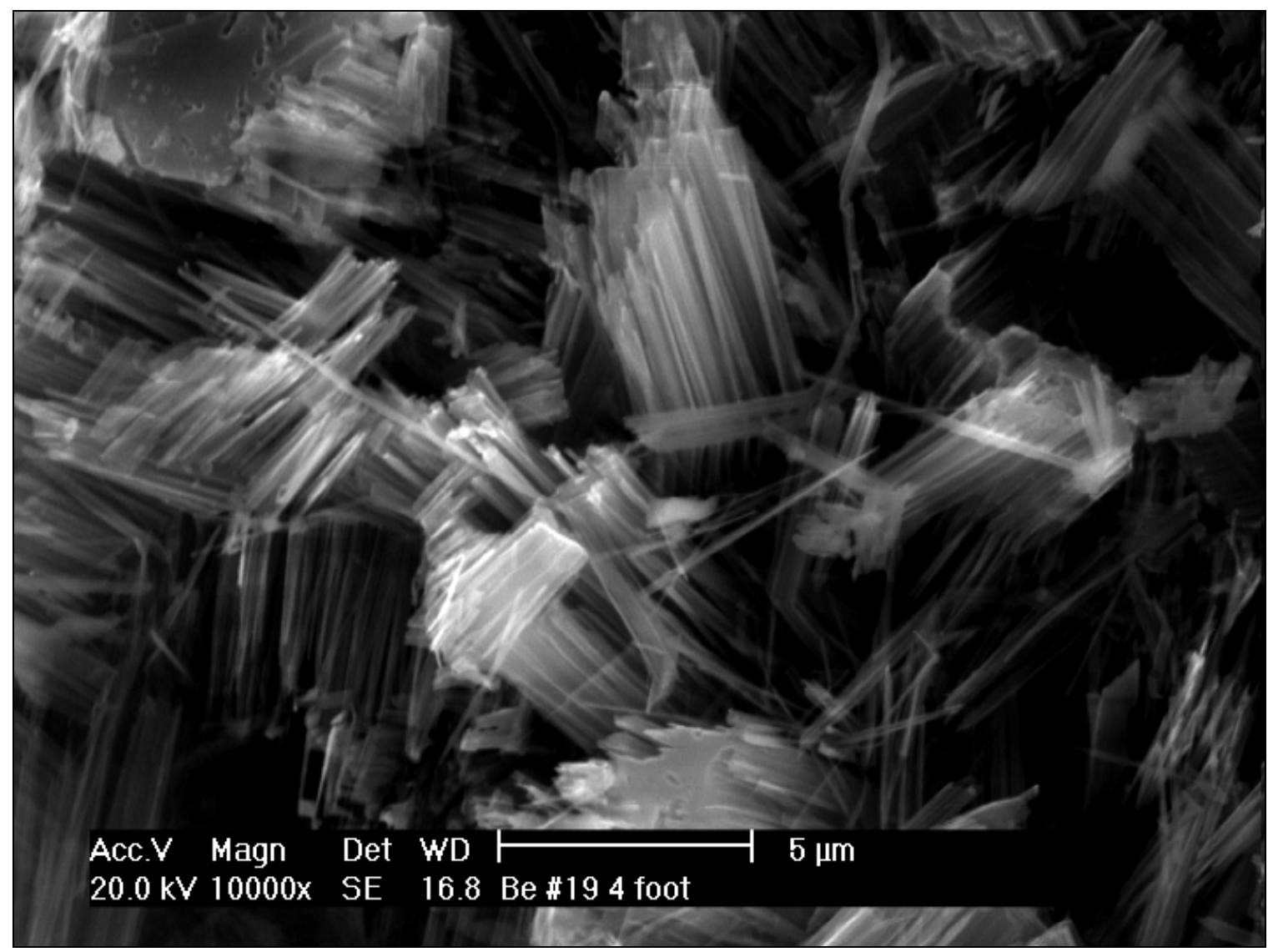

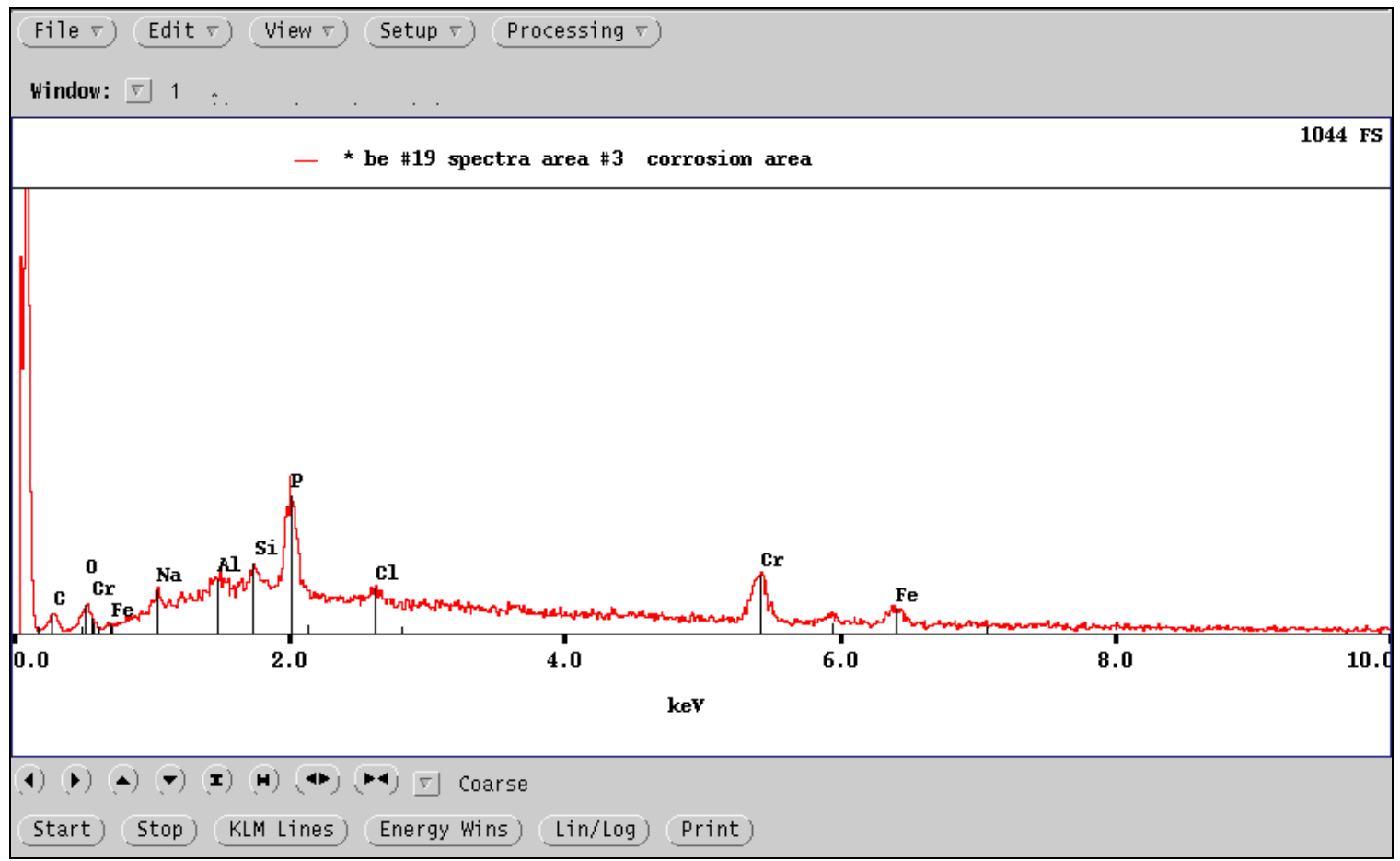




\section{Beryllium \#19, 6-yr Exposure - 4 ft. (Scan \#3) \\ (Continued)}

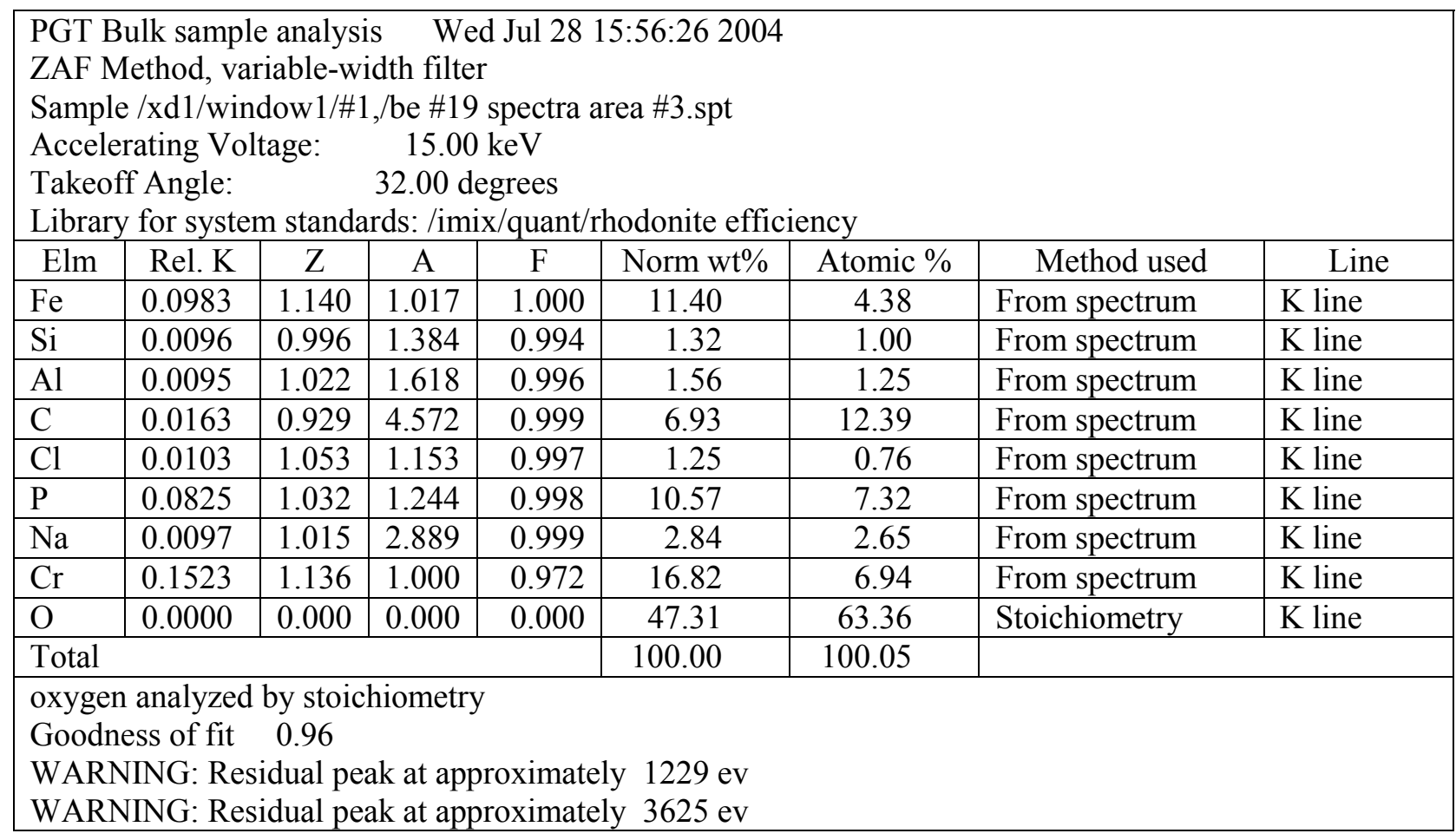




\section{Beryllium\#24, 6-yr Exposure - 10 ft. (Scan \#1)}

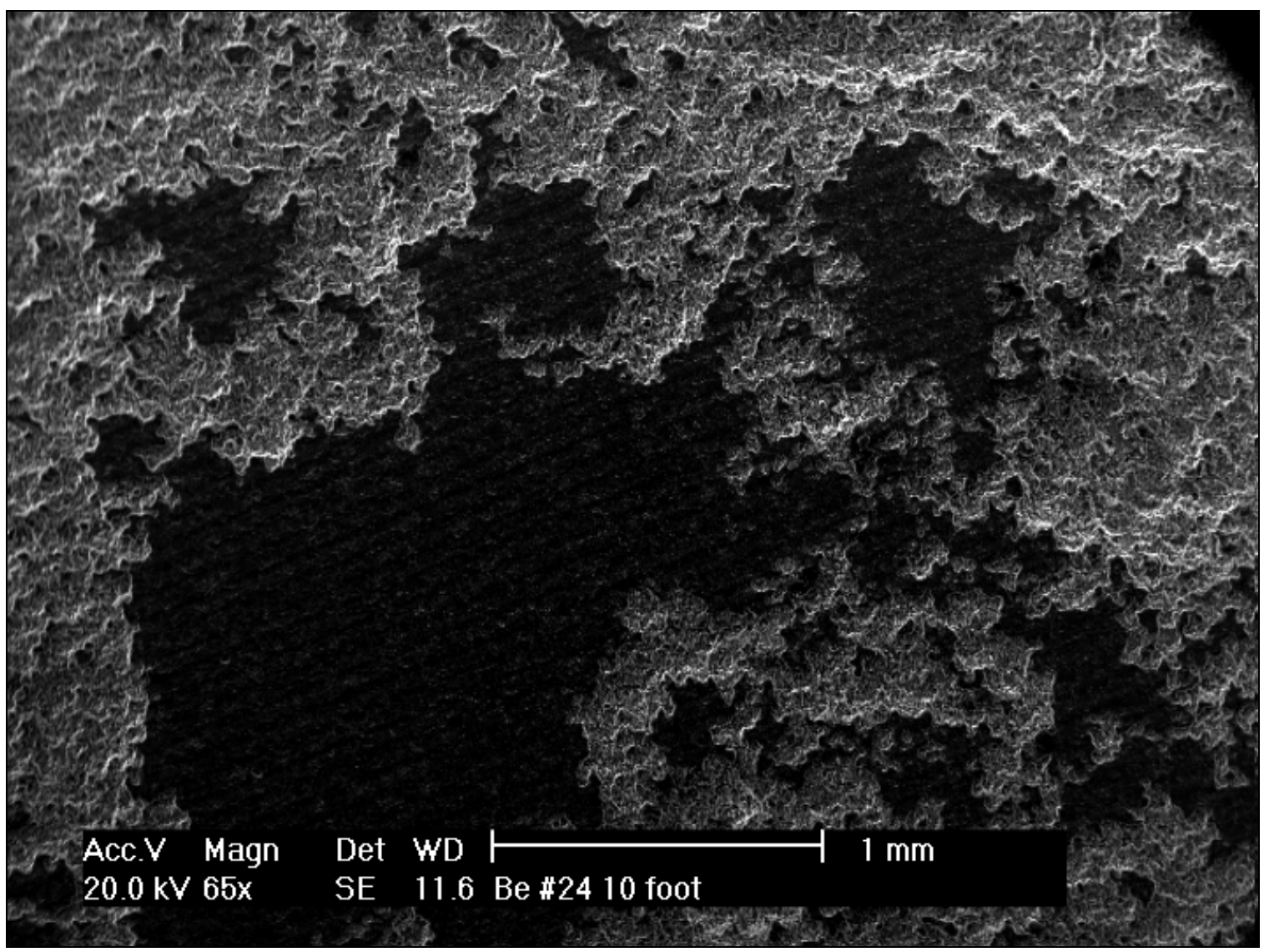

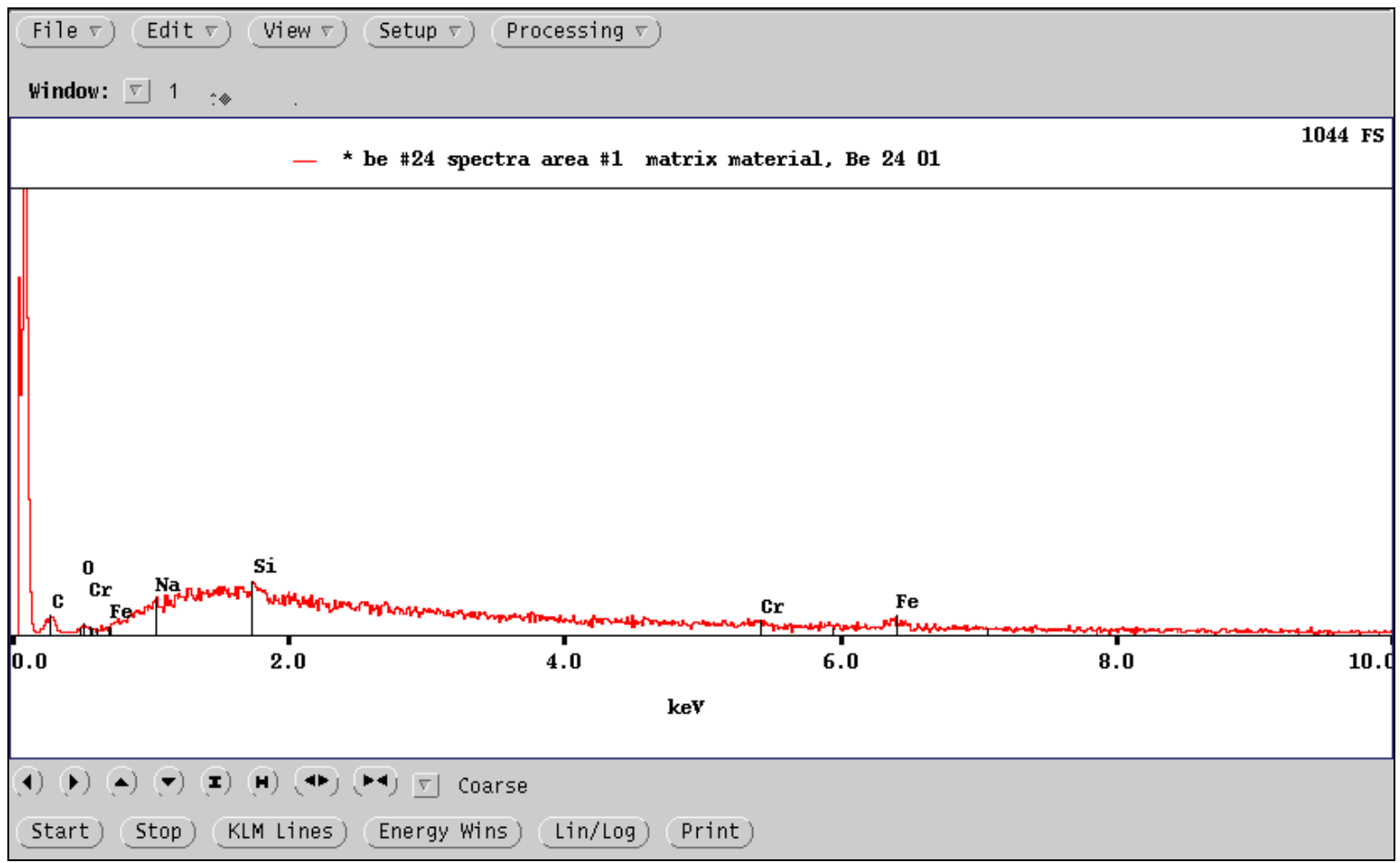




\section{Beryllium \#24, 6-yr Exposure - 10 ft. (Scan \#1) \\ (Continued)}

\begin{tabular}{|c|c|c|c|c|c|c|c|c|}
\hline \multicolumn{9}{|c|}{$\begin{array}{l}\text { PGT Bulk sample analysis Wed Jul } 28 \text { 15:58:48 } 2004 \\
\text { ZAF Method, variable-width filter } \\
\text { Sample /xd1/window1/\#1,/be \#24 spectra area \#1.spt }\end{array}$} \\
\hline Elm & Rel. K & Z & $\mathrm{A}$ & $\mathrm{F}$ & Norm wt $\%$ & Atomic $\%$ & Method used & Line \\
\hline $\mathrm{Fe}$ & 0.1961 & 1.158 & 0.998 & 1.000 & 22.65 & 7.68 & From spectrum & $\mathrm{K}$ line \\
\hline $\mathrm{Si}$ & 0.0007 & 1.012 & 1.411 & 1.000 & 0.10 & 0.13 & From spectrum & $\mathrm{K}$ line ? \\
\hline $\mathrm{C}$ & 0.0654 & 0.943 & 2.603 & 0.999 & 16.02 & 25.40 & From spectrum & $\mathrm{K}$ line \\
\hline $\mathrm{Cr}$ & 0.0518 & 1.154 & 0.992 & 0.907 & 5.38 & 1.98 & From spectrum & $\mathrm{K}$ line? \\
\hline $\mathrm{Na}$ & 0.0093 & 1.030 & 3.163 & 1.000 & 3.03 & 2.47 & From spectrum & $\mathrm{K}$ line? \\
\hline $\mathrm{O}$ & 0.0000 & 0.000 & 0.000 & 0.000 & 52.82 & 62.51 & Stoichiometry & $\mathrm{K}$ line \\
\hline \multicolumn{5}{|l|}{ Total } & 100.00 & 100.17 & & \\
\hline $\begin{array}{l}\text { oxyge } \\
\text { Goodr } \\
\text { ? Mar } \\
\text { WAR } \\
\text { WAR } \\
\text { WAR } \\
\text { WAR } \\
\text { WAR }\end{array}$ & $\begin{array}{l}\text { analyzed } \\
\text { ss of fit } \\
\text { s elemen } \\
\text { ING: Res } \\
\text { ING: Res } \\
\text { ING: Res } \\
\text { ING: Res } \\
\text { ING: Res }\end{array}$ & $\begin{array}{l}\text { by stoic } \\
0.74 \\
\text { with p } \\
\text { dual pe } \\
\text { dual pe } \\
\text { dual pe } \\
\text { dual pe } \\
\text { dual pe }\end{array}$ & $\begin{array}{l}\text { niometr } \\
\text { or prec } \\
\text { k at apı } \\
\text { k at apı } \\
\text { k at apı } \\
\text { k at apı } \\
\text { k at ap! }\end{array}$ & $\begin{array}{l}\text { ion. } \\
\text { oximate } \\
\text { oximate } \\
\text { oximate } \\
\text { oximate } \\
\text { oximate }\end{array}$ & $\begin{array}{l}750 \mathrm{ev} \\
1510 \mathrm{ev} \\
1781 \mathrm{ev} \\
2406 \mathrm{ev} \\
3041 \mathrm{ev}\end{array}$ & & & \\
\hline
\end{tabular}




\section{Beryllium \#24, 6-yr Exposure - 10 ft. (Scan \#2)}

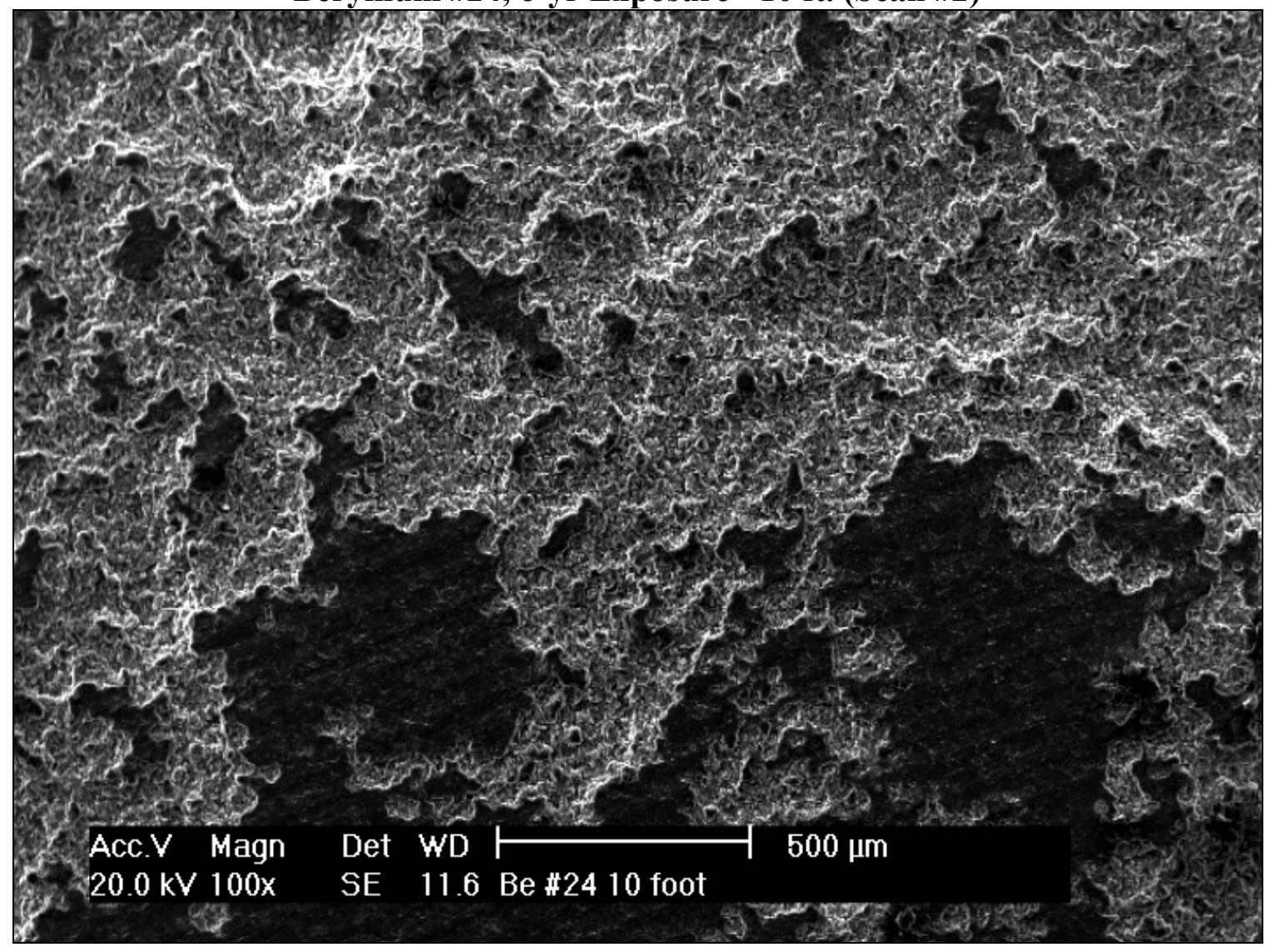

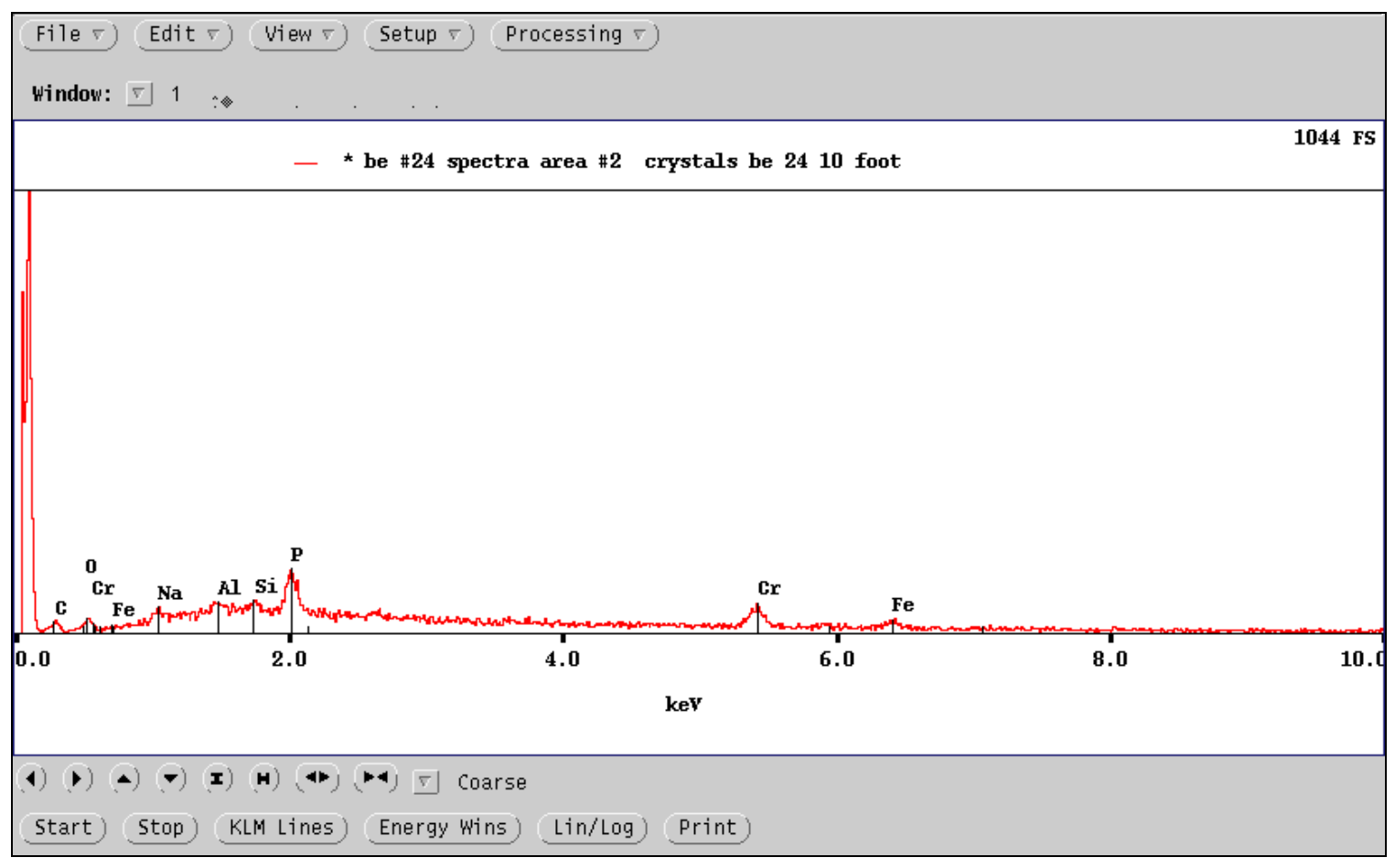




\section{Beryllium \#24, 6-yr Exposure - 10 ft. (Scan \#2) \\ (Continued)}

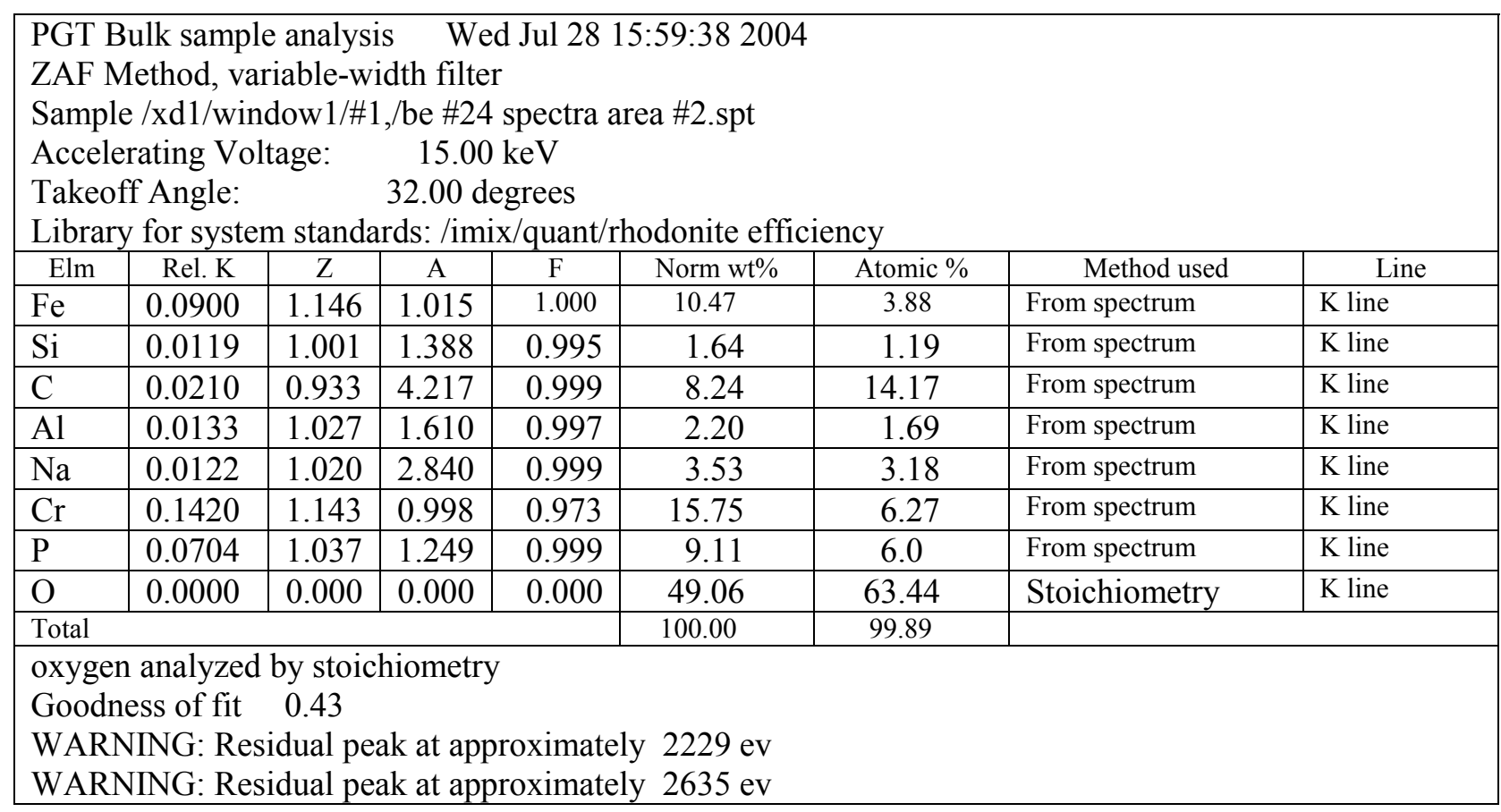


Beryllium \#24, 6-yr Exposure - 10 ft. (Scan \#3)

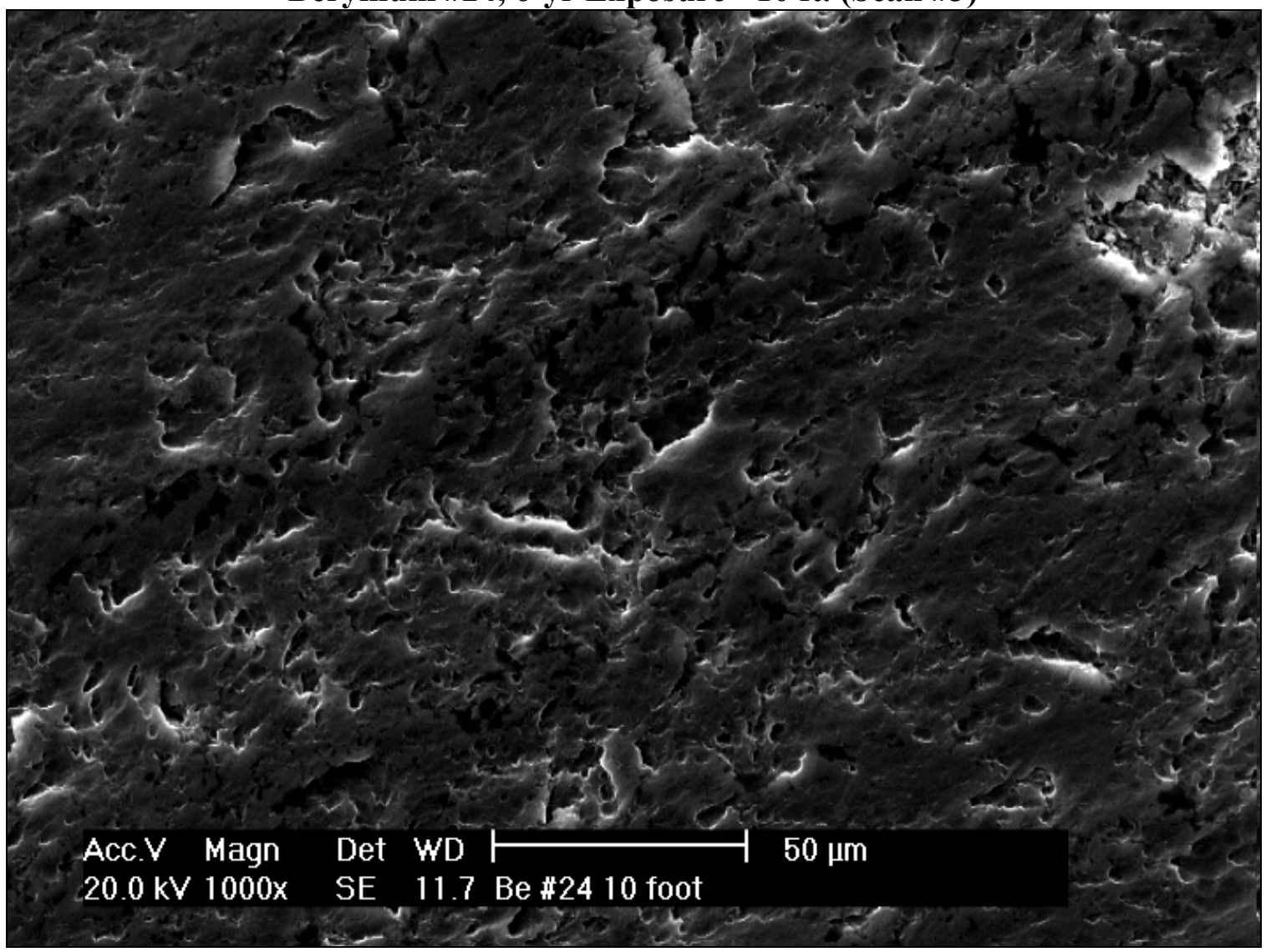

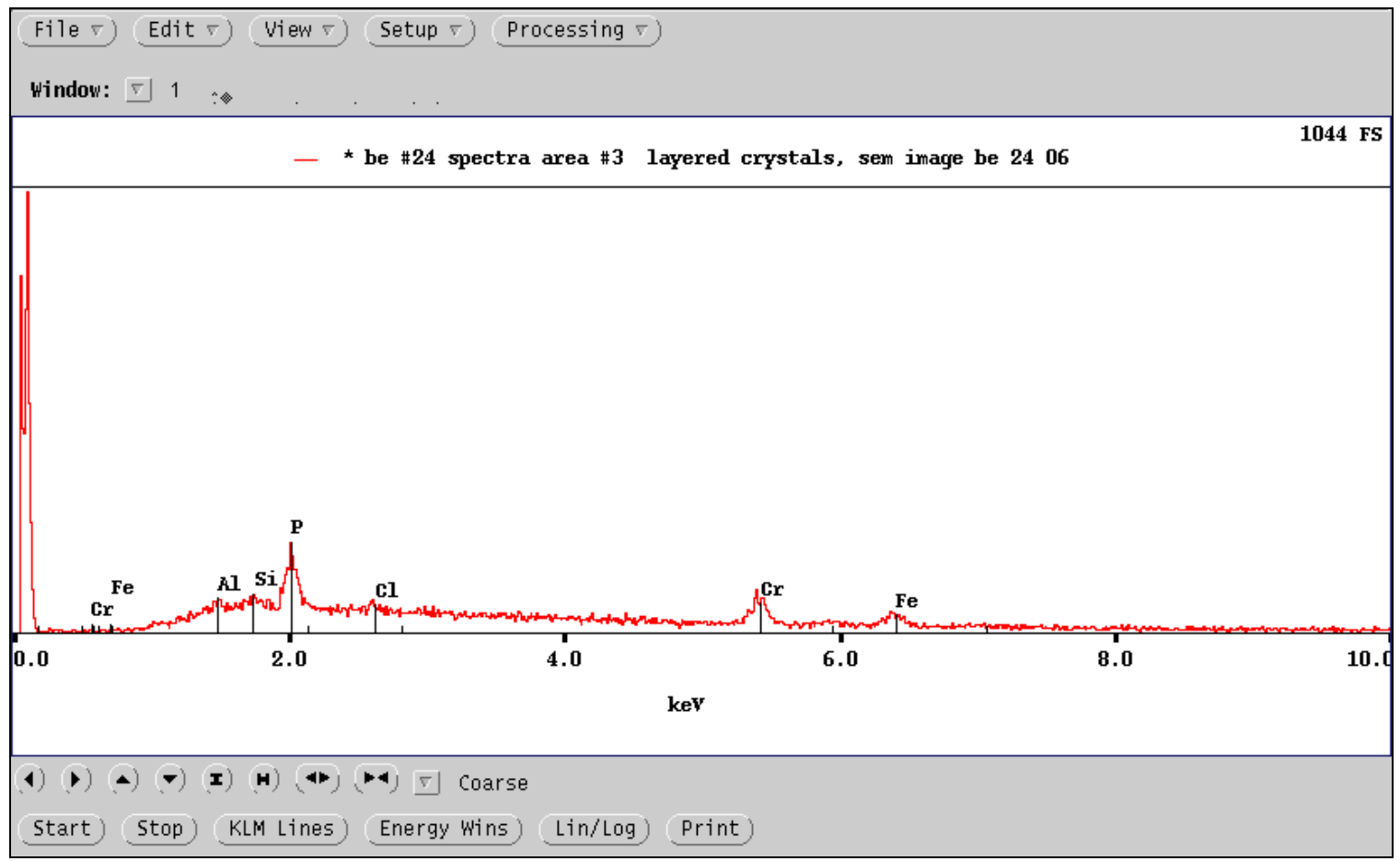




\section{Beryllium \#24, 6-yr Exposure - 10 ft (Scan \#3) \\ (Continued)}

\begin{tabular}{|c|c|c|c|c|c|c|c|c|}
\hline \multicolumn{9}{|c|}{ PGT Bulk sample analysis } \\
\hline \multicolumn{9}{|c|}{ ZAF Method, variable-width filter } \\
\hline \multicolumn{9}{|c|}{ Sample /xd1/window1/\#1,/be \#24 spectra area \#3.spt } \\
\hline \multicolumn{3}{|c|}{ Accelerating Voltage: } & 15.00 & $\mathrm{eV}$ & & & & \\
\hline \multicolumn{3}{|c|}{ Takeoff Angle: } & $32.00 \mathrm{~d}$ & grees & & & & \\
\hline \multicolumn{9}{|c|}{ Library for system standards: /imix/quant/rhodonite efficiency } \\
\hline Elm & Rel. K & $\mathrm{Z}$ & $\mathrm{A}$ & $\mathrm{F}$ & Norm $w t \%$ & Atomic $\%$ & Method used & Line \\
\hline $\mathrm{Fe}$ & 0.2668 & 1.036 & 1.051 & 1.000 & 29.04 & 22.45 & From spectrum & K line \\
\hline $\mathrm{Si}$ & 0.0110 & 0.903 & 1.532 & 0.990 & 1.50 & 2.24 & From spectrum & $\mathrm{K}$ line \\
\hline $\mathrm{Cr}$ & 0.3833 & 1.034 & 1.016 & 0.961 & 38.72 & 32.10 & From spectrum & $\mathrm{K}$ line \\
\hline $\mathrm{P}$ & 0.1753 & 0.938 & 1.345 & 0.997 & 22.05 & 30.71 & From spectrum & $\mathrm{K}$ line \\
\hline $\mathrm{Al}$ & 0.0274 & 0.934 & 1.781 & 0.994 & 4.54 & 7.24 & From spectrum & $\mathrm{K}$ line \\
\hline $\mathrm{Cl}$ & 0.0343 & 0.962 & 1.264 & 0.995 & 4.15 & 4.98 & From spectrum & $\mathrm{K}$ line? \\
\hline \multicolumn{5}{|l|}{ Total } & 100.00 & 99.72 & & \\
\hline $\begin{array}{l}\text { Good } \\
\text { ? Ma } \\
\text { WAR } \\
\text { WAR }\end{array}$ & $\begin{array}{l}\text { ss of fit } \\
\text { s elemen } \\
\text { ING: Re } \\
\text { ING: Re }\end{array}$ & $\begin{array}{l}0.52 \\
\text { with p } \\
\text { dual pe } \\
\text { dual pe }\end{array}$ & $\begin{array}{l}\text { or prec } \\
\mathrm{k} \text { at app } \\
\mathrm{k} \text { at apr }\end{array}$ & $\begin{array}{l}\text { ion. } \\
\text { oximate } \\
\text { oximate }\end{array}$ & $\begin{array}{l}\text { y } 1031 \mathrm{ev} \\
\text { y } 2447 \mathrm{ev}\end{array}$ & & & \\
\hline
\end{tabular}




\section{Beryllium \#24 6-yr Exposure - 10 ft. (Scan \#4)}
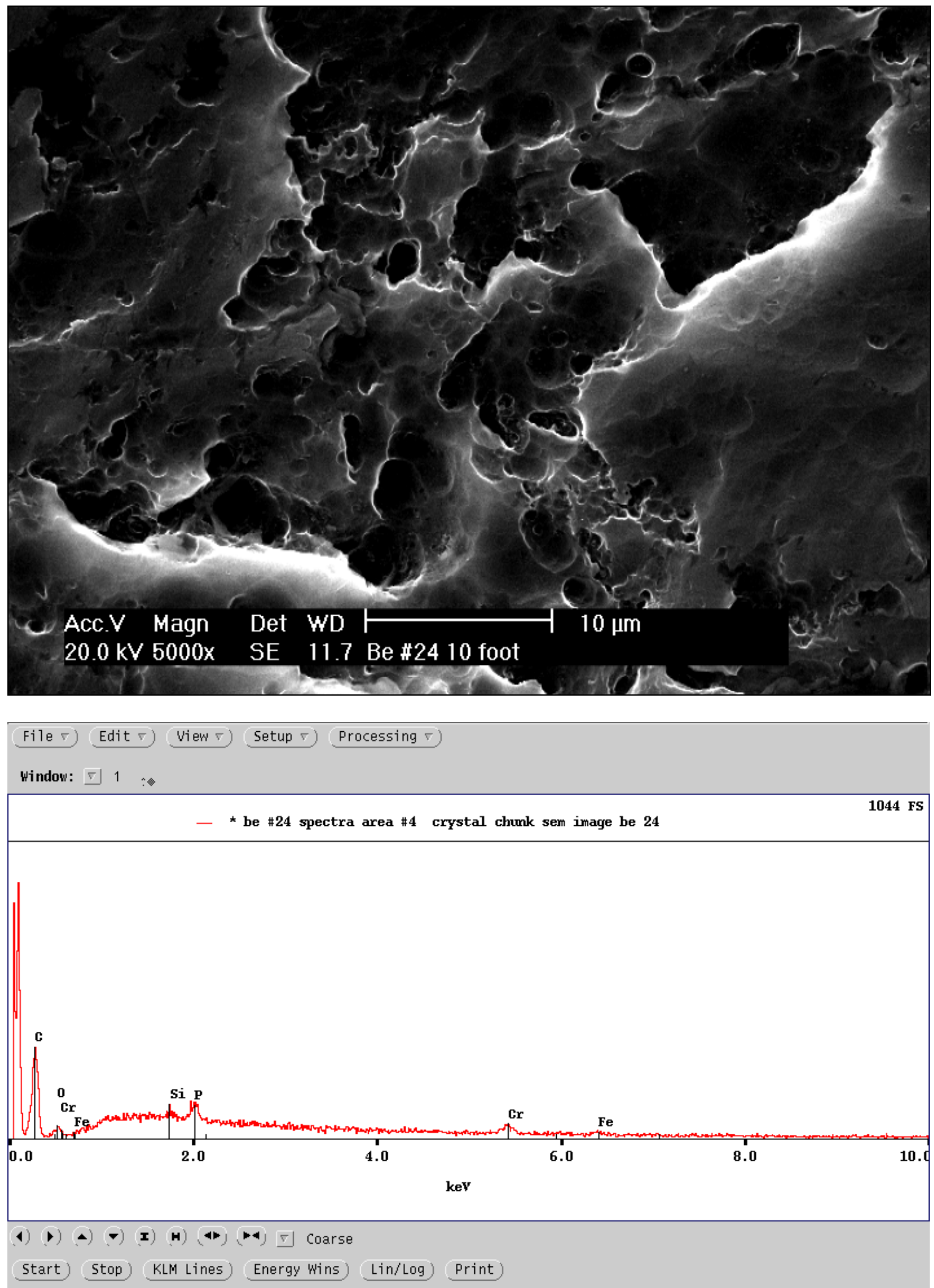


\section{Beryllium \#24, 6-yr Exposure - 10 ft. (Scan \#4) \\ (Continued)}

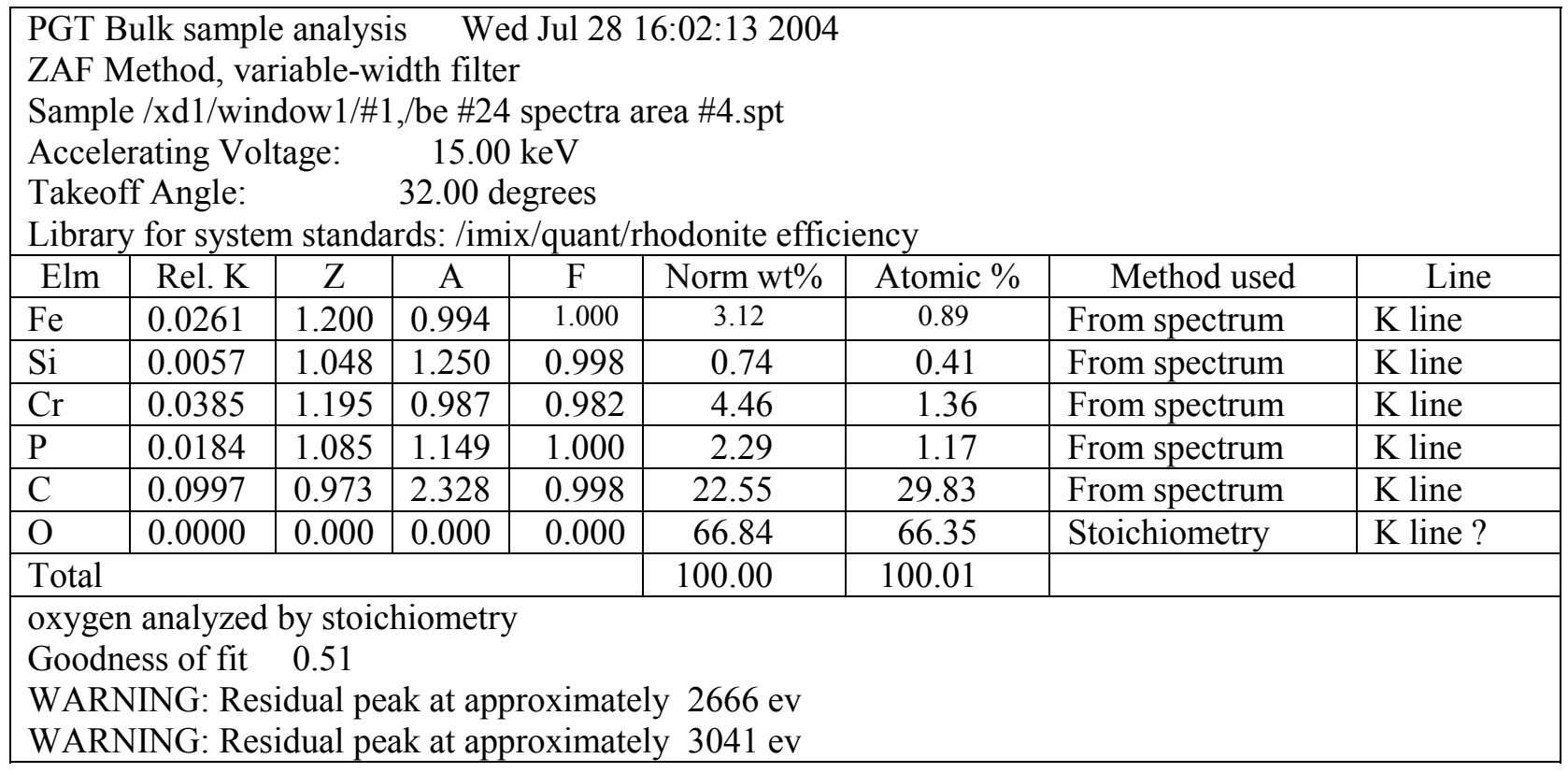


Beryllium \#24, 6-yr Exposure - 10 ft. (Scan \#5)
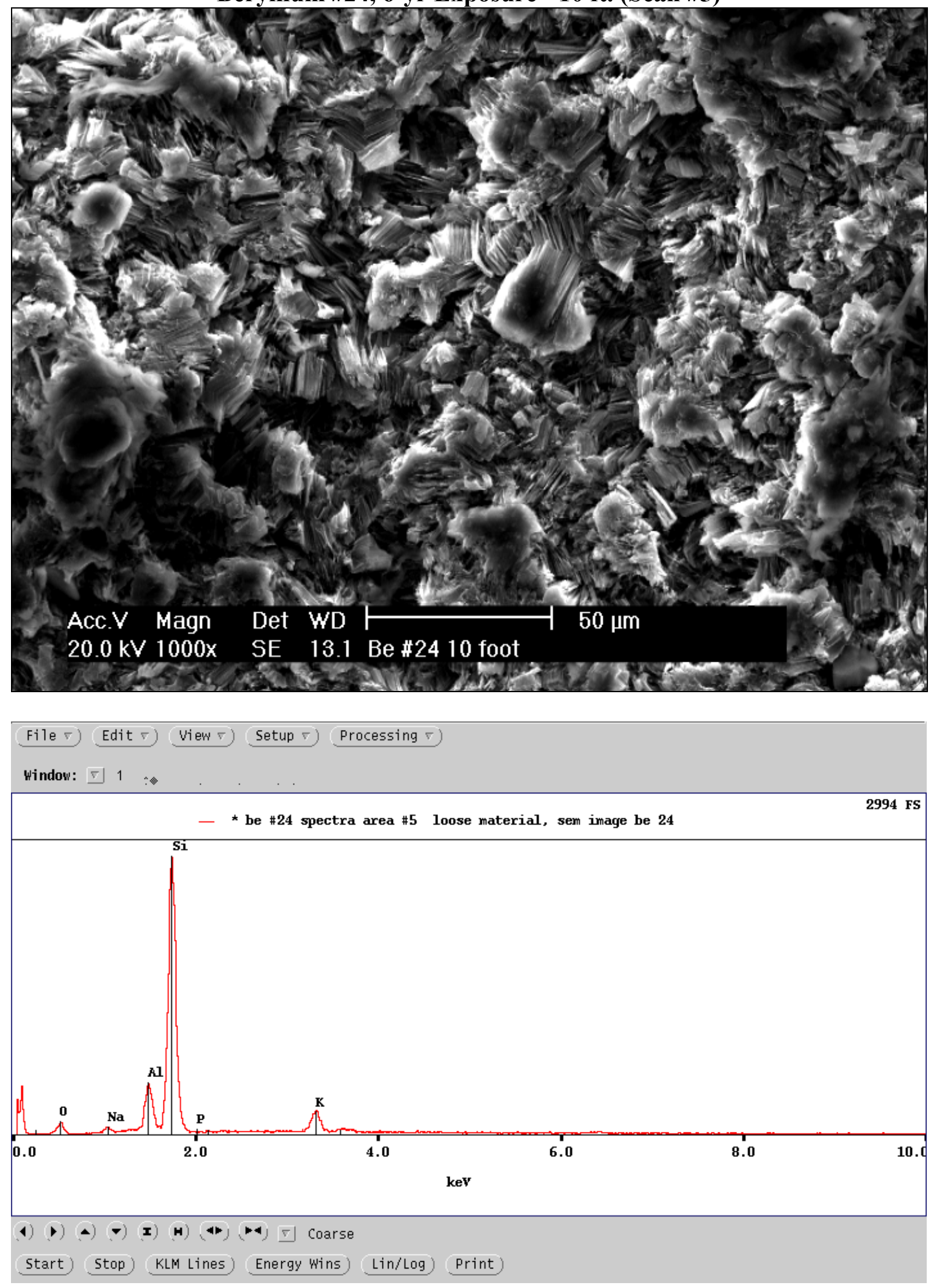


\section{Beryllium \#24, 6-yr Exposure - 10 ft. (Scan \#5) \\ (Continued)}

\begin{tabular}{|c|c|c|c|c|c|c|c|c|}
\hline \multicolumn{9}{|c|}{ PGT Bulk sample analysis $\quad$ Wed Jul 28 16:03:28 2004} \\
\hline \multicolumn{9}{|c|}{ ZAF Method, variable-width filter } \\
\hline \multicolumn{9}{|c|}{ Sample /xd1/window1/\#1,/be \#24 spectra area \#5.spt } \\
\hline \multicolumn{9}{|c|}{ Accelerating Voltage: $\quad 15.00 \mathrm{keV}$} \\
\hline \multicolumn{9}{|c|}{ Takeoff Angle: } \\
\hline \multicolumn{9}{|c|}{ Library for system standards: /imix/quant/rhodonite efficiency } \\
\hline Elm & Rel. K & $\mathrm{Z}$ & $\mathrm{A}$ & $\mathrm{F}$ & Norm $w t \%$ & Atomic $\%$ & Method used & Line \\
\hline $\mathrm{Si}$ & 0.3048 & 1.025 & 1.218 & 0.999 & 38.04 & 27.85 & From spectrum & $\mathrm{K}$ line \\
\hline $\mathrm{P}$ & 0.0000 & 1.062 & 1.542 & 0.999 & 0.999 & 0.00 & From spectrum & K line \\
\hline $\mathrm{Na}$ & 0.0041 & 1.042 & 1.926 & 0.995 & 0.81 & 0.73 & From spectrum & $\mathrm{K}$ line \\
\hline $\mathrm{Al}$ & 0.0444 & 1.050 & 1.272 & 0.979 & 5.81 & 4.43 & From spectrum & $\mathrm{K}$ line \\
\hline $\mathrm{K}$ & 0.0460 & 1.080 & 1.095 & 1.000 & 5.44 & 2.86 & From spectrum & $\mathrm{K}$ line \\
\hline $\mathrm{O}$ & 0.0000 & 0.000 & 0.000 & 0.000 & 49.90 & 64.13 & Stoichiometry & K line? \\
\hline \multicolumn{5}{|c|}{ Total } & 100.00 & 100.00 & & \\
\hline $\begin{array}{l}\text { oxyge } \\
\text { Good } \\
\text { WAR } \\
\text { WAR } \\
\text { WAR } \\
\text { WAR } \\
\end{array}$ & $\begin{array}{l}\text { analyzed } \\
\text { ss of fit } \\
\text { ING: Res } \\
\text { ING: Res } \\
\text { ING: Res } \\
\text { ING: Res }\end{array}$ & $\begin{array}{l}\text { by stoic } \\
0.94 \\
\text { dual pe } \\
\text { dual pe } \\
\text { dual pe } \\
\text { dual pe }\end{array}$ & $\begin{array}{l}\text { iometr } \\
\text { k at ap } \\
\text { k at ap } \\
\text { k at ap } \\
\text { k at ap }\end{array}$ & $\begin{array}{l}\text { oximate } \\
\text { oximate } \\
\text { oximate } \\
\text { oximate }\end{array}$ & $\begin{array}{ll}y & 1281 \mathrm{ev} \\
\mathrm{y} & 1489 \mathrm{ev} \\
\mathrm{y} & 3697 \mathrm{ev} \\
\mathrm{y} & 6395 \mathrm{ev} \\
\end{array}$ & & & \\
\hline
\end{tabular}


Beryllium \#24, 6-yr Exposure - 10 ft. (Scan \#6)

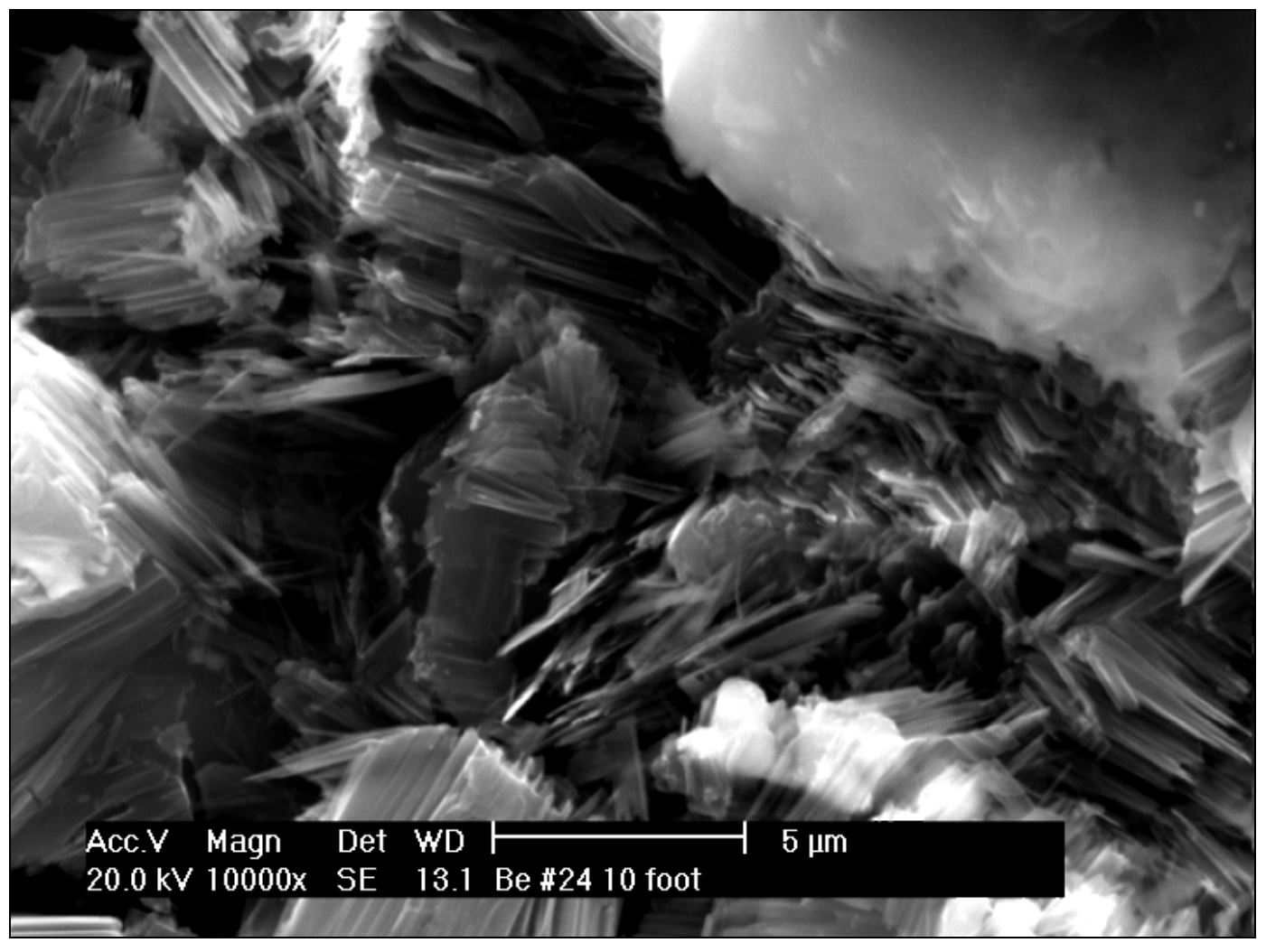


Beryllium Coupon \#24 - Scan \#7 6 yr Exposure at 10 ft

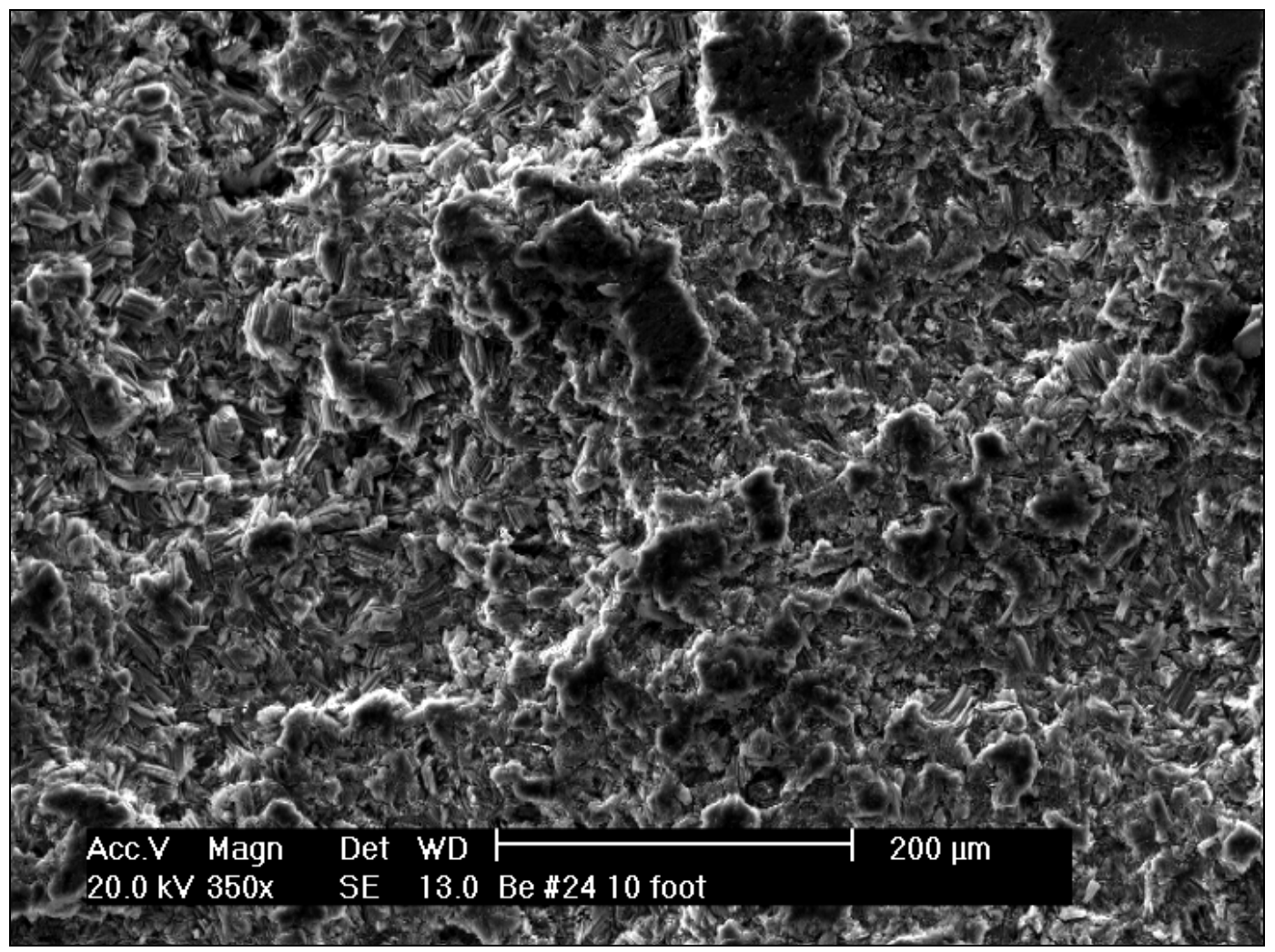

F-30 


\section{APPENDIX G}

\section{Mass-Loss Graphs}

Individual coupon mass losses, calculated as percent mass loss, from the 1-, 3-, and 6-year coupons for each composition with balance uncertainties and combined cleaning/balance uncertainties noted as error bands as applicable are detailed in this Appendix. These data plots illustrate the fact that for most compositions, with exposure times increasing, the mass losses are being to have significance. For those compositions with mass losses falling within the uncertainty boundaries, the rate was reported as "no reportable corrosion". 
(This page intentionally left blank.) 
Type 304L Coupons \% Mass Change at 4-Ft Depth

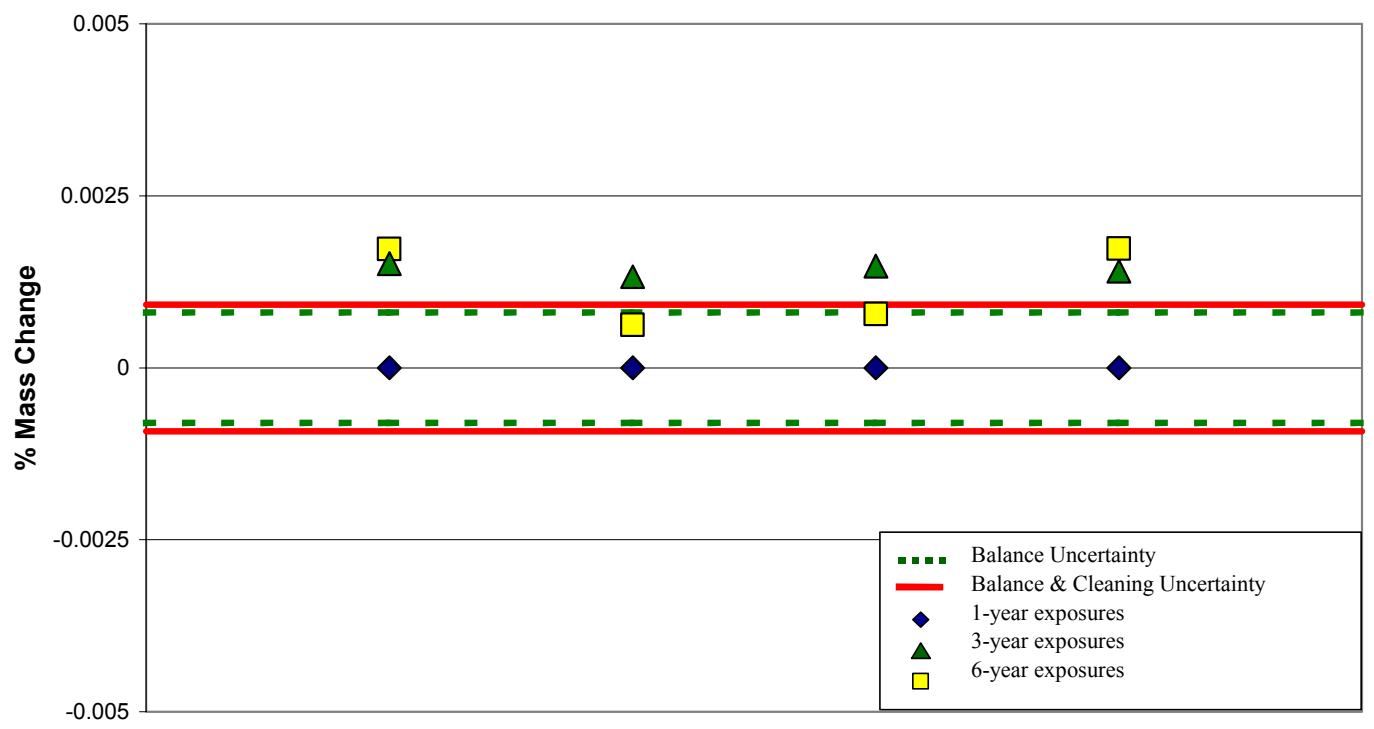

Figure G1. 4-ft depth - Type 304L \% mass change.

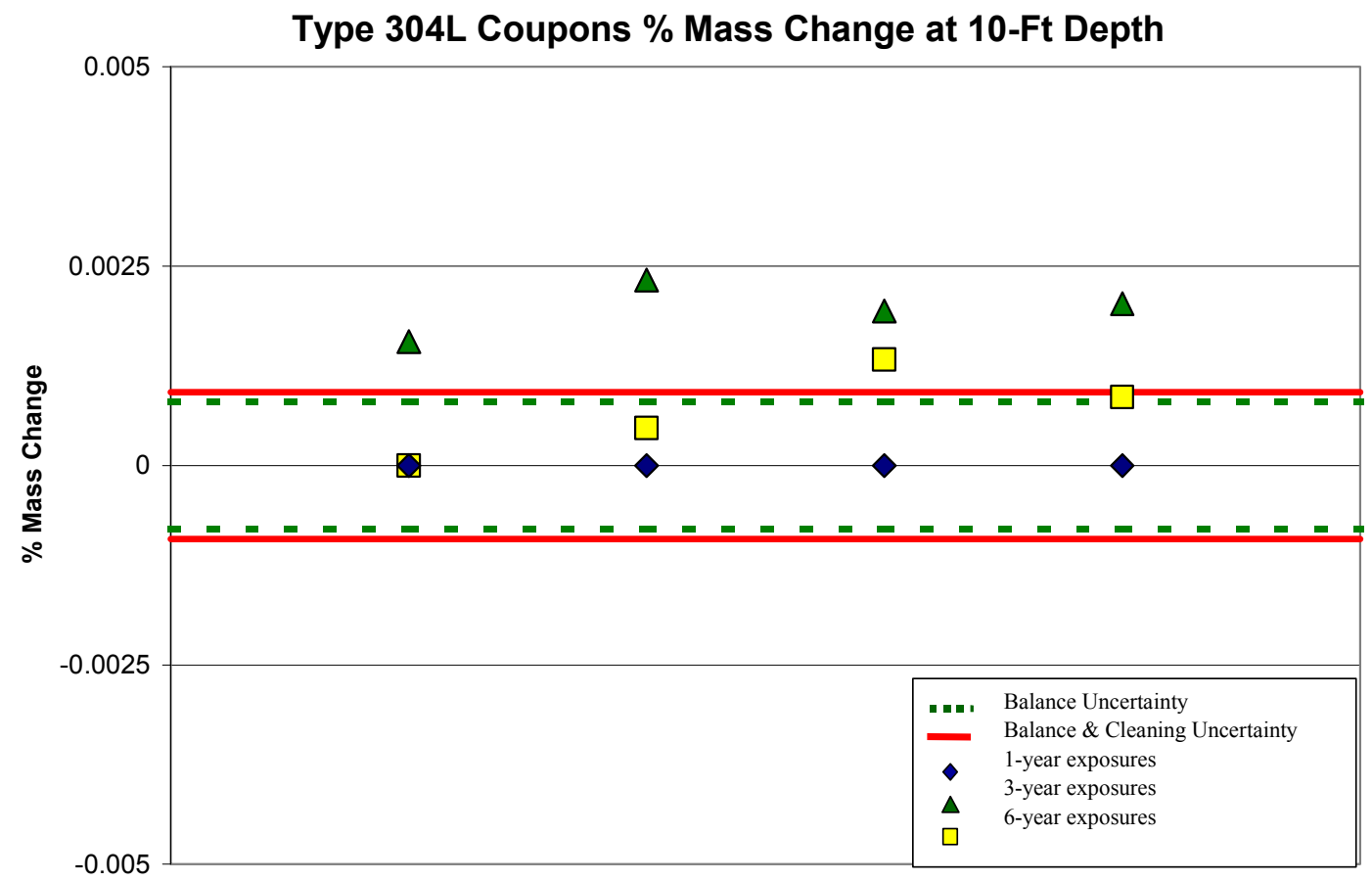

Figure G2. 10-ft depth - Type 304L \% mass change. 
Type 316L Coupons \% Mass Change at 4-Ft Depth

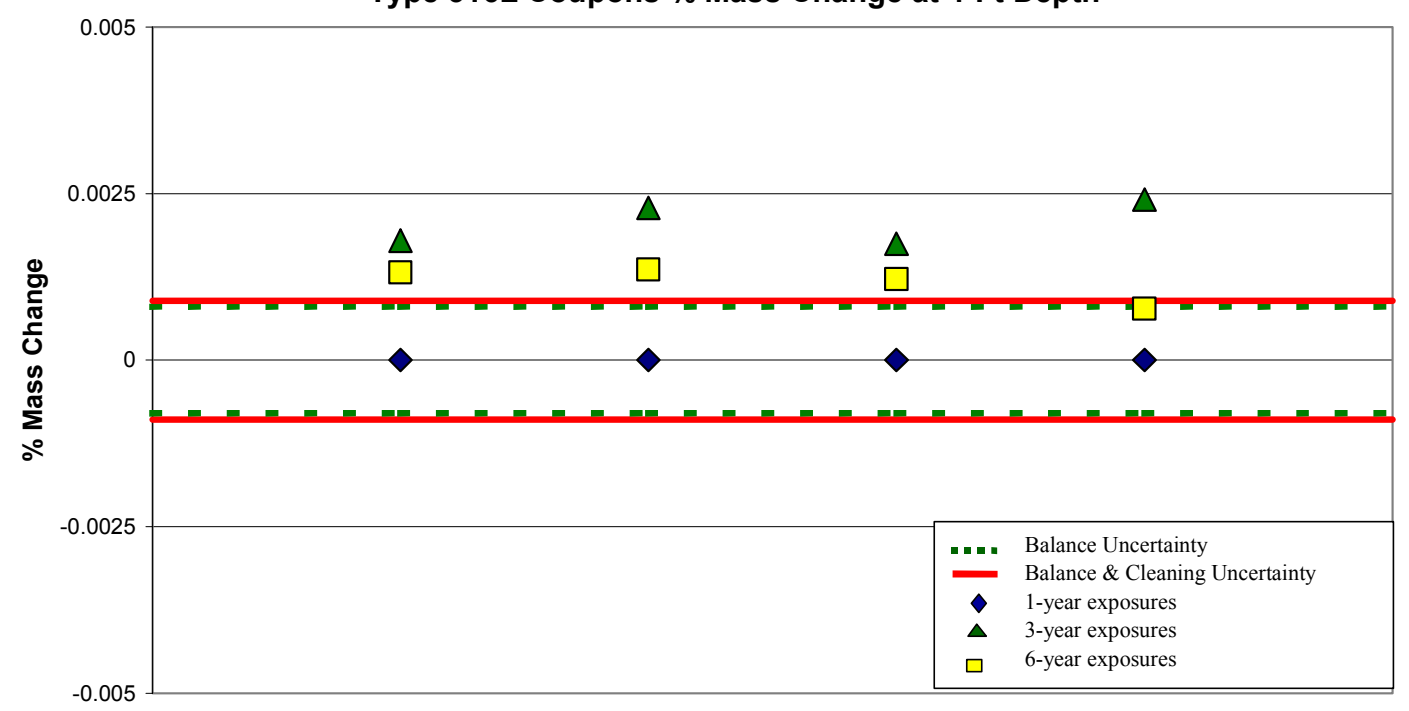

Figure G3. 4-ft depth - Type 316L \% mass change.

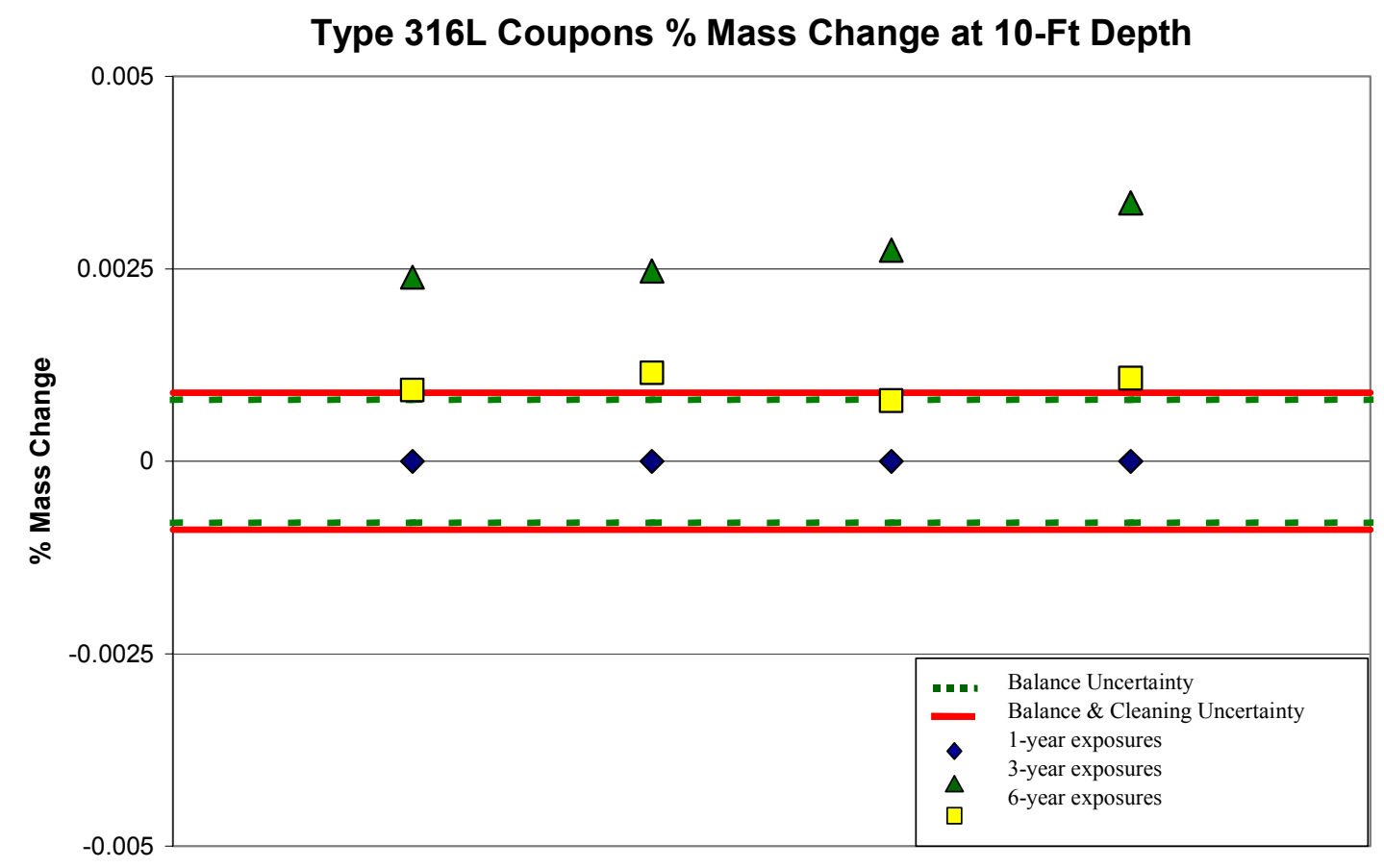

Figure G4. 10-ft depth - Type 316L \% mass change. 


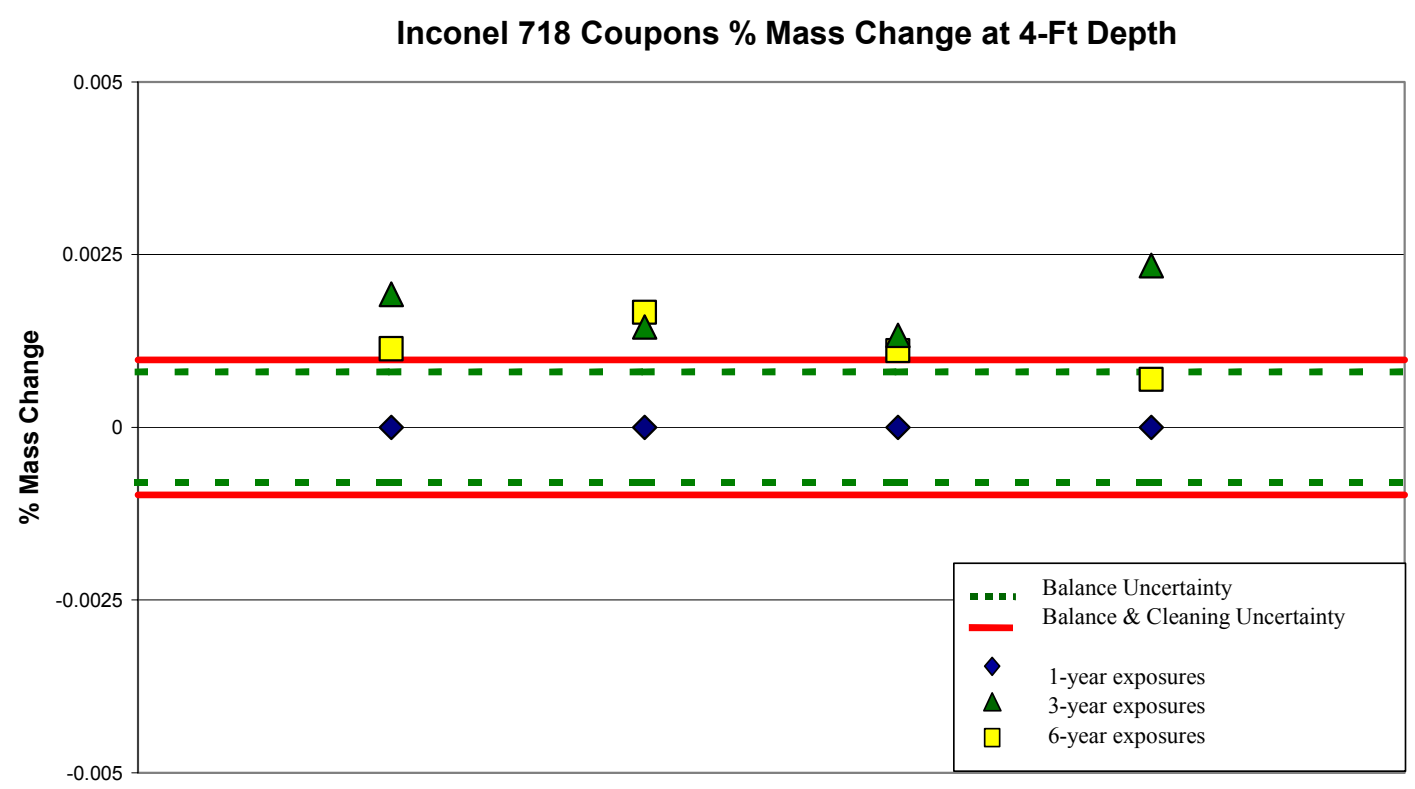

Figure G5. 4-ft depth - Inconel $718 \%$ mass change.

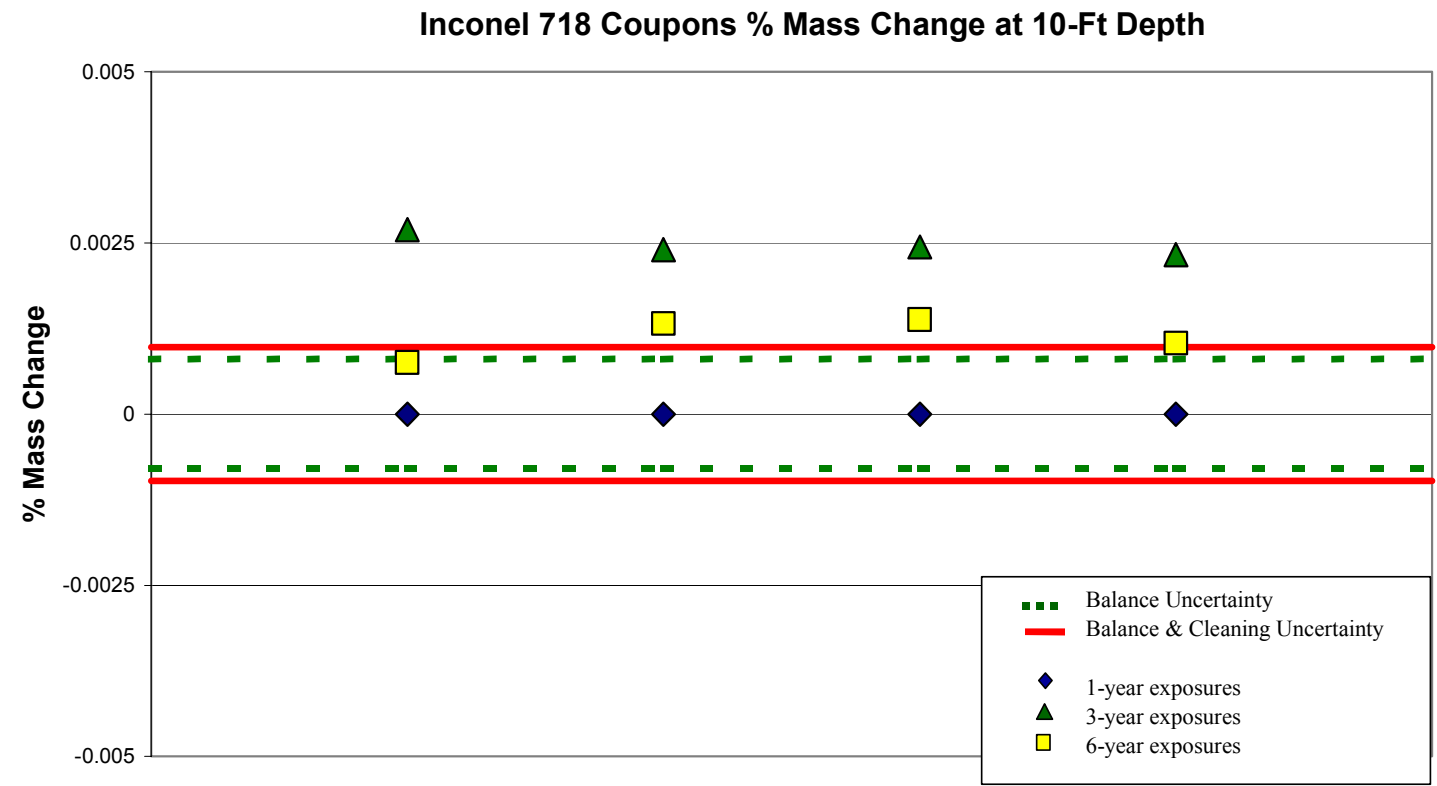

Figure G6. 10-ft depth - Inconel $718 \%$ mass change. 


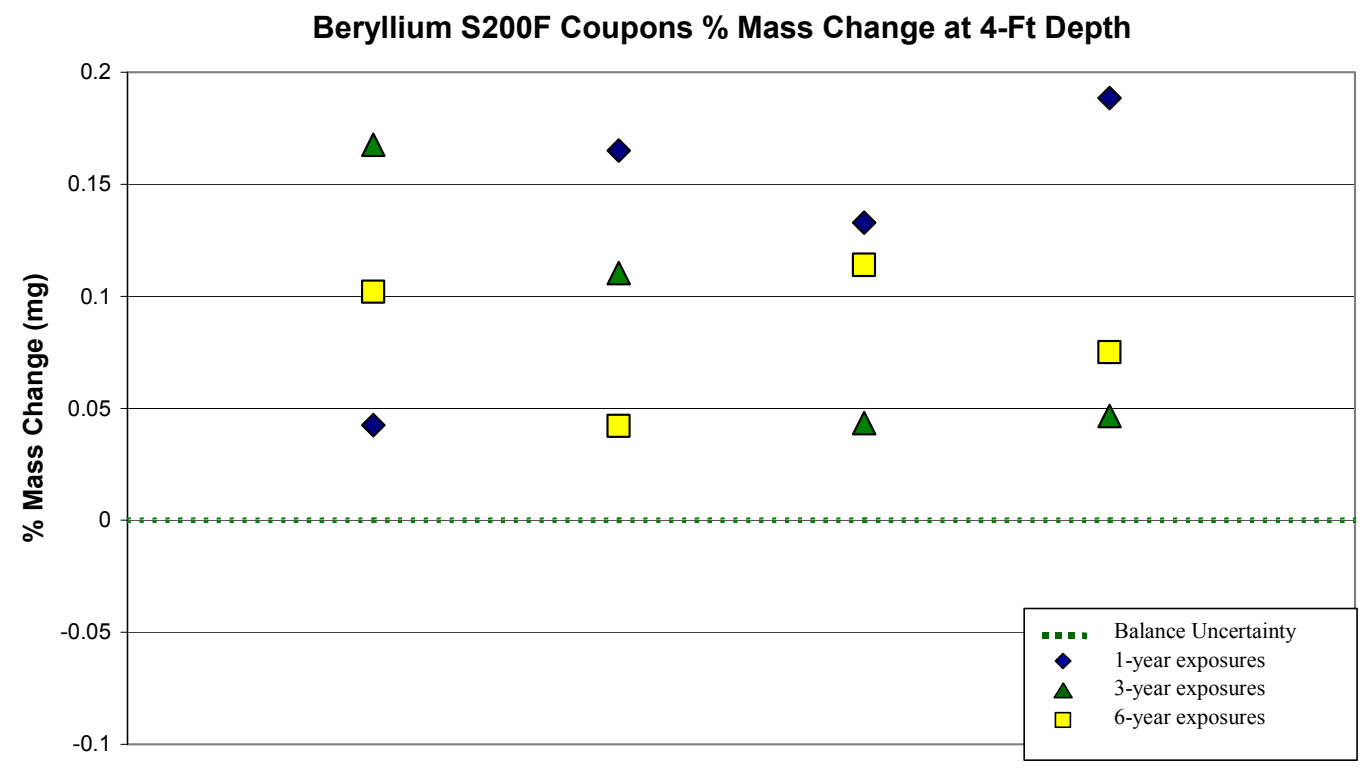

Figure G7. 4-ft depth - beryllium S200F \% mass change.

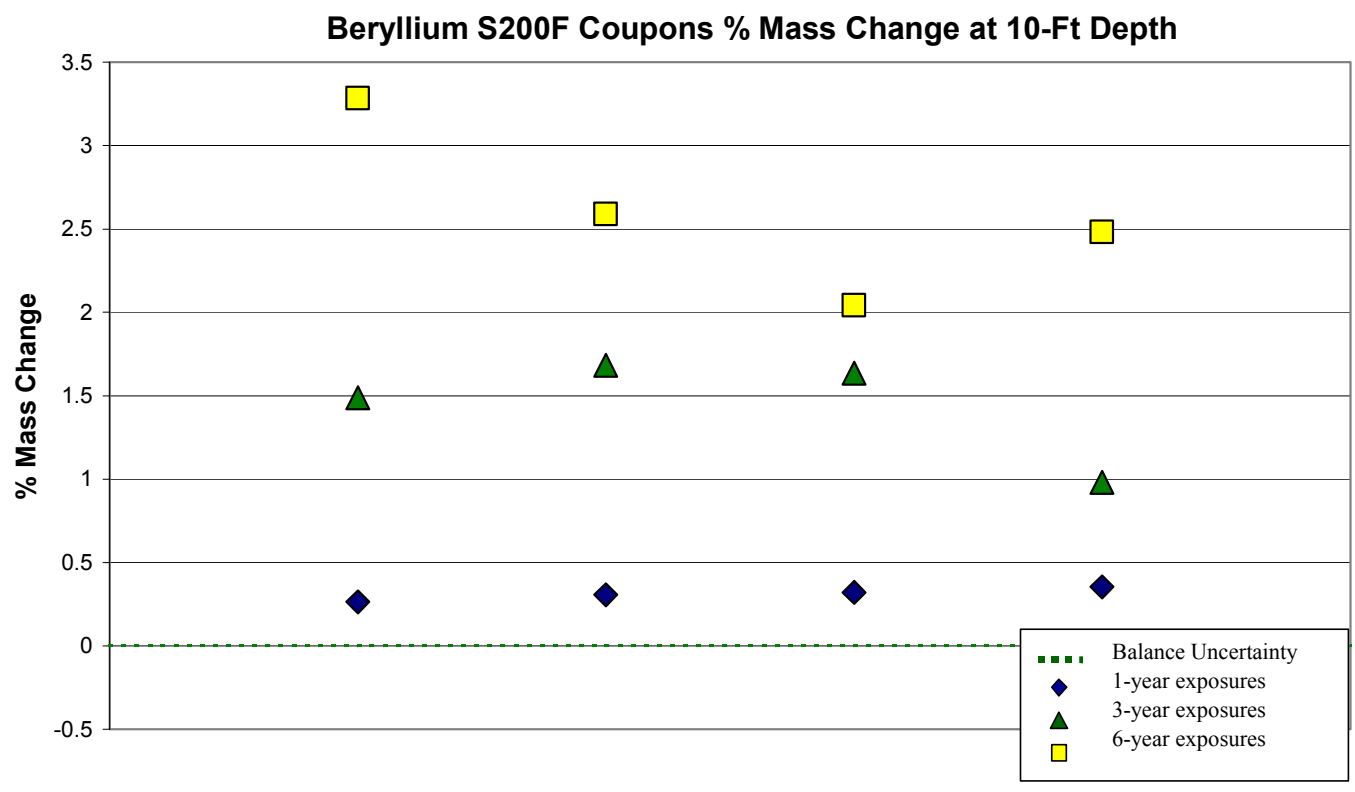

Figure G8. 10-ft depth - beryllium S200F \% mass change. 


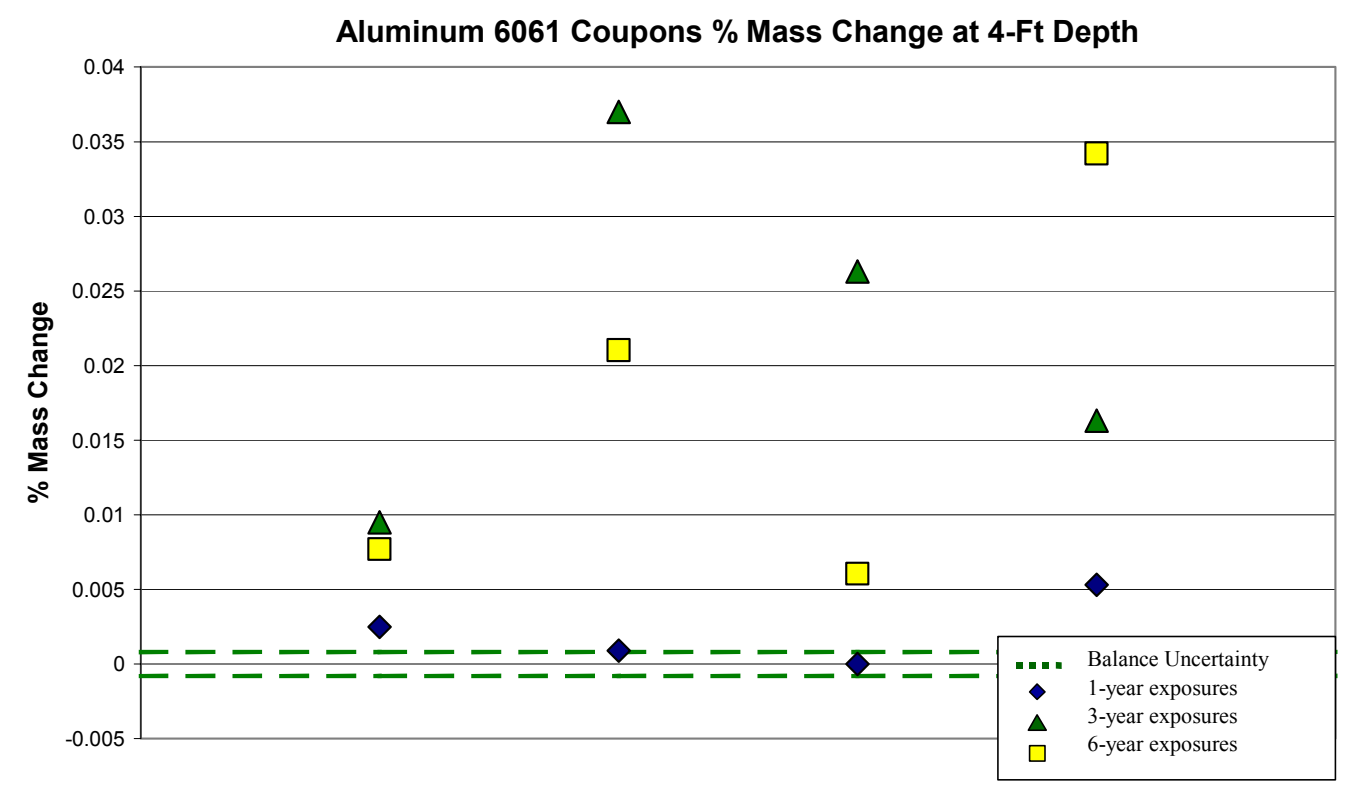

Figure G9. 4-ft depth - aluminum $6061 \%$ mass change.

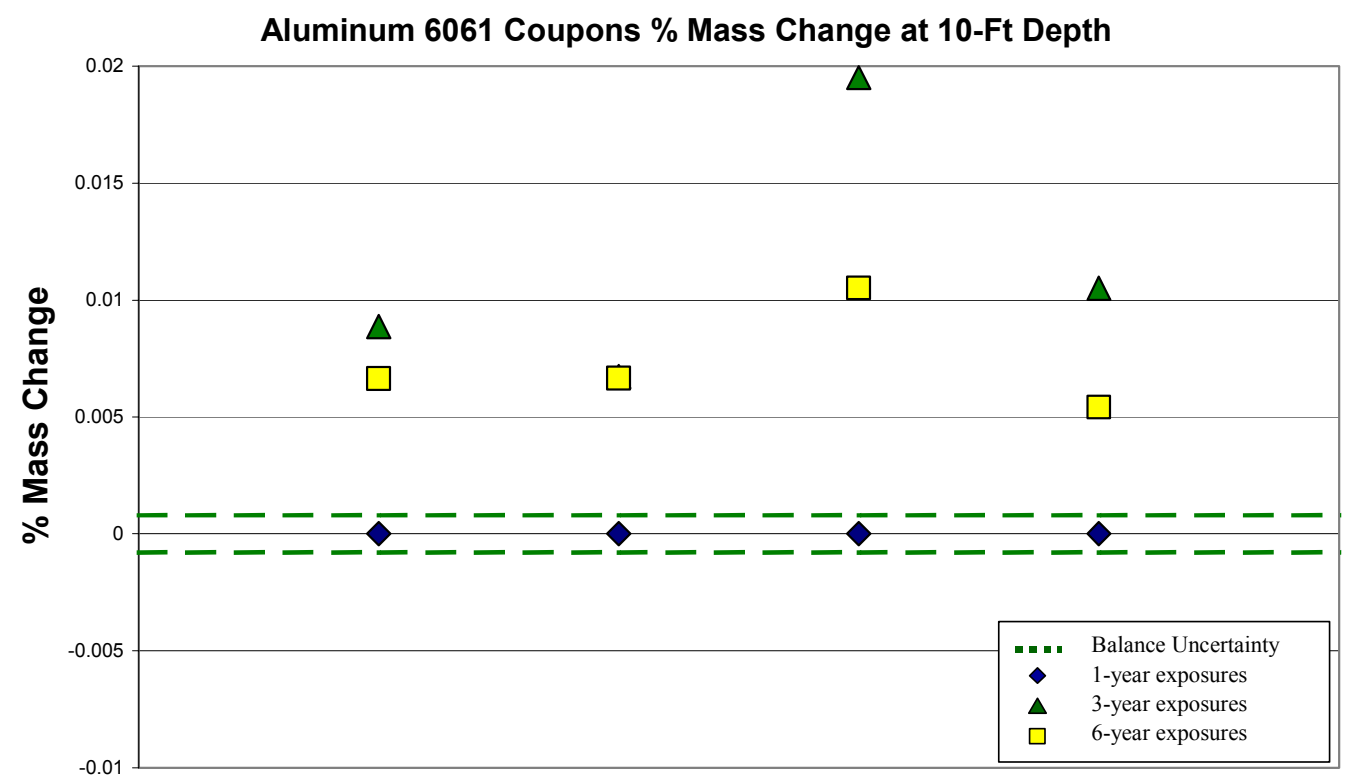

Figure G10. 10-ft depth - aluminum $6061 \%$ mass change. 


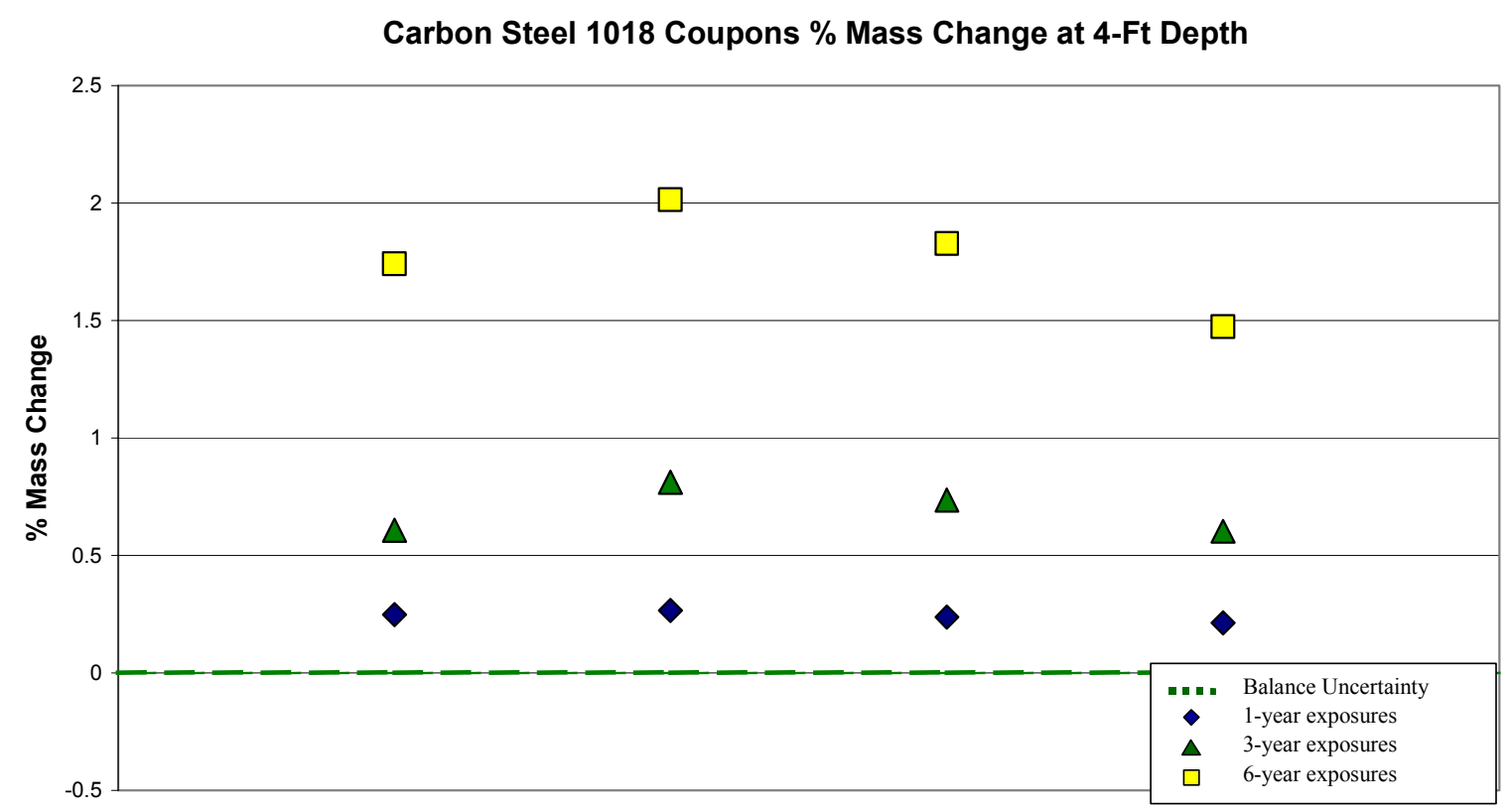

Figure G11. 4-ft depth - carbon steel $1018 \%$ mass change.

Carbon Steel 1018 Coupons \% Mass Change at 10-Ft Depth

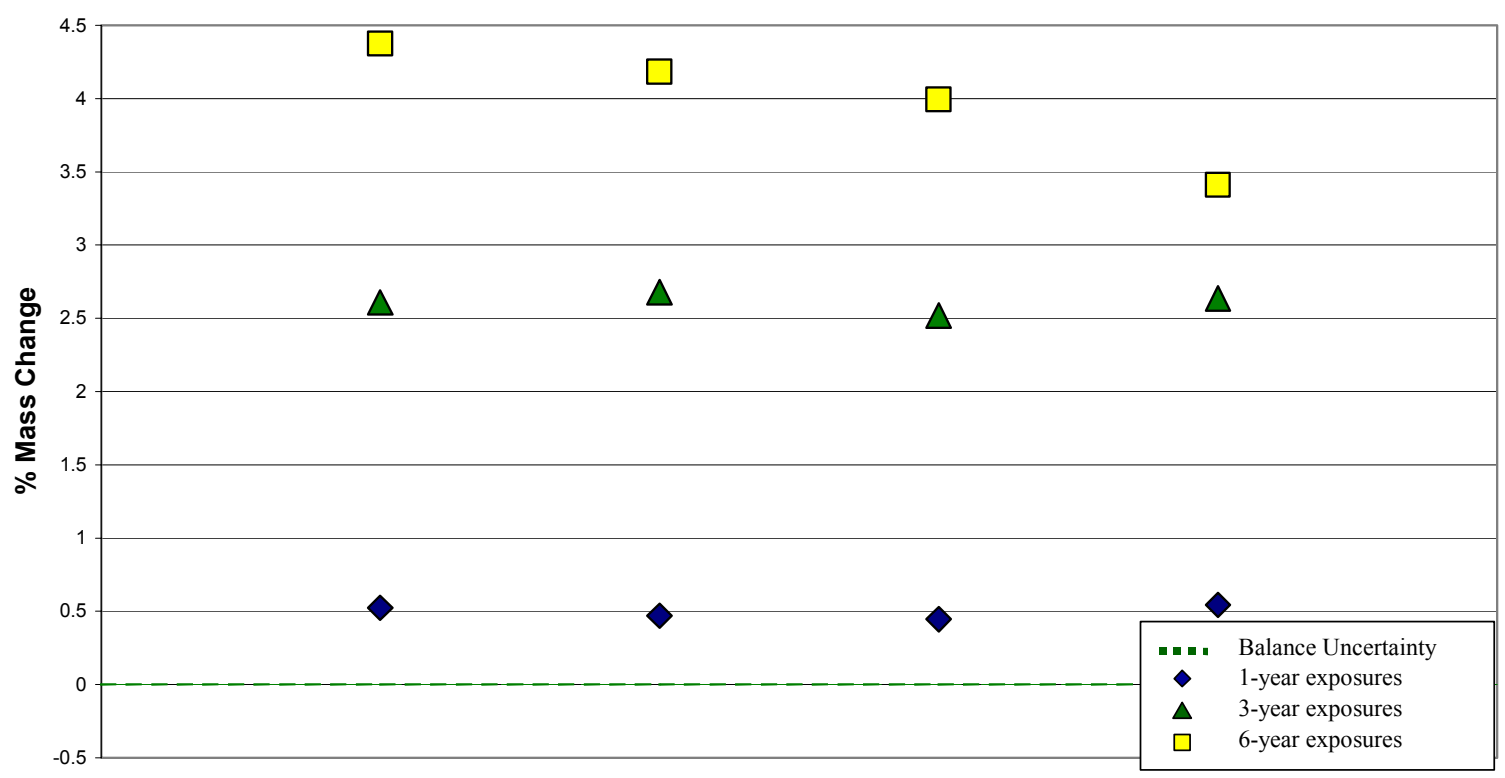

Figure G12. 10-ft depth - carbon steel $1018 \%$ mass change. 


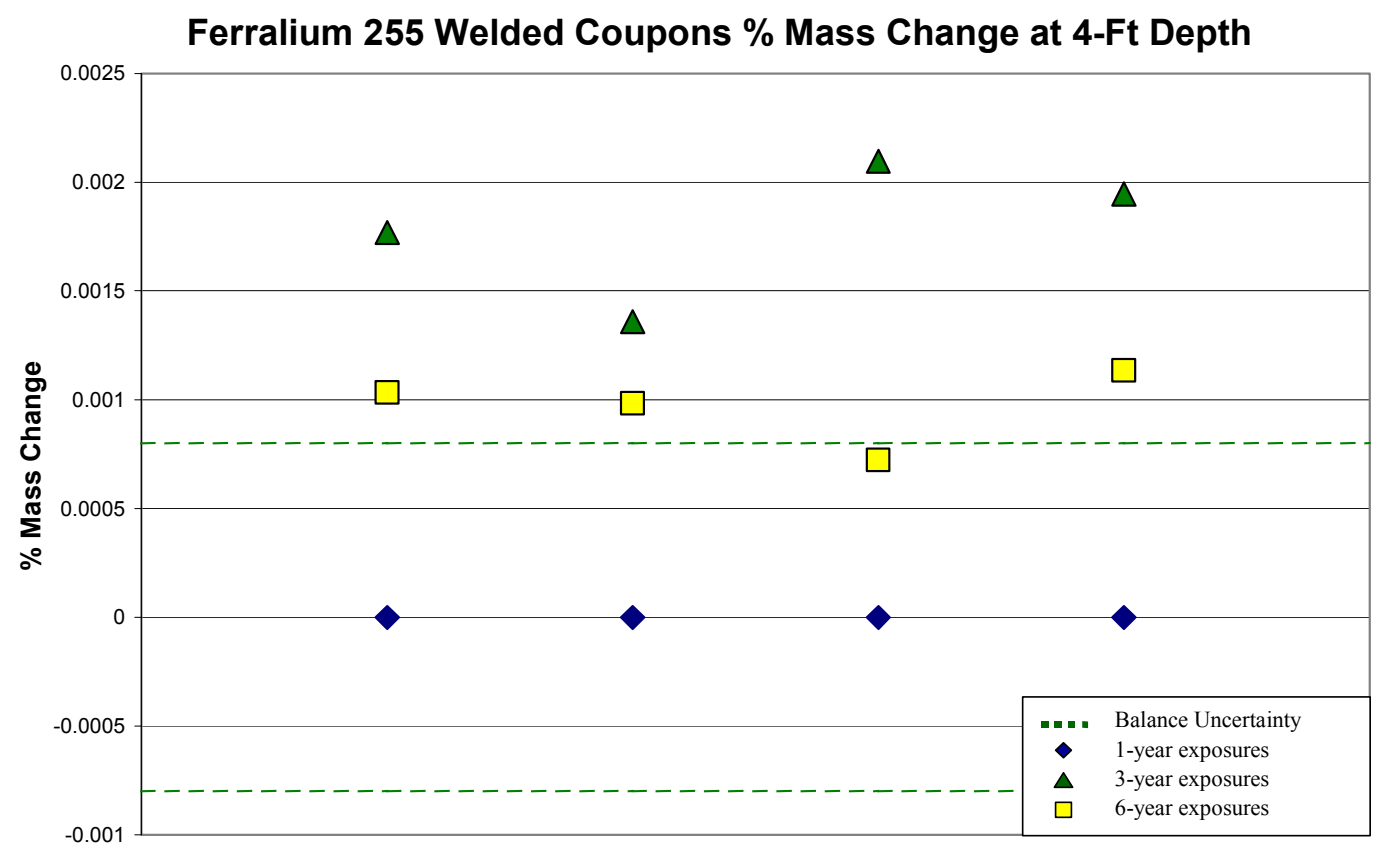

Figure G13. 4-ft depth - Ferralium $255 \%$ mass change

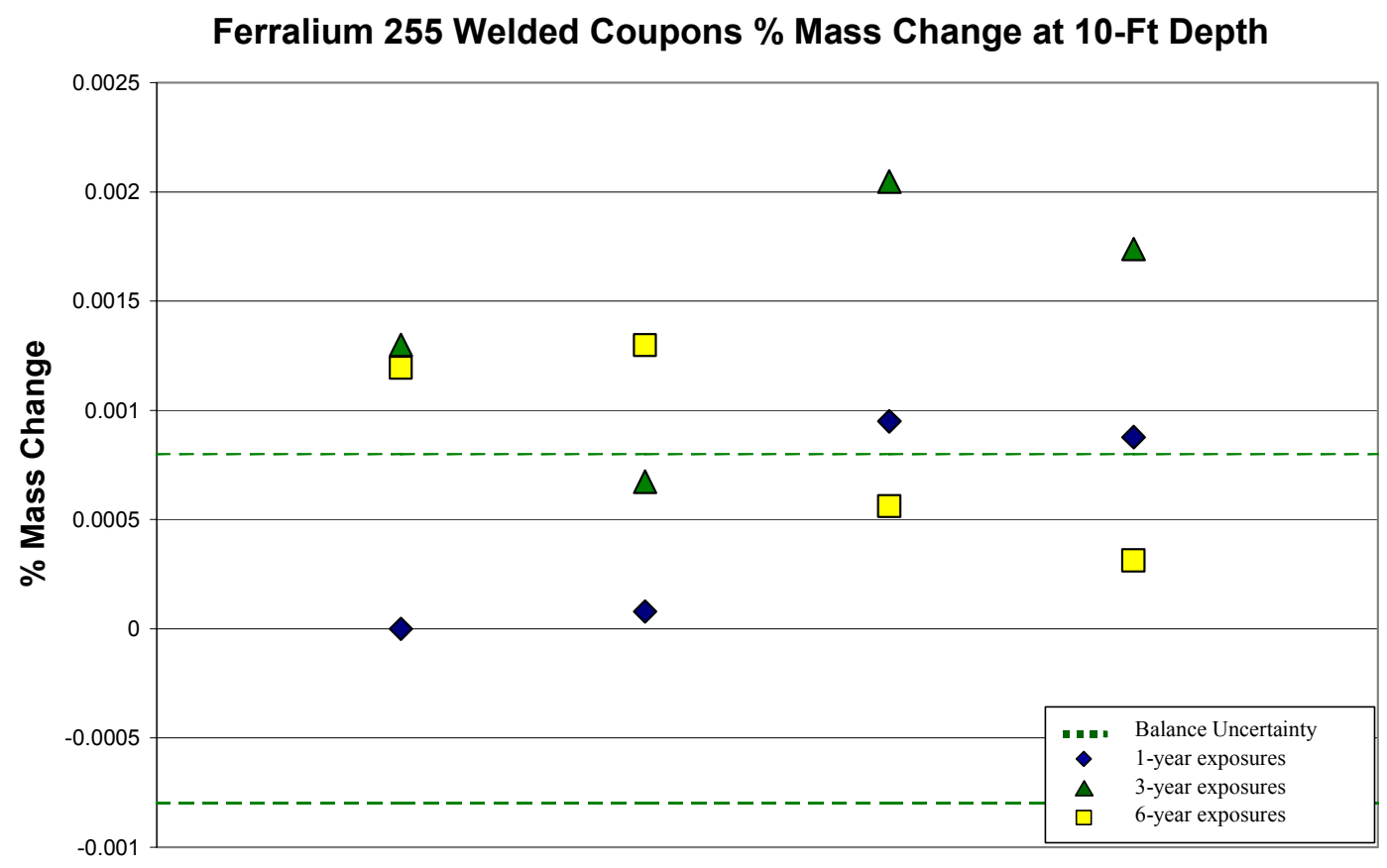

Figure G14. 10-ft depth - Ferralium $255 \%$ mass change. 
Type 316L Welded Coupons \% Mass Change at 4-Ft Depth

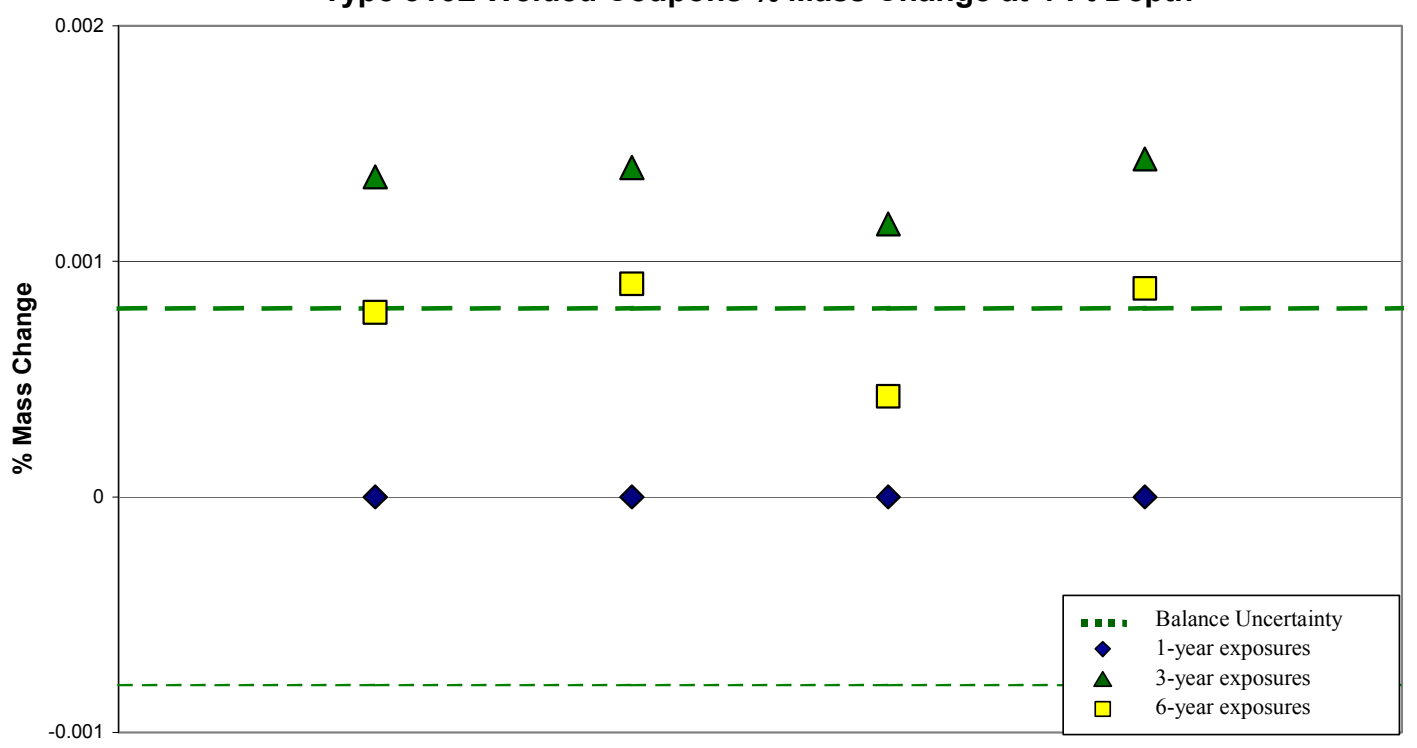

Figure G15. 4-ft depth $-316 \mathrm{~L}$ welded \% mass change.

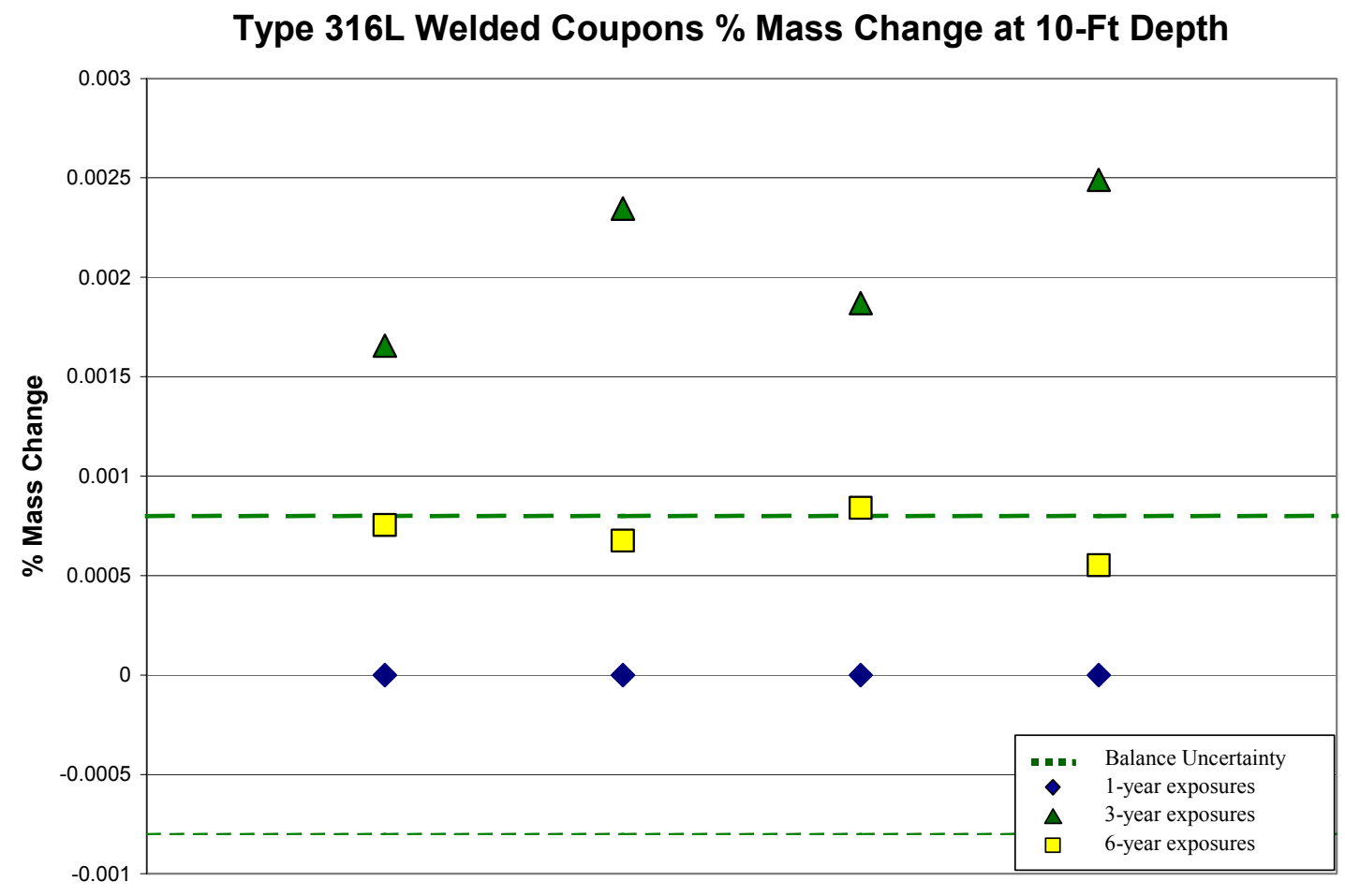

Figure G16. 10-ft depth $-316 \mathrm{~L}$ welded \% mass change. 


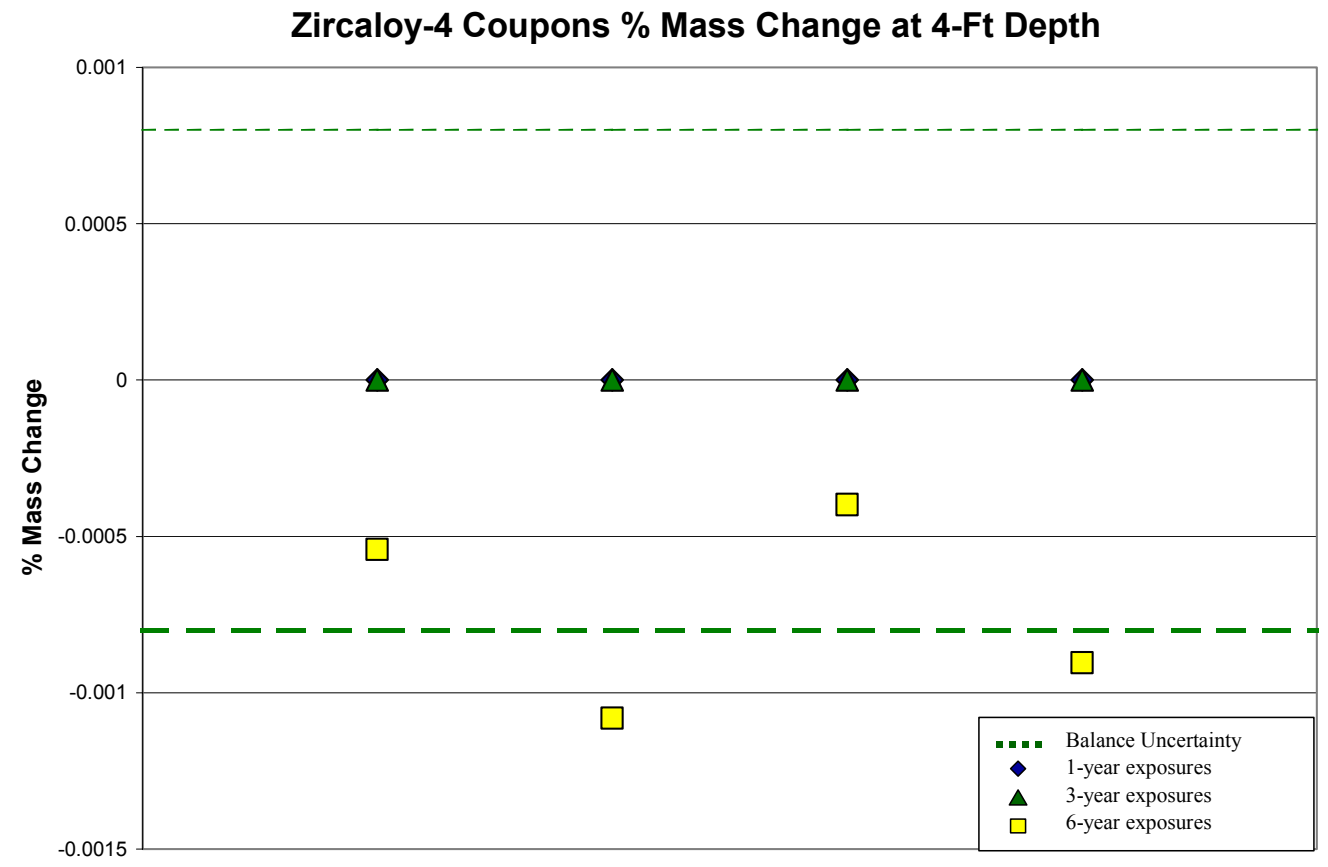

Figure G17. 4-ft depth - Zircaloy-4 \% mass change.

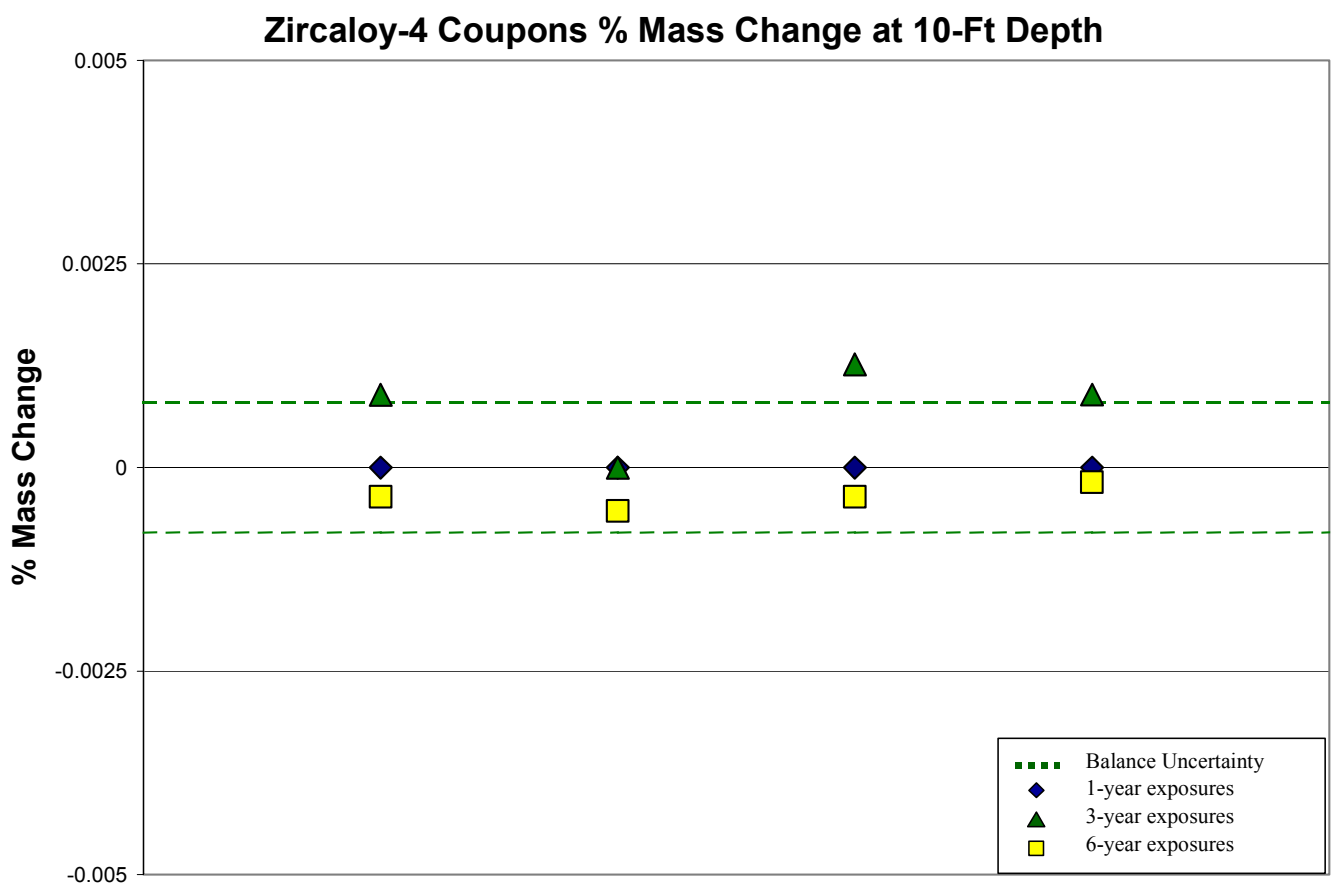

Figure G18. 10-ft depth - Zircaloy-4 \% mass change. 
(This page intentionally left blank.) 


\section{APPENDIX H}

Electrical Resistance Probes 
(This page intentionally left blank.) 


\section{E/R PROBES LOCATION II - 4-FT DEPTH}
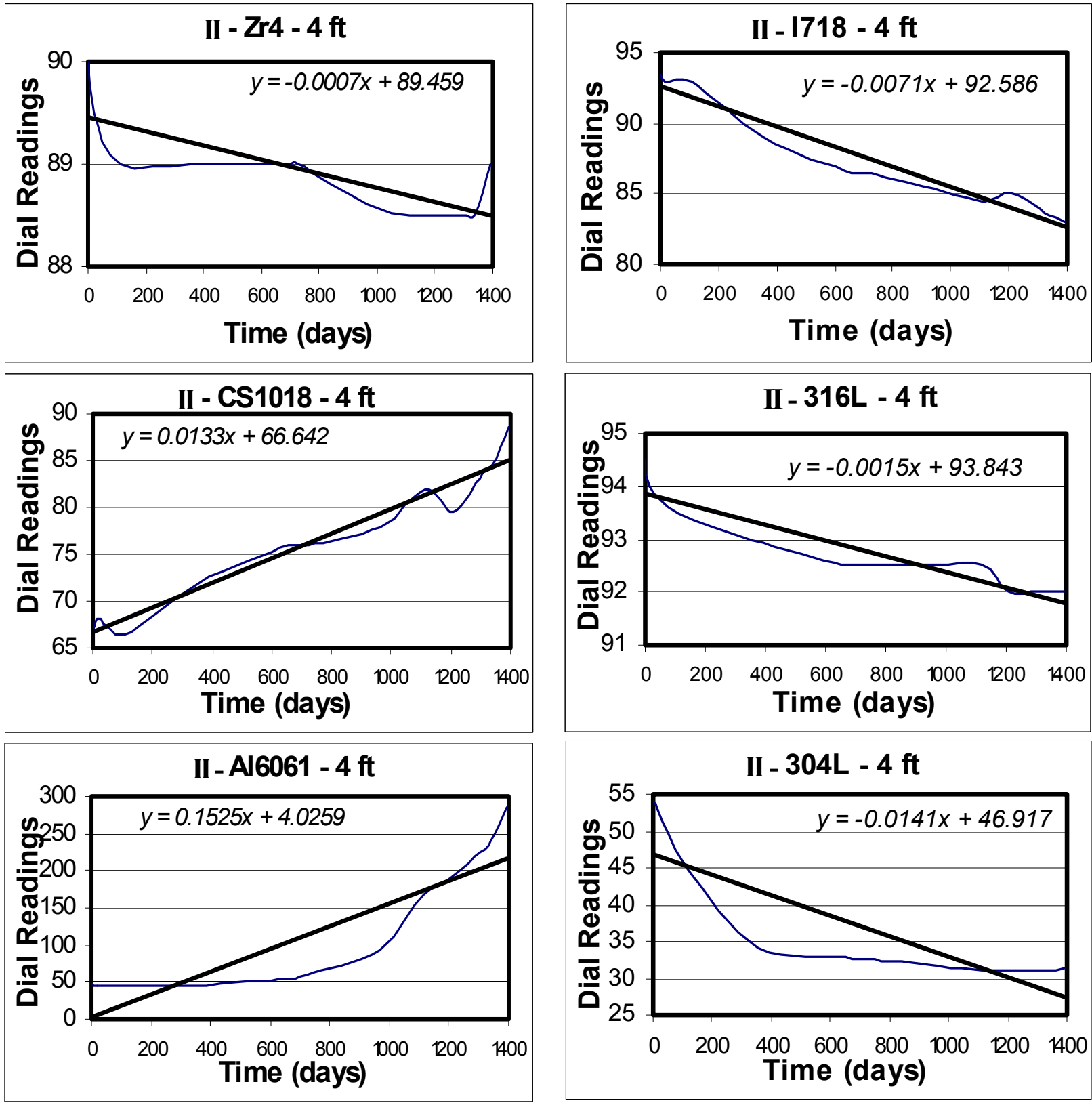

Table H-1. Corrosion rates for E/R probes at location II at 4-ft depth.

\begin{tabular}{llccc}
\hline \multicolumn{1}{c}{ Material } & \multicolumn{1}{c}{ Span } & Slope & Mils per year & $\mathrm{mm} /$ year \\
\hline Inconel 718 & 2.5 & -0.0071 & -0.0065 & $-2 \mathrm{E}-04$ \\
Zircaloy-4 & 5 & -0.0007 & -0.0013 & $-3 \mathrm{E}-05$ \\
Type 316L SS & 2.5 & -0.0015 & -0.0014 & $-3 \mathrm{E}-05$ \\
Type 304L SS & 2.5 & -0.0141 & -0.0129 & $-3 \mathrm{E}-04$ \\
Carbon Steel 1018 & 10 & 0.0133 & 0.0485 & 0.0012 \\
Aluminium 6061 & 10 & 0.1525 & 0.5566 & 0.0141 \\
\hline
\end{tabular}




\section{E/R PROBES LOCATION II - 10-FT DEPTH}
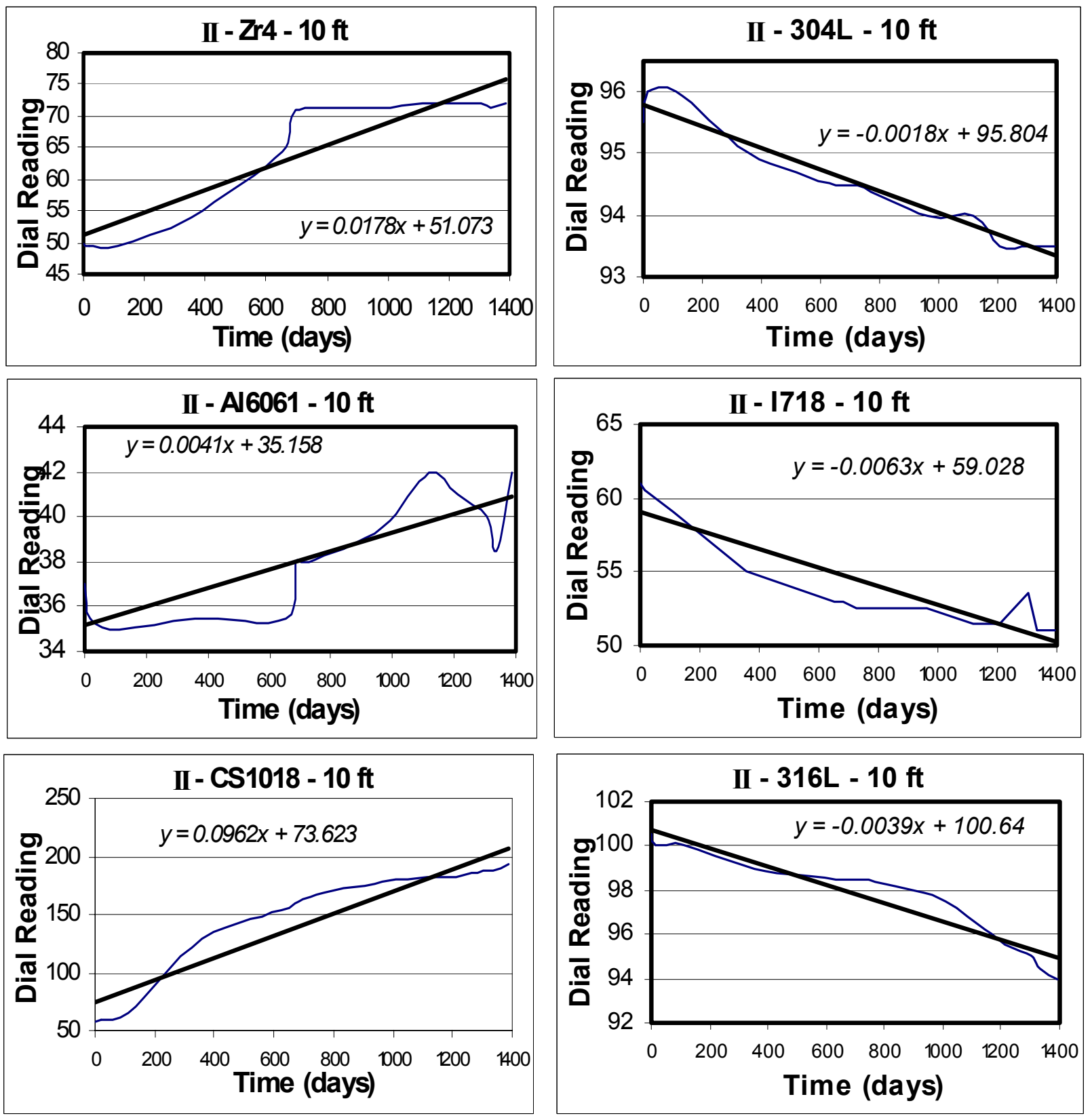

Table H-2. Corrosion rates for E/R probes at location II at 10-ft depth.

\begin{tabular}{llccc}
\hline \multicolumn{1}{c}{ Material } & \multicolumn{1}{c}{ Span } & Slope & Mils per year & $\mathrm{mm} /$ year \\
\hline Inconel 718 & 2.5 & -0.0063 & -0.0057 & $-1 \mathrm{E}-04$ \\
Zircaloy-4 & 5 & 0.0178 & 0.0325 & 0.0008 \\
Type 316L SS & 2.5 & -0.0039 & -0.0036 & $-9 \mathrm{E}-05$ \\
Type 304L SS & 2.5 & -0.0018 & -0.0016 & $-4 \mathrm{E}-05$ \\
Carbon Steel 1018 & 10 & 0.0962 & 0.3511 & 0.0089 \\
Aluminium 6061 & 10 & 0.0041 & 0.0149 & 0.0004 \\
\hline
\end{tabular}




\section{E/R PROBES LOCATION III - 4-FT DEPTH}
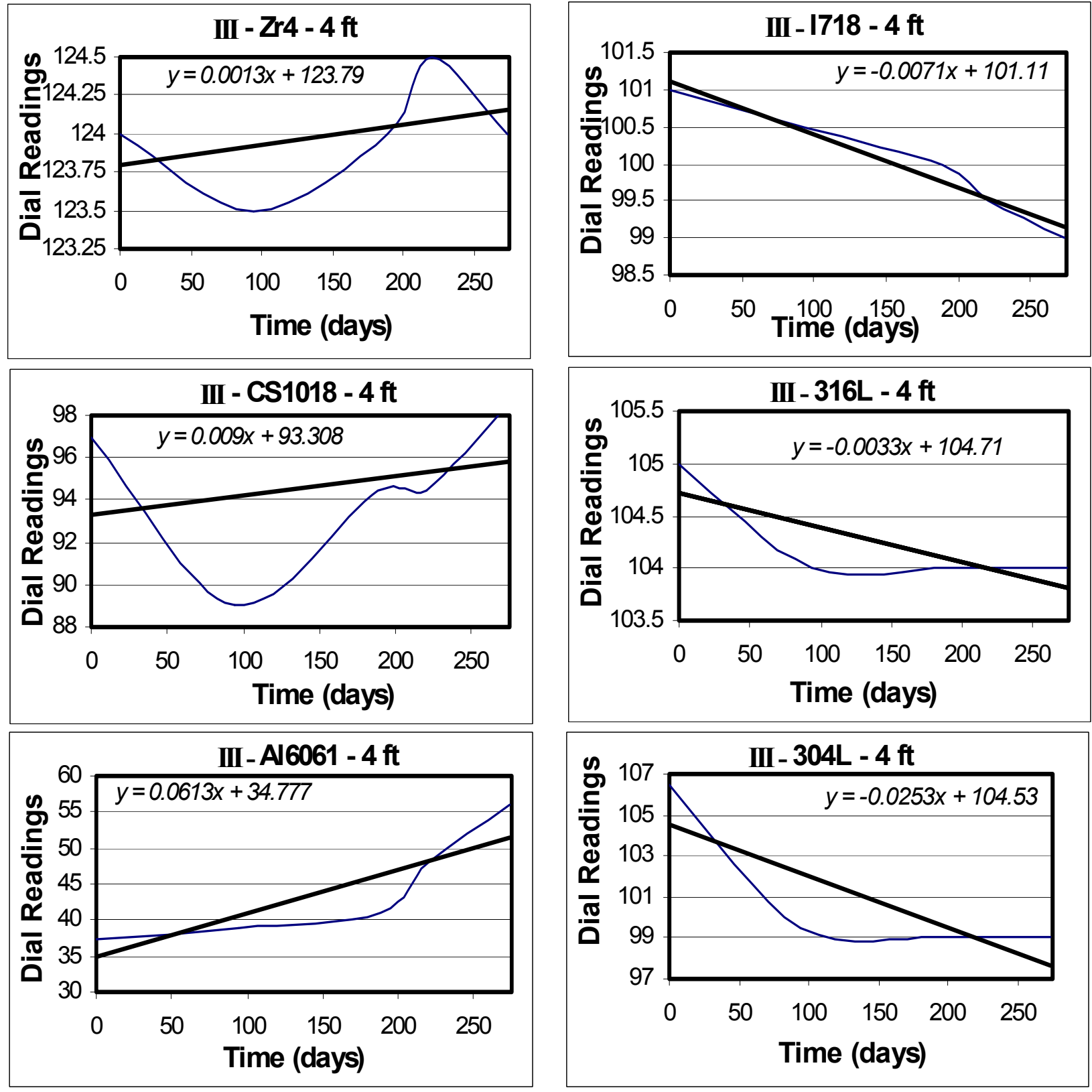

Table H-3 Corrosion rates for E/R probes at location III at 4-ft depth.

\begin{tabular}{llccc}
\hline \multicolumn{1}{c}{ Material } & \multicolumn{1}{c}{ Span } & Slope & Mils per year & $\mathrm{mm} /$ year \\
\hline Inconel 718 & 2.5 & -0.0071 & -0.0060 & -0.0002 \\
Zircaloy-4 & 5 & 0.0013 & 0.0024 & $6 \mathrm{E}-05$ \\
Type 316L SS & 2.5 & -0.0033 & -0.0030 & $-8 \mathrm{E}-05$ \\
Type 304L SS & 2.5 & -0.0253 & -0.0230 & -0.0006 \\
Carbon Steel 1018 & 10 & 0.0090 & 0.0329 & 0.0008 \\
Aluminium 6061 & 10 & 0.0613 & 0.2237 & 0.0057 \\
\hline
\end{tabular}




\section{E/R PROBES LOCATION III - 10 FT DEPTH}
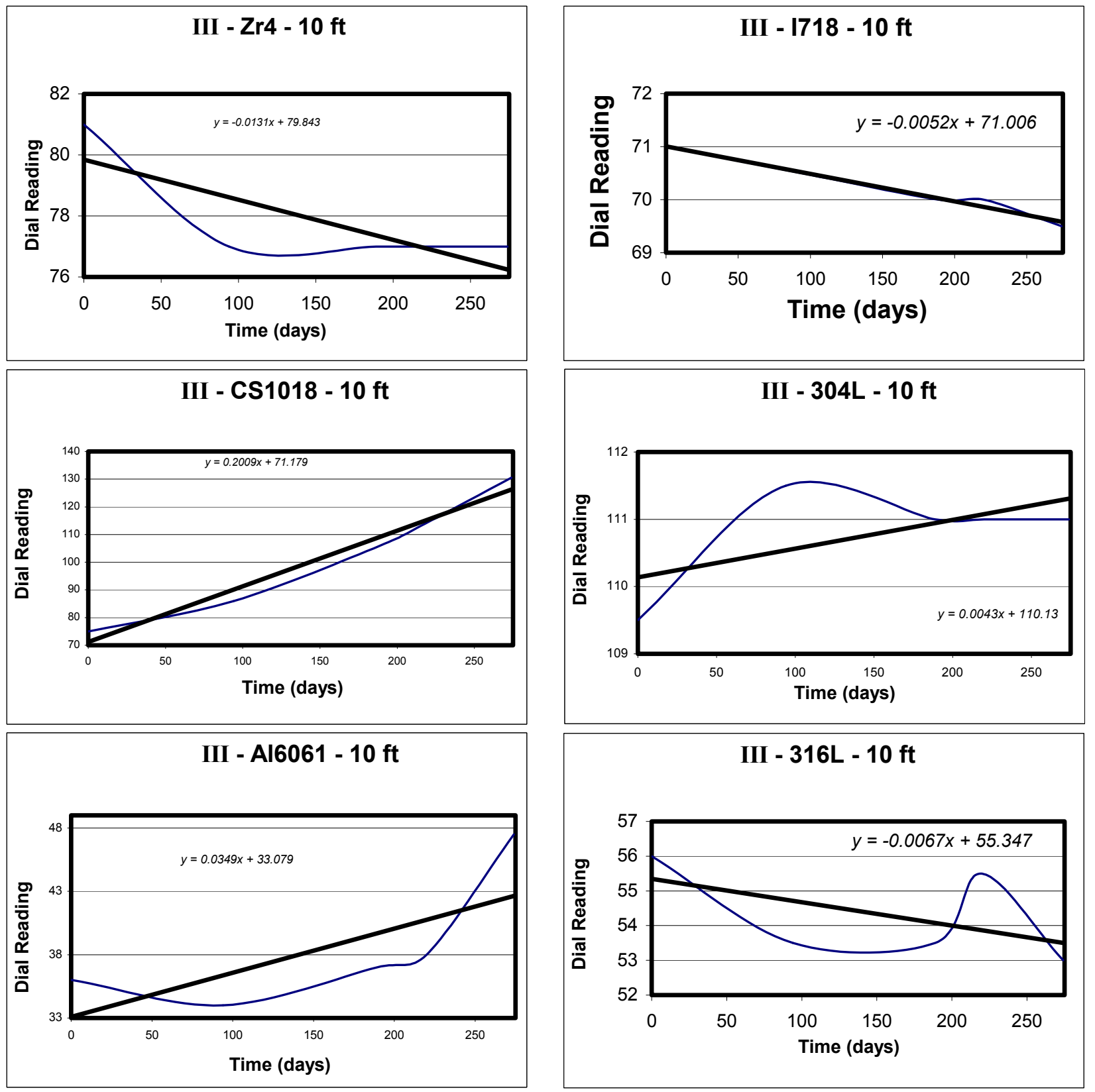

Table H-4. Corrosion rates for E/R probes at location III at 10-ft depth.

\begin{tabular}{llccc}
\multicolumn{1}{c}{ Material } & \multicolumn{1}{c}{ Span } & Slope & Mils per year & $\mathrm{mm} /$ year \\
\hline Inconel 718 & 2.5 & -0.0052 & -0.0047 & -0.0001 \\
Zircaloy-4 & 5 & -0.0131 & -0.0239 & -0.0006 \\
Type 316L SS & 2.5 & -0.0067 & -0.0061 & -0.0002 \\
Type 304L SS & 2.5 & 0.0043 & 0.0039 & $1 \mathrm{E}-04$ \\
Carbon Steel 1018 & 10 & 0.2009 & 0.7333 & 0.0186 \\
Aluminium 6061 & 10 & 0.0349 & 0.1274 & 0.0032 \\
\hline
\end{tabular}


APPENDIX I

Soil Properties 
(This page intentionally left blank.) 
Table I-1. Comparison of soil analyses from INEEL and Hanford Site.

\begin{tabular}{|c|c|c|}
\hline DATA & INEEL & HANFORD SITE \\
\hline Resistivity: Wenner array ohm-cm. & 10,000 & - \\
\hline Resistivity: Miller box ohm-cm.(saturated) & $2,750-4,500$ & 16,000 \\
\hline Moisture content $(\%)$ & $3.45-13.7$ & $0.67-6.49$ \\
\hline Soil $\mathrm{pH}\left(\right.$ in $\left.0.01 \mathrm{M} \mathrm{CaCl}_{2}\right)$ & $8.1-8.3$ & $7.08-7.66$ \\
\hline Acidity $(\mathrm{meq} / 100 \mathrm{~g})$ & $3.4-16.2$ & $2-4$ \\
\hline \multicolumn{3}{|l|}{ Soluble Ions (meq/100 g) } \\
\hline Calcium $\left(\mathrm{Ca}^{-2}\right)$ & $0.11-0.25$ & $0.0039-0.0082$ \\
\hline Magnesium $\left(\mathrm{Mg}^{+2}\right)$ & $0.07-0.26$ & $0.0045-0.033$ \\
\hline Potassium $\left(\mathrm{K}^{+}\right)$ & $0.004-0.01$ & $0.0022-0.011$ \\
\hline Sodium $\left(\mathrm{Na}^{+}\right)$ & $0.028-0.05$ & $0.0055-0.18$ \\
\hline Carbonate $\left(\mathrm{CO}_{3}^{-2}\right)$ & ND & - \\
\hline Bicarbonate $\left(\mathrm{HCO}_{3}{ }^{-1}\right)$ & $0.10-0.29$ & $0.013-0.086$ \\
\hline Sulfate $\left(\mathrm{SO}_{4}{ }^{-2}\right)$ & $0.02-0.05$ & $0.004-0.042$ \\
\hline Sulfide $\left(\mathrm{S}^{-2}\right)$ & ND & ND-0.00025 \\
\hline Chloride $\left(\mathrm{Cl}^{-}\right)$ & $0.006-0.02$ & $0.00096-0.16$ \\
\hline \multicolumn{3}{|l|}{ Exchangeable cations (meq/100 g) } \\
\hline Calcium $\left(\mathrm{Ca}^{2+}\right)$ & $14.1-44.1$ & $6.7-26.0$ \\
\hline Magnesium $\left(\mathrm{Mg}^{2+}\right)$ & $3.94-11.9$ & $0.91-2.1$ \\
\hline Potassium $\left(\mathrm{K}^{+}\right)$ & $0.54-1.19$ & $1.4-9.6$ \\
\hline Sodium $\left(\mathrm{Na}^{+}\right)$ & 0.09-0.22 & $0.072-1.0$ \\
\hline \multicolumn{3}{|l|}{ Cation Exchange Capacity (meq/100 g) } \\
\hline Exchangeable Bases & $19.05-57.41$ & 19 \\
\hline Exchangeable acidity & $3.4-16.2$ & 2 \\
\hline Cation exchange capacity & $27.1-50.4$ & 21 \\
\hline
\end{tabular}


Table I-2. Background - Core Sample from Berm (analysis 1/30/01).

\section{Particle Size Results}

$\underline{\text { Sieve of }+10 \quad \text { Total Sample Wt: } 163.8}$

All Materials passed (100\%) through Sieves 3", 2", 1 1/2”, 1”, 3/4", 3/8" and \#4.

$\begin{array}{cccc}\text { Sieve } & \text { Wt Retained } & \% \text { Retained } & \% \text { Pass } \\ \# 10 & 0.32 & 0.2 & 99.8\end{array}$

Sieve of $-20 /+200$

$\begin{array}{cccccc}\text { Sieve } & \begin{array}{c}\text { Wt Retained } \\ \text { each sieve }\end{array} & \text { Yield } & \text { Wt Retained } & \text { \% Retained } & \text { \% Pass } \\ \# 20 & 0.88 & 2.47 & 2.79 & 1.7 & 98.3 \\ \# 40 & 0.87 & 4.91 & 5.23 & 3.2 & 96.8 \\ \# 60 & 0.58 & 6.54 & 6.86 & 4.2 & 95.8 \\ \# 100 & 0.72 & 8.56 & 8.88 & 5.4 & 94.6 \\ \# 200 & 4.59 & 21.45 & 21.77 & 13.3 & 86.7\end{array}$

Specific Gravity: 2.33

\begin{tabular}{cccccccc} 
Temp & $\begin{array}{c}\text { Reading } \\
\text { Time }\end{array}$ & $\begin{array}{c}\text { Hydro } \\
\text { Reading }\end{array}$ & $\begin{array}{c}\text { Hydrometer } \\
\text { Correction }\end{array}$ & $\begin{array}{c}\text { Corrected Hydrometer } \\
\text { Reading }\end{array}$ & L & $\begin{array}{c}\text { Diam } \\
(\mathrm{mm})\end{array}$ & $\begin{array}{c}\text { Finer } \\
21\end{array}$ \\
2 & 36 & 4 & 32 & 10.4 & 0.0342 & 60.181 \\
21 & 5 & 32 & 4 & 28 & 11.1 & 0.0223 & 52.658 \\
21 & 15 & 29 & 4 & 25 & 11.5 & 0.0131 & 47.016 \\
21 & 30 & 27 & 4 & 23 & 11.9 & 0.0094 & 43.255 \\
21 & 60 & 26 & 4 & 22 & 12.0 & 0.0067 & 41.374 \\
21 & 250 & 22 & 4 & 18 & 12.7 & 0.0034 & 33.852 \\
21 & 1440 & 18 & 4 & 14 & 13.3 & 0.0014 & 26.329 \\
\hline
\end{tabular}

\section{Clay Mineralogy Results}

\begin{tabular}{cccc}
\hline $\begin{array}{c}\text { \%Mica (Illite) } \\
16 \%\end{array}$ & $\begin{array}{c}\% \text { Kaolinite } \\
23 \%\end{array}$ \\
\hline *Smectite also includes a small amount of smectite-chlorite intergrade. \\
\hline Extractable Metals Results \\
\hline $\mathrm{SiO}_{2}$ & $\mathrm{Al}_{2} \mathrm{O}_{3}$ & $\mathrm{Fe}_{2} \mathrm{O}_{3}$ & $\mathrm{MnO}$ \\
$\%$ as Oxide & $\%$ as Oxide & $\%$ as Oxide & $\%$ as Oxide \\
0.236 & 0.0857 & 0.809 & 0.0334 \\
\hline
\end{tabular}

\begin{tabular}{cc}
\hline \multicolumn{2}{c}{ Specific Surface Area Results $\left(\mathrm{m}^{2} / \mathrm{g}\right)$} \\
\hline Result & \pm error \\
\hline 48.59 & 1.60 \\
\hline
\end{tabular}

\begin{tabular}{cccccc}
\hline \multicolumn{6}{l}{ Exchangeable Cations Results $(\mathrm{meq} / 100 \mathrm{~g})$} \\
\hline Calcium & Potassium & Magnesium & Sodium & Strontium & Cations \\
48.7 & 0.499 & 6.44 & 0.215 & 0.0669 & 55.9 \\
\hline
\end{tabular}

\section{Cation Exchange Capacity Results (meq/g)}

$$
0.495
$$

Background, Sample CB-3-CACH205. Laboratory doing the analysis was Southwest Research Institute, SOW \#377, 12/05/00. 


\section{APPENDIX J}

Microbially Induced Corrosion 
(This page intentionally left blank.) 


\section{Microbially Induced Corrosion}

Repeatable procedures are key to quality data in time series studies. Of particular concern to this investigation is coupon cleaning prior to processing for microbes. It is easy to imagine that microorganisms in direct contact with metal coupons will be totally different than those free living in soil in very close proximity to the coupon, and it is important to remember that systems like this involve complex feed-back loops including microbial byproducts and community changes over time, soil moisture and chemistry and dissolving metals. Future sampling events, while keeping within the original scope of work, could apply previous year's observations to redirect efforts to closely examine the soil-substrate interface to address specific questions about long-term burial of metal containers.

Table J-1. Positive liquid culture enrichments from 4 media types.

\begin{tabular}{|c|c|c|c|c|}
\hline $\begin{array}{c}\text { Sample Depth } \\
(\mathrm{ft})\end{array}$ & Sulfate Reducers & Nitrate Reducers & Heterotrophs & Org. Acid Producers \\
\hline 4 & 10 & 47 & 60 & 60 \\
\hline 10 & 14 & 52 & 54 & 59 \\
\hline
\end{tabular}

Note: There are a total of 60 enrichments of each media type including extinction dilutions at each depth.

Table J-2. Comparison of microbial results from 1, 3 and 6 year samples:

\begin{tabular}{|c|c|c|c|c|c|c|c|c|c|c|c|c|c|}
\hline \multirow[t]{2}{*}{$\begin{array}{l}\text { Material } \\
\text { Type }\end{array}$} & \multirow[t]{2}{*}{$\begin{array}{l}\text { Depth } \\
(\mathrm{ft})\end{array}$} & \multicolumn{3}{|c|}{$\begin{array}{c}\text { Sulfate Reducers } \\
\text { Yrs. Exposure }\end{array}$} & \multicolumn{3}{|c|}{$\begin{array}{l}\text { Nitrate Reducers } \\
\text { Yrs. Exposure }\end{array}$} & \multicolumn{3}{|c|}{$\begin{array}{l}\text { Org. Acid Producers } \\
\text { Yrs. Exposure }\end{array}$} & \multicolumn{3}{|c|}{$\begin{array}{c}\text { Heterotroph } \\
\text { Yrs. Exposure }\end{array}$} \\
\hline & & 6 & 3 & 1 & 6 & 3 & 1 & 6 & 3 & 1 & 6 & 3 & 1 \\
\hline \multirow[t]{2}{*}{$316 \mathrm{~L} \mathrm{~W}$} & 4 & 1 & & & 3 & & & 4 & 3 & & 4 & 4 & \\
\hline & 10 & & & & 4 & & & 4 & 4 & 1 & 4 & 4 & \\
\hline \multirow[t]{2}{*}{$316 \mathrm{~L}$} & 4 & & & & 3 & & & 4 & 3 & 2 & 4 & 4 & 2 \\
\hline & 10 & 1 & & & 4 & & & 4 & 4 & 3 & 4 & 4 & \\
\hline \multirow[t]{2}{*}{ Aluminum } & 4 & 3 & & & 4 & & & 4 & 3 & 1 & 4 & 4 & 2 \\
\hline & 10 & 2 & 1 & & 4 & & & 4 & 4 & 2 & 4 & 4 & \\
\hline \multirow[t]{2}{*}{ Carbon steel } & 4 & 3 & 2 & & 4 & & & 4 & 4 & 1 & 4 & 4 & 1 \\
\hline & 10 & 3 & & & 4 & & & 4 & 4 & 2 & 4 & 4 & \\
\hline \multirow[t]{2}{*}{ 304L } & 4 & & & & 2 & & & 4 & 4 & & 4 & 4 & \\
\hline & 10 & & & & 4 & & & 4 & 4 & 1 & 4 & 4 & \\
\hline \multirow[t]{2}{*}{ Beryllium } & 4 & 1 & 1 & & 4 & & & 4 & 4 & & 4 & 4 & \\
\hline & 10 & 1 & 2 & & 4 & & & 4 & 4 & 3 & 4 & 4 & \\
\hline \multirow[t]{2}{*}{ Zircaloy } & 4 & 1 & & & 4 & & & 4 & 4 & 2 & 4 & 4 & \\
\hline & 10 & & & & 4 & & & 4 & 4 & 3 & 4 & 4 & \\
\hline \multirow[t]{2}{*}{ Ferralium W } & 4 & & & & 4 & & & 4 & 3 & 1 & 4 & 4 & 2 \\
\hline & 10 & 2 & & & 4 & & & 4 & 4 & 1 & 4 & 4 & \\
\hline \multirow[t]{2}{*}{ Inconel } & 4 & 1 & & & 3 & & & 4 & 4 & & 4 & 4 & 2 \\
\hline & 10 & 2 & & & 4 & & & 4 & 4 & 2 & 4 & 4 & \\
\hline
\end{tabular}

Note: Numbers shown are the number of coupons of each metal type $(n=4)$ at each depth that tested positive for a given type (i.e., there was at least 1 viable cell of that type per $\mathrm{cm}^{2}$ coupon surface area). 
(This page intentionally left blank.) 
APPENDIX K

Soil Moisture 
(This page intentionally left blank.) 
Moisture levels in the corrosion berm have been monitored since the start of calendar year 1998. In the first year, monitoring was more frequent than in subsequent years. Data collection followed the schedule shown in Table K-1.

Table K-1. Dates data were collected.

\begin{tabular}{|c|c|c|c|c|}
\hline NP-1 & NP-2 & NP-3 & NP-4 & NP-5 \\
\hline January 13, 1998 & January 13, 1998 & January 13, 1998 & December 2, 1998 & March 15, 2004 \\
\hline February. 18, 1998 & February. 18, 1998 & February. 18, 1998 & March 15, 1999 & September 20, 2004 \\
\hline March 16, 1998 & March 16, 1998 & March 16, 1998 & June 3, 1999 & \\
\hline March 31, 1998 & March 31, 1998 & March 31, 1998 & August 12, 2002 & \\
\hline April 16, 1998 & April 16, 1998 & April 16, 1998 & July 15,2003 & \\
\hline May 11, 1998 & May 11,1998 & May 11,1998 & March 15, 2004 & \\
\hline June 1, 1998 & June 1, 1998 & June 1, 1998 & September 20, 2004 & \\
\hline June 23, 1998 & June 23, 1998 & June 23, 1998 & & \\
\hline July 7, 1998 & July 7, 1998 & July 7, 1998 & & \\
\hline September 15,1998 & September 15, 1998 & September 15,1998 & & \\
\hline December 2, 1998 & October 12,1998 & October 12,1998 & & \\
\hline March 15, 1999 & December 2, 1998 & November 25, 1998 & & \\
\hline June 3, 1999 & March 15, 1999 & March 15, 1999 & & \\
\hline August 12, 2002 & June 3, 1999 & June 3, 1999 & & \\
\hline July 15, 2003 & August 12, 2002 & August 12, 2002 & & \\
\hline March 15, 2004 & July 15, 2003 & July 15, 2003 & & \\
\hline \multirow[t]{2}{*}{ September 20, 2004} & March 15, 2004 & March 15, 2004 & & \\
\hline & September 20, 2004 & September 20, 2004 & & \\
\hline
\end{tabular}

\section{NP-1}

Figures K-1 and K-2 show the NP-1 volumetric moisture profiles. Figure K-1 shows all the collected NP-1 data while Figure K-2 shows selected NP-1 data profiles. The left side of the graph shows the monitoring depth (feet), and the top of the graph shows the percent moisture content (volumetric). Because the moisture traces move left or to drier conditions, Figure K-1 indicates that the soils surrounding the access tube have continued an overall drying trend with the most recent readings (September 2004) generally reflecting the driest conditions. The berm has dried to about $6 \mathrm{ft}$. Deeper, the soil moisture content seems to have fluctuated slightly.

The greatest recharge (infiltration) event reflected in the data occurred between September 1998 and December 1998 with recharge through the entire profile. Precipitation was above average (9.5 in) in 1998, and in subsequent years has fallen off to less than half of that level. Therefore, it is not surprising that in those years little or no recharge is observed. In any case, little recharge seems to have reached the $9.5 \mathrm{ft}$ level. However, less data on a yearly basis make it difficult to quantify the amount of recharge occurring in any of the events after 1998. Because the moisture profiles for 1999, 2002, 2003 and 2004 are all similar, the berm seems either to be approaching or have reached equilibrium with the moisture regime at the corrosion berm. The original moisture content of the soil placed in the berm was moister than it is currently because 
the spreading area from which the soil was obtained may have had a moister environment or, in some cases, water may have been added during berm construction to achieve optimum compaction requirements. The September 2004 profile shows volumetric moisture contents ranging from about $17 \%$ near the surface to about $24 \%$ at $9.5 \mathrm{ft}$.

Figure K-2 shows selected profiles for NP-1. The data are fairly tightly clustered with the December 1998 profile indicating wetter conditions to about the $5.5 \mathrm{ft}$ level. This indicates recharge, as discussed above. Overall, moisture contents do not appear to have varied significantly.

NP-1 (AII)

Moisture Content (\%)

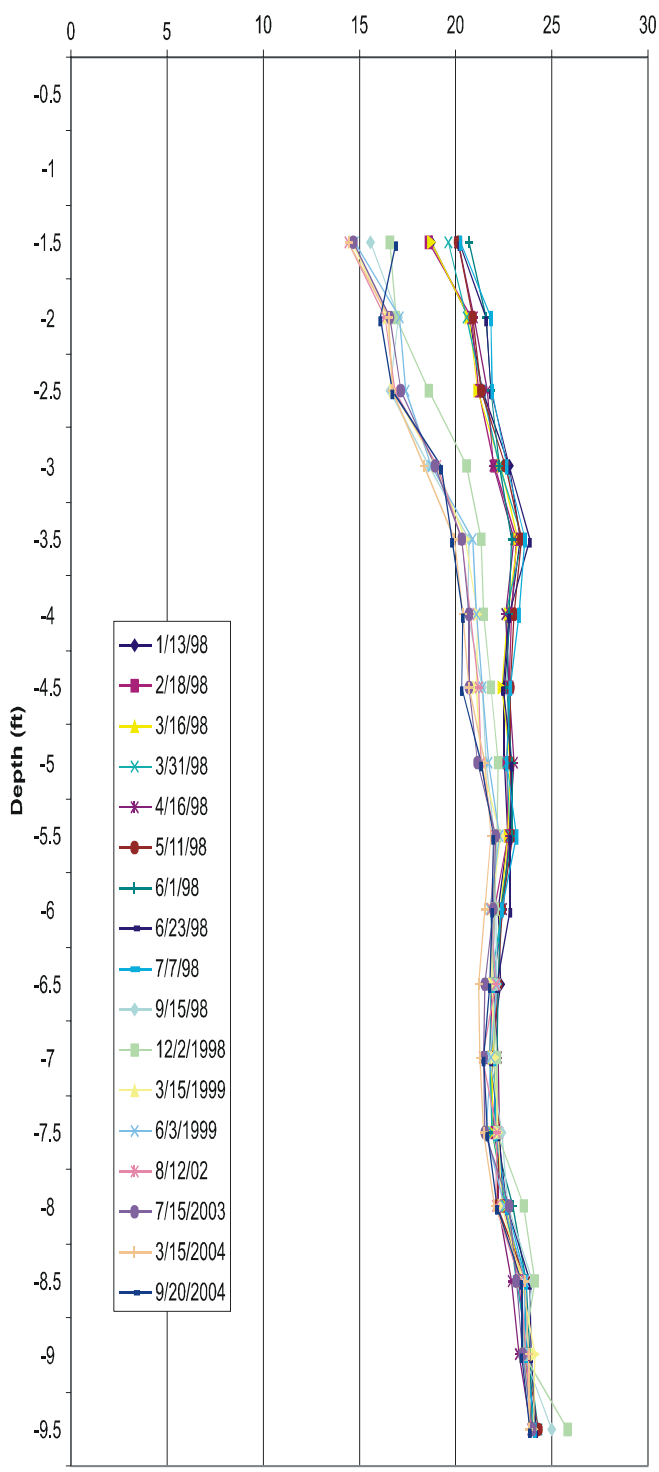

Figure K-1. NP-1 moisture profiles for each monitoring event.

\section{NP-1 (Selected Data)}

Moisture Content (\%)

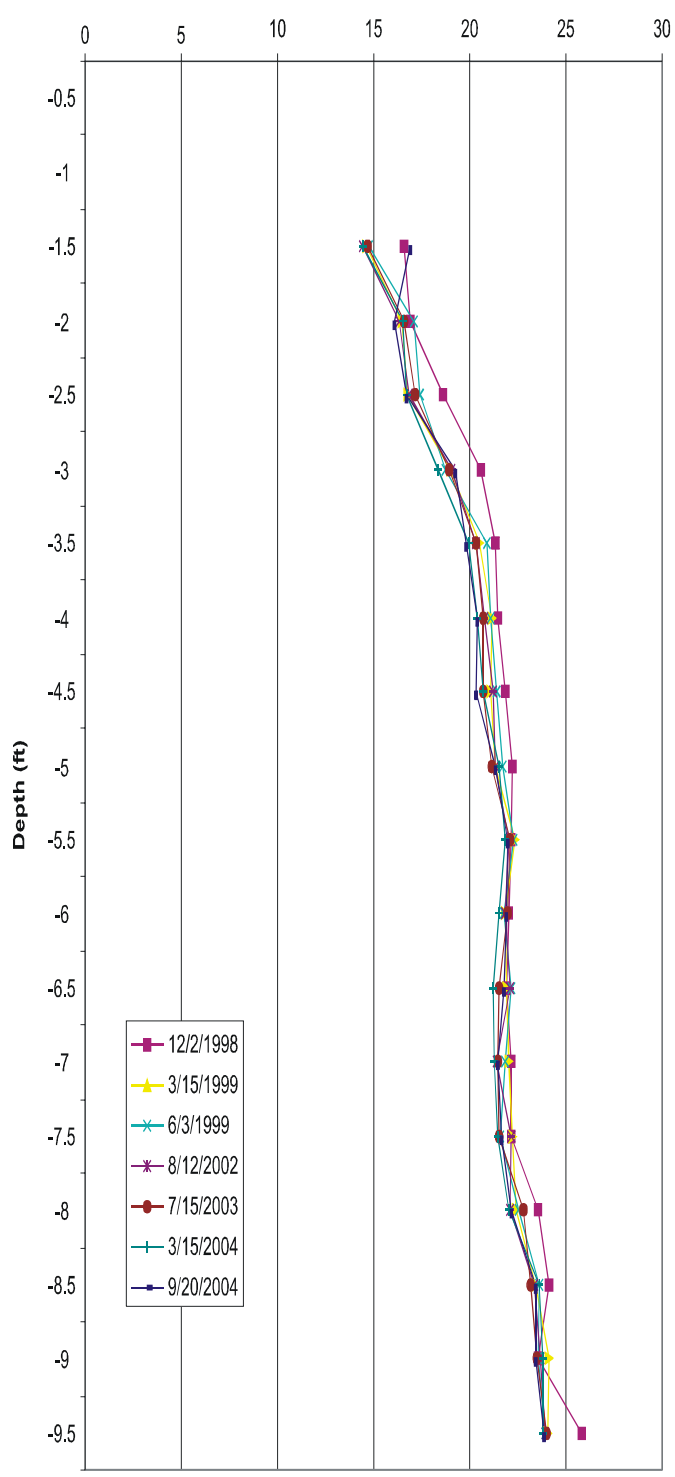

Figure K-2. Selected NP-1 moisture profiles. 


\section{NP-2}

The NP-2 data are shown in Figure K-3. The data indicate limited wetting in early 1998, but since that time the berm has continued to dry out throughout the entire profile. Figure K-4 is a plot of the last seven NP-2 profiles. The 2004 moisture profiles show conditions are slightly drier through out the entire profiled depth. Even though the latest data are drier, the similarity in the data suggests that this area of the berm is also approaching equilibrium. The spurious August 12,2002 measurement at $7 \mathrm{ft}$ is assumed to be in error. Volumetric moisture contents for profiles shown in Figure K-4 range from about $14 \%$ at the surface to about $25 \%$ at the bottom of the hole.

NP-2 (AII)

Moisture Content (\%)

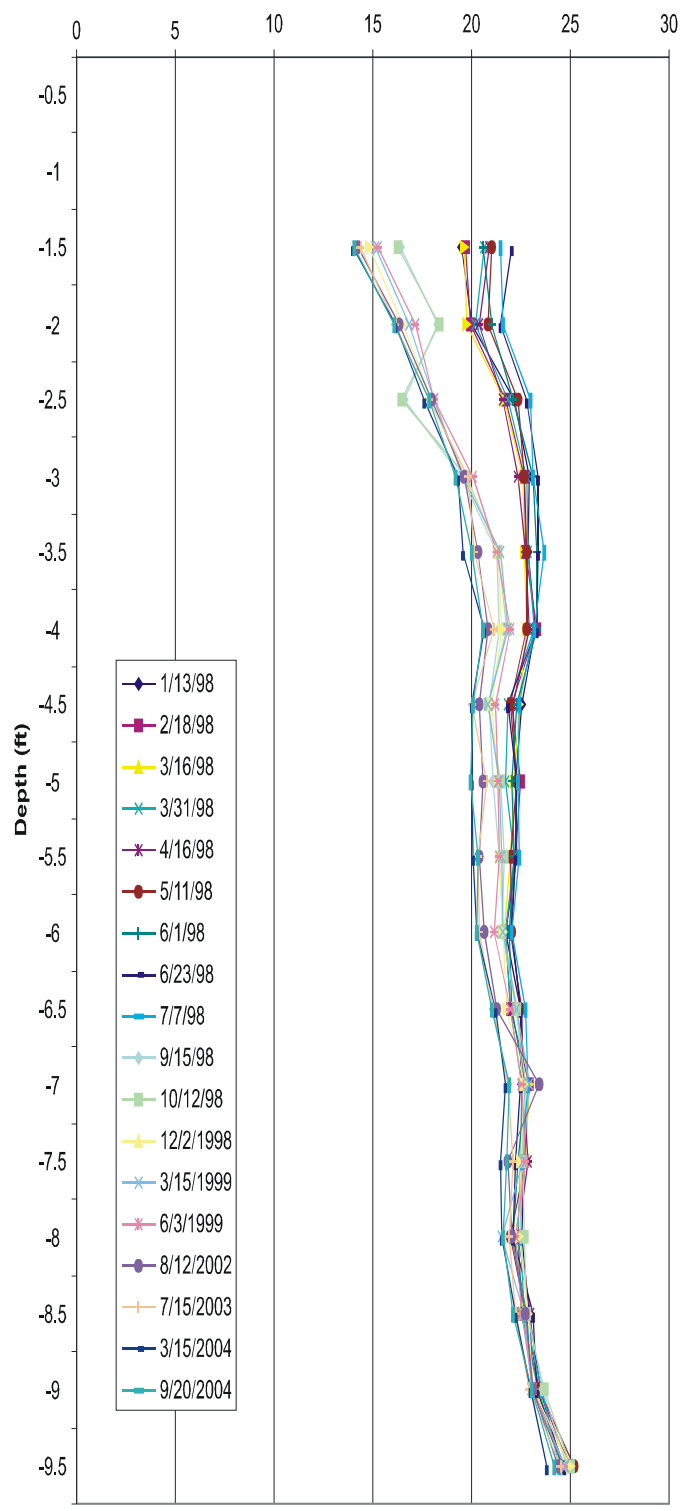

Figure K-3. All NP-2 moisture profiles.

\section{NP-2 (Selected Data)}

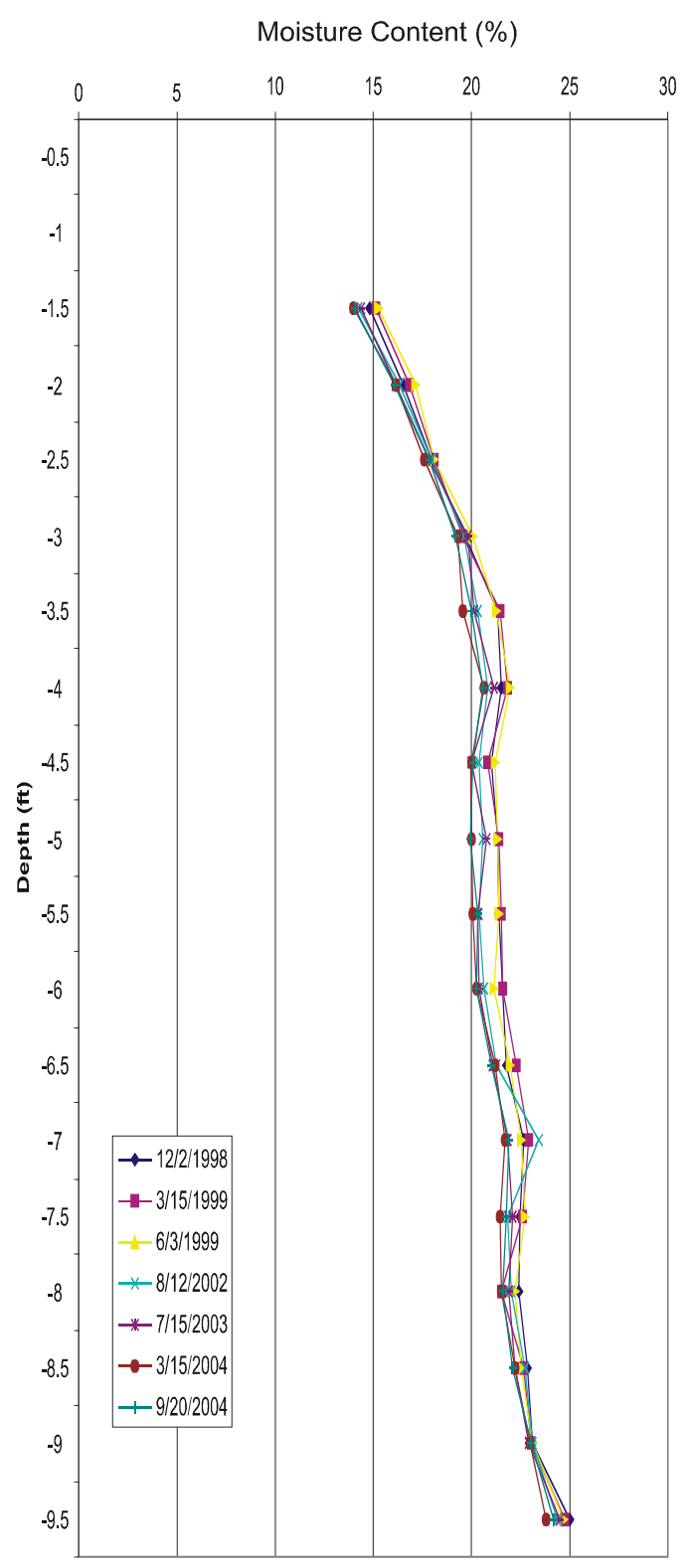

Figure K-4. NP-2 Moisture profiles for selected months. 


\section{NP-3}

The drying pattern exhibited in NP-3 is similar to NP-1 and NP-2, because the 2004 September data also indicate drying of the soil through the entire profile. Figure K-5 shows all the data while Figure K-6 shows selected data. The volumetric moisture contents monitored in 2004 range from about $13 \%$ at the surface to about $23 \%$ at depth.

NP-3 (AII)

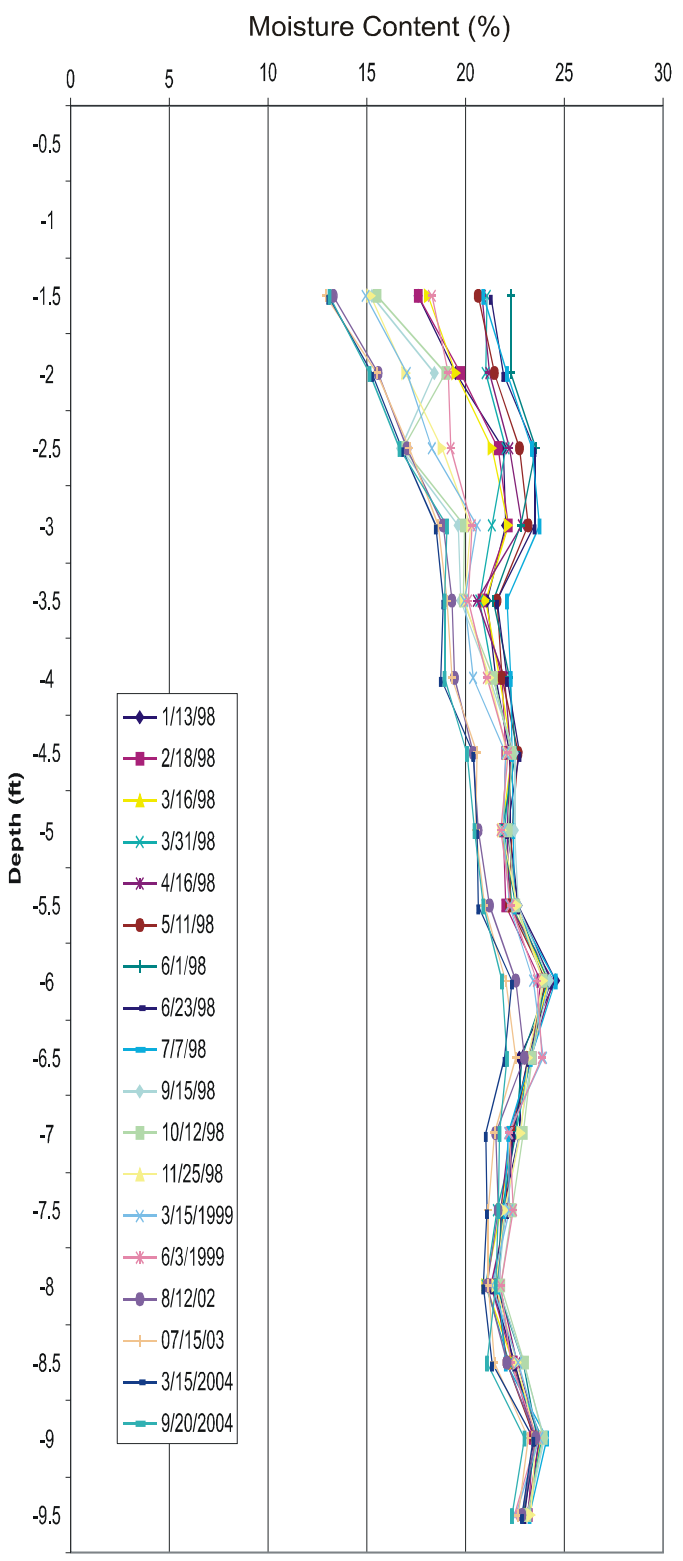

Figure K-5. All NP-3 moisture profiles.
NP-3 (Selected)

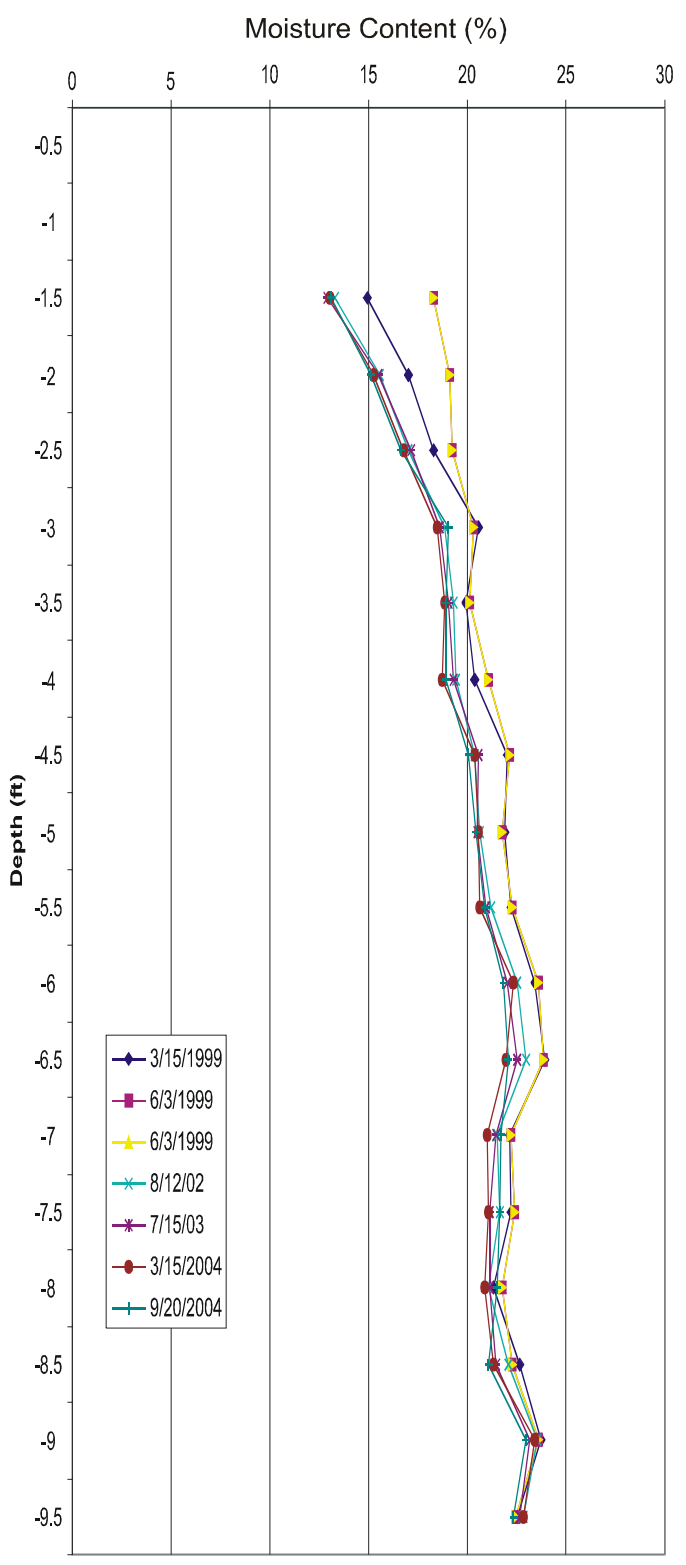

Figure K-6. NP-3 Moisture profiles for selected months. 


\section{NP-4}

NP-4 is installed within a 6-ft diameter augered hole. The soils surrounding NP-4 can be characterized as less dense and more porous with more numerous and larger airspaces than the surrounding berm. Thus, the soil has less capillary force to hold water and this is reflected by the overall drier profile (lower moisture content) shown in Figure K-7. Soils surrounding NP-4 range in moisture content from about $13 \%$ at the surface to about $18 \%$ at the bottom of the hole. The September 2004 data indicate soils are slightly drier down to about $3.5 \mathrm{ft}$ than measured in March. The rest of the profile is similar to the earlier monitoring. Overall, the data indicate that there has been some recharge along the entire depth, but the recharge has probably been insufficient to impact the moisture content greatly.

\section{NP-4 (AII)}

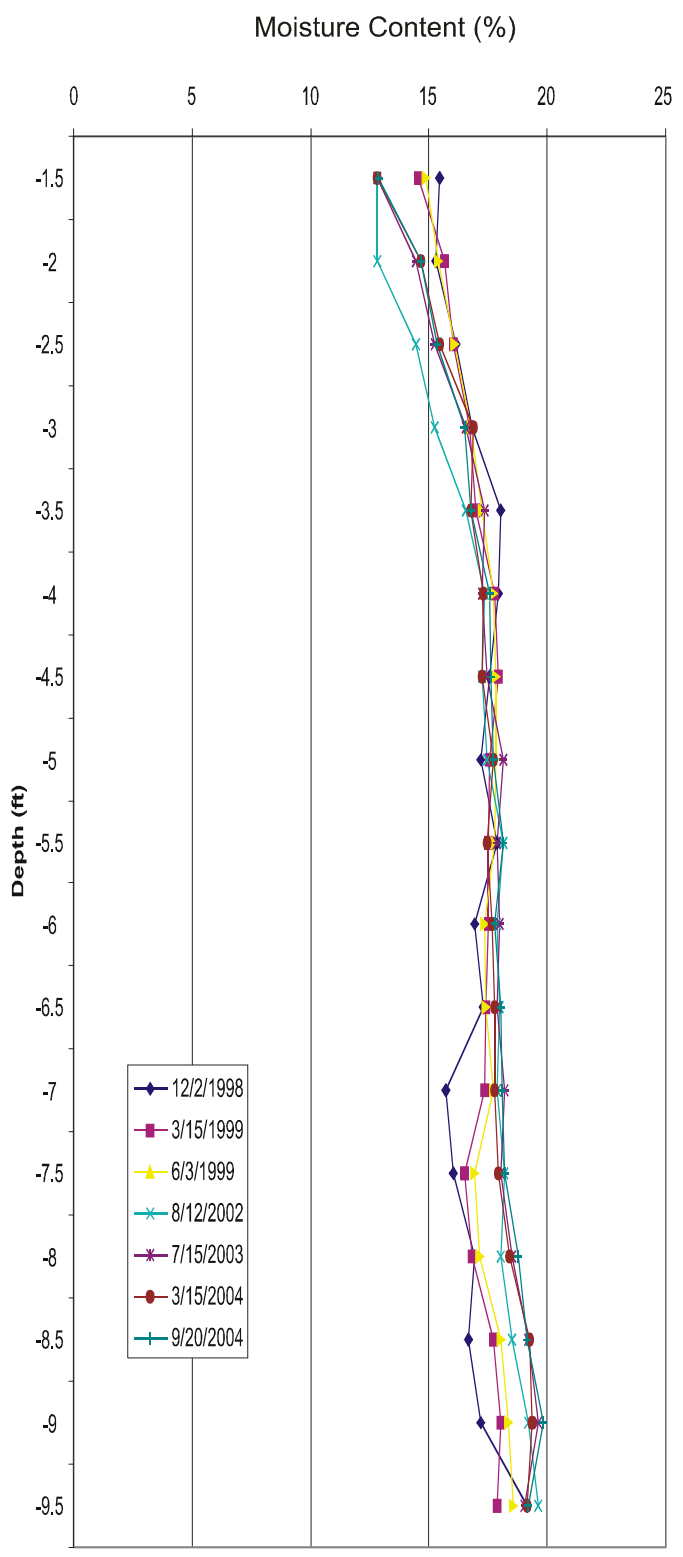

Figure K-7. NP-4 moisture profiles. 


\section{NP-5}

NP-5 is installed within a 6-ft diameter augered hole. No attempt was made to compact the backfill material as it was placed in the hole. The soil was randomly dumped into the hole, similar to the methods used in cover soil at the disposal area. Figure K-8 shows the initial moisture measurement collected on March 15, 2004 and the September 20, 2004 measurement.

\section{NP-5 (AII)}

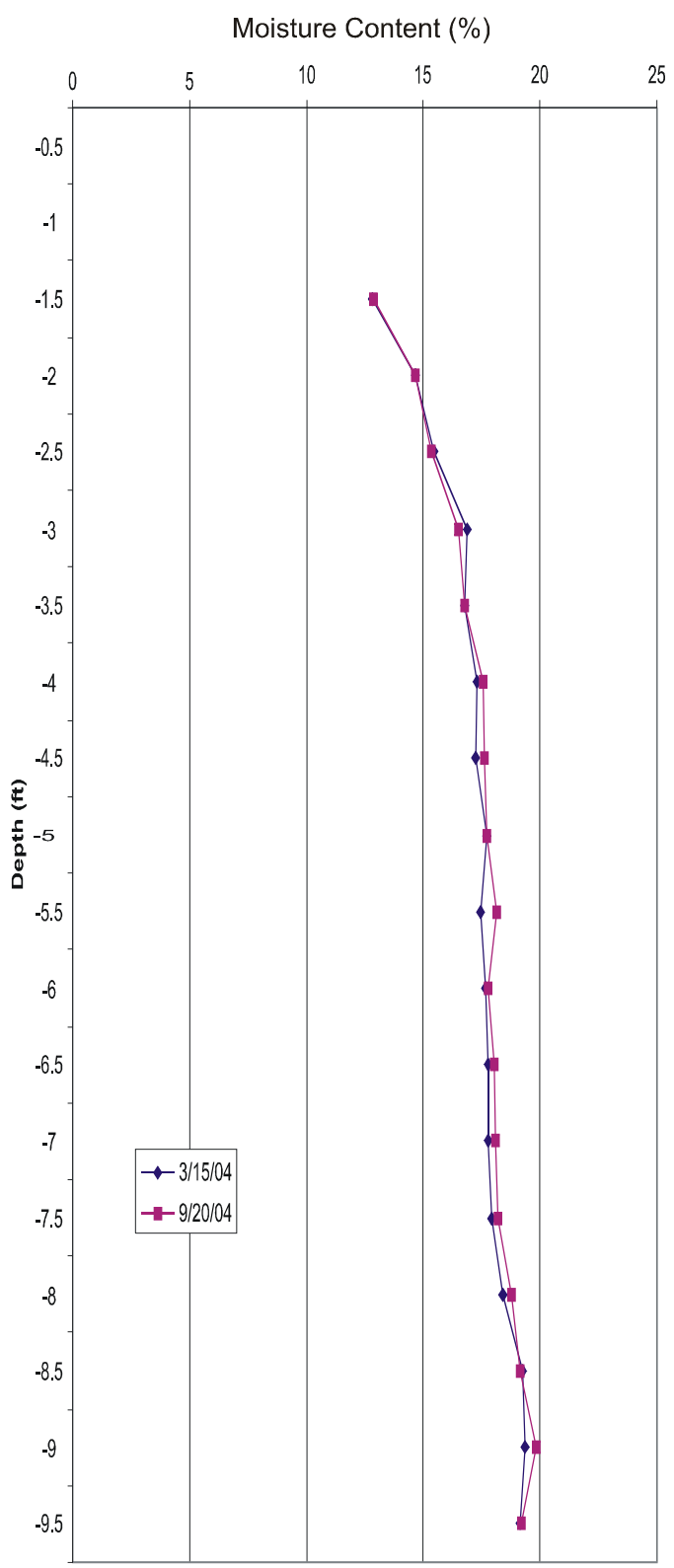

Figure K-8. NP-5 moisture profiles. 


\section{APPENDIX L}

Soil Gas Monitoring 
(This page intentionally left blank.) 
Known gas concentrations were used to calibrate analytical procedures before the soil atmosphere samples were analyzed. Concentrations of $\mathrm{N}_{2}$ and $\mathrm{O}_{2}$ in the laboratory atmosphere were used as standards while, because of their normally low atmospheric content, specialty calibration gases were used for $\mathrm{CO}_{2}$ and $\mathrm{CH}_{4}$. As can be seen from the data, (Table L-1 and L-2) comparisons of the concentrations of $\mathrm{N}_{2}$ and $\mathrm{O}_{2}$ in the laboratory atmosphere fit very well with that of clean dry air at sea level (an average of $79.39 \pm 0.02$ vs 78.09 for $\mathrm{N}_{2}$ and $20.61 \pm 0.02 \mathrm{vs}$ 20.94 for $\mathrm{O}_{2}$ ). Analyzed quantities of $\mathrm{CO}_{2}$ and $\mathrm{CH}_{4}$ were correct for each calibration gas sample. These calibration data provided efficacy for the results from the atmospheric gas analysis.

Table L-1. Soil gas samples, data collected and analyzed Fall 1998.

\begin{tabular}{|c|c|c|c|c|}
\hline Sample Description & $\begin{array}{c}\text { Nitrogen } \\
\text { (\% vol) }\end{array}$ & $\begin{array}{l}\text { Oxygen } \\
\text { (\% vol) }\end{array}$ & $\begin{array}{l}\text { Carbon } \\
\text { Dioxide } \\
(\% \text { vol) }\end{array}$ & $\begin{array}{c}\text { Methane } \\
\text { (ppmv) }\end{array}$ \\
\hline \multirow{5}{*}{$\begin{array}{l}\text { GP1 - } 4 \text { ft } \\
\text { (background) }\end{array}$} & 78.14 & 19.46 & 0.84 & 4.45 \\
\hline & 75.90 & 18.89 & 0.79 & 3.00 \\
\hline & 78.65 & 19.60 & 0.77 & 1.60 \\
\hline & 75.70 & 18.87 & 0.77 & 2.57 \\
\hline & 75.21 & 18.76 & 0.74 & 1.00 \\
\hline Ave. $4 \mathrm{ft}$ & $76.72 \pm 1.56$ & $19.12 \pm 0.38$ & $0.78 \pm 0.04$ & $2.04 \pm 0.91^{\mathrm{a}}$ \\
\hline \multirow{4}{*}{$\begin{array}{l}\text { GP1 - } 10 \mathrm{ft} \\
\text { (background) }\end{array}$} & 81.79 & 19.28 & 1.75 & 18.01 \\
\hline & 78.03 & 18.41 & 1.62 & 2.11 \\
\hline & 78.96 & 18.67 & 1.70 & 1.14 \\
\hline & 79.47 & 18.78 & 1.67 & 2.58 \\
\hline Ave. $10 \mathrm{ft}$ & $79.56 \pm 1.60$ & $18.78 \pm 0.36$ & $1.68 \pm 0.05$ & $1.94 \pm 0.73^{\mathrm{a}}$ \\
\hline
\end{tabular}

a. First determination not included in average.

Table L-2. Atmospheric gas analysis (Fall 1998).

\begin{tabular}{|l|l|l|l|l|}
\hline \multicolumn{1}{|c|}{ Sample Description } & \multicolumn{1}{|c|}{$\begin{array}{c}\text { Nitrogen } \\
(\% \text { vol })\end{array}$} & $\begin{array}{c}\text { Oxygen } \\
(\% \text { vol })\end{array}$ & $\begin{array}{c}\text { CO } \\
(\% \text { vol })\end{array}$ & $\begin{array}{c}\text { Methane } \\
(\mathbf{p p m v})\end{array}$ \\
\hline Atmosphere & 79.39 & 20.61 & & \\
\hline Atmosphere & 79.41 & 20.59 & & \\
\hline Atmosphere & 79.37 & 20.63 & & \\
\hline \multicolumn{1}{|c|}{ Ave. Atmosphere } & $79.39 \pm 0.02$ & $20.61 \pm 0.02$ & & \\
\hline 50 ppm methane & & & & 50.00 \\
\hline $0.1 \% \mathrm{CO}_{2}$ & & & 0.10 & \\
\hline $1.0 \% \mathrm{CO}_{2}$ & & & 1.00 & \\
\hline $10.0 \% \mathrm{CO}_{2}$ & & & 10.00 & \\
\hline Clean dry air sea level & 78.09 & 20.94 & 0.0332 & 1.50 \\
\hline
\end{tabular}


Table L-3. Soil gas sample analysis, data collected Fall 2003.

\begin{tabular}{|c|c|c|c|c|c|c|}
\hline $\begin{array}{c}\text { Sample } \\
\text { Location }\end{array}$ & $\begin{array}{c}\text { Depth } \\
\text { (Ft) }\end{array}$ & $\begin{array}{c}\text { Sample } \\
\text { ID }\end{array}$ & $\begin{array}{c}\text { Nitrogen } \\
(\%)\end{array}$ & $\begin{array}{c}\text { Oxygen } \\
(\%)\end{array}$ & $\begin{array}{c}\text { Methane } \\
\text { (ppmv) }\end{array}$ & $\begin{array}{c}\mathrm{CO}_{2} \\
(\mathrm{ppmv})\end{array}$ \\
\hline \multirow{8}{*}{$\begin{array}{l}\text { GP1 } \\
\text { (background) }\end{array}$} & \multirow[t]{4}{*}{4} & $1-\mathrm{A}-1$ & 78.3 & 20.2 & 18.5 & 3907.4 \\
\hline & & $1-A-2$ & 77.5 & 20.0 & 36.9 & 3998.3 \\
\hline & & $1-A-3$ & 79.1 & 20.4 & 64.0 & 4388.6 \\
\hline & & $1-\mathrm{A}-4$ & 77.1 & 19.9 & 84.4 & 3987.1 \\
\hline & \multirow[t]{4}{*}{10} & $2-A-1$ & 80.1 & 20.4 & 30.0 & 6347.9 \\
\hline & & $2-A-2$ & 78.3 & 19.7 & 28.7 & 8545.2 \\
\hline & & $2-A-3$ & 77.3 & 19.5 & 38.1 & 8247.9 \\
\hline & & $2-\mathrm{A}-4$ & 79.0 & 19.2 & 33.9 & 7609.2 \\
\hline \multirow{8}{*}{$\begin{array}{l}\text { GP2 } \\
\text { (Location I) }\end{array}$} & \multirow[t]{4}{*}{4} & 1-B-1 & 80.1 & 20.8 & 28.2 & 2387.9 \\
\hline & & $1-B-2$ & 79.3 & 20.6 & 23.2 & 2417.0 \\
\hline & & $1-B-3$ & 79.8 & 20.7 & 31.0 & 2524.5 \\
\hline & & $1-B-4$ & 78.4 & 20.3 & 56.2 & 2555.1 \\
\hline & \multirow[t]{4}{*}{10} & $2-B-1$ & 78.0 & 19.9 & 32.9 & 5895.5 \\
\hline & & $2-B-2$ & 79.8 & 20.2 & 81.5 & 9710.0 \\
\hline & & $2-B-3$ & 79.1 & 20.1 & 62.4 & 7070.0 \\
\hline & & $2-B-4$ & 77.7 & 19.7 & 31.4 & 7554.8 \\
\hline
\end{tabular}

